UNIVERSIDADE DE SÃO PAULO

FACULDADE DE FILOSOFIA, LETRAS E CIÊNCIAS HUMANAS

DEPARTAMENTO DE LINGUÍSTICA

PROGRAMA DE PÓS-GRADUAÇÃO EM SEMIÓTICA E LINGUÍSTICA GERAL

Em Convênio de Dupla Titulação com

UNIVERSITÄT BAYREUTH

BAYREUTH INTERNATIONAL GRADUATE SCHOOL OF AFRICAN STUDIESBIGSAS

PAULO JEFERSON PILAR ARAÚJO

\title{
DOMÍNIOS CONCEITUAIS DAS CONSTRUÇÕES LOCATIVAS, Existenciais, Comitativas e Possessivas em Línguas
}

BANTAS 
UNIVERSIDADE DE SÃO PAULO

FACULDADE DE FILOSOFIA, LETRAS E CIÊNCIAS HUMANAS

DEPARTAMENTO DE LINGUÍSTICA

PROGRAMA DE PÓS-GRADUAÇÃO EM SEMIÓTICA E LINGUÍSTICA GERAL

Em Convênio de Dupla Titulação com

UNIVERSITÄT BAYREUTH

BAYREUTH INTERNATIONAL GRADUATE SCHOOL OF AFRICAN STUDIES

\section{DOMÍNIOS CONCEITUAIS DAS CONSTRUÇões LOCATIVAS, Existenciais, Comitativas e Possessivas em Línguas BANTAS}

Paulo Jeferson Pilar Araújo

Tese apresentada ao Programa de Pós-Graduação em Semiótica e Linguística Geral do Departamento de Linguística da Universidade de São Paulo como requisito para a obtenção do título de Doutor em Linguística.

Orientadora brasileira: Profa. Dra. Margarida Maria Taddoni Petter/USP Orientador alemão: Prof. Dr. Manfred von Roncador/BIGSAS 


\section{FOLHA DE APROVAÇÃO}

Paulo Jeferson Pilar Araújo

Domínios conceituais das construções locativas, existenciais, comitativas e possessivas em línguas bantas

Tese apresentada ao Programa de Pós-Graduação em Semiótica e Linguística Geral do Departamento de Linguística da Universidade de São Paulo como requisito para a obtenção do título de Doutor em Linguística.

Aprovada em:

BANCA EXAMINADORA

Orientadora: Profa. Dra. Margarida Maria Taddoni Petter

$\mathrm{USP} / \mathrm{DL}$

Membros da Banca:

Prof. Dr. Manfred von Roncador

UBT/BIGSAS

Profa. Dra. Clarissa Vierke

UBT/BIGSAS

Prof. Dr. José da Silva Simões

USP/DLM

Prof. Dr. Marcelo Módolo

USP/DLCV 
Aos meus pais, Sunamita e João Paulo, Meus "pontos de referência"

Ao Bernardino Légua, Alter-ego de um ateu "incorporado". 
"Tudo que é imaginado existe, é e tem."

(Estamira) 


\section{AGRADECIMENTOS}

Agradeço imensamente à professora Margarida Petter, pela orientação sempre atenta e solícita e por aceitar os desafios deste trabalho que foram surgindo ainda durante nosso trabalho de mestrado. Para além de sua orientação sempre voltada para a formação de linguistas africanistas no Brasil, devo deixar registrado aqui a forma como suas intervenções contribuíram grandemente para minha formação, sem com isso impedir qualquer liberdade nas minhas escolhas científicas ou direcionamentos na minha carreira acadêmica. Agradeço o respeito e a seriedade na acolhida de minhas intuições teóricas, mesmo quando elas pareciam totalmente contraintuitivas.

Agradeço a Lívia Oushiro e ao professor Leland McCleary, pelos primeiros debates sobre as metáforas conceituais para "estar com", o que resultou em minha teimosia de ir mais longe com os possessivos comitativos. Não posso esquecer as boas conversas com o prof. Ronald Beline sobre a velha questão de casamentos teóricos e sobre ateóricos camaleônicos, e isso com a marca do seu inconfundível bom humor. Agradeço também ao professor Emilio Pagotto, sobre a mesma questão e por me falar dos "linguistas-tiranossauros rex".

Agradeço à professora Íris Bachmann, pelas nossas conversas sobre "estar com" durante o período em que ela passou como professora visitante na USP. Ao professor Marcelo Módolo, pela insistência para que eu "pegasse" o "pulo do gato" no problema de possessivos, durante a arguição do exame de qualificação. Fico satisfeito de ver que o professor Marcelo tem acompanhado essa tese praticamente desde a sua forma embrionária, na primeira vez que apresentei em um evento a hipótese de "estar com” línguas bantas no português brasileiro.

Ao professor José da Silva Simões agradeço as sugestões no exame de qualificação, e usando seu nome, agradeço aos colegas do "Grupo dos Duvidosos", pelas boas discussões cognitivistas que sempre tivemos e que espero que continuem.

Devo agradecer a Juliana Macek, mwalimu wangu, pelas aulas de suaíli e o "estalo" que eu precisava para adentrar na linguística bantuísta com um tema sobre possessivos.

Aos colegas do Grupo de Estudos de Línguas Africanas - GELA. Ao Everton, à Day e à Edna, pela leitura de alguns capítulos da tese. Meu grande obrigado!

Agradeço à FAPEMA, pela bolsa de estudos durante todo o período da minha formação, mestrado e doutorado. À CAPES pela bolsa sanduíche entre 2011-2012. 
Agradeço à Bayreuth International Graduate School of African Studies-BIGSAS, pela acolhida durante meu estágio de doutorando no exterior e por me aceitar entre seus Junior Fellows.

Meus sinceros agradecimentos ao prof. Manfred von Roncador, pelas horas de orientação e primeiras incursões por textos do umbundo e por sua contribuição para a minha formação africanista. À profa. Clarissa Vierke agradeço a atenção e paciência por ouvir algumas das minhas dúvidas e angústias teóricas, em alguns momentos da minha pesquisa.

Meus agradecimentos fraternais a Mimboabe Bakpa, Daouda Traoré e Marie-Laure Kozi, pela companhia e amizade durante meu estágio de doutorando na Universidade de Bayreuth.

Meus agradecimentos em especial ao amigo Afonso Teca, pessoa extraordinária e sem a qual esta tese perderia muito do brilho das línguas angolanas. Obrigado por ter tornado meus últimos meses em Bayreuth um pouco mais "um lar", durante nossas longas horas de trabalho de eliciação e conversas sobre Angola e Brasil.

Agradeço também ao Paulo Ingles e pela acolhido em sua residência, pelas boas conversas e por ter compartilhado um pouco do seu ambiente em família.

Devo agradecer aos professores que foram bastante solícitos sempre que os contactei por email, requisitando teses, trabalhos e compartilhando dúvidas. Ao professor Dennis Creissels, por ter me enviado sua tese. Ao prof. Alex Fleisch, à profa Esmeralda Negrão e à profa. Hakyung Jung, pelo envio de materiais de pesquisa valiosos. À profa. Asifa Majid por ter me recebido e ouvido algumas das minhas dúvidas sobre categorias cognitivas, durante minha breve passagem por Nijmegen. Agradeço também ao Sebastian Drude, por ter me hospedado em Nijmegen.

Meus agradecimentos à Ana Stela, por ter me recebido em Lisboa e sempre ter sido o exemplo de pesquisadora que conhece bem os meandros entre a academia e o campo.

Aos funcionários do Departamento de Linguística FFLCH-USP, Érica, Robson e Ben Hur, pela solicitude e esclarecimentos.

Aos amigos de todas as horas e "horas nenhumas", nas figuras inconfundíveis do Ivan e Maraca, verdadeiros irmãos, no plano mundano e sobrenatural. Ao Nahim, pela leitura do Capítulo 4.

À minha família, apesar da distância, sempre presente. Meus agradecimentos em especial à minha mãe, Sunamita. Aos meus irmãos, Carlos, Jayro, Jayme e Amanda, agradeço pela força que me dão para continuar nessa caminhada.

Aos meus de longe que sinto sempre perto, tio Antonio, Gracinha, Isaías, Rita, sem a ajuda dos quais eu não teria chegado até aqui. 
Agradeço a inestimável atenção do escritor angolano Gociante Patissa, por alguns esclarecimentos sobre umbundo e suas letras de "ombembwa". Agradeço também à Antonieta Kulanda, que em nome do Etumbuluko Lye Limi Lyumbundu (Associação para a Língua Umbundo) tem contribuído para o estudo e divulgação da língua umbundo.

À minha Cynthia, meu "possessivo comitativo", por trazer de volta minha poesia, durante o doutorado, e por ela mesma ser "poesia"... E claro, agradeço também pela sua paciência e auxílio com os gráficos e tudo mais na produção da tese. Eu não poderia deixar de agradecer também à família dela, pelas semanas em que passei em São José dos Campos escrevendo alguns dos capítulos do meu trabalho. Foi muito bom e importante pra mim, ter tido as risadas da criançada, enquanto as ideias se recusavam de vez em quando a dar as caras. 


\section{LISTA DE FIGURAS}

Figura 1.1 - O tronco Nigero-congolês (Willanson; Blench, 2000, p 12) -------------------------17

Figura 1.2 - O grupo banto na família nigero-congolesa (Schadeberg, 2003, p. 155) -------------18

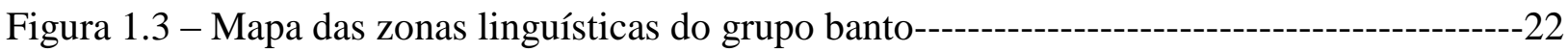

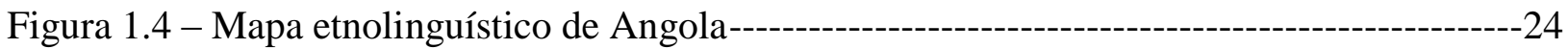

Figura 2.1 - Estrutura do verbo banto (Ngunga, 2004, p. 148) - -

Figura 3.1 - Análise do Ponto de Referência (Langacker, 2009) ---------------------------------63

Figura 3.2 - Orientação espacial na análise do ponto de referência ---------------------------------64

Figura 3.3 - Codificação de posse predicativa (Stassen, 2009, p. 723) --------------------------74

Figura 4.1 - Rede conceitual de "Funções Pontes" de Stolz (2001, p. 340)------------------------98

Figura 4.2 - Distinção entre possessivos a partir da Análise do Ponto de Referência --------------100

Figura 4.3 - Hierarquia de domínios-fonte (Evans; Green, 2006, p. 715) -------------------------104

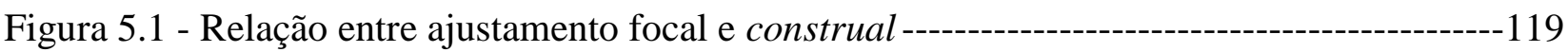

Figura 5.2 Possessivo do tipo “ter” na APR (Langacker, 2009, p. 93) --------------------------125

Figura 5.3 Possessivo do tipo “ser” na APR (Langacker, 2009, p. 104) -------------------------125

Figura 5.4 - Comitativo na Análise do Ponto de Referência ----------------------------------------129

Figura 5.5 - Distinção entre localização e existência (Langacker, 2003) ----------------------------130

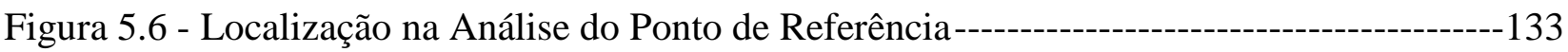

Figura 5.7 - Relação entre domínios conceituais de EXIST, LOC, COM e POSS ---------------135

Figura 5.8 - Codificação de posse predicativa e domínios conceituais ---------------------------137

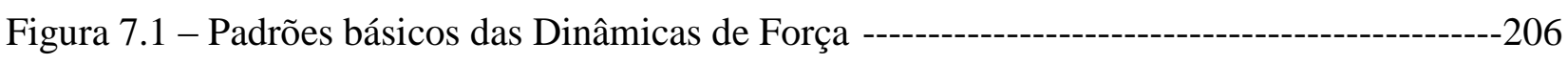

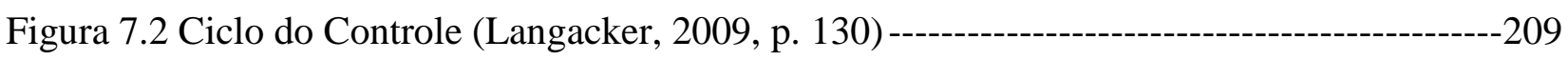

Figura 7.3 - Mapeamentos perfilados no Ciclo do Controle ----------------------------------------211

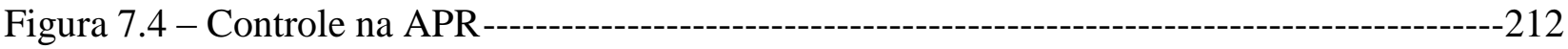




\section{LISTA DE TABELAS}

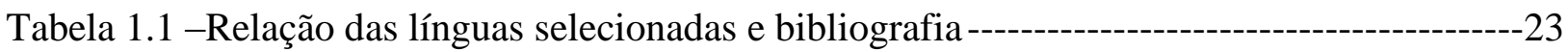

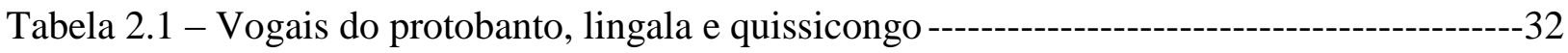

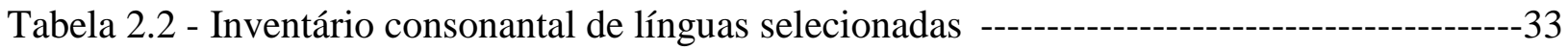

Tabela 2.3 - Pré-prefixos e prefixos nominais de línguas selecionadas ---------------------------38

Tabela 2.4 - Estrutura morfológica das formas verbais finitas em banto -----------------------------41

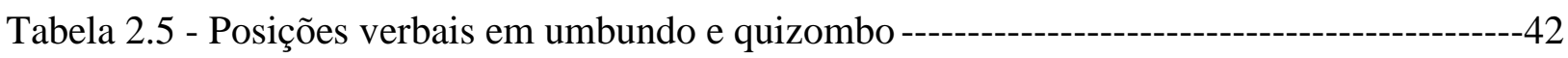

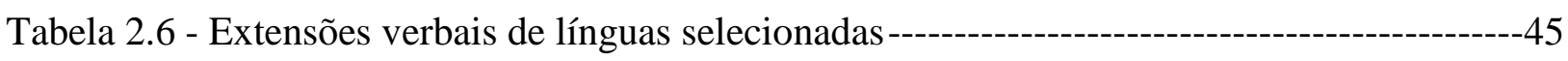

Tabela 2.7 - Tempo, Aspecto e Modo em ochindonga, quisicongo e ganguela---------------------48

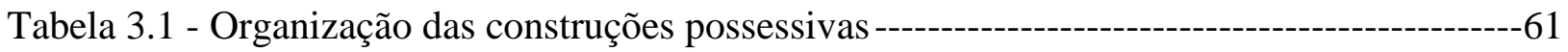

Tabela 3.2 - Parâmetros semântico/cognitivos de possessivos (Stassen, 2009, p. 17) -------------66

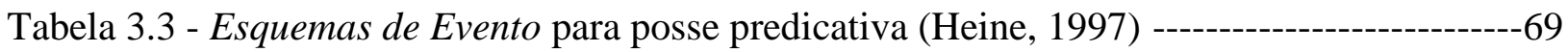

Tabela 3.4 - Principais Tipos de Construções Possessivas (Stassen, 2009) -------------------------71

Tabela 4.1 - Classes de papéis temáticos do Modelo de Corrente Causal ---------------------------96

Tabela 5.1 - Usos e sentidos de “ter” pleno no português brasileiro ------------------------------131

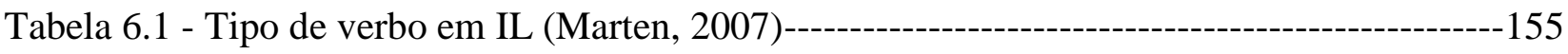

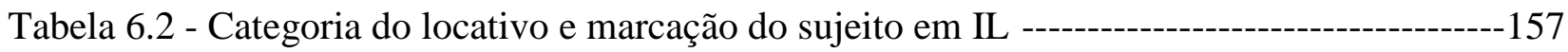




\section{Abreviaturas e Glosas}

\begin{tabular}{|c|c|c|c|}
\hline $1-19$ & classes nominais & M & masculino \\
\hline $1,2,3 \mathrm{sg}$ & $1,2,3^{\mathrm{a}}$ pessoa do singular & MLP & morfema de ligação prosódica \\
\hline $1,2,3 \mathrm{pl}$ & $1,2,3^{a}$ pessoa do plural & MO & Marca do Objeto \\
\hline$\varnothing$ & alomorfe zero & MS & Marca do sujeito \\
\hline $\mathrm{ABL}$ & ablativo & $\mathrm{N}$ & neutro \\
\hline ABS & absolutivo & NOM & nominativo \\
\hline $\mathrm{ACC}$ & acusativo & NUM & numeral \\
\hline ALA & alativo & NEG1 & Negativo 1 \\
\hline ANT & anterior hodierno & NEG2 & Negativo 2 \\
\hline AN & animado & PASD & passado \\
\hline APL & aplicativo & PASS & passiva \\
\hline APR & análise do ponto de referência & PD & possuído \\
\hline ART & artigo & $\mathrm{pl}$ & plural \\
\hline AUX & auxiliar & POSC & posicional \\
\hline CAU & causativo & POSS & Possessivo frasal \\
\hline $\mathrm{CA}$ & companhia & Poss & possessivo nominal \\
\hline $\mathrm{CD}$ & acompanhado & $\mathrm{PPF}$ & pré-prefixo \\
\hline $\mathrm{COM}$ & comitativo & PR & possuidor \\
\hline CONC & conectivo & PREP & preposição \\
\hline \multirow[t]{2}{*}{ CONJ } & partícula com valor & PRE & presente \\
\hline & conjuncional & Pron & Pronome \\
\hline $\mathrm{COP}$ & cópula & PRS & presente; \\
\hline DAT & dativo & PERF & perfectivo \\
\hline DET & determinante & QUOT & marca de quotativo \\
\hline ESS & essivo & REC & passado recente \\
\hline EXIST & existencial & REL & relativo \\
\hline Fo & formativo de tempo & REM & passado remoto \\
\hline FUT & futuro & $\mathrm{sg}$ & singular \\
\hline GEN & marcador genitival & Subs & substitutivo \\
\hline HAB & habitual & SUF & sufixo \\
\hline IMPF & imperfectivo & $\mathrm{VF}$ & vogal final \\
\hline INF & infinitivo & VOC & vocativo \\
\hline INST & instrumento & & \\
\hline IT & itivo & & \\
\hline LB & línguas bantas & & \\
\hline LOC & locativo & & \\
\hline
\end{tabular}


ARAÚJO, P. J. P. Domínios conceituais das construções locativas, existenciais, comitativas e possessivas em línguas bantas. 245p. Tese (Doutorado) - Faculdade de Filosofia, Letras e Ciências Humanas, Universidade de São Paulo, São Paulo, 2013.

\section{RESUMO}

Esta tese se concentra sobre os debates referentes à relação entre as construções locativas, existenciais e possessivas nas línguas do mundo, dando especial atenção para o caso particular das línguas bantas, para as quais o entendimento mais completo da relação entre aquelas construções só se dá se o domínio conceitual do comitativo for levado em conta. A tese se desenvolve na linha de três grandes questionamentos, que constituem três partes. A primeira se ocupa de questões referentes ao trabalho de campo ou o campo da pesquisa, o da descrição de línguas africanas no Brasil, nesse caso, o de uma linguística africana na Diáspora. São apresentados os principais aspectos gramaticais das línguas do estudo, com ênfase das línguas bantas das zonas H, K e R, englobando assim todo o território de Angola. A segunda parte trata das questões teóricas, apresentando as diversas propostas que almejaram analisar as construções possessivas e outras a elas relacionadas, sendo classificadas em duas: (i) as propostas localistas, para as quais o domínio de possessivos e existenciais são em última instância locativos; e (ii) as propostas não localistas, que buscaram identificar outros fatores na relação de possessivos e as demais construções. Apresentam-se também os questionamentos epistemológicos seguindo as reflexões de um anarquismo epistemológico em linguística. Partindo dos pressupostos da Gramática Cognitiva, os domínios conceituais de locativos, existenciais, comitativos e possessivos são analisados a partir do construto da Análise do Ponto de Referência, considerado como a base conceitual comum àquelas quatro construções. A terceira e última parte é devotada às questões relativas à descrição das construções locativas, existenciais, comitativas e possessivas em línguas bantas. Para cada construção, são consideradas as subconstruções que devem receber uma maior atenção dos estudiosos, para que se tenha um quadro mais completo dos estudos sobre possessivos. Por exemplo, para as construções locativas, uma discussão sobre inversão locativa; para as construções existenciais, a questão do efeito de definitude em línguas bantas; para as construções comitativas, a relação delas com o da coordenação entre NPs, por fim, para as construções possessivas, a relação dessas com os diferentes processos de gramaticalização responsáveis pela grande diversidade das construções de posse predicativa, como o processo de transitivização ou "Have-drift". Para uma análise conjunta dessas construções, preocupada com a particularidade tipológica das línguas bantas, propõe-se que se faz necessário um refinamento teórico da categoria semântico-gramatical Controle, encarada como o fator que diferencia locativos, existenciais e comitativos de possessivos.

Palavras-chave: Domínios conceituais, locativos, existenciais, comitativos, possessivos, línguas bantas, Análise do Ponto de Referência, Controle. 
ARAÚJO, P. J. P. Conceptual domains of locative, existential, comitative and possessive constructions in Bantu languages. 245p. Dissertation (PhD in African Linguistics) Faculdade de Filosofia, Letras e Ciências Humanas, Universidade de São Paulo, São Paulo, 2013.

\begin{abstract}
This dissertation focuses on the debates concerning the relationship between locative, existential and possessive constructions in the languages of the world, paying special attention to the particular case of the Bantu languages, for which a more complete understanding of the relationship between those constructions can only happen if the conceptual domain of comitative is taken into account. The dissertation is developed according to three major questions, which constitute three parts of the work. The first part deals with issues related to field work or the field of the research, the description of African languages in Brazil, in this case, an African linguistics in the Diaspora. The main grammatical aspects of the languages of this study are presented, with emphasis to the Angolan languages, Bantu languages of zones $\mathrm{H}, \mathrm{K}$ and $\mathrm{R}$. The second part deals with theoretical issues, presenting the various proposals that have wished to analyze possessive constructions and related ones. Those proposals are classified into two types: (i) localist proposals, for which the domain of possessive and existential are ultimately locative; and (ii) Non localist proposals, which tried to identify other factors in the relations of possessive to other constructions. The epistemological questions are also presented, following a reflection of an epistemological anarchism standpoint in linguistics. Based on the assumptions of Cognitive Grammar, the conceptual domains of locative, existential, comitative and possessive are analyzed under the construct of the Reference Point Analysis, considered as the conceptual common basis to those four grammatical constructions. The third and last part is devoted to issues relating to the description of locative, existential, comitative and possessive constructions in Bantu languages. For each construction we considered sub-constructions that should receive a greater attention from scholars, for those who wish a more complete study on predicative possession. For example, for discussion locative constructions one should pay attention to issues related to locative inversion, for existential constructions, the question of the definiteness effect in Bantu languages also should be considered; for comitative constructions, one should relate this construction to that of comitative coordination between NPs, and finally, for possessive constructions, the relation of it with different grammaticalization processes responsible for the great diversity of predicative possession constructions, such as the process of transitivization or "Have-drift". For a joint analysis of these constructions concerned with typological characteristic of Bantu languages, it is proposed that it is necessary to refine theoretically the semantic-grammatical category of Control, regarded as the factor that differentiates locative, existential and comitative from possessives.
\end{abstract}

Keywords: Conceptual domains, locative, existential, comitative, possessive, Bantu languages, Control. 
ARAÚJO, P. J. P. Konzeptionelle Domänen der lokativen, existenziellen, besitzergreifenden und komitativen Konstruktionen in Bantu-Sprachen. 245p. Dissertation (Doktorat) Faculdade de Filosofia, Letras e Ciências Humanas, Universidade de São Paulo, São Paulo, 2013.

\section{ZUSAMMENFASSUNG}

Diese Arbeit konzentriert sich auf die Debatten über den Zusammenhang von den lokative, existenzielle und besitzergreifende Konstruktionen in den Sprachen der Welt, wobei besonderes Augenmerk auf den besonderen Fall der Bantu-Sprachen, wofür das bessere Verständnis der Beziehung unter diesen Konstruktionen nur geschehen kann, wenn die konzeptuelle Domäne von Komitativ berücksichtigt. Die Dissertation entwickelt sich mit Focus in drei wichtigsten Fragen, die drei Teile der Dissertation bilden. Die Erste befasst sich mit der Feldarbeit oder Feldforschung der Beschreibung der afrikanischen Sprachen in Brasilien, in diesem Fall eine afrikanische Linguistik in der Diaspora. Es stellt die wichtigsten grammatikalischen Aspekte der Sprache der Studie dar, mit besonderem Akzent auf die angolanischen Sprachen der Zonen H, K und R. Der zweite Teil beschäftigt sich mit theoretischen Fragen und stellt die verschiedenen Vorschläge dar, die die possessive und andere gemeinsame Konstruktionen eine Analyse ersehnten und sind in zwei Kategorien eingeteilt: (i) die lokalistischen Vorschläge, für die die Domäne der Besitzergreifenden und Existentiellen letztlich locativ sind; und (ii) die nicht lokalistischen Vorschläge, die versucht haben andere Faktoren in der Beziehung $\mathrm{zu}$ den Besitzergreifenden und die anderen Konstruktionen zu identifizieren. Es stellt auch die erkenntnistheoretischen Fragen nach den Überlegungen von einer erkenntnistheoretischen Anarchismus in der Linguistik dar. Ausgehend von den Annahmen der Kognitiven Grammatik sind die lokativen, konzeptuellen, existenziellen, komitativen und besitzergreifenden Domäne aus dem Konstrukt der Analyse von Referenzpunkt analysiert, der als gemeinsame konzeptuelle Grundlage diesen vier Konstruktionen betrachtetist. Der dritte und letzte Teil ist zu Fragen im Zusammenhang mit der Beschreibung der lokativen, existenziellen, komitativen und besitzergreifenden Konstruktionen in Bantu-Sprachen gewidmet. Für jede Konstruktion berücksichtigt die subKonstruktionen, die für eine umfassendere Studien über Besitzergreifende größere Aufmerksamkeit von Wissenschaftlern erhalten sollen. Zum Beispiel: für die lokative Konstruktionen eine Diskussion über locative Inversion; für existentielle Konstruktionen die Frage nach der Wirkung von Bestimmtheit in Bantu-Sprachen; für die komitative Konstruktionen ihre Beziehung mit der Koordinierung unter NPs; und schließlich für die besitzergreifende Konstruktionen die Beziehung von diesen mit verschiedenen Prozessen der Gramatikalisierung, die für die große Vielfalt der Prädikativbesitzkonstructionen verantworlich ist, wie der Prozess "Have-drift". Für eine gemeinsame Analyse dieser Konstruktionen und mit Fokus der typologischen Charakteristik der Bantu-Sprachen vorzunehmen, wird es vorgeschlagen, die Notwendigkeit einer theoretischen Verfeinerung der semantisch-grammatischen Kategorie Kontrolle, die als der Faktor der Differenzierung der Lokativen, Existenziellen und Komitativen von den Besitzergreifenden ist.

Schlüsselwörter: konzeptuelle, lokative, existentielle, komitative und besitzergreifende Domäne; Bantu-Sprachen; Kontrolle. 


\section{SUMÁRIO}

INTRODUÇÃO

Parte I QUESTÕES PARA O CAMPO DA PESQUISA 6

Capítulo 1 Linguística Africana na Diáspora 8

$\begin{array}{ll}\text { 1.1 Apresentação } & 8\end{array}$

$1.2 O$ objeto de estudo em construção 9

1.2.1 POSSE É COMPANHIA: "Estar com” línguas bantas no português brasileiro 10

1.30 campo da pesquisa ou esboço de uma Linguística Africana da Diáspora 17

$\begin{array}{ll}\text { 1.3.1 Angola e sua situação linguística } & 17\end{array}$

1.3.2 Sobre fazer campo "fora" do campo: Diáspora africana e Linguística Africana 20

1.4 Línguas bantas deste estudo

1.5 Metodologia $\quad 25$

$\begin{array}{ll}1.5 .1 \mathrm{O} \text { corpus } & 27\end{array}$

1.6 Limites e alcance desta pesquisa $\quad 28$

1.7 Em síntese 29

CAPÍtulo 2 As Línguas Bantas nUM CAleidoscópio 30

2.1 Apresentação $\quad 30$

2.2 Fonologia segmental e suprassegmental 31

2.3 Morfologia nominal 36

2.3.1 Classes nominais $\quad 36$

2.3.2 Classes nominais locativas $\quad 39$

2.4 Morfossintaxe do verbo $\quad 40$

2.4.1 A estrutura do verbo banto $\quad 40$

2.4.2 Extensões verbais $\quad 44$

2.4.3 Tempo, aspecto e modo (TAM) 49

2.5 Aspectos semânticos e discursivos $\quad 50$

2.5.1 Cópula e negação $\quad 50$

2.5.2 Foco e tópico 53

2.6 Tratamento de categorias cognitivas em línguas bantas 54

2.7 Em síntese $\quad 56$ 
Capítulo 3 A Expressão de Posse Predicativa

3.1 Apresentação

3.2 O que um possessivo tem?

3.2.1 Perspectivas tipológicas $\quad 67$

3.3 A tipologia de Heine (1997)

3.4 A tipologia de Stassen (2009)

3.4.1 Um modelo para a codificação de posse predicativa $\quad 74$

3.5 Apreciação das propostas tipológicas $\quad \mathbf{7 5}$

3.5.1 Por uma tipologia de posse predicativa em línguas faladas e sinalizadas $\quad 77$

3.6 Desafios teóricos e descritivos

$\begin{array}{lc}3.7 \text { Em síntese } & 80\end{array}$

CAPÍTUlo 4 As RELAÇÕES ENTRE LOCATIVOS, EXISTENCIAIS

e Possessivos (e Comitativos?)

$\begin{array}{ll}\text { 4.1 Apresentação } & 81\end{array}$

4.1.1 Localizando a problemática $\quad 81$

4.2 As abordagens localistas $\quad 82$

4.2.1 Primeiras propostas localistas (Benveniste, 1966; Bach, 1967; Lyons, 1968) 82

4.2.2 Abordagem funcionalista e tipológica (Clark, 1978) 83

4.2.3 Abordagens formalistas (Freeze, 1992; Kayne, 2000 [1993]) 85

4.3 Críticas e desenvolvimentos das abordagens localistas 91

4.4 As abordagens não localistas $\quad 94$

4.4.1 Primeiras propostas não localistas (Bickerton, 1981; Croft, 1991; Koch, 1999) 94

4.4.2 Abordagem tipológica e funcionalista (Stolz; Stroh; Urdze, 2006) 96

4.4.3 Abordagem cognitivista (Langacker, 2003; 2009) 99

4.5 As diferentes abordagens teórico-metodológicas e uma postura epistemológica 102

4.5.1 Gramaticalização, incorporação e construções de pontos de referência 102

4.6 Um lugar para o comitativo: casando as tipologias com os debates

$\begin{array}{ll}\text { sobre possessivos e domínios relacionados } & 108\end{array}$

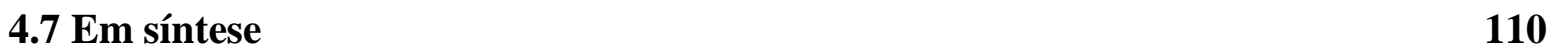


CAPÍTUlo 5 Domínios ConCEITUAIS de POSSESSIVOS E A ANÁlise do PONTO DE REFERÊNCIA

5.1 Apresentação 112

5.2 Construtos teóricos, metodologia e anarquismo epistemológico 113

5.2.1 Um linguista-camaleão feyerabendiano 113

5.2.2 Gramáticas cognitivas, descrição e análises linguísticas 116

5.2.2.1 A base conceitual da gramática 118

5.2.2.2 Caracterização conceitual de categorias relacionadas a possessivos $\quad 120$

5.3 Análise do Ponto de Referência em domínios conceituais 123

5.3.1 Posse e possessivos 123

5.3.2 Companhia e comitativos 126

5.3.3 Existência e existenciais $\quad 130$

5.3.4 Localização e locativos 132

5.4 Delimitando domínios conceituais 134

5.5 Subdomínios e subconstruções $\quad 138$

5.6 Para além da Análise do Ponto de Referência 142

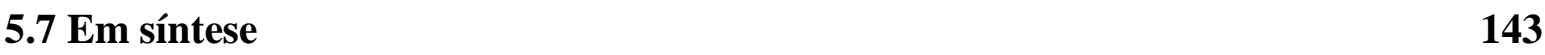

Parte III QUESTÕES DE DESCRIÇÃO E ANÁLISE

Capítulo 6 Construções Locativas, Existenciais, Comitativas

e Possessivas em Línguas Bantas 146

6.1 Apresentação 146

$\begin{array}{ll}\text { 6.2 Construções locativas } & 147\end{array}$

6.2.1 Localização 147

6.2.2 Origem e destino de um percurso $\quad 150$

6.2.3 Mudança de um percurso 152

6.2.4 Inversão locativa $\quad 154$

6.3 Construções existenciais $\quad 159$

6.3.1 O pré-prefixo 161

6.3.2 Efeito de definitude 163

6.4 Construções comitativas $\quad 165$

6.4.1 Coordenação comitativa 168

$\begin{array}{ll}\text { 6.4.2 Instrumento } & 170\end{array}$ 
6.5 Construções possessivas

6.5.1 Construções com verbos comitativos [PR COP + COM PD]

6.5.2 O estatuto de COP e COM [PR COP.COM + COM PD]

6.5.3 Construções com o esquema [PR PD COP + POSS]

6.5.4 Construções transitivas [PR $\mathrm{V}$ PD]

6.6 Transitivização: “deriva de ter” de possessivos comitativos

6.7 Em síntese

\section{CAPÍTUlo 7 DOMÍNIOS CONCEITUAIS DE POSSE PREDICATIVA} em línguas bantas e a Categoria Controle

188

7.1 Apresentação

7.2 Descrição de línguas bantas e implicações para os debates sobre possessivos e domínios relacionados

7.3 Possessivos e locativos

7.4 Possessivos e existenciais

7.6 Controle: uma categoria gramatical necessária, mas não suficiente?

7.6.1 Formalização para a validade de uma categoria semântico-gramatical

7.6.2 Incorporando a categoria Controle na Análise do Ponto de Referência

CONCLUSÃo

REFERÊNCIAS

APÊNDICES

APÊNDICE A- Trechos do conto "O pescador e o filho" 134

APÊNDICE B - Lista de línguas bantas presentes na tese 136

ANEXOS 241

ANEXO A - Mapa político de Angola (United Nations Cartographic Section, 2004) 241

ANEXO B - Mapa etnolinguístico de Angola (Lewis; Simons, 2013) 242

ANEXO C - Mapa da WALS - Posse predicativa (Stassen, 2005a) 243 


\section{INTRODUÇÃo}

"A minha linha de pesquisa é a curiosidade."

César Ades

"O que aprendi com a etnologia?

O hábito incômodo da verificação."

Hubert Fichte

Esta pesquisa teve início com a constatação da grande produtividade de expressões com "estar com" para estados e relações de posse no português brasileiro durante nossa participação em uma disciplina introdutória à Linguística Cognitiva e reuniões de grupos de estudos. Em uma discussão sobre possíveis metáforas conceituais em português, uma colega de pesquisa notou que brasileiros aprendizes de inglês como segunda língua sempre usavam "to be with" para expressões de estado do inglês, como "I am with hunger", "I am with fever" para dizerem "I am hungry" e "I got a fever". A relação de uma expressão para companhia usada para posse temporária em português nos chamou a atenção. Logo no início de nossas discussões, encontramos em Stolz (2001) um primeiro tratamento sobre "estar com" em português, considerado pelo autor como expressão comitativa para possessivo e utilizado em português brasileiro de forma idiomática.

Por esse mesmo tempo, em uma aula de curso introdutório de língua suaíli, do Centro de Línguas da Universidade de São Paulo, constatamos que o uso da partícula com valor de comitativo naquela língua banta era a alternativa preferida para a expressão de posse, o que indicava ser um traço tipológico das línguas do grupo banto. Num primeiro momento intrigou-nos a possibilidade de haver alguma relação entre a construção "estar com" do português com a estratégia comitativa para a expressão de posse, como encontrado em suaíli e outras línguas bantas. Começamos a associar o fato à hipótese de contato linguístico e decalques semânticos como possíveis causas para o uso de uma estratégia comitativa para possessivos em português. Tal hipótese foi deixada de lado para que nos concentrássemos primeiramente em uma melhor descrição e análise das construções possessivas em línguas bantas de modo que um trabalho com a hipótese dos contatos linguísticos fosse possível 
posteriormente, seguindo na linha dos trabalhos encontrados em Fiorin e Petter (2008) e Petter e Vanhove (2011) quanto à relação entre o português brasileiro e línguas africanas.

Durante o desenvolvimento de nossa pesquisa, percebemos que o domínio das construções possessivas é comumente relacionado a dois outros na literatura, o das construções locativas e existenciais (Clark, 1978; Freeze, 1992). Ficou claro que seria uma lacuna indesejável não tratar dessas duas outras construções em relação às de possessivos em línguas bantas. Juntamente com essa constatação, veio a de que a estratégia comitativa para possessivos das línguas bantas não aparecia ao lado das estratégias de locativos e existenciais de outras famílias linguísticas. Como as construções possessivas são fortemente relacionadas ao comitativo em línguas do domínio banto, percebemos que para lidar com possessivos deveríamos levar em conta esse outro valor semântico dos verbos com sentido comitativo utilizados para a expressão de possessivos, ou seja, os verbos possessivos-comitativos das línguas bantas.

Neste trabalho, propomos uma descrição e análise dos domínios conceituais relacionados às construções possessivas em línguas bantas em relação com o domínio das construções locativas e existenciais, além de trazer para o âmbito das discussões sobre essas construções a particularidade das línguas do grupo banto, para as quais o domínio do comitativo está bastante relacionado àquelas três construções, tão bem tratadas na literatura sobre possessivos (Heine, 1997; Stassen, 2009).

De uma preocupação teórica, partimos da necessidade de orientar nossa descrição linguística a um grupo específico de línguas tipologicamente relacionadas e, como resultado da necessidade primordial de se fazer escolhas para o desenvolvimento de uma investigação, decidimos por trabalhar com as línguas bantas de Angola. Como em toda escolha científica, a imparcialidade não é totalmente um imperativo. A escolha dessas línguas do domínio banto se justifica pela ligação histórica das línguas pertencentes a esse grupo linguístico com o português brasileiro, a exemplo do quimbundo, quicongo e umbundo, que tiveram importante papel na formação histórica de variedades do português falado no Brasil (Petter, 2008). Acrescenta-se a isso a indubitável necessidade de mais estudos e pesquisas sobre as línguas nacionais angolanas que, infelizmente, em relação a outras línguas das mesmas zonas, mas localizadas nos países vizinhos, como o herero e o ochindonga, já foram realizados estudos pormenorizados como gramáticas de referências. Ressaltamos com isso que, além dessas justificativas, buscar selecionar na medida do possível as línguas de Angola foi também uma escolha metodológica relacionada com planos futuros de desenvolver projetos de descrição e 
ensino das línguas nacionais daquele país, contribuindo, assim, com o anseio de modificar a situação de poucos estudos voltados para o conhecimento das línguas de Angola.

Assim, este estudo carrega duas preocupações principais, uma descritiva, voltada para a descrição de construções gramaticais de um conjunto particular de línguas, onde tentaremos demonstrar que para uma melhor caracterização de possessivos em línguas bantas outros domínios relacionados devem ser levados em conta como locativos, existenciais e comitativos. A segunda preocupação, teórica, tem a ver com a contribuição de línguas que utilizam verbos comitativos para possessivos para o enriquecimento das teorias a partir do uso de novos dados, trazendo para o rol dos debates sobre a relação entre os domínios de possessivos, existenciais, locativas, o domínio do comitativo.

Durante o desenvolvimento deste trabalho de pesquisa, alguns questionamentos conduziram de certa forma todas as etapas de elaboração, produção e finalização da tese. Os primeiros questionamentos dizem respeito à realização do trabalho de campo, já que uma das principais dificuldades de realização de uma tese em linguística africana no Brasil é justamente o trabalho de campo. À parte de nossos questionamentos voltados para a pesquisa de campo, levantamos algumas questões de natureza epistemológica, que também perpassaram as diversas etapas da pesquisa. Como a motivação inicial foi de cunho teórico e a tradição de estudos de línguas bantas segue uma linha mais descritivista (a exemplo os trabalho coletado em Nurse e Philippson, 2003), não raramente encaramos a necessidade de justificar um estudo voltado para questões teóricas em línguas com uma forte tradição de estudos descritivos. Com grande frequência tivemos que responder à questão se o nosso trabalho se qualificava como de linguística geral ou linguística africana. Esperamos que os próximos capítulos, organizados em três partes de acordo com nossos questionamentos, sejam convincentes sobre a possibilidade de que esta tese possa estar na intersecção dessas duas áreas, de modo que tanto as questões linguísticas mais gerais como as mais específicas, voltadas para o caso das línguas africanas, possam ganhar em uma maior adequação, tanto descritiva quanto explicativa.

Com isso, buscamos partir de um debate teórico em linguística geral para descrever construções específicas em um conjunto de línguas também específico, cuja parcela significativa delas, por vários motivos, recebeu pouco ou nenhum tratamento sobre a semântica de possessivos, seja em gramáticas de referência ou em esboços gramaticais. Pretendemos com isso trazer para a descrição das línguas bantas alguns questionamentos teóricos que poderão aprimorar futuras descrições dessas mesmas línguas. Em outras palavras, esta tese faz um trajeto de mão dupla: apresenta, no palco das questões teóricas sobre 
possessivos, línguas que até o momento não tiveram o merecido estudo sobre a temática da relação de possessivos com outras construções inter-relacionadas, ao mesmo tempo em que busca apontar lacunas nas discussões sobre possessivos justamente por essas discussões terem até o momento ignorado a particularidade tipológica das línguas bantas para construções de posse predicativa. E, sem dúvida, reafirmamos que os debates teóricos poderão ser enriquecidos com as particularidades tipológicas das línguas bantas.

Com a continuidade do interesse de linguistas pelas questões semânticas relativas a possessivos, acreditamos que esta tese oferecerá aos teóricos motivos para que se observe com mais atenção dados das línguas bantas. Em contrapartida, esperamos também que os linguistas africanistas atentem mais para categorias cognitivas na descrição de línguas africanas, contribuindo assim para um aprimoramento dos aspectos semânticos das suas descrições.

Como mencionado, a tese está dividida em três partes de forma que cada capítulo está organizado seguindo os principais questionamentos que direcionaram nossa investigação: questionamentos sobre a pesquisa de campo; questionamentos teóricos e epistemológicos e por fim os questionamentos de descrição e análise linguística.

Na primeira parte, das questões para o campo da pesquisa, apresentamos o percurso da pesquisa sob a rubrica que denominamos aqui de Linguística Africana na Diáspora. Apresentamos a forma como foi elaborado o corpus, a metodologia utilizada e fazemos algumas ponderações sobre os limites e alcance deste estudo. Ainda na primeira parte, apresentamos os principais aspectos gramaticais das línguas bantas, enfatizando as línguas das zonas $\mathrm{H}, \mathrm{K}$ e $\mathrm{R}$, tomando como referência as línguas que contam com gramáticas de referência ou publicações mais extensas. A segunda parte é dedicada aos debates e à fundamentação teórica sobre possessivos, seguidos de alguns apontamentos epistemológicos. Nessa parte são resenhados os principais trabalhos sobre posse predicativa nas línguas do mundo (Heine, 1997; Stassen, 2009) e os trabalhos que se ocuparam da relação entre construções locativas, existenciais e possessivas. Centramos nossa atenção sobre os domínios conceituais de cada construção em particular, em relação a localização, existência, companhia e posse. Discutimos também a relevância de uma postura epistemológica em Linguística mais próxima das ideias do filósofo Paul Feyerabend (2007), a de um anarquismo epistemológico, como forma de lidar com temas em Linguística para os quais uma postura excessivamente racionalista (aos moldes de Lakatos) pouco contribuiria para um entendimento mais completo das questões científicas objeto de pesquisa. 
Por fim, na terceira parte, das questões de descrição e análise, expõem-se as particularidades das línguas bantas para a questão da relação entre as construções possessivas, existenciais e locativas, além, claro, das construções comitativas. Juntamente a essa parte descritiva, propomos análises para cada construção, considerando o papel que o grupo de línguas bantas tem para uma contribuição para os estudos das línguas denominadas como de possessivos comitativos (Stassen, 2009), uma das estratégias de línguas que que usam verbos de cópula (COP) para a expressão de posse (Jung, 2011).

O último capítulo, na parte três, busca uma síntese das discussões, com a formulação da hipótese de que para um tratamento semântico e cognitivo das relações entre possessivos, existenciais, locativos e comitativos, apenas uma melhor caracterização da categoria Controle poderá lançar novas luzes para a problemática da inter-relação daquelas construções nas línguas do mundo. 


\section{Parte I QUESTÕES PARA O CAMPO DA PESQUISA}


"Le verbe AVOIR n'existe pas en kikôngo. On le traduit par ÊTRE AVEC: KALA YE."

(Dereau, 1955, p. 30)

Vomenla wukwene ku sikila mo ovilwa "Não é possível assobiarmos pela boca alheia." (Provérbio umbundo coletado por Gociante Patissa,

Disponível em: 〈http://ombembwa.blogspot.com.br/> Acesso em: 22 de maio de 2012) 


\section{CAPÍtulo 1}

\section{Linguística AFricana Na DiÁSPORA}

\section{1 Apresentação}

Este capítulo apresenta o universo da pesquisa e os procedimentos metodológicos concernentes à realização dos trabalhos de campo. Apresentamos uma rápida trajetória de como tem se dado o percurso da construção do objeto de estudo e como foram se desenvolvendo nossos questionamentos sobre possessivos e, particularmente para as línguas bantas. Para a realização deste estudo um dos primeiros desafios foi o de selecionar quais línguas bantas fariam parte de nossa descrição e análise. Após a escolha de dedicar este estudo às línguas angolanas, ficaram logo evidentes, desde o início, algumas dificuldades para a realização de campo em Angola. Dificuldades essas que perpassam tanto razões políticas como acadêmicas.

Diante das dificuldades, a primeira alternativa foi a de tentar realizar um trabalho preliminar com falantes de línguas angolanas fora de Angola. Já estávamos cientes que na impossibilidade de ir a campo para a África, nosso trabalho teria que ser desenvolvido como diversos outros, a serem mencionados mais adiante. Nesse caso, estávamos, mesmo que implicitamente, adentrando no que mais tarde iríamos encontrar um termo que poderia agrupar muitos desses trabalhos desenvolvidos sobre a África fora da África ou com a Diáspora africana. Ainda neste capítulo são delineadas as questões centrais de todo o trabalho, além de apresentar as informações sobre as línguas bantas que serão estudadas em nossa investigação. Com isso, exploramos neste capítulo nossas primeiras dificuldades como motivação para fazemos uma discussão preliminar sobre o que pode vir a ser o papel da Linguística nas discussões sobre a Diáspora e a contribuição para o estreitamento entre essas duas disciplinas no âmbito dos estudos sobre a Diáspora (Olaniyan; Sweet, 2010), para a realização de uma Linguística Africana da/na Diáspora.

Em seguida, discutimos os principais temas teóricos que estarão presentes nos capítulos a seguir. A elaboração do corpus da pesquisa como também os procedimentos metodológicos empregados são apresentados. Por fim, delineamos os alcances e limites deste estudo. 


\title{
$1.2 O$ objeto de estudo em construção
}

O nosso objeto de estudo são os domínios conceituais de possessivos, mais especificamente, as relações de possessivos com existenciais, locativos e comitativos, por razões que ficarão mais claras no decorrer de nossa apresentação. Pela natureza cognitiva dos fenômenos ligados a possessivos, consideramos esse tópico de estudo como um objeto em constante construção. Definir e descrever o domínio das construções possessivas tem sido uma tarefa bastante controversa e instigante em Linguística. Uma das principais questões tem a ver justamente com o domínio conceitual de posse, nas palavras de Heine:

\begin{abstract}
Em um número de trabalhos, dúvidas têm sido levantadas quanto ao fato de se posse realmente constitui um domínio independente da conceptualização humana ou se ela poderia ser descrita mais adequadamente em referência a algum outro domínio ou domínios. Sendo assim, tem-se argumentado que posse pode ser entendida como um caso especial de localização. (Heine, 1997, p. 25) ${ }^{1}$
\end{abstract}

Partindo inicialmente de uma preocupação teórica, da forma como foi apontada por Heine, nosso trabalho tem se centrado em dois grandes polos, um polo dos questionamentos teóricos e epistemológicos, ${ }^{2}$ outro de questionamentos de descrição e análise. Permeando esses dois, temos encarado diferentes problemas referentes à realização da pesquisa de campo, de forma que esses mesmos problemas têm afetado, num trocadilho pertinente, todo o campo da pesquisa, que englobaria, em linhas gerais, os estudos que têm sido realizados sobre línguas africanas fora da África, tocando no que poderia ser chamada de Linguística Africana na Diápora, realidade de linguistas brasileiros interessados com o conhecimento das línguas africanas, mas que por diversas razões, acabam por realizar seus trabalhos fora do Continente africano. Essa situação, que a princípio poderia ter causado problemas ainda maiores para a nossa pesquisa, acabou por se tornar uma oportunidade para refletirmos sobre as possibilidades de se fazer Linguística Africana no Brasil.

Nas próximas seções nos ocupamos de traçar a trajetória de nossa pesquisa para então discutirmos sua possível inserção nos estudos da Diáspora, mesmo que indiretamente.

\footnotetext{
1 "In a number of works, doubts have been raised as to whether possession indeed constitutes an independent domain of human conceptualization, or whether it might not be described more profitably with reference to some other domain or domains. Thus, it has been argued that possession can be regarded as a special case of location."

${ }^{2} \mathrm{~A}$ preocupação epistemológica neste trabalho tem sido uma constante, e acabou por tornar-se uma parte imprescindível para o desenvolvimento de nossa investigação. Em Araújo (2011b) esboçamos algumas primeiras linhas sobre o assunto. Uma parte do Capítulo 5 é dedicada a esses questionamentos.
} 
1.2.1 Posse É COMPANHIA: "Estar com” línguas bantas no português brasileiro

A constatação de que o comitativo tem íntima relação com possessivo veio inicialmente do português e as construções com "estar com" usadas principalmente para posse transitória e estados mentais. No primeiro trabalho dedicado a essas construções a que tivemos acesso (Stolz, 2001) verificamos que não só o português permitia tais construções, como também outras línguas indo-europeias, como o islandês e o finlandês. Como primeira tentativa de verificar o porquê da relação de possessivos com comitativos, aplicamos os resultados de estudos cognitivistas na área de pesquisa de metáforas conceituais (Lakoff; Johnson, 1987) e propusemos a metáfora POSSE É COMPANHIA, seguindo os mesmos termos da Metáfora da Companhia proposta por Lakoff e Johnson para o caso da relação entre Comitativo e Instrumento: InSTRUMENTOS SÃO COMPANHIAS. No entanto, com o desenvolvimento da pesquisa vimos que o quadro era um pouco mais complicado.

Além da relação de possessivos com comitativos, o trabalho de Stolz nos chamou a atenção para a relação também com locativos e existenciais. Assim, adentrávamos no labirinto conceitual entre os quatro domínios focalizados nesta tese: de possessivos (posse), locativos (localização), existenciais (existência) e comitativos (companhia). Para uma primeira definição de domínio conceitual, vejamos estas rápidas linhas de Evans e Green (2006, p. 14): "Um domínio conceitual é um corpo de conhecimento dentro de nosso sistema conceptual o qual contém e organiza ideias e experiências relacionadas."3 As quatro construções objeto deste estudo remetem inevitavelmente para os conceitos básicos de "posse", "localização", "existência" e "companhia". A partir daqui estaremos sempre relacionando as construções gramaticais a esses domínios conceituais, reiterando dessa maneira, base experiencialista de cada construção, sempre que necessário.

Como exemplo da relação entre os domínios conceituais de construções possessivas, existenciais, locativas e comitativas, vejamos o caso do português brasileiro, para o uso de verbos de posse predicativa e da preposição comitativa:

\footnotetext{
3 "A conceptual domain is a body of knowledge within our conceptual system that contains and organises related ideas and experiences." No Capítulo 5 ocupamos-nos de forma mais aprofundada e detalhada sobre esses quatro domínios conceituais.
} 
(1) Português brasileiro
a. O homem tem um carro novo.
(Possessivo)
b. Tem um carro na garagem.
(Existencial/Locativo)
c. Tem gente que não tem carro.
(Existencial)
d. Tem três anos que não vejo ele.
(Existencial/ETD)

(2) Português brasileiro
a. O homem tá com um carro novo.
(Possessivo)
b. Tá com um carro na garagem.
(Existencial/Locativo)
c. Ele tá com um carro perto dele.
(Comitativo)
d. Tá com três anos que não vejo ele.
(Existencial/ETD)

Nos exemplos em (1) o verbo "ter" é utilizado nas construções possessivas, existenciais e locativas. Nos exemplos em (2) a construção com "estar com" pode substituir, em certa medida, aquelas com "ter", porém com algumas restrições. Por exemplo, (1c) é pouco aceito por falantes de português, caso o verbo ter seja substituído por "estar com". (i) “?Tá com gente que não tem carro". ${ }^{4}$ Além de possessivos, locativos e existenciais, o domínio do comitativo é utilizado também para expressões de tempo decorrido (ETD), conforme (2)d (AVELAR, 2012), que pode ser considerado um tipo de existencial.

Dando continuidade às leituras sobre a intrincada relação entre os quatro domínios conceituais desta tese, vimos que a literatura é bastante vasta e diversificada no que diz respeito às orientações teóricas. Desde os primeiros trabalhos que se ocuparam com a temática (Benveniste, 1976 [1966]; Bach, 1967; Lyons, 1979 [1968]), até a consolidação do que ficou conhecido como "Paradigma Localista" com Freeze (1992) e outras propostas seguindo na mesma linha deste último, como Kayne (2000 [1993]), a temática tem sido bem produtiva nos últimos anos principalmente com trabalhos de cunho tipológicos (Heine, 1997; Stassen, 2009; Stolz, et al., 2006; Stolz et al, 2008). Verificamos que o grupo das línguas bantas possuía como principal estratégia para expressão de posse predicativa o domínio do comitativo, apesar de esse domínio não estar presente nas discussões sobre a relação de possessivos com outros domínios conceituais da literatura voltada especificamente para a questão dessa relação. ${ }^{5}$

\footnotetext{
${ }^{4} \mathrm{O}$ sinal de interrogação indica a pouca aceitabilidade da sentença com "estar com".

${ }^{5}$ Esses temas serão tratados nos capítulos 3 e 4.
} 
Redirecionamos, então, nossa atenção para uma primeira hipótese sobre contatos linguísticos entre o português brasileiro e línguas bantas. Tal hipótese recebia algum suporte como o dos primeiros estudos sobre a influência de línguas africanas no português do Brasil, com a constatação feita por Raimundo (1933) de que o português brasileiro empregava expressão similar à das línguas bantas:

Nas frases em que o português emprega o verbo ter com objeto imediato, indicando posse ou aquisição habitual, usa-se no ambundo do verbo ku-kala com o regime de $n i$, com: en engala ni tumatari, estou com (tenho) umas pedrinhas; no conguês o verbo kala ou ina, com o regime de ie, io, ia, com: mono nsakala ie kinkutu ou mono iina ie kinkutu, estou com (tenho) a camisa. (Raimundo, 1933, p. 66) ${ }^{6}$

Fazendo com que o autor então concluísse que:

A influência das línguas sul-africanas ${ }^{7}$ não se restringiu apenas à copiosa importação de vocábulos primários e derivados; alargaou-se, ainda que escassamente, à própria sintaxe, actuando de preferência no amanho da frase popular, que resiste á polícia gramatical:

[...]

c) O emprego preferencial de estar com por ter, que é o vernáculo e clássico: aquela mulher está com (tem) febre, etc. (Raimundo, 1933, p. 85)

A hipótese de contato só seria plausível com um melhor entendimento de como se apresentam os possessivos em línguas bantas. Observamos, pela literatura, que além da ausência do comitativo nas discussões sobre possessivos, tratar das construções de posse em línguas bantas sem considerar o domínio cognitivo do comitativo deixaria fora da descrição e da análise uma das facetas mais intrigantes de como diversas línguas expressam posse predicativa, não apenas fazendo uso de locativos, existenciais ou verbos do tipo have do inglês ou ter do português. Ao tomar como objeto de estudo sobre posse predicativa línguas da família nigero-congolesa, do grupo banto, intentamos trazer para o centro das discussões sobre possessivos esse domínio ainda pouco representado naqueles estudos, da mesma forma explorar nessas línguas uma descrição mais aprofundada dessas quatro construções.

Praticamente todas as línguas do grupo banto compartilham uma estratégia de expressão de posse chamada por alguns autores de posse de conjunção (conjuction possessive) ou posse comitativa (comitative possession), como classificam Stolz, Stroh e Urdze (2006), ou nos termos de Stassen (2009) e Creissels (2006), a WITH-construction e nas de Heine

\footnotetext{
${ }^{6}$ Onde o autor usa o nome "ambundo" provavelmente ele quis se referir ao quimbundo, o que podemos supor pelo exemplo utilizado e pela marca de comitativo ni. E onde ele usa o nome "conguês" possivelmente é a língua quicongo, também pelo exemplo e a marca de comitativo ie, io,ia.

${ }^{7}$ Aqui o autor se refere não às línguas da África do Sul, mas às do sul do Continente africano.
} 
(1997) uma construção no Esquema de Companhia (Companion schema). Como exemplificação de como se dá uma construção possessiva na maioria das línguas do grupo banto, vejamos abaixo algumas sentenças em línguas bantas de diferentes zonas: ${ }^{8}$

$$
\begin{array}{ll}
\text { Suaíli }_{(\mathrm{G} 42)^{9}} & \\
\text { Ni-na } & \text { kitabu }
\end{array}
$$

1Sg-ter livro

'Eu tenho um livro' (Lit. Eu estou-com livro)

(4) Ochindonga (R22) (Fivaz, 2003, p. 58)

$\begin{array}{lllll}\text { Aayambá } & \text { o-yé } & \text { ná } & \text { omagúmbó } & \text { omanené. } \\ \text { Rico } & \text { MS-COP } & \text { com } & \text { casa } & \text { grande }\end{array}$

'O rico tem casas grandes.'

(5) Tsuana (S31) (Creissels, 2013, p. 469)

$$
\begin{array}{llll}
\text { Ke } & n a & \text { le } & \text { ma-di. } \\
\text { 1SG } & \text { estar.com } & \text { com } & \text { CL6-dinheiro }
\end{array}
$$

'Eu tenho dinheiro.'

(6) Iaca (H31) (Kidima 1991, p. 231)

\begin{tabular}{|c|c|c|c|}
\hline na & mw-ánáykérí ka & tuvr-áá & jgúrúbalara \\
\hline com & 1-sobrinho & insultar-HAB & 1.tio \\
\hline
\end{tabular}

$\begin{array}{llllll}\text { Maamba } & \text { wakála } & \text { ye baána } & \text { bóolé; kaanzi } & \text { Nzala } & \text { khatu báana. } \\ \text { Água } & \text { estava } & \text { com crianças duas; mas } & \text { Fome } & \text { não crianças }\end{array}$

'Água tinha duas crianças, mas Fome não tinha nenhuma criança.'

(7) Leembama (B62) (Okoudowa, 2010, p. 182)

'O que se faz aos outros acontece a si.' ('Se você tem sobrinho, não insulte seu tio')

\footnotetext{
${ }^{8}$ É comum haver referência a uma língua banta com indicação do seu prefixo nominal $k i-$, usado para indicar a língua de um povo, como QUIssuaíli, QUImbundo ou outra variante, como CHIcheua, OCHIndonga, etc.

${ }^{9}$ Exemplos retirados de notas de aula do curso de Língua e Cultura Suaíli do Centro de Línguas da USP, ministrado pela profa. Juliana Macek em 2009. Os exemplos serão sempre apresentados como segue: o nome da língua com a classificação das zonas bantas, para o caso das línguas bantas, e as referências logo em seguida. Tentaremos na medida do possível apresentar os exemplos da forma como se encontram nas fontes originais, como no exemplo (5) no qual Creissels glosa a partícula na como "estar.com". No entanto, por necessidade de uma certa padronização dos exemplos a serem apresentados incluiremos as glosas mesmo quando os autores não o fazem, como é muito comum, a exemplo do (4) do oshindonga. As glosas, porém, só serão incluídas nos exemplos e línguas onde há a possibilidade para tal. OS exemplos resultantes de nosso trabalho de campo não trarão quaisquer referências. Sempre que necessário, indicaremos os colaboradores para cada língua específica, como neste exemplo do suaíli.
} 
Nos poucos exemplos apresentados acima (3)-(7), vimos que os autores geralmente glosam o verbo comitativo das línguas bantas como ter ou estar com, outros usam a preposição com ou usam como glosa CONJ para dar o sentido de item conjuntivo. Neste ponto faz-se necessário justificar a forma como iremos denominar o item lexical com valor comitativo da maioria das línguas de nossa amostra. Nos próximos exemplos de construções possessivas, vamos dar preferência por COM para glosar o item geralmente na forma $n a$, enfatizando assim o seu valor comitativo, apesar de cada língua categorizá-lo de forma bem diferente. Alguns autores o tratam como equivalente à preposição "com”, outros o denomina como “ item de valor conjunção". Autores como Seidel (2008) usam a etiqueta "clítico sintático". Sem mencionar que para muitos casos, como para o suálili, o na é chamado de verbo comitativo. Frente a essa variedade de sentidos e rótulos gramaticais, preferimos utilizar o termo "partícula de comitativo", mesmo sabendo que esse item lexical não se comporta unicamente como partícula, mas por acharmos que esse termo seria relativamente mais "neutro" para abarcar todos os casos a serem exemplificados, de tantas línguas diferentes. Nurse (2008, p. 54) apresenta da seguinte forma esse item lexical:

\begin{abstract}
\#na foi originalmente, e continua sendo em muitas línguas bantas, a conjunção não flexional e independente 'com, e' geralmente ligando nominais (no protobanto). Ela ainda serve, largamente, como a base para 'ter = estar com'. Ela ocorre como clítico ou prefixo em uma escarsa distribuição de línguas fora do noroeste, mas ocorre principalmente em duas zonas descontínuas, K10-30-40 e G20-40-E56-E71-E72. Suas funções são diversas: com infinitivos, com subjuntivos, com passados (narrativos ou não narrativos) e com futuros. Sua distribuição geográfica esparsa e seu leque de funções sugerem que ela se gramaticalizou em diferentes épocas e espaços de $n a$ 'e, com, ter'. (Nurse, 2008, p. 54)
\end{abstract}

Uma primeira pergunta que surgiu ao atestarmos a particularidade de possessivos das línguas bantas foi a de como seriam as discussões sobre locativos, existenciais e possessivos se línguas que fazem uso dessa estratégia comitativa para posse predicativa fossem levadas em conta? Christie (1970) foi o primeiro autor a tentar responder a essa questão para o caso de uma língua banta, nesse caso, o suaíli. Nos exemplos abaixo, sem glosas no original, Christie agrupa as construções da seguinte forma:

\footnotetext{
10 "\#na was originally, and still is in most Bantu languages, the independent, uninflecting conjunction 'with, and', usually linking nominals. It also widely forms the basis for 'have = be with'. It occurs as clitic or prefix in a scattered distribution in languages outside the northwest, but mainly in two unconnected areas, K10-30-40 and G20-G40- E56-E71-E72. Its functions are diverse: with infinitives, with subjunctives, with pasts (narrative and non-narrative) and with futures. The scattered geographical distribution and the range of functions suggest it became grammaticalized at different times and places from $n a$ 'and, with, have'."
} 
(8) Suaíli (G42) (Christie 1970 p. 166-7)
a. Pa-na watu nyumba-ni. (Locativo/Existencial)
LOC-COP pessoas casa-LOC
'As pessoas estão em casa.' ('Tem pessoas na casa')
b. watu wa-na nyumba (Possessivo)
pessoas MS-ter casa
'Pessoas têm casas.'
c. Mungu yupo
Deus MS-LOC
(Existencial)
'Deus existe.'

Christie segue a mesma linha de raciocínio de Bach (1967) e acredita que os fenômenos encontrados em suaíli condizem com as previsões de Bach, apesar de indicar várias lacunas na análise de alguns dados da língua. Por exemplo, em (8a) e (8b), o autor nota que o mesmo item lexical na é utilizado para locativos/existenciais e possessivos, respectivamente. E que para locativos e existenciais são utilizados o mesmo marcador locativo pa em (8c) e (8a). Desse modo, a conclusão de Christie é a de que a análise de Bach deveria também se aplicar ao suaíli. No entanto, em umbundo encontramos as sequintes construções:

(9) Umbundo (R11) (Valente, 1964, p. 189) $)^{11}$
a. mwele i-kasi v'onjo (Locativo)
1.dono MS-COP 18.casa
'o dono está em casa'
b. oviti vi-li v'usenge (Existencial)
3.árvore MS-COP 18.floresta
'na floresta há árvores' (Lit.: 'As árvores estão na floresta')
c. utwe u-kwete asinga
3.cabeça MS-ter 6.cabelo
'a cabeça tem cabelo'

Nos exemplos acima, temos as mesmas construções enumeradas por Christie para o suaíli, acontece que para essa língua os verbos de cópula são todos diferentes. O que dizer

${ }^{11}$ Sem glosas no original. 
então do caso do umbundo, para o qual nenhuma relação aparente é possível estabelecer entre as construções por empregarem verbos bem diferentes? Inclusive para o possessivo, em que o verbo kwete não parece em nada ter qualquer semelhança com a cópula. Retornaremos com mais detalhes para essas questões no Capítulo 7. Por agora, e em resumo, descrevemos um rápido percurso da nossa pesquisa, como forma de contextualizarmos nossas principais linhas de investigação.

O ponto de partida de nossas dúvidas foi o uso de uma construção comitativa para estados e posse predicativa em português, passando por uma hipótese de contatos linguísticos com línguas africanas (LAs) até, por fim, chegarmos à necessidade de um estudo mais amplo sobre como se dá(ão) a(s) relação(ões) entre construções possessivas, locativas, comitativas e possessivas em línguas bantas. ${ }^{12}$ Para um trabalho de descrição linguística perseguiremos possíveis respostas para alguns questionamentos de ordem teórica, de forma que a análise dos dados seja beneficiada com um diálogo deste trabalho com aqueles que se dedicaram à mesma temática. Talvez a primeira e mais instigante pergunta tenha sido a de se existe uma base conceitual comum para as construções possessivas, existenciais, locativas e comitativas. Pode parecer muita presunção tentar responder essa questão que até o momento tem sido causa de grandes debates na literatura, no entanto, acreditamos que o domínio conceitual de posse predicativa não é reduzível a outro considerado mais básico como o de localização, conforme as propostas mais aceitas (Clark, 1978; Freeze, 1992; Kayne, 1993; inter alia).

Como forma de perseguir algumas respostas iremos considerar línguas que utilizam estratégias comitativas para a expressão de posse predicativa em relação com as construções locativas e existenciais buscando contribuir para um quadro mais completo das discussões sobre as construções possessivas com as demais construções a ela relacionadas. Por fim, buscaremos generalizações sobre construções possessivas, tentando verificar as implicações para os estudos sobre possessivos e domínios relacionados ao centrarmos nosso estudo nas características tipológicas das línguas bantas.

Como mencionado antes, o fato a ser notado é que boa parte dos estudos sobre a interrelação de possessivos com outros domínios conceituais sempre foram realizados a partir de línguas que se utilizam de uma estratégia com verbos do tipo have ou HAVE-construction, como o inglês, ou de línguas com estratégia locacional, como o caso do russo. Nesta pesquisa buscamos fazer uma investigação aprofundada sobre a forma como se dá a relação entre os domínios conceituais de posse predicativa em línguas nas quais a estratégia básica para a

\footnotetext{
${ }^{12}$ Apresentamos nossas primeiras suposições em Araújo (2008).
} 
expressão de posse predicativa se faz com comitativo ou WITH-construction, ou seja, as línguas bantas. ${ }^{13}$

\subsection{O campo da pesquisa ou esboço de uma Linguística Africana da Diáspora}

\subsubsection{Angola e sua situação linguística}

Tendo uma preocupação descritiva além de teórica, uma das primeiras etapas do nosso trabalho seria a preparação e realização do trabalho de campo com os falantes das línguas de interesse para esta pesquisa. Como consequência de nossa escolha, de enfatizar em nosso trabalho as línguas angolanas, encontramos diversas dificuldades operacionais, sendo que as principais foram a de realizar as atividades de campo in situ e o contato com os falantes nativos das línguas bantas fora de seu local de origem.

O domínio banto, de interesse desta pesquisa, abrange um vasto território da África, como mostrado na Figura 1.1, para uma melhor apresentação dessas línguas e sua distribuição; na Figura 1.2, localizamos o grupo banto dentro da família linguística do nigerocongolês.

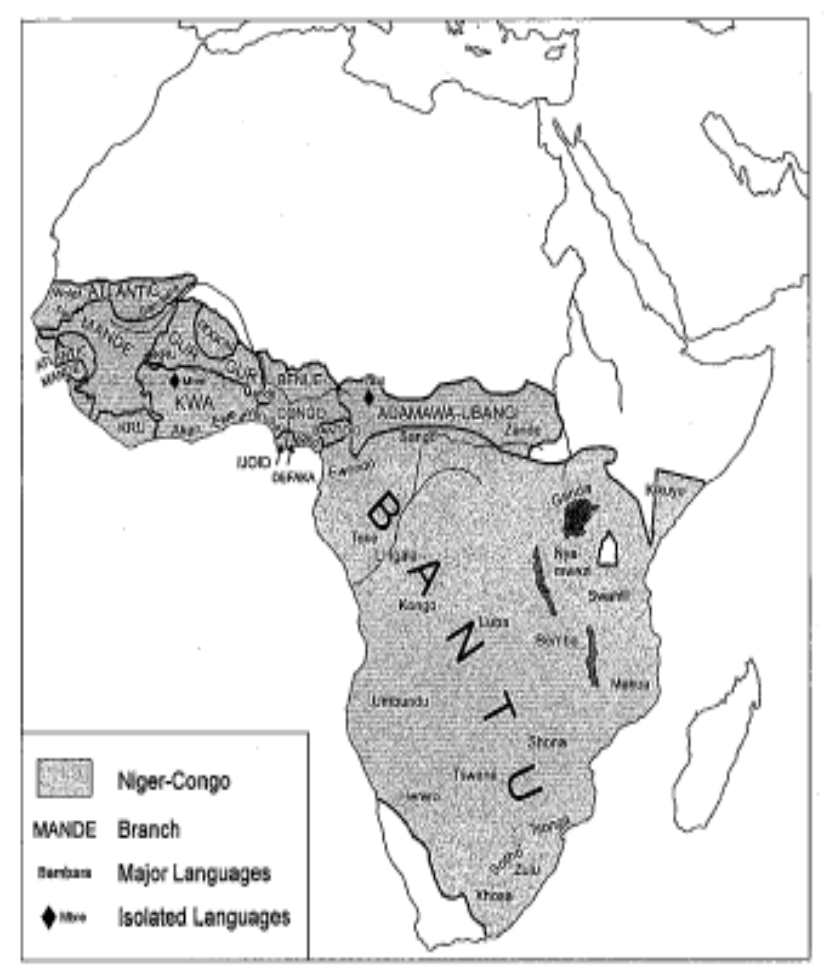

Figura 1.1 - O Tronco Nigero-congolês (Williamson; Blench, 2000, p. 12)

\footnotetext{
${ }^{13}$ No Capítulo 3 nos ocupamos de uma resenha dos trabalhos de Heine (1997) e Stassen (2009) nos quais são indicadas outras línguas que não as bantas que também fazem uso de comitativo para posse predicativa.
} 

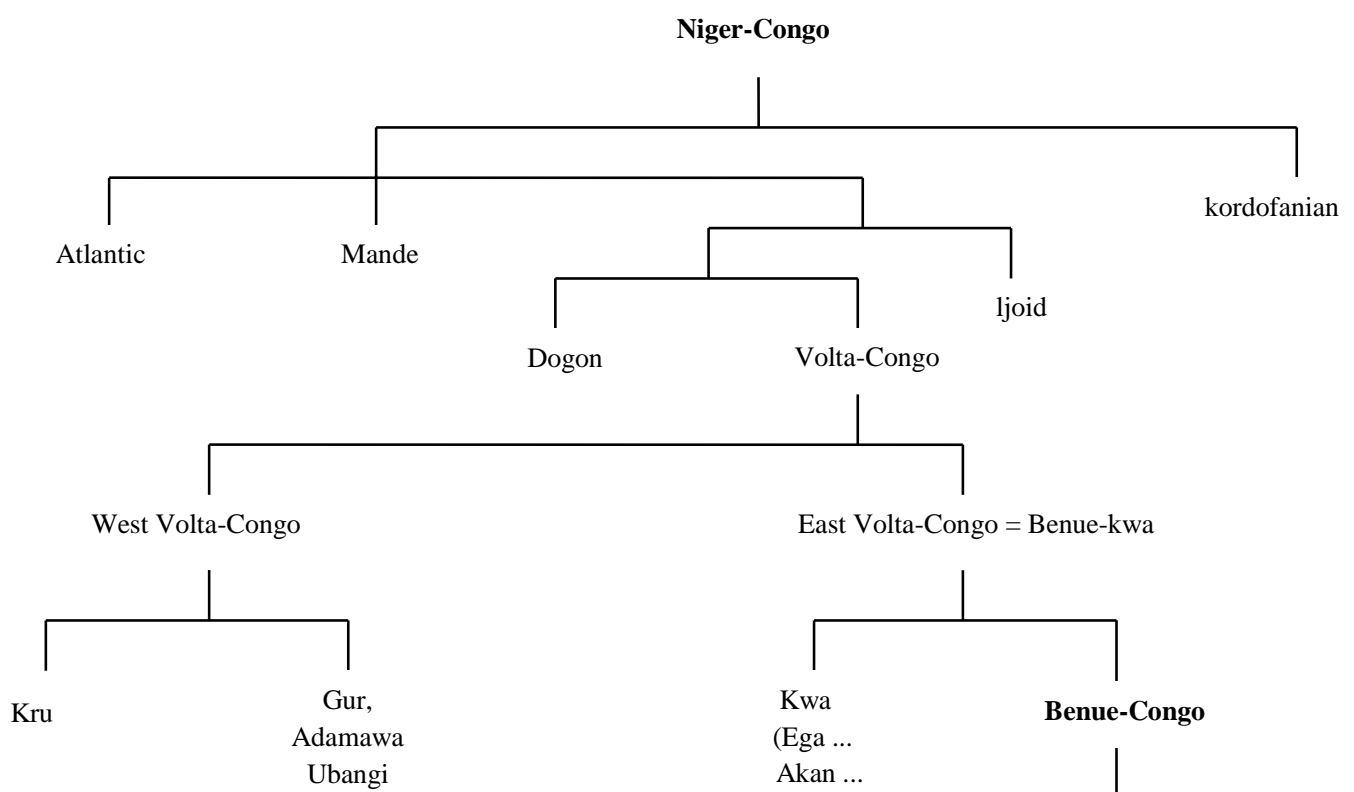

East Volta-Congo = Benue-kwa
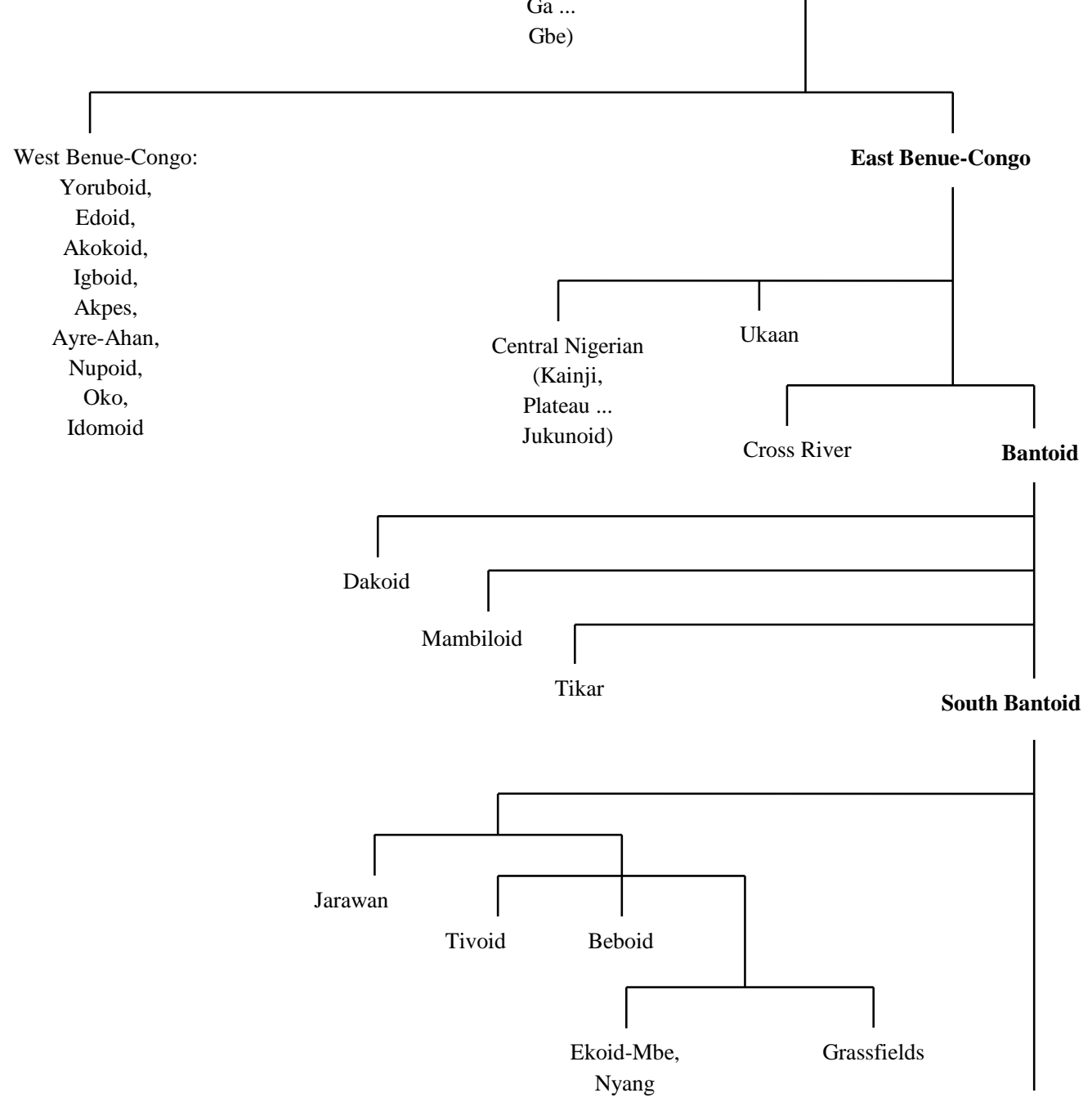

Bantu

Figura 1.2 - O grupo banto na família nigero-congolesa (Schadeberg, 2003, p. 155) 
Angola possui uma história que tem contribuído para um quase que total descaso com as línguas nativas dos seus povos. De acordo com o Ethnologue (Lewis, 2013), cerca de 40 línguas são faladas em todo o território do país, mas infelizmente, devido a acontecimentos históricos como o tráfico de escravos do século XV ao XIX, a política proibitiva do uso das línguas nativas no período colonial por parte de Portugal, entre 1919 e 1960, e as guerras entre 1961 até 2002 foram fatores que influenciaram lamentavelmente para a escassez de estudos e pesquisas das línguas faladas nesse país, conforme Xavier (2010) que também se deparou com os mesmos problemas para a realização de pesquisa de campo para o seu estudo da fonologia do quimbundo. Todos esses fatos juntos exerceram algum papel para a configuração de uma Diáspora Africana. Muitos angolanos, devido à guerra, abandonaram seus locais, suas aldeias, para se refugiarem em países vizinhos, principalmente na atual República Democrática do Congo, e países da Europa ou América.

Diante das dificuldades para realizar trabalho de campo diretamente nas zonas onde as línguas são realmente utilizadas, tivemos como opção realizar nossa investigação com os falantes fora das regiões bantófonas, em nosso caso, o das línguas angolanas. Podemos chamar a esse conjunto de línguas africanas fora do continente africano como, de certa forma, línguas da/na Diáspora. Iniciamos assim a empreitada de localizar e contactar pessoas que tivessem conhecimento de suas línguas étnicas, falantes das línguas nacionais angolanas. Nosso trabalho só começou a progredir com a possibilidade de um estágio de doutorando no exterior, momento em que passamos o período de 2011 a 2012 como Junior Fellow na Bayreuth International Graduate School of African Studies-BIGSAS, na Alemanha. Como resultado desse estágio, conseguimos ter contato com falantes de quicongo, lingala e umbundo residindo na Alemanha e em Portugal, a partir de onde conseguimos realizar as primeiras eliciações de dados e uma análise preliminar.

Ainda durante nosso estágio de doutorando no exterior, tivemos as mesmas dificuldades encontradas por Xavier (2010), a de localizar falantes de línguas bantas com disponibilidade para trabalhos de eliciação, principalmente falantes que realmente tivessem proficiência em suas línguas étnicas. Além dos fatores históricos apontados acima, outro fator que dificultou de certo modo o nosso trabalho de pesquisa foram as atitudes linguísticas dos falantes com quem tivemos contato fora do território angolano. A maioria dos angolanos que entrevistamos dizia não ter boa proficiência das suas línguas étnicas e, portanto, não puderam colaborar com a pesquisa de maneira satisfatória. Como justificativa para a pouca proficiência, os próprios angolanos relatavam que isso se dava devido ao português estar se tornando a língua veicular ou materna para muitos deles. Além disso, nossos colaboradores de 
pesquisa apontavam a existência de um preconceito linguístico explícito para com aqueles que fazem uso das línguas nacionais dentro do território angolano, o que tem tolhido o desejo de muitos de aprender e utilizar suas línguas étnicas. Muitos dos nossos interlocutores se ressentiam de não dominarem completamente suas línguas maternas devido à pouca importância dada para o aprendizado e uso das línguas nacionais em Angola. Foi surpreendente encontrar ambundos na cidade de Lisboa usando entre si o lingala, em detrimento do quimbundo, e cujo aprendizado do lingala para alguns ocorreu justamente fora da África.

Esse fato explica o motivo de, apesar de termos tido contato com um número razoável de angolanos fora de Angola, só nos foi possível trabalhar adequadamente com aqueles que tinham proficiência nas suas línguas, e que se dispuseram a colaborar de uma forma sistemática com a nossa pesquisa. Em decorrência disso, o trabalho de elaboração do corpus se deu praticamente com a participação de menos de uma dúzia de falantes. Para as três línguas com as quais foi possível fazer um trabalho de eliciação de dados, quicongo, umbundo e lingala, tivemos a participação de pelo menos dois falantes com um nível bom de proficiência para cada língua. O lingala era segunda língua (L2) para os nossos colaboradores falantes de quicongo.

Diante disso, nos indagamos sobre a situação desses angolanos na Diáspora e o papel que suas línguas exerciam para eles. Essas indagações foram necessárias pelo simples motivo de que estávamos trabalhando com línguas angolanas fora de Angola, o que nos levou a considerar quais seriam as possíveis relações entre o campo da Linguística Africana com os Estudos da Diáspora Africana.

\subsubsection{Sobre fazer campo "fora” do campo: Diáspora africana e Linguística Africana}

Acreditamos que dificuldades como as que são encontradas por brasileiros para a realização de pesquisas na África têm tornado cada vez mais forte a ideia apresentada por Bodomo em palestra na Universidade de Bayreuth sobre uma "Linguística Africana da Diáspora". ${ }^{14}$ Tal ideia não é tão estranha assim para muitos linguistas, para os quais a pesquisa linguística é realizada com falantes nativos fora de sua terra natal ou área de origem, ou seja,

\footnotetext{
${ }^{14}$ A palestra supracitada teve como título "Africans in China". O professor Adams Bodomo tem desenvolvido diversos trabalhos com africanos fora da África, notadamente na China (Cf. Bodomo, 2010 e Bodomo e Silva, 2012).
} 
fazer campo "fora" do campo, conforme relatado por Munro (2001). ${ }^{15}$ Tal situação é bem mais comum do que parece. Por exemplo, Carter (1973) produziu sua tese sobre o quizombo (H16h), dialeto do quicongo, da mesma forma, com a colaboração de um único falante. Mais recentemente, uma gramática de uma língua banta até então desconhecida foi escrita durante um curso de métodos de campo na Universidade da Califórnia, em Berkeley, com o auxílio de um falante (Crane; Hyman; Tukumu, 2011). A língua em questão é o nzadi (B865). Os autores reconhecem as limitações do trabalho e apontam algumas medidas que foram tomadas para mitigar as possíveis deficiências do trabalho produzido. A questão que se levanta é a validade dos dados coletados com falantes fora do seu local. Concordamos com as palavras de Munro (2001, p. 140): “Em grande parte, dados linguísticos coletados longe dos locais tradicionais dos falantes podem ser considerados tão válidos quanto aqueles coletados nas comunidades tradicionais. Mas claro, não deixa de haver perdas." 16

No Brasil, teses de doutorado foram defendidas sob as mesmas condições (Pal, 2010; Xavier, 2010). Com isso não queremos opor a linguística africana realizada na África com uma linguística africana realizada fora da África. Ressaltamos apenas as particularidades dos trabalhos realizados na Diáspora. De qualquer forma, advogar a existência de uma "Linguística Africana Diaspórica" pode trazer ganhos para o conjunto de disciplinas que também se ocupam dos Estudos Africanos da Diáspora (Olaniyan; Sweet, 2010), sugestão que deixamos para um debate mais demorado em um outro momento.

\subsection{Línguas bantas deste estudo}

Considerando as motivações para trabalhar com línguas angolanas, nos empenhamos em coletar o máximo de dados possíveis de línguas das três zonas linguísticas do grupo banto de Angola, as zonas H, K e R, que também abrange alguns países fronteiriços. Como já mencionado, as línguas do grupo banto são classificadas em zonas designadas por letras do alfabeto (A, B, C, D...) subdividads por dezenas (H. 10; H. 16; R. 10; R. 20, etc.). Para uma melhor visualização das zonas das línguas angolanas, temos o seguinte mapa:

\footnotetext{
${ }^{15}$ É inevitável não lembrar que a primeira gramática do quimbundo foi escrita fora de Angola (Bonvini, 2008, p. $33)$.

16 "For the most part, linguistic data gathered away from speakers' traditional homelands can be just as valid as linguistic data gathered in those homelands. But of course there are tradeoffs."

No website do LinguistList, http://linguistlist.org/ é comum encontrarmos referências a estudos realizados com falantes de línguas em perigo de extinção em grandes centros urbanos como Toronto e Nova York. Apesar da diferença das situações, as línguas angolanas na Diáspora são ainda um campo a ser explorado. Conferir dissertação de mestrado defendida por Lourdes dos Santos (2005) para a situação de angolanos em São Paulo.
} 


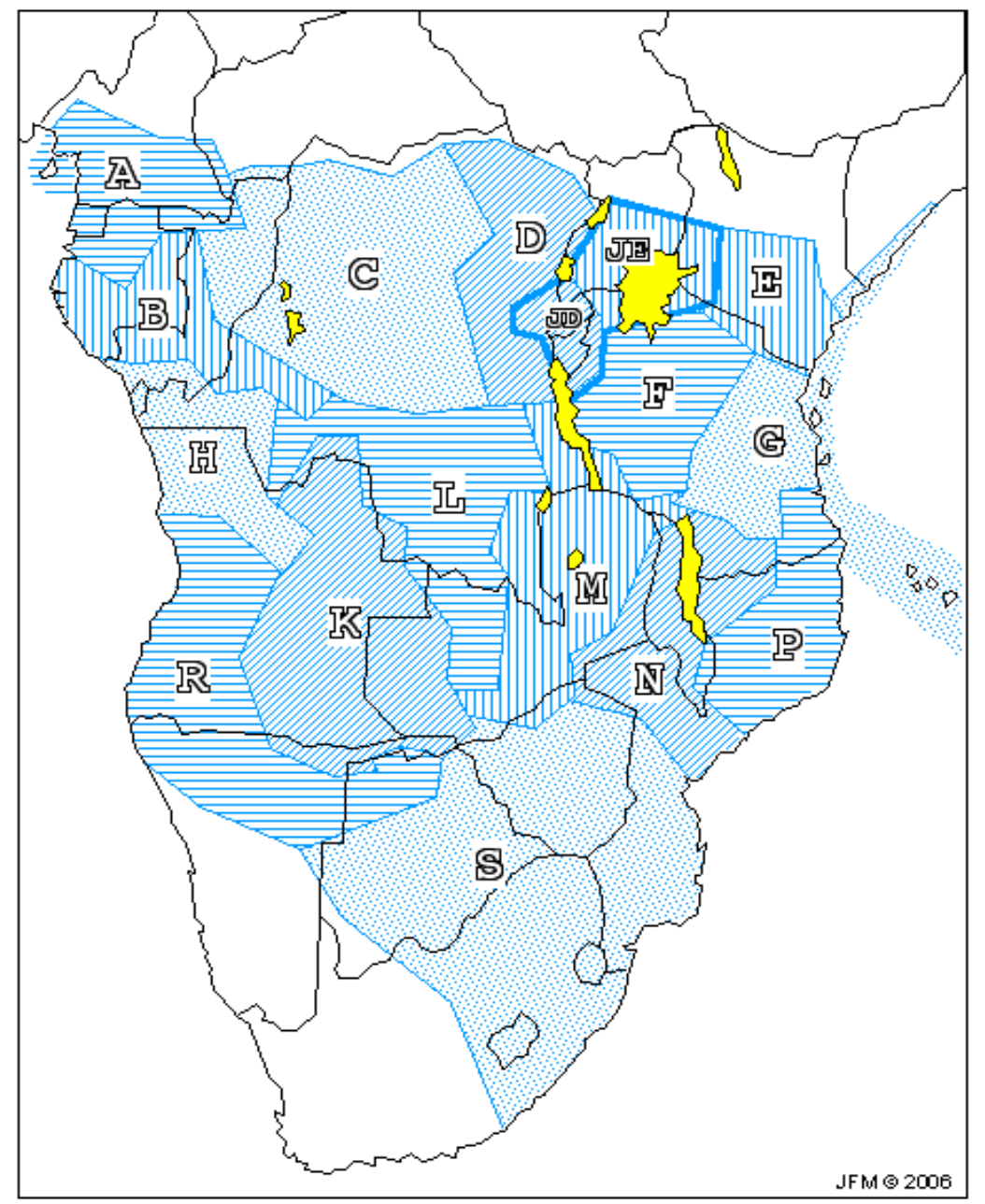

Figura 1.3 - Mapa das zonas linguísticas do grupo banto (adaptado de Maho (1999), baseado em Guthrie (1948))

Devemos dizer que não foi uma tarefa fácil coletar todo o material que precisávamos para elaborar um corpus preliminar. Por questão de viabilidade de acesso a material bibliográfico e contato com falantes fora da África, a elaboração de nosso corpus se concentrou muito mais sobre algumas línguas em particular, tais como dialetos do quicongo (H16) principalmente o quissolongo, quissicongo e quizombo; e o umbundo (R11), além do lingala (C36d), a qual decidimos incluir em nossa pesquisa pelo seu papel de língua de contato e o crescente uso dessa língua por parte de jovens angolanos (Ndonga, 2010), além de outros motivos sobre os quais falaremos adiante. Para outras línguas angolanas, tivemos acesso apenas a material publicado. Nem todos os trabalhos publicados foram utilizados inteiramente, como fabulários (Valente, 1973), coletâneas de provérbios (Kunzika, 2008) e adivinhas (Etaungo Daniel, 2002), devido às dificuldades de realizar um trabalho sobre 
categorias cognitivas baseado em textos coletados por terceiros. Uma amostra das principais línguas utilizadas para a elaboração do corpus escrito está na Tabela 1.1:

Tabela 1.1 - Relação das línguas selecionadas e bibliografia ${ }^{17}$

\begin{tabular}{ll}
\hline Zona & Língua: material bibliográfico \\
Linguística &
\end{tabular}

Zona H Quicongo (H16): Ndonga, (1995; 2010); Carter (1973); Carter; Makoondekwa (1987); Fernando (2008); Lumwamu (1973); Diarra (1989); Dereau (1955); Tavares (1915) ${ }^{18}$

Quimbundo (H21): Xavier (2010); Pedro (1993); Chatelain (1888/1889); Dias (1697/2006)

Zona $K \quad$ Luchazi (K13): Fleisch (2000)

Ganguela (K12): Maniacky (2003); Baião (1939)

Zona $R \quad$ Umbundo (R11): Alves (1951); Valente (1964; 1973); Schadeberg (1991; 1986; 1982); Chacusanga (2006)

Kwanyama (R21): Halme, (2004)

Herero (R31): Möhlig; Kavari (2008); Möhlig; Marten; Kavari (2002); Elderkin (2003)

Yeyi (R41): Seidel (2008)

Ochindonga (R22): Fivaz (2003)

Zona C Lingala (C36d): Meeuwis (1998)

O lingala está incluído na Tabela 1.1 porque, embora seja uma língua de contato e veicular, essa língua oferece alguns traços que podem auxiliar em nossa análise, como a inexistência de classes nominais locativas e a grande produtividade da partícula comitativa na, além de contar com material bibiográfico mais atual (Cf. Meeuwis, 1998). De certa forma, o lingala está se tornando uma língua angolana, pelo seu crescente uso no Norte de Angola e principalmente nas províncias de fronteira com a República Democrática do Congo (Ndonga, 2010). Além das línguas da Tabela acima, sempre que pertinente e necessário faremos menção a outras línguas bantas, dessas mesmas zonas $\mathrm{H}, \mathrm{K}$ e R, ou de outras zonas mais

\footnotetext{
${ }^{17}$ Seguimos a proposta de Fiorin e Petter (2008) para a utilização de formas aportuguesadas de nomes de línguas africanas. No Apêndice B relacionamos os nomes de línguas africanas aportuguesadas e as diferentes grafias empregadas, da forma como são encontradas na literatura específica.

${ }^{18}$ Não fazemos distinção aqui dos dialetos do quicongo, decidimos englobar todos os trabalhos a que tivemos acesso, independente de que variedade os autores estavam tratando. No entanto, no uso dos exemplos, indicamos a que variedade cada trabalho trata. O mesmo vale para o caso do quimbundo.

${ }^{19}$ É importante que se note o papel do lingala como língua franca na Diáspora. Como observamos em Lisboa, o seu uso pela comunidade de angolanos era bastante forte, o que não nos deixa dúvida de que o lingala tem se tornado cada vez mais presente até mesmo no território angolano (Ndonga, 2010).
} 
distantes, mas que tenham alguma relação com os tópicos em discussão, como por exemplo, o chicheua, presente em diversos trabalhos sobre inversão locativa. Dentre outras zonas bantas presentes nesta tese, temos as que já possuem uma boa tradição de estudos como o suaíli (G42), zulu (S12), chona (S10), chicheua (N31), como também outras com poucas descrições, como o leembama (B62) e o nzadi (B865).

Para uma melhor visualização da distribuição espacial das zonas linguísticas do domínio banto, apresentamos o mapa abaixo:

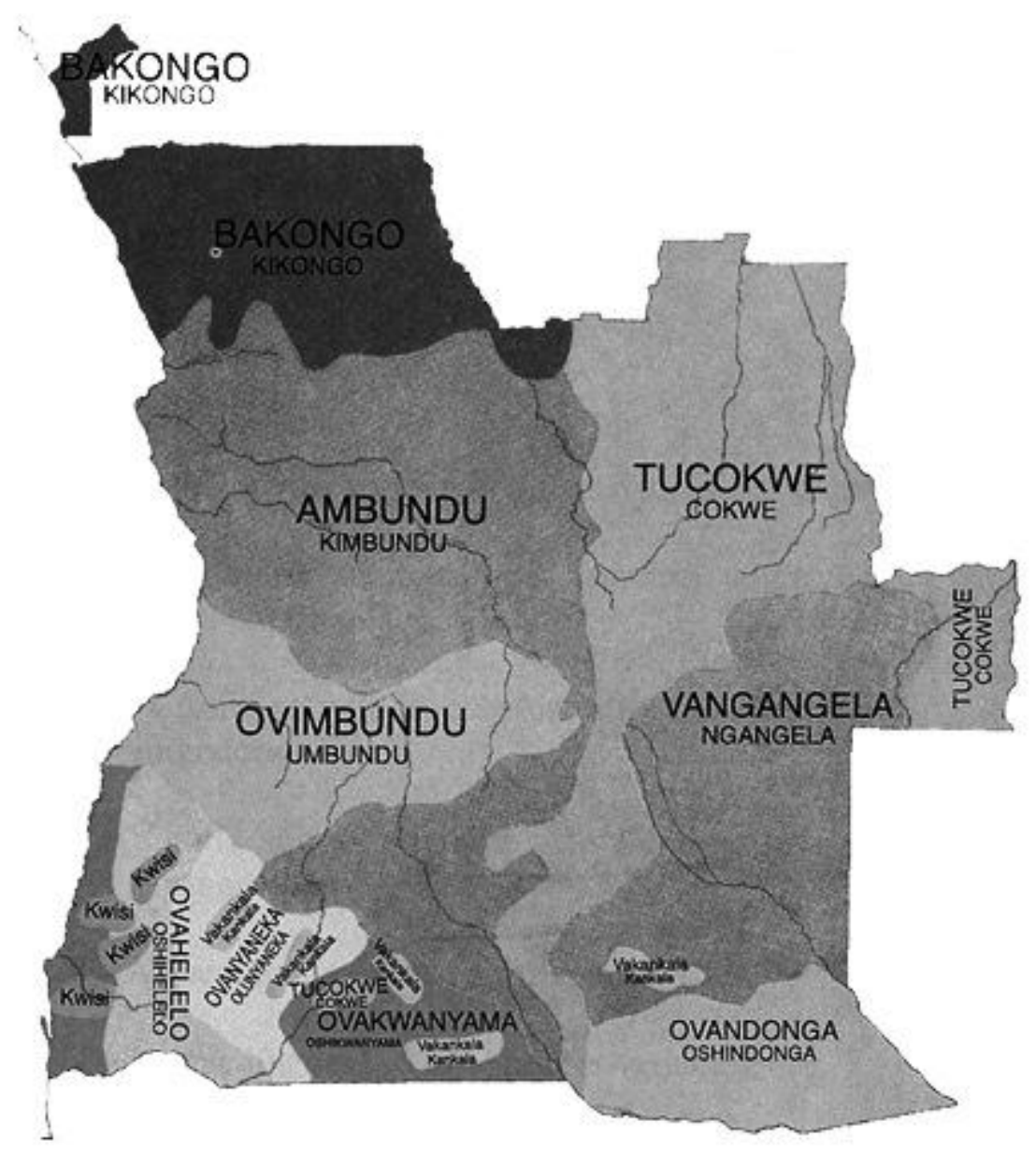

Figura 1.4 - Mapa etnolinguístico de Angola ${ }^{20}$

\footnotetext{
${ }^{20}$ Mapa adaptado de Fernandes e Ntondo (2002, p. 57).
} 


\subsection{Metodologia}

Esta pesquisa teve, inicialmente, dois objetivos certos: descrever e analisar as construções possessivas em relação com outras construções relacionadas e o de trazer os debates sobre possessivos as particularidades tipológicas das línguas bantas, enfatizando as zonas linguísticas de Angola. O primeiro objetivo já desde sua elaboração era um desafio, tratar de uma temática semântica e cognitiva em línguas que ainda não tiveram estudos mais abrangentes em outras áreas, como para a fonologia e morfossintaxe. O segundo objetivo agravava mais ainda o primeiro: o pouco conhecimento das línguas angolanas e as dificuldades de realização de ida a campo, como descrito nas seções anteriores.

Uma primeira alternativa foi a de trabalhar com o material disponível sobre essas línguas, na sua maioria, gramáticas e dicionários produzidos por religiosos (Alves, 1951; Valente, 1964; 1973; Chatelain, 1988/1989, etc.). A essa altura, intentávamos realizar um trabalho seguindo as diretrizes de outros em linhas comparativistas e que se basearam especialmente em fontes publicadas de línguas bantas, como o estudo sobre classes nominais de Maho (1999) ou sobre tempo e aspecto em banto, de Nurse (2008). Guardadas as devidas particularidades, logo vimos que a natureza de nosso trabalho exigiria muito mais do que um banco de dados de línguas bantas com material publicado de possessivos em relação com outros domínios conceituais. Diferentemente de Maho e Nurse, o primeiro lidando com classes nominais e o segundo com categorias verbais, fontes publicadas de línguas bantas dedicam geralmente alguns capítulos focalizando classes nominais ou as categorias de tempo, aspecto e modo (TAM), enquanto para categorias cognitivas como possessivos, comitativos, etc., infelizmente não acontece o mesmo.

Considerando as diversas possibilidades de expressão de posse que uma língua oferece para seus falantes, percebemos logo de início que trabalhar com textos escritos, mesmo que fábulas, contos, etc., acabaríamos por coletar dados insuficientes para a natureza do trabalho que desejávamos fazer, e que somente sessões de eliciação de dados poderiam ser satisfatórias para nossa empreitada. Pensando nisso e na impossibilidade de se fazer um trabalho de campo in situ, utilizamos todo o material ao qual tivemos acesso das línguas bantas das zonas de interesse, até que, por fim, houve a chance de trabalhar com alguns falantes de quicongo, umbundo e lingala, fato que nos permitiu realizar a eliciação de dados. Nosso primeiro contato com falantes se deu durante nosso estágio de doutorando no exterior, na Universidade de Bayreuth, Alemanha, durante o ano letivo de 2011. Durante os meses de maio e junho de 
2012, realizamos viagem de missão de pesquisa para Lisboa, para contactar e entrevistar angolanos residentes em Portugal.

Elaboramos questionários preliminares nos quais pedíamos para o falante para traduzir algumas frases do português para suas línguas. O questionário foi dividido em quatro partes: (1) Construções Locativas; (2) Construções Existenciais; (3) Construções Comitativas; e (4) Construções Possessivas. Com esses questionários, percebemos a grande dificuldade de tratar de categorias semânticas, como possessivos e locativos. Não raramente, ao pedirmos para nossos colaboradores a tradução da sentença: "Há açúcar no café" a preferência era por um locativo: "O açúcar está no café”, por mais que explicássemos que a sentença pretendida era com o sentido de existência. Vimos com isso que diferenças na conceitualização espacial estavam em jogo. Uma alternativa foi a de elaborar uma pequena história, explicando a cena pretendida para a sentença. Assim, elaboramos um pequeno conto "O pescador e o filho" e selecionamos 14 trechos com as construções objeto de nosso estudo (Cf. Apêndice A).

Frente às limitações de trabalho com fontes publicadas, nosso trabalho só progrediu de forma significativa, tanto no aspecto teórico quanto descritivo, após o recurso à eliciação de dados com falantes das línguas de nosso interesse. Dos 6 colaboradores de nossa pesquisa que contribuíram na eliciação de dados, temos o seguinte perfil sociolinguístico: a maioria é do sexo masculino, acima de 40 anos, cursando no momento das entrevistas pós-graduação em Portugal e Alemanha. Dentre eles, apenas uma era mulher, residente em Angola, e que contribuiu, via internet, na elaboração do corpus. Todos os nossos colaboradores que estavam fora de Angola relataram que viveram até o fim da adolescência em suas regiões de origem, onde só eram faladas suas línguas étnicas. No período das guerras, dois deles se ausentaram do país.

Resolvemos utilizar o lingala pelos motivos já apresentados. Ironicamente, tivemos contato com um maior número de falantes de umbundo, porém os trabalhos de eliciação com essa língua foram mais limitados, principalmente pela disponibilidade de tempo dos falantes. Esta é uma das razões de não termos explorado mais detidamente a questão do tom nessa língua. Devido a isso, os exemplos retirados de nosso corpus para essa língua não apresentam a marcação tonal, o que demanda novos trabalhos nesse sentido.

Inevitavelmente, a representatividade das línguas no corpus não é a mesma. Da mesma forma, o corpus retirado das fontes publicadas é bastante heterogêneo. De esboços gramaticais (Schadeberg, 1990) ou gramáticas tonais (Halme, 2004) a gramáticas de referência (Möhlig; Kavari, 2008; Seidel, 2008; Fivaz, 2003). Do corpus escrito conseguimos 
coletar um conjunto de exemplos que possibilitou empreender um de eliciação minimamente satisfatório, em sintonia com nossos questionamentos teóricos e descritivos.

Para diminuir as diferenças na coleta de cada língua, consideramos, também, o uso de meios de comunicação digitais disponíveis na atualidade para mantermos contato com falantes de línguas nacionais angolanas via internet, por meio de programas de mensagem de texto instantâneo e conversas via Skype. Foi interessante encontrar na Rede Mundial de Computadores blogs voltados exclusivamente para textos, músicas, provérbios nas línguas nacionais angolanas, além de rápidas eliciações da forma que o contato virtual permitia. ${ }^{21} \mathrm{O}$ corpus foi então sendo elaborado aos poucos, e apenas com a eliciação foi possível delinearmos melhor nossas expectativas e perspectivas de descrever e analisar as construções possessivas, existenciais, comitativas e locativas em línguas bantas.

\subsubsection{O corpus}

O corpus pode ser classificado da seguinte forma:

Corpus escrito: dicionários, gramáticas, teses, dissertações e outras publicações de línguas bantas com ênfase das línguas que contam com gramáticas já publicadas;

Corpus eliciado: com o apoio de falantes residentes fora de Angola e falantes residentes em Angola que colaboraram via internet, a partir de um questionário previamente elaborado. Um conto, "O pescador e o filho", elaborado para nossas sessões de eliciação. No Apêndice A, apresentamos a transcrição desse conto em quicongo. As transcrições para as gravações realizadas com falantes de umbundo e lingala foram prejudicadas pela impossibilidade de os colaboradores nos auxiliarem com a referida transcrição.

Todos os nossos colaboradores afirmaram ter aprendido suas línguas maternas juntamente com o português, no entanto, a atitude linguística da maioria deles foi a de considerar o português como a língua de mais uso, sendo que suas línguas étnicas foram citadas como usadas preferencialmente no âmbito familiar ou contextos sociais mais propícios para o uso de suas línguas, como igrejas, casamentos, etc. Devido ao pouco consenso no que tange a um sistema ortográfico para as línguas angolanas, decidimos adotar a sugestão de cada colaborador, todos eles alfabetizados em português e com desenvoltura para escrever em suas línguas étnicas, seguindo assim suas sugestões durante os trabalhos de eliciação. O Instituto

\footnotetext{
${ }^{21} \mathrm{O}$ escritor angolano, de Benguela, Gociante Patissa, também um dos nossos colaboradores, escreve no blog http://ombembwa.blogspot.de/ notícias, provérbios, contos, etc., todos em umbundo, seguidos de uma tradução para o português.
} 
de Línguas Nacionais de Angola tem trabalhado para padronizar a ortografia das principais línguas faladas no território angolano, mas até o momento ainda não foi apresentada uma proposta consistente para a escrita dessas línguas. Uma transcrição fonética se fez impossível devido ao pouco tempo dos colaboradores e à heterogeneidade das fontes utilizadas para a produção do corpus.

Para as fontes publicadas, buscamos utilizar a transcrição de cada autor e seguir na medida do possível as glosas de cada trabalho. Para o caso dos trabalhos descritivos nos quais os autores não disponibilizaram as glosas, tentamos na medida do possível indicar minimamente as abreviaturas e segmentações necessárias para um melhor entendimento dos exemplos. Na impossibilidade de identificar todas as unidades morfológicas, recorremos à indicação por meio do ponto de interrogação para os segmentos não identificáveis de cada língua. Buscamos evitar a disponibilização apenas da tradução provida pelos autores, tentando assim, padronizar um pouco mais a apresentação dos dados retirados de terceiros. Devemos então ressaltar que os dados das línguas parecerão bastante diversos, isso no que diz respeito ao grau de refinamento explicativo em cada exemplo. Alguns dados são apresentados sem a indicação numérica das classes nominais às quais pertencem cada palavra ou a não marcação dos tons. Em outros exemplos, principalmente aqueles retirados de gramáticas de referência, tivemos pouco problema para a identificação de morfemas ou processos morfossintáticos envolvidos em cada caso particular.

\subsection{Limites e alcance desta pesquisa}

Nossa pesquisa buscará sempre percorrer a mão dupla da teoria para a descrição e da descrição para a teoria. Ao mesmo tempo em que partimos da problemática de como se relacionam as construções locativas, existenciais, comitativas e possessivas, de um modo geral para as línguas do mundo, seguiremos na direção de uma descrição mais detalhada voltada para o caso particular das línguas bantas. Nesse ínterim, acreditamos que observar os fatos gramaticais próprios das línguas bantas relacionados à expressão de posse predicativa poderá contribuir sobremaneira para o entendimento dos fenômenos conhecidos e poucos conhecidos sobre a grande proximidade entre os domínios conceituais focalizados em nosso estudo.

Neste ponto, nos perguntamos sobre os limites e alcance desta pesquisa. Como enfatizamos no que se refere ao corpus, buscamos destacar as línguas bantas das zonas $\mathrm{H}, \mathrm{K}$ e $\mathrm{R}$, esperamos, no entanto, que os fatos a serem apresentados e discutidos para as línguas 
selecionadas para nosso estudo, possam servir futuramente como parâmetro para o caso de outras línguas do domínio banto. Não nos foi possível elaborar um corpus mais robusto, nos moldes dos trabalhos tipológicos, mas acreditamos que o conjunto de línguas relacionadas neste trabalho é relativamente representativo para o tipo de fenômeno a ser estudado (Cf. Apêndice B). Apesar dessa limitação do universo da pesquisa, temos a total confiança de que as línguas apresentadas manifestam algumas das principais estratégias para a expressão de posse predicativa. Enquanto, por um lado, temos a limitação da representatividade do corpus, por outro lado, acreditamos que as discussões teóricas, desenvolvidas a partir dos fatos coletados desse pequeno corpus, são suficientemente satisfatórias para abarcar algumas das principais características da expressão de posse predicativa nesse grupo de línguas. Como exemplo, no capítulo 6, apresentamos pelo menos quatro estratégias utilizadas pelas línguas de nosso corpus para possessivos.

Um dos alcances mais significativos desta tese diz respeito às conclusões finais. Apesar de nos concentrarmos em um conjunto de línguas que dispõem amplamente do tipo de possessivo a ser denominado de comitativo, acreditamos que graças justamente a essa particularidade das línguas bantas, nos foi possível extrapolar as propostas teóricas até então aceitas para possessivos e que tentaram solucionar a forma como possessivos são relacionados a locativos e existenciais.

\subsection{Em síntese}

Neste capítulo sintetizamos o percurso da problemática da pesquisa, desde a motivação inicial para tratar de possessivos, as primeiras hipóteses sobre contatos linguísticos até o atual desenvolvimento da busca por uma explicação, em termos cognitivos, para as relações conceituais entre as quatro principais construções encontradas nas línguas do mudo para a expressão de posse predicativa, como será apresentado no Capítulo 3. Justificamos assim a nossa escolha de focalizar um grupo particular de línguas como o palco das nossas discussões teóricas por elas apresentarem um tipo de possessivo ainda pouco explorado na literatura, o de possessivos comitativos.

A particularidade desta pesquisa reside no fato de se ocupar mais a fundo da relação entre as construções locativas, existenciais, comitativas e possessivas em um grupo particular de línguas. Diferentemente dos estudos que trataram dessa relação, nesta pesquisa o domínio do comitativo deverá receber uma maior atenção, o que achamos ser justo para um estudo sobre posse predicativa que se preocupe com das línguas bantas. 
Capítulo 2

As Línguas Bantas num Caleidoscópio

\subsection{Apresentação}

Este capítulo apresenta alguns aspectos gramaticais das línguas bantas, enfatizando as estruturas das línguas selecionadas para nossa pesquisa, além de outras línguas do domínio banto, como forma de se fazer um trabalho ilustrativo da complexidade dessas línguas. Tomamos como ponto de partida os fatos gramaticais apontados por Sommer (2003) para as zonas K e R, das denominadas línguas bantas da savana ocidental, e então expandimos para o caso de outras línguas que estarão presentes neste trabalho.

Para seu capítulo dedicado às línguas das zonas K e R, Sommer (2003) parte principalmente das línguas umbundo (R11), ochindonga (R22) e yeyi (R41) para a zona R. Da zona K estão o mbukushu (K43), gciriku (K38b), kwangari (K33), luyana (K31) e luvale (K14). Para este capítulo resolvemos usar os dados das línguas umbundo, oshindonga e yeyi e no lugar das demais, incluir as seguintes línguas: ochiherero (R31) para completar a lista das línguas da zona R; o quicongo (H16) e o quimbundo (H21) como representantes da zona H; o luchazi (31) e o ganguela (K12), das zonas K e o lingala (C36), na categoria de língua de contato (Mufwene, 2003). Com a inclusão dessas línguas, esperamos dar uma visão mais geral das línguas bantas, além de balancear, de certa forma, a amostra de línguas a serem contrastadas.

Uma primeira constatação inevitável quando se é iniciado no estudo das línguas bantas é a de que todas essas línguas são imensamente similares, dando a impressão de se estar olhando para elas como se estivessem num caleidoscópio. Apesar da grande semelhança, as línguas bantas podem guardar diferenças significativas. $\mathrm{O}$ mesmo pode ser dito quanto à distribuição espacial e temporal dessas línguas, principalmente se forem observadas no seu desenvolvimento histórico. Nas palavras de Nurse e Philippson (2003, p. 5): “Olhar na inteira área (das línguas bantas) e em todo o período (do seu desenvolvimento histórico) é como olhar dentro de um caleidoscópio, com padrões constantemente em mudança." (Acréscimos nossos $)^{1}$. Compartilhamos com Nurse e Philippson essa mesma sensação de olhar para as

\footnotetext{
1 "Looking at the whole area (of the Bantu languages) and the whole period (of their historical development) is like looking into a kaleidoscope, with constantly changing patterns."
} 
línguas do grupo banto como se estivessem num caleidoscópio, o que às vezes parece que elas mesmas sejam o caleidoscópio, não deixando de apreciar, no entanto, as sutilezas dessas mudanças de padrão observados em um conjunto de língua, quando se produz um estudo comparativista ou contrastivo entre elas, seja com línguas de uma mesma zona ou de zonas diferentes.

Esta apresentação não tem o intuito de ser uma descrição exaustiva e pormenorizada da gramática das línguas do nosso estudo, mas pretende apresentar as particularidades das línguas bantas em alguns dos seus aspectos tipológicos e estruturais que estarão presentes na nossa descrição e análise das construções de interesse desta tese. Sendo assim, alguns aspectos gramaticais deverão ser deixados de lado. Salientaremos, na morfologia nominal, o caráter das classes nominais de um modo geral e das classes nominais locativas em particular. $\mathrm{Na}$ morfologia verbal, destacaremos a estrutura do verbo banto e sua natureza aglutinante. Uma apresentação como esta se faz necessária, por um lado, como uma forma de familiarizar o leitor com as estruturas mais comumente encontradas nas línguas bantas. Por outro lado, para os estudiosos que tenham conhecimento das línguas aqui apresentadas, buscamos apresentar um quadro contrastivo entre as línguas do território angolano que mereceram a atenção de linguistas até o momento. Algumas dessas línguas contam com um material descritivo considerável, enquanto outras ainda não receberam um estudo devido. A partir disso, tentaremos apresentar os pontos mais comuns presentes nas descrições dessas línguas e que nas gramáticas por nós consultadas são apresentadas de forma mais elaborada, e juntamente a isso, sempre que possível, buscaremos apontar as lacunas que ainda necessitam ser preenchidas nos estudos das línguas angolanas. As próximas seções estão organizadas como segue: apresentamos alguns aspectos segmentais e suprassegmentais da fonologia; da morfologia nominal e verbal e, em sintaxe, tocamos nos assuntos mais pertinentes para nossas futuras discussões.

\subsection{Fonologia segmental e suprassegmental}

O sistema vocálico das línguas bantas constitui-se geralmente de 7 ou 5 vogais orais breves, raramente opostas pela duração vocálica. Praticamente, a grande parte das línguas bantas refletem as 5 vogais do protobanto, fora as vogais super-fechadas *ị e *ụ. Um traço considerado raro para as línguas da savana ocidental ( $\mathrm{K}$ e $\mathrm{R}$ ) é a duração vocálica, representado na Tabela abaixo pelo quissicongo, da área $\mathrm{H}$, e a ocorrência de vogais nasalizadas, o caso do umbundo, zona R (Sommer, 2003, p. 568). O lingala apresenta um 
conjunto de 7 vogais, não apresentando, porém, vogais longas como traço distintivo. O quadro abaixo contrasta o lingala com o quissicongo, tendo como quadro comparativo as vogais reconstruídas do protobanto:

Tabela 2.1 - Vogais do protobanto, lingala e quissicongo (Schadeberg, 2003; Meeuwiss, 1998; Diarra, 1989)

\begin{tabular}{|c|c|c|c|c|c|c|c|c|c|}
\hline \multirow[b]{3}{*}{ Super-Fechadas/Super-Abertas } & \multicolumn{3}{|c|}{ *Protobanto } & \multicolumn{3}{|c|}{ Lingala } & \multicolumn{3}{|c|}{ Quissicongo } \\
\hline & Ant. & Cen. & Pos. & Ant. & Cen. & Pos. & Ant. & Cen. & Pos. \\
\hline & $*_{\mathrm{i}}$ & & $* u$ & & & & & & \\
\hline Fechadas & $*_{\mathrm{i}}$ & & $*_{\mathrm{u}}$ & $\mathrm{i}$ & & $\mathrm{u}$ & $\mathrm{i}$ & & $\mathrm{u}$ \\
\hline Fechadas longas & & & & & & & ii & & $\mathrm{uu}$ \\
\hline Meio-fechadas & $* \mathrm{e}$ & & $*_{\mathrm{O}}$ & e & & o & e & & o \\
\hline Meio-fechadas longas & & & & & & & ee & & oo \\
\hline Meio-abertas & & & & $\varepsilon$ & & o & & & \\
\hline Aberta & & $* \mathrm{a}$ & & & $\mathrm{a}$ & & & $\mathrm{a}$ & \\
\hline Aberta longa & & & & & & & & aa & \\
\hline
\end{tabular}

Para exemplo de palavras distinguidas pela duração vocálica, vejamos algumas palavras do quissicongo: ${ }^{2}$

(1) Quissicongo (H16) Ndonga (1995, p. 29) ${ }^{3}$

$\begin{array}{llll}\text { Bákà } & \text { 'Prender' } & \text { Bàákà } & \text { 'Destruir' } \\ \text { Nkàkà } & \text { 'Peixe' } & \text { Nkàákà } & \text { 'Avô' } \\ \text { Sálà } & \text { 'Trabalhar' } & \text { Sàálà } & \text { 'Ficar' } \\ \text { Tùtù } & \text { 'Rato' } & \text { Tùùtù } & \text { 'Bambu' } \\ \text { Vátà } & \text { 'Cultivar' } & \text { Váátà } & \text { 'Cavar' }\end{array}$

O fenômeno conhecido como harmonia vocálica é atestado em muitas línguas da savana ocidental (Sommer, 2003, p. 570), comumente mencionado na literatura africanista como assimilação vocálica por altura. A assimilação ocorre geralmente entre as vogais do radical e os morfemas derivativos ou sufixos. Em alguns casos pode ocorrer também em prefixos, como é o caso do ochindonga (Fivaz, 2003, p. 16). Abaixo listamos alguns exemplos do quimbundo e herero para o caso do perfectivo:

\footnotetext{
${ }^{2}$ A numeração dos exemplos é reiniciada a cada capítulo.

${ }^{3}$ Em outro dialeto do quicongo, no quizombo, em um curso voltado para aprendizes (Carter;Makoondekwa, 1987) e na tese de Carter (1973), as vogais longas são indicadas em todas as palavras, no sistema ortográfico desenvolvido pelos autores.
} 
(2) Quimbundo (H21) (Xavier, 2010, p. 28)
a. nì-á\#bít-è
ngábítí
'passei'
b. á\#túnd-è
á-túndù
'saíram'

(3) Herero (R31) (Möhlig; Kavari, 2008, p. 31-2)
a. -pítá
mbá\#pítít-e
'eu saí'
b. -pata
mbá\#patere
'eu fechei'

A Tabela 3 apresenta o inventário consonantal de oito línguas da nossa amostra. $\mathrm{O}$ umbundo e o yeyi se destacam pela presença da palatal surda[c], que também é encontrada em luyana, conforme Sommer (2003, p. 568). O umbundo também apresenta um outro traço raro nas línguas bantas, consoantes nasalizadas. Das consoantes apresentadas por Schadeberg

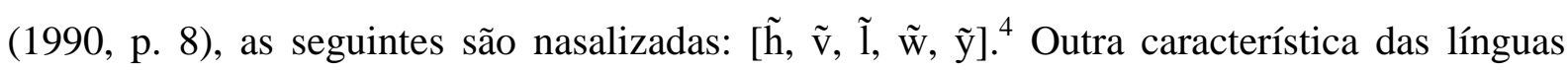
angolanas que merece menção é a ocorrência de cliques incorporados, notadamente nas línguas da zona K. Sommer (2003, p. 569) apresenta uma tabela com as principais ocorrências de cliques na língua yeyi falada em Ngamilandia, num total de vinte e sete diferentes cliques com valor fonológico.

Tabela 2.2 - Inventário consonantal de línguas selecionadas ${ }^{5}$

\begin{tabular}{|c|c|c|c|c|c|c|c|c|}
\hline & $\begin{array}{l}\text { QCG } \\
\text { (H16) }\end{array}$ & $\begin{array}{l}\text { QBD } \\
\text { (H21) }\end{array}$ & $\begin{array}{l}\text { LCZ } \\
\text { (K13) }\end{array}$ & $\begin{array}{l}\text { GGL } \\
\text { (K12) }\end{array}$ & $\begin{array}{l}\text { OCD } \\
\text { (R22) }\end{array}$ & $\begin{array}{l}\text { YEY } \\
\text { (R41) }\end{array}$ & $\begin{array}{l}\text { UBD } \\
\text { (R11) }\end{array}$ & $\begin{array}{l}\text { HRR } \\
\text { (R31) }\end{array}$ \\
\hline Oclusiva & $\begin{array}{l}p, t, k \\
b, d\end{array}$ & $\begin{array}{l}p, t, k \\
b,\end{array}$ & $p, t, k$ & $p, t, \underset{n}{t}, k$ & $\begin{array}{l}p, t, k, ? \\
(b, d, g)\end{array}$ & $\begin{array}{l}p, t, c, k \\
b, b b, d, f, g\end{array}$ & $p, t, c, k$ & $p, \underset{\sim}{t}, t, k$ \\
\hline Fricativa & & $\begin{array}{l}f, s, \int, h, \\
v, z, 3\end{array}$ & & $\theta, \delta, \int, h$ & $\begin{array}{c}f, \theta, s, \int, x, h \\
v, \delta, z,(3), \gamma\end{array}$ & $\begin{array}{l}f, s, \int, h \\
v, z, 3\end{array}$ & $f, s, h, v$ & $\begin{array}{l}(f), \theta, f, s, \\
h, \\
v, \partial, y\end{array}$ \\
\hline Africada & $t s$ & & $t s, t f$ & & $t s$ & $\begin{array}{l}(t s) \\
d z\end{array}$ & & $t f$ \\
\hline Tepe & & & $r$ & & & $r$ & & $r$ \\
\hline Lateral & $l$ & $l$ & $l$ & $l$ & $l$ & $l$ & $l$ & (l) \\
\hline Glide & $w, y$ & $w, y$ & & $w, y$ & $w, y$ & $w, y$ & $w, y$ & $w, y$ \\
\hline $\begin{array}{l}\text { Nasal } \\
\text { Nasal } \\
\text { Nasal. }\end{array}$ & $m, n, n$ & $m, n$ & $m, n, n, \eta$ & $m, n, n$ & $\begin{array}{l}m, n, n \\
(+)\end{array}$ & $m, n, n, \eta$ & $\begin{array}{l}m, n, n, \eta \\
+ \\
\tilde{h}, \tilde{v}, \tilde{w}, \tilde{y}, \tilde{l}\end{array}$ & $m, n, n, n$ \\
\hline
\end{tabular}

\footnotetext{
${ }^{4}$ Em Schadeberg (1982) é apresentada uma discussão detalhada sobre nasalização em umbundo.

${ }^{5}$ A Tabela 3 é baseada em Sommer (2003) com algumas adaptações.
} 
A maioria das línguas bantas distingue duas alturas tonais: um tom alto e um baixo, representadas por $/ \%$ e $\Gamma /$, respectivamente. A complexidade dos fenômenos tonais em línguas africanas nos exime de um tratamento mais pormenorizado, no entanto, seguindo nas linhas da apresentação de Sommer (2003, p. 570-1), apresentamos alguns fatos para ilustração. Uma primeira observação feita por Sommer é a do padrão tonal do umbundo (-làndà 'comprar', kwátà 'pegar') que pode mudar no imperativo, fazendo com que a vogal final sempre carregue um tom alto (làndá 'compre!', kwátá 'pegue!'). Em seguida, a autora descreve em rápidas linhas o que tem sido discutido na literatura como casos tonais. Em König (2008) há uma discussão mais completa e recente sobre a expressão de casos nas línguas africanas, e conforme a mesma autora (König, 2008), as categorias de caso são raras nas línguas africanas, ocorrendo apenas nas famílias nilo-saariana e afro-asiática. Para o caso do nigero-congolês, um sistema de marcação de caso por meio de tons tem sido advogado para muitas línguas, principalmente do oeste africano. ${ }^{6}$ Dentre as línguas angolanas estudadas neste capítulo, o umbundo, herero, luchazi e ganguela são consideradas como línguas que podem marcar caso por meio de tons. Partindo dos trabalhos de Schadeberg (1982; 1990), König (2008, p. 204219) sugere dois casos tonais, ao invés dos três propostos por Schadeberg (caso de objeto, caso comum e caso predicativo), pois a autora inclui este último no caso de objeto, por serem expressos pelos mesmos meios. Dessa forma, haverá sempre um tom alto para o acusativo, enquanto um tom baixo marcará o nominativo, segundo os exemplos abaixo: ${ }^{7}$

(4) Umbundo (R11) (König, 2008, p. 207)

$\begin{array}{llll} & \text { ACC } & \text { NOM } & \text { Glosa } \\ \text { a. ú-lúme } & \text { ù-lúme } & \text { 'homem' } \\ \text { b. á-sénjele } & \text { à-sénjele } & \text { 'leite' } \\ \text { c. é-celálá } & \text { è-celálá } & \text { 'oito' } \\ \text { d. óngeve } & \text { òngeve } & \text { 'hipopótamo' }\end{array}$

Sommer (2003) faz menção à interação entre intervalos tonais com outros traços prosódicos, como acento e duração vocálica, para o caso da língua gciriku (K38b). Como selecionamos outras línguas para esta apresentação, vale aqui trazer uma discussão para o

\footnotetext{
${ }^{6}$ Creisselset al. (2007, p. 88) indicam que esse traço se caracteriza como areal em línguas bantas, desde o Gabão até Angola.

${ }^{7}$ Maniacky (2003) discute a possibilidade de casos tonais para o ganguela. Marten e Kavari (em preparação) também discutem a possibilidade de quatro marcações de caso em herero, sendo: caso default; caso de complemento; caso apresentativo e caso vocativo.
} 
caso de uma língua da zona H. Há para o quimbundo (H21) uma discussão iniciada com Pedro (1993) e levada a cabo por Xavier (2010; 2009) sobre a existência de tom e acento em quimbundo. O primeiro autor parte de três pares mínimos como justificativa para o estatuto distintivo do acento em quimbundo:

Quimbundo (H21) (Pedro, 1993, p. 29)

$\begin{array}{llccc}\text { a. } & \text { kú. 'djà } & \text { 'comer' } & \text { 'kú.djà } & \text { 'comida' } \\ \text { b. } & \text { kú.'nwà } & \text { 'beber' } & \text { 'kú.nwà } & \text { 'bebida' } \\ \text { c. } & \text { kú. 'fwà } & \text { 'morrer' } & \text { 'kú.fwà } & \text { 'morte' }\end{array}$

Após a apresentação desses exemplos, Pedro (1993) se diz disposto a uma investigação sobre esse fenômeno em um momento posterior, já que naquele momento havia as dificuldades intensificadas pela guerra e outras questões sociolinguísticas em Angola. Tal empreitada foi assumida por Xavier $(2009 ; 2010)$ para quem a interpretação de pares mínimos acentuais em quimbundo se dá como ocorrência secundária ocasionada por questões de movimento, ou espraiamento tonal, de um tom alto dentro de combinação de palavras (Xavier, 2010, p. 103). Para comprovar essa ideia, Xavier demonstra, nos exemplos abaixo, que fenômenos específicos, como o de sândi tonal, podem vir a dar a impressão de uma distinção acentual:

(6) Quimbundo (H21) (Xavier, 2010, p. 105)

$\begin{array}{llll}\text { a. } & \text { Fúngé } & \text { kúdjá } & \text { kwámbòtè. } \\ & \text { Funje } & \text { comida } & \text { boa } \\ \text { 'Funje é uma comida boa.' } & \\ \text { b. } & \text { ygá-ndálá } & \text { kúdjà } & \text { Jitù } \\ & \text { 1ps-querer comer } & \text { carne } \\ & \text { 'Quero comer carne.' }\end{array}$

Xavier não descarta, no entanto, a possibilidade de mudança na língua, o que poderia levar o quimbundo a um sistema tonal e acentual. 


\subsection{Morfologia nominal}

\subsubsection{Classes nominais}

As línguas bantas são bem conhecidas pelo seu sistema de classes nominais, um sistema de prefixos bastante produtivo na classificação de nomes em gêneros, servindo também como uma base de concordância entre sintagmas nominais e seus constituintes, sejam determinantes e/ou modificadores. Na verdade, toda a família nigero-congolesa exibe um complexo sistema de concordância (Childs, 2003, 99; Katamba, 2003, p. 105), apesar de haver diversas línguas bantas que já não apresentam um sistema complexo de classes nominais e são chamadas por alguns estudiosos como línguas de sistemas de classes nominais reduzidas, em oposição àquelas consideradas como de classes nominais canônicas. ${ }^{8}$

Um exemplo de como funcionam as classes nominais em línguas bantas pode ser observado abaixo, em uma sentença do quimbundo:

\begin{tabular}{|c|c|c|c|c|}
\hline má-lá & mà-á-mbánzá & má-كíkì & nì & mà-ákínì \\
\hline 6-homem & 6-da-cidade & 6-cantou & CONJ & 6-dançou \\
\hline
\end{tabular}

O nome referente a homem é da classe 6 , servindo de núcleo no sintagma nominal. A partir desse nome, os prefixos em "mbánzá” e nos verbos "Síkì” e “ákínì”, o primeiro antecedendo a marca do genitivo, os seguintes como marcas do sujeito. Esses prefixos são emparelhados a partir da distinção entre singular e plural. Pela tradição bantuísta convencionou-se que as classes de número ímpar representam o singular dos nomes e as de número par o plural. Para ficar mais claro esse emparelhamento entre singular e plural, vejamos o seguinte exemplo do quizombo, sem a marcação tonal, para nomes das classes 5 e $6 \mathrm{di}-/ \mathrm{ma}-$ :

Quizombo(H16h) (Fernando, 2008, p. 16)
a. $d i$-nkondo $\quad d y$ a Luzolo $d i$-vid-idi.
5-banana 5-de Luzolo 5-desaparecer-REC
'a banana do Luzolo desapareceu'

${ }^{8}$ Conferir Maho (1999) para uma crítica a esses termos. 


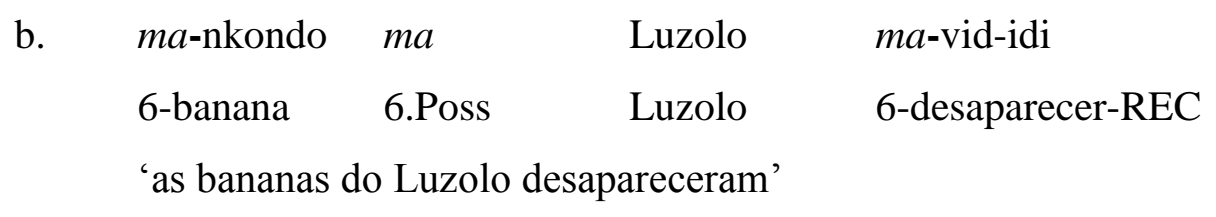

(9) Herero (R31) (Möhlig; Kavari, 2008, p. 209)
a. O-ka-
tí o-ka-títí
'o pequeno palito está quebrado'
$k$-á
kóyóka.
PPF-13- palito PPF-13-pequeno
13.MS-COP.REC
quebrado
b. O-u-
tí $\quad$ o- $\boldsymbol{u}$ - títí
PPF-14- palito PPF-14-pequeno 'os pequenos palitos estão quebrados'
w-á
kóyóka.
14.MS-COP. REC quebrado

Na Tabela 2.3 estão dispostos os prefixos nominais de línguas selecionadas. É possível perceber alguma semelhança entre os prefixos nominais das línguas bantas, nomeadamente as classes $1,2,3,4,5,6,7,8$. As classes 9 e 10 são caracterizadas em grande parte das línguas bantas pelo caráter homorgânico de seus morfemas, geralmente representado por N- ou $\varnothing$-. As variações entre as demais classes são mais perceptíveis. Para o caso das classes nominais locativas, 16, 17 e 18, para as línguas que as possuem, a principal variação se encontra na classe 16. É bom que se observe que nem todas as línguas bantas apresentam todas as classes. No quicongo, por exemplo, falta a classe 12 , enquanto que no umbundo falta a classe 8 . O lingala é um exemplo de língua que não possui as classes nominais locativas, por isso, foi incluído na presente tabela como forma de contrastar com as demais línguas angolanas. 
Tabela 2.3 - Pré-prefixos e prefixos nominais de línguas selecionadas ${ }^{9}$

\begin{tabular}{|c|c|c|c|c|c|c|c|c|c|c|c|c|}
\hline Classe & & & $\begin{array}{l}\text { QMB } \\
\text { (H21) } \\
\end{array}$ & $\begin{array}{l}\mathrm{LCZ} \\
(\mathrm{K} 13) \\
\end{array}$ & $\begin{array}{l}\text { GGL } \\
\text { (K12b) }\end{array}$ & & $\begin{array}{l}\text { CD } \\
\text { 22) } \\
\end{array}$ & & $\begin{array}{l}\text { IRR } \\
\text { R31) } \\
\end{array}$ & $\begin{array}{l}\mathbf{U N} \\
(\mathbf{R} \\
\end{array}$ & & $\begin{array}{l}\text { LGL } \\
\text { (C36d) }\end{array}$ \\
\hline 1 & $O-$ & $\begin{array}{l}m u-, \\
N^{\prime}- \\
\varnothing-\end{array}$ & $m u-$ & $m u-$ & $m u-$ & $\begin{array}{l}O- \\
O-\end{array}$ & $\begin{array}{l}m- \\
m w-\end{array}$ & $O-$ & $\begin{array}{l}m u- \\
\varnothing-\end{array}$ & $O-$ & $\begin{array}{l}u- \\
m u-\end{array}$ & $\begin{array}{l}m o- \\
\varnothing-\end{array}$ \\
\hline 2 & $o-$ & $\begin{array}{l}a- \\
w a- \\
b a-\end{array}$ & $a-$ & $v a-$ & $v a-$ & $o-$ & $a-$ & $\begin{array}{l}o- \\
o-\end{array}$ & $\begin{array}{l}v a- \\
o-\end{array}$ & $\begin{array}{l}O- \\
o-\end{array}$ & $\begin{array}{l}a^{-}, \\
v a- \\
m a-\end{array}$ & $b a-$ \\
\hline 3 & $O-$ & $\begin{array}{c}m u- \\
N^{\prime}-\end{array}$ & $m u-$ & $m u-$ & $m u-$ & $\begin{array}{l}o- \\
o-\end{array}$ & $\begin{array}{l}m- \\
m w-\end{array}$ & $O-$ & mu- & $\begin{array}{l}o- \\
o-\end{array}$ & $\begin{array}{l}u-, \\
w-, \\
m u-\end{array}$ & mo- \\
\hline 4 & $e-$ & $\begin{array}{c}m i- \\
N^{\prime}-\end{array}$ & $m i-$ & $m i-$ & $m i-$ & $\begin{array}{l}o- \\
o-\end{array}$ & $\begin{array}{l}m i- \\
m w\end{array}$ & $o-$ & $m i-$ & $O-$ & $\begin{array}{l}v i- \\
i-\end{array}$ & $m i-$ \\
\hline 5 & $e-$ & $\begin{array}{l}d i- \\
\varnothing-\end{array}$ & $l i-$ & $l i-$ & $l i-$ & $e-$ & $\varnothing-$ & $e-$ & $\varnothing-$ & & $\begin{array}{l}e-, \\
\varnothing-\end{array}$ & $l i-$ \\
\hline 6 & $e-$ & $m a-$ & $m a-$ & $m a-$ & $m a-$ & $o-$ & $m a-$ & $o-$ & $m a-$ & $O-$ & $\begin{array}{l}a-, \\
v a-,\end{array}$ & $m a-$ \\
\hline 7 & $e-$ & $\begin{array}{l}k i^{-}, \\
\varnothing-\end{array}$ & $k i-$ & $c i-$ & $\mathrm{ci}-$ & $o-$ & shi- & $O-$ & tji- & $O-$ & $\mathrm{Ci}^{-}$ & $\begin{array}{l}e- \\
k i-\end{array}$ \\
\hline 8 & $e-$ & $\begin{array}{l}i- \\
\varnothing-\end{array}$ & $i-$ & $v i-$ & $v i-$ & $i-$ & $i-$ & $O-$ & $v i-$ & & & $b i-$ \\
\hline 9 & $\begin{array}{l}e- \\
a(k i)-\end{array}$ & $\begin{array}{l}N- \\
\varnothing-\end{array}$ & $\varnothing / i-$ & $\varnothing /(i) N-$ & (i) $N-$ & $o-$ & $N-$ & $o-$ & $(N)-$ & $o-$ & $N-$ & $\varnothing-$ \\
\hline 10 & $e-$ & $(Z i) N-$ & $j i-$ & $z i(N)-$ & $\partial i(N)-$ & $o-$ & $o N-$ & $o-$ & $z o(N)-$ & $O-$ & lon- & $\emptyset-$ \\
\hline 11 & $O-$ & $l u-$ & $l u-$ & $l u-$ & $l u-$ & $\begin{array}{l}o- \\
o-\end{array}$ & $\begin{array}{l}l u- \\
l w-\end{array}$ & $O-$ & $r u-$ & $O-$ & $l u-$ & lo- \\
\hline $\begin{array}{l}12 \\
13\end{array}$ & $O-$ & $t u-$ & $\begin{array}{l}k a- \\
t u-\end{array}$ & $\begin{array}{l}k a- \\
t u-\end{array}$ & $\begin{array}{l}k a- \\
t u-\end{array}$ & $o-$ & $k a-$ & $\begin{array}{l}O- \\
O-\end{array}$ & $\begin{array}{l}t u- \\
k a-\end{array}$ & $\begin{array}{l}O- \\
O-\end{array}$ & $\begin{array}{l}k a- \\
t u-\end{array}$ & \\
\hline 14 & $O-$ & $w u-$ & $u-$ & $v u-$ & $v u-$ & $u$ - & $u$ - & $O-$ & $u-$ & & & bo- \\
\hline 15 & $o-$ & $k u-$ & $k u-$ & $k u-$ & $k u-$ & $o-$ & $k u-$ & $O-$ & $k u-$ & $o-$ & $k u-$ & ko- \\
\hline $\begin{array}{l}16 \\
17 \\
18 \\
19 \\
\end{array}$ & $\begin{array}{l}o- \\
o- \\
o- \\
e-\end{array}$ & $\begin{array}{l}v a- \\
k u- \\
m u- \\
\text { fi- }\end{array}$ & $\begin{array}{l}b u- \\
k u- \\
m u-\end{array}$ & $\begin{array}{l}\text { ha- } \\
\text { ku- } \\
m u-\end{array}$ & $\begin{array}{l}\text { ha- } \\
\text { ku- } \\
m u-\end{array}$ & & $\begin{array}{l}p u- \\
k u- \\
m u-\end{array}$ & $\begin{array}{l}? \\
? \\
? \\
\end{array}$ & $\begin{array}{l}p u- \\
k u- \\
m u- \\
o u- \\
\end{array}$ & & $\begin{array}{l}p a- \\
k u- \\
v u-\end{array}$ & \\
\hline
\end{tabular}

Nota:As referências: quicongo QCG (Ndonga, 1995, p. 129); quimbundo QMB (Pedro, 1993, p. 115); luchazi LCZ (Fleisch, 2000, p. 54); ganguela GGL (Maniacky, 2003, p. 24); ochindonga OCD (Fivaz, 2003, p. 32); hereroHRR (Möhlig; Kavari, 2008, p. 82); umbundo UBD (Schadeberg, 1990, p. 10); e lingala LGL (Meeuwis, 1998, p. 8).

Na Tabela 2.3, nas colunas das línguas quicongo, ochindonga, herero e umbundo, são apresentados os pré-prefixos, ou aumentos, como são mais conhecidos na tradição bantuísta. Por vezes é também denominada vogal inicial, por ser um morfema que vem antes dos prefixos de cada nome.Tem-se com de Blois (1970) um primeiro estudo contrastivo sobre a distribuição geográfica e as funções do pré-prefixo em um conjunto de línguas bantas, indicando que o uso de pré-prefixo é bem difundido em toda a área do domínio banto, sendo,

\footnotetext{
${ }^{9}$ Uma tabela semelhante a esta pode ser encontrada em Ngunga (2004, p. 120), nesse caso, com prefixos de línguas moçambicanas.
} 
talvez, a área das línguas do noroeste uma exceção (1970, p. 152). Apesar de a tradição bantuísta preferir o termo "aumento", alguns autores têm preferido usar o termo "préprefixo", tentado evitar com isso que haja confusão com outros termos como "aumentativo", e por pensarem que a motivação inicial para o termo "aumento", a de uma vogal que era "adicionada" a um nome já com seu prefixo, o que "aumentaria" o nome, já não faz tanto sentido. Utilizaremos as etiquetas indistitivamente por acreditarmos que nenhuma delas acarreta qualquer prejuízo conceitual para este trabalho. Sempre que for utilizado o termo "aumento", estaremos fazendo referência a como cada autor trata desses morfemas, nos demais casos daremos preferência ao termo "pré-prefixo", aparentemente um termo mais neutro.

Dentre as línguas que mereceram atenção de Sommer (2003, p. 571), a autora indica a existência de pré-prefixo em umbundo, ochindonga, yeyi e luyana, mas não para as línguas kavango e luvale. Quanto ao material consultado por nós, de línguas angolanas, pelo menos em Ndonga (1995, p. 170-7), há uma seção dedicada às funções do pré-prefixo em quissicongo, enquanto nos demais trabalhos, as informações sobre o pré-prefixo são sempre esparsas. Schadeberg (1990, p. 12-4) aponta algumas particularidades do umbundo, como a que segue abaixo:

(10) Umbundo (Schadeberg, 1990, p. 14)

$\begin{array}{ll}\text { a. Ó-ngevé } & \text { 'é um hipopótamo' } \\ \text { b. Ngévé } & \text { 'é o Ngévé'10 }\end{array}$

Por hora não nos aprofundaremos sobre a semântica e sintaxe do pré-prefixo nas línguas bantas, deixando para a seção 6.3.1 uma discussão mais detalhada. Retomamos o assunto logo adiante, em 2.5.2, ao tratarmos de foco e tópico.

\subsubsection{Classes nominais locativas}

As três classes nominais locativas, 16, 17 e 18, são conhecidas também pela regularidade do sentido locativo de cada uma. Em Welmers (1973, p. 167) encontramos uma primeira caracterização que será recorrente na descrição dessas três classes: "Em algumas poucas línguas bantas, e em muitas línguas não bantas do nigero-congolês, reflexos e

\footnotetext{
${ }^{10}$ Nome próprio.
} 
cognatos de */pa-/, */ko-/ e */mo-/ funcionam de alguma forma como preposições. Geralmente a classe 16 refere-se à proximidade ou localização explícita, a classe 17 à localização remota ou geral, e a classe 18 à localização interna" ". Alguns exemplos ilustram melhor essa caracterização dessas três classes:

(11) Umbundo (R11) (Schadeberg, 1990, p. 11)
a. pólwí 'perto do rio'
b. kólwí 'para rio'
c. vólwí 'dentro do rio'

(12) Herero (R31) (Möhlig; Kavari, 2008, p. 89)
a. pondjúwó 'perto da casa'
b. kondjúwó 'para casa'
c. mondjúwó 'na casa'

Observamos, no entanto, em dialetos do quicongo, que a classe 16 parece carregar muito mais um sentido de 'lugar em cima de', além do de proximidade, conforme Ndonga (1995, p. 140) e Maia (1961, p. 216).

\subsection{Morfossintaxe do verbo}

\subsubsection{A estrutura do verbo banto}

Nas línguas bantas, o verbo possui uma morfologia bastante complexa, com sua natureza aglutinante. A estrutura básica de um sintagma verbal gira em torno da base verbal e os afixos que se acoplam ao verbo antes e depois, carregando as informações sintáticas e semânticas de tempo, aspecto e modo, foco, negação, voz, dentre outras. A estrutura do verbo nas línguas bantas apresenta uma ordenação que a princípio parece regular para a maioria das línguas. Diversos autores têm tentado elaborar um esquema que represente melhor a estrutura da palavra verbal em banto. A depender de cada autor, pode haver uma variação na

\footnotetext{
11 "In a few Bantu languages, and in many non-Bantu Niger-Congo languages, reflexes or cognates of */pa- $/$, */ko-/, */mo-/ function somewhat like prepositions. Generally, 16 refers to near or explicit location, 17 to remote or general location, and 18 to location inside."
} 
nomenclatura e no número dos elementos constitutivos do verbo. Em Nurse (2008, p. 31) encontram-se 9 posições para a estrutura do verbo banto. ${ }^{12}$

Atualmente, uma forma de exemplificar a estrutura do verbo banto pode ser com a ordenação das posições (slots) do verbo e como elas são preenchidas de acordo com as categorias comumente alojadas em cada posição, posições essas que seguem uma ordem considerada relativamente fixa de língua para língua, como se verá. Na Tabela 2.4 estão as posições e as funções sintático-semânticas geralmente relacionadas a elas.

Tabela 2.4 - Estrutura morfológica das formas verbais finitas em banto (Güldemann, 2003, p. 184)

\begin{tabular}{|c|c|c|c|c|c|c|c|c|}
\hline Posições & $\begin{array}{l}\text { (pre- } \\
\text { inicial) }\end{array}$ & Inicial & (pós-inicial) $^{\mathrm{n}}$ & $\begin{array}{l}\text { (pré- } \\
\text { radical) }\end{array}$ & radical & $(\text { pré-final })^{\mathrm{n}}$ & final & (pós-final) $^{\mathrm{n}}$ \\
\hline Funções & $\begin{array}{l}\text { TAM }^{\text {it/ }} \\
\text { Negação/ } \\
\text { Tipo } \\
\text { oracional }^{\text {it }}\end{array}$ & $\begin{array}{c}\text { Marca } \\
\text { do } \\
\text { Sujeito }\end{array}$ & $\begin{array}{c}\text { TAM/ } \\
\text { Negação/ } \\
\text { Tipo } \\
\text { oracional }^{\text {it }}\end{array}$ & $\begin{array}{c}\text { Marca } \\
\text { do } \\
\text { Objeto }\end{array}$ & $\begin{array}{c}\text { Raíz } \\
\text { verbal }\end{array}$ & $\begin{array}{c}\text { TAM/ } \\
\text { Mudança } \\
\text { de valência }\end{array}$ & TAM & $\begin{array}{l}\text { Participante/ } \\
\text { Negação }^{\text {it }} / \\
\text { Tipo } \\
\text { oracional }^{\text {it }}\end{array}$ \\
\hline
\end{tabular}

(...) opcional, ${ }^{\mathrm{n}}$ ocorrências múltiplas, ${ }^{\text {it }}$ inovação tardia

Frente a essa ordenação entre os elementos do verbo e suas funções é preciso atentar que não necessariamente todas as posições devam ser preenchidas numa determinada sentença. A presença ou não de cada elemento constitutivo vai depender de diversos fatores, e sendo assim, numa só sentença todas as posições podem vir preenchidas, resultando em um complexo verbal característico das línguas bantas. Por outro lado, na maioria dos casos uma sentença poderá valer-se apenas dos elementos considerados obrigatórios, aqueles que não estão entre parênteses na Tabela acima, nesse caso, a Inicial, com a marca do sujeito e os morfemas de tempo, aspecto e modo (TAM), o Radical e a Final ou vogal final. Vejamos um exemplo da estrutura do verbo banto com sentenças de duas línguas, nas quais todas as posições são preenchidas:

\footnotetext{
${ }^{12}$ Sugerimos a consulta ao trabalho de Nurse (2008) como também ao original em Meeussen (1967) de onde o autor se baseia para a sua proposta.
} 
Tabela 2.5 - Posições verbais em umbundo e quizombo (adaptado de Sommer (2003, p. 576))

\begin{tabular}{|c|c|c|c|c|c|c|c|}
\hline \multicolumn{8}{|c|}{ Posições, morfemas e funções: exemplo do umbundo e quizombo } \\
\hline Pré-inicial & Inicial & Pós-inicial & Pré-radical & Radical & Pré-final & final & Pós-final \\
\hline (i) $=K a$ & $T w$ & $\grave{a}-k a$ & $v a-u$ & pandw & il & $i l-\varnothing$ & $-i-k o ́$ \\
\hline (ii) $=$ Dìkà & tù- & $a-$ & lì- & kìn- & is-ín & $\grave{a}-$ & kó \\
\hline$(\mathrm{REL}) / \mathrm{NEG}$ & MS & TAM & MO & $\mathrm{BV}$ & EXT & TAM/VF & $\begin{array}{l}\text { CL-NEG- } \\
\text { LOC }\end{array}$ \\
\hline \multicolumn{2}{|c|}{ (i) = Umbundo: } & \multicolumn{6}{|c|}{ 'Nós não fomos lá para agradecer a eles por você.' } \\
\hline (ii) $=$ Quizom & & Por is & nós não fizer & os vocês & arem.' & & \\
\hline
\end{tabular}

É preciso chamar a atenção para a colocação do relativo na pré-inicial, como indicado no exemplo do quizombo, fizemos questão de utilizar um exemplo como este para sugerir o que Nurse (2003, p. 90-91) já havia atestado quanto ao início da estrutura do verbo banto, a de que esta é a posição na qual novo material geralmente se torna gramaticalizado, além de mostrar que esta é apenas uma das formas de visualizar a estrutura do verbo banto.

Abaixo, apresentamos os dois exemplos, do umbundo e quizombo, com as devidas glosas:

(13) Umbundo (R11) (Schadeberg, 1990, p. 29) ${ }^{13}$

Ka tw à-ka va-u-pand-wíl-íl-i-kó

NEG MS TAM-IT MO.3pl-MO.2sg-agradecer-APL-TAM-VOC.pl-LOC

'Nós não fomos lá para agradecer a eles por você.'

(14) Quizombo (H16h) (Araújo; Teca; Fernando, em preparação).

Dì kà tù-á-lù-kìn-ís-ín-à-kó

REL NEG1 1pl-REC-MO-dançar-CAU-APL-VF-NEG2

'por isso nós não fizemos você dançar.'

As posições do exemplo (12) e (13) não condizem com todos os elementos sugeridos por Nurse (2008), mas dão uma visão de como os elementos se organizam no complexo verbal banto. Como dissemos, nem sempre todas as posições serão preenchidas. Nos exemplos acima, percebemos que apesar das diferenças terminológicas e da variação dos elementos que podem ocorrer em cada posição específica, os esforços dos linguistas

\footnotetext{
${ }^{13}$ Schadeberg chama o morfema "-ka" como marca de "itivo" (do latim itum) e o morfema glosado como VOC como uma marca de vocativo plural.
} 
bantuístas continuam sendo despendidos para a elaboração de um modelo que seja flexível o bastante para enquadrar a estrutura verbal de todas as línguas bantas (Maho, 2007). Como parte desses esforços, encontramos em Ngunga (2004) uma representação para a estrutura do verbo banto de forma hierárquica:

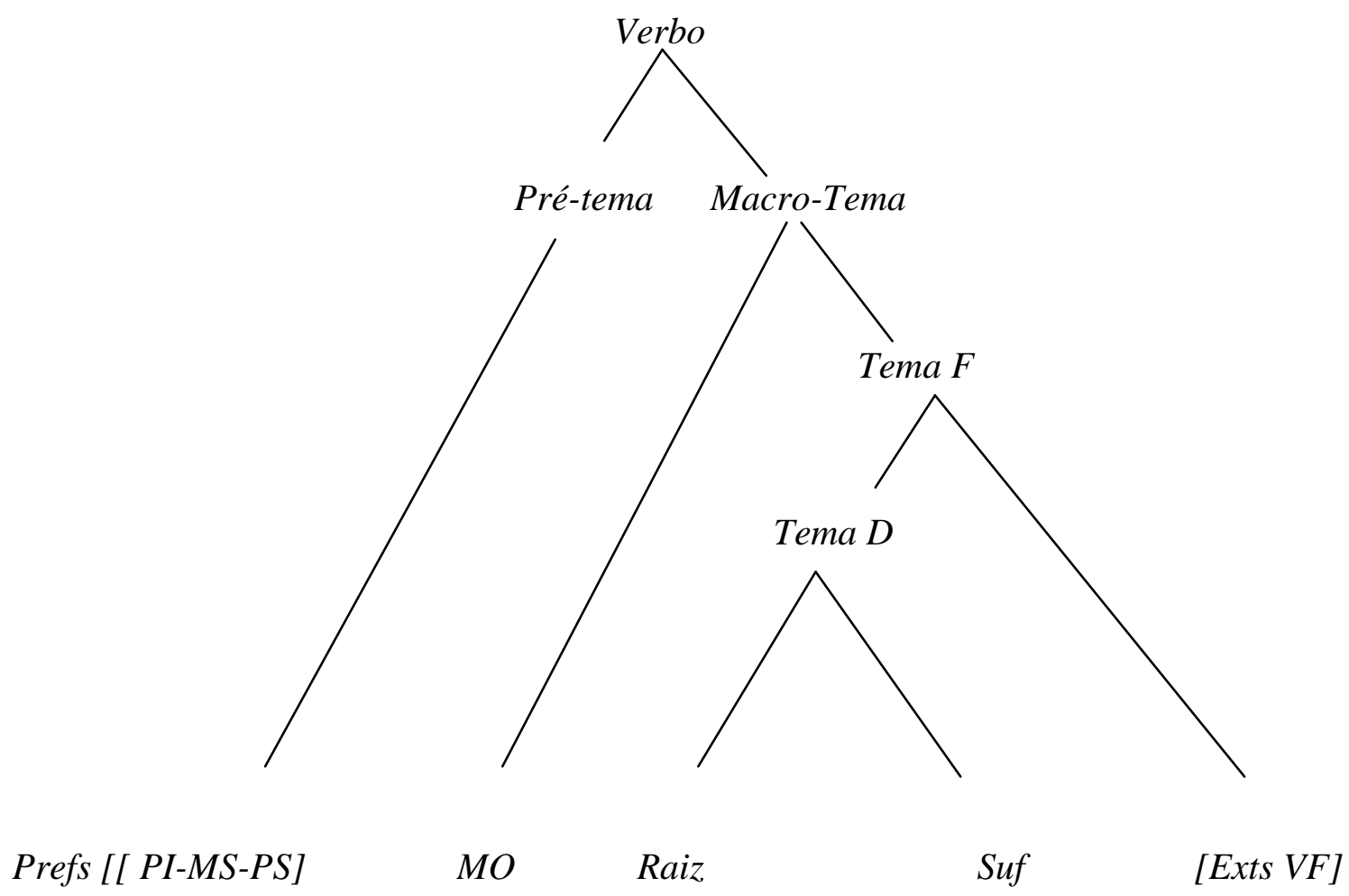

Figura 2.1 - Estrutura do verbo banto (Ngunga, 2004, p. 148)

Nessa figura, Ngunga divide o verbo em pré-tema e macro-tema. O pré-tema pode apresentar os prefixos, a pós-inicial (PI); a marca do sujeito (MS); e a pós-marca do sujeito (PS). O macro-tema constitui-se do tema flexionado (Tema F), enquanto o Tema D é o tema derivado, contendo a raiz, os sufixos do verbo derivado. No TF há as extensões e a vogal final, VF. Ngunga acredita que o verbo banto se encaixa adequadamente em tal representação, lembrando que nem todas as posições precisam estar preenchidas. Halmer (2004) exemplifica a complexidade do verbo banto com dois exemplos do kwanyama, com o que ele chama de uso mínimo e máximo das posições: 
(15) Kwanyama (R21) (Halme, 2004, p. 73)

a. Pul-a

perguntar-VF

'Pergunte!'

b. O- há- tu- ké- shi- lí- monén- á ko

VI- PRE 1pl IM 7.MO REF ver.APL VF 17.LOC

'Nós não veremos isso por nós mesmos'.

\subsubsection{Extensões verbais}

As extensões verbais são morfemas derivacionais acrescentados após o radical verbal, modificando o sentido do verbo e geralmente as relações de transitividade. ${ }^{14}$ Dentre as extensões mais produtivas em banto, enumeramos algumas nos exemplos abaixo:

(16) Quizombo (H16h) (Teca, 2012)

-sal-

'trabalhar'

sad-il-a

'trabalhar para, por alguém'

extensão aplicativa

sad-is-a

'fazer trabalhar'

extensão causativa

sal-w-a

'estar/ter trabalhado'

extensão passiva

salasi-an-a

'trabalhar para si'

extensão recíproca

sal-ul-ul-a

'desfazer o trabalho'

extensão reversiva

sal-ul-wel-a

'retrabalhar'

extensão iterativa

A Tabela 2.6 relaciona os morfemas das extensões verbais de sete línguas bantas. Na última coluna estão os morfemas do protobanto, como forma de comparação. A forma como cada autor trabalha a semântica das extensões verbais varia muito, dificultando a identificação de cada morfema. Devido a isso, nem sempre foi possível identificar todas as extensões existentes e mencionadas em cada língua.

\footnotetext{
${ }^{14}$ Para uma discussão mais detalhada sobre a ordem de sufixos em banto, Hyman (2002)apresenta uma primeira proposta em teoria da otimalidade como alternativa para o mirror principle de Baker.
} 
Tabela 2.6 - Extensões verbais de línguas selecionadas ${ }^{15}$

\begin{tabular}{|c|c|c|c|c|c|c|c|c|}
\hline & $\begin{array}{l}\text { QCG } \\
\text { (H16) }\end{array}$ & $\begin{array}{l}\text { QBD } \\
\text { (H21) }\end{array}$ & $\begin{array}{l}\mathbf{L C Z} \\
(\mathrm{K} 31)\end{array}$ & $\begin{array}{l}\text { HRR } \\
\text { (R31) }\end{array}$ & $\begin{array}{l}\text { NGL } \\
\text { (K12) }\end{array}$ & $\begin{array}{l}\text { OSD } \\
\text { (R22) }\end{array}$ & $\begin{array}{l}\text { UMB } \\
\text { (R11) }\end{array}$ & PROTOBANTO \\
\hline APL & $\begin{array}{l}\text {-il-,-el- } \\
\text {-in-,- } \\
\text { en- }\end{array}$ & $-e l-,-i l-$ & $\begin{array}{l}\text {-il-,-el-, } \\
-i n-,-e n-\end{array}$ & $\begin{array}{l}\text {-era-,- } \\
\text { ira-, } \\
\text {-ena,- } \\
\text { ina- }\end{array}$ & $\begin{array}{l}\text {-el-,-il- } \\
-e n-,-i n-\end{array}$ & $\begin{array}{l}\text {-il-,-el- } \\
\text { en-,-in- }\end{array}$ & $\begin{array}{l}-i l-,-e l- \\
\tilde{\imath} l-,-\tilde{e} l-\end{array}$ & $*_{\text {-id- }}$ \\
\hline CAU & $-i s-,-e s-$ & $-e s-,-i s-$ & $-e s-,-i s-$ & $\begin{array}{l}-i s a- \\
-e k a,- \\
i k a-\end{array}$ & $-i \theta-,-e \theta-$ & $\begin{array}{l}-i k-,-e k- \\
-i t h-,-t h-\end{array}$ & $-i s-$ & $*$-ic-i- \\
\hline NEUT & $-i k-,-e k-$ & $-e k-$ & $-e k-,-i k-$ & $\begin{array}{l}-z \\
-i k a-\end{array}$ & $\begin{array}{l}\text {-uk-,-ok-, } \\
\text {-olok-, } \\
\text {-unuk-, } \\
\text {-onok- }\end{array}$ & $-i k-,-e k-$ & $-i k-,-e k-$ & $*_{-\mathrm{ik}-}$ \\
\hline REV & $-o l-$ & $\begin{array}{l}-u l-,- \\
u k-\end{array}$ & $\begin{array}{l}\text {-ol(ol)-, } \\
\text {-ul(ul)-, } \\
\text {-on(on)- } \\
\text {-un(un)- }\end{array}$ & $\begin{array}{l}\text {-ora-,- } \\
\text { ura-, } \\
\text {-oka-,- } \\
\text { uka- }\end{array}$ & $\begin{array}{l}-u l-,-o l- \\
-u n-,-o n-\end{array}$ & $-u l-,-o l-$ & $-u l-,-o l-$ & *-ひd-,-ひk- \\
\hline PASS & $\begin{array}{l}-w-,- \\
e w- \\
-i w-\end{array}$ & & & $\begin{array}{l}-w a-,- \\
e w a- \\
-i w a-\end{array}$ & $-u-,-O-$ & $-(i, e) w-$ & $-i w-$ & $*_{-i b-\mho-}$ \\
\hline REC & $\begin{array}{l}\text {-an-, } \\
\text {-azyan- }\end{array}$ & $-a n-$ & & -asana & & -athan- & & $*_{-} a n-$ \\
\hline POSC & & $\begin{array}{l}-a m-,- \\
a l-\end{array}$ & -ama- & $-a m a$ & $-a m-$ & & $-a m-*$ & \\
\hline $\begin{array}{l}\text { Pré- } \\
\text { final }\end{array}$ & & & & & -ayg- & $-a(n) g-$ & & \\
\hline
\end{tabular}

* Extensão não mais produtiva ou que não ocorre frequentemente; As referências: quicongo QCG (Ndonga, 1995, p. 333); quimbundo QBD (Pedro, 1993, p. 288-300); luchazi LCZ (Fleisch, 2000, p. 119-138); ganguelaGGL (Maniacky, 2003, p. 163-169); Oshindonga OSD (Fivaz, 1986, p. 32); Herero HRR (Möhlig; Kavari, 2008, p. 146); umbundo UBD (Schadeberg, 1990, p. 24-5); e Protobanto PBT (Schadeberg, 2003, p. 8).

Pela Tabela acima é possível verificar a semelhança na forma das extensões verbais nas línguas bantas. Algumas delas, como o aplicativo e causativo podem aumentar a valência do verbo, enquanto outras, como o recíproco e a passiva, servem para diminuir a valência. Abaixo selecionamos alguns exemplos retirados de diferentes línguas:

(17) Aplicativo

Umbundo (R11) (Valente, 1964, p. 304) ${ }^{16}$

e-longa ly-okul-il-a-po

5-prato 5.comer-onde-APL-VF-LOC

'prato onde se come' (Lit.: 'Prato para comer nele')

\footnotetext{
${ }^{15} \mathrm{O}$ sufixo ang-é usado tanto para progressivo como habitual em quizombo (Cf. Carter, 1987, p. 23).

${ }^{16}$ Glosas adicionadas.
} 
(18) Causativo

Yeyi (R41) (Seidel, 2008, p. 239) ${ }^{17}$

Nda-mu-yuvw-is-a pu-uwara wa-nga

1sg.-MO-provar-CAU-VF 16-14.cerveja 14-minha

'Eu o fiz provar da minha cerveja'

(19) Passivo

Quissicongo (H16) (Ndonga, 1995, p. 348)

ò-mú-nzò kè-mù-kál-w-à k kwà múntú kò

PPF-18-9.casa NEG-MS.NEUT-COP-PASS-VF PREP 9-homem NEG2

'Ninguém estava em casa.' (Lit. 'a casa não era estada por ninguém.')

(20) Posicional

Luchazi (K13) (Fleisch, 2000, p. 137) ${ }^{18}$

Ngu-eni, man-a nji-y-e aha ha-sung-am-a nzivoi-ze

QUOT-3sg. esperar-VF 1sg.ir-SUBJ 16.DEM 16-ficar-POSC-VF 9.casa 9.DEM

'Ele disse: espere, deixe-me ir onde a casa fica'.

O exemplo em (16) é apenas um dos diversos usos do aplicativo. No exemplo do umbundo, a extensão do aplicativo dá a entender a função do utensílio. Em (17), a extensão -is- dá ao verbo 'provar' do yeyi a semântica de um causativo. O exemplo em (18) do quissicongo é interessante por ser o emprego da forma passiva com a cópula kala, de uma forma uma tradução literal em português ficaria um pouco estranha. No original, o verbo 'sungama' (também 'sunkama') é um verbo posicional glosado por Fleisch (2000) como 'direto a' (em inglês aim, direct). $\mathrm{O}$ autor chama a atenção para a pouca produtividade da extensão posicional -ama- em luchazi, mas que continua servindo como um tipo de verbalizador, conferindo aos verbos a semântica de verbos posicionais.

Em estudos voltados para a questão da valência verbal, como o de Fernando (2008), é comum que o morfema do reflexivo seja incluído às demais extensões, mas é necessário que se chame a atenção para o fato de que o reflexivo em línguas bantas geralmente vem prefixado à raiz verbal, enquanto as demais extensões vêm após a raiz verbal, ensejando assim

\footnotetext{
${ }^{17}$ Sem marcação de tom no original.

${ }^{18}$ Sem marcação de tom no original.
} 
análises que considerem as marcas de reflexivo como marcas de objeto, por ela preencher a mesma posição de MOs. Esse parece ser o caso do chicheua (Mchombo, 2004, p. 103). Há a possibilidade de combinação entre as extensões verbais, como o uso de causativo com aplicativo ou de recíproco com causativo, como também o uso de uma mesma extensão para mais de uma função. Esse é o caso da extensão -an- do lingala, utilizada para o recíproco, estativo e reflexivo. Em outros casos, quando um morfema perde sua produtividade na língua, pode acontecer de se tornar uma forma cristalizada, adquirindo um novo sentido bem diferente da semântica original. Um exemplo disso é o que acontece com a combinação entre o reflexivo e o aplicativo em quizombo. Nas sentenças abaixo, temos em (20)a uma sentença simples com o verbo fwa (morrer); em (20)b, apesar do uso do aplicativo, de que Luzolo morreu pela criança, o sentido produzido é na verdade o de que a criança morreu. Em (20)c o uso do reflexivo com o aplicativo produz também um outro sentido, não o de que Luzolo “morreu por ele mesmo" na vila, mas a de que Luzolo não saiu para lugar nenhum:

(21) Quizombo (H16h) (Matsinhe; Fernando, 2008, p. 352-3)
a. Luzolo fw-idi.
L. morrer-PASS
'Luzolo morreu'

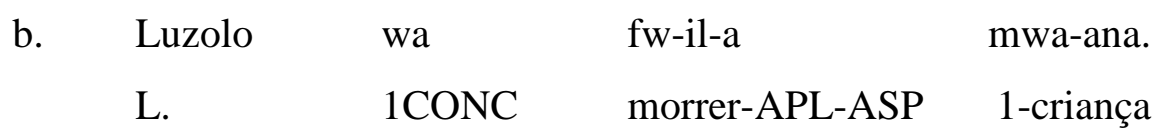

'Luzolo perdeu uma criança.' (Lit. 'Luzolo morreu pela criança.' ou 'o morreu pela criança do Luzolo’ )

$\begin{array}{lll}\text { c. Luzolo } & \text { u-ki-fw-id-idi } & \text { mu-vata } \\ \text { L. } & \text { 2.MS-REF-morrer-APL-PASD } & \text { 18.LOC-vila }\end{array}$

'Luzolo não foi a lugar algum.' (Lit. 'Luzolo morreu por ele mesmo na vila') 
Tabela 2.7 - Tempo, Aspecto e Modo em ochindonga, quissicongo e ganguela

\begin{tabular}{|c|c|c|}
\hline $\begin{array}{l}\text { Ochindonga (R22) } \\
\text { (Fivaz, 2003) } \\
\text { o-ku\#lánd-a 'comprar' }\end{array}$ & $\begin{array}{l}\text { Quissicongo(H16) } \\
\text { (Ndonga, 1995) } \\
\text { Ku\#tunga 'construir' }\end{array}$ & $\begin{array}{l}\text { Ganguela(K12) } \\
\text { (Maniacky, 2003) } \\
\text { Ku\#túúng-a 'construir' }\end{array}$ \\
\hline $\begin{array}{l}1 \text { Passado completo } \\
\text { o-MS-a-BV-ile/ } \\
\text { o-MS-á-BV-ile } \\
o-n d \text {-a\#lánd-elé } \\
\text { 'Eu terminei comprando' }\end{array}$ & $\begin{array}{l}1 \text { Passado imediato } \\
\text { MS- } \theta \text {-BV-IDI } \\
N-\theta \text {-tùng-ìdïténzò } \\
\text { 'eu acabei de construir a casa' }\end{array}$ & $\begin{array}{l}1 \text { Passado progressivo } \\
\text { MS-keele-(MO)-BV-a } \\
\text { Njá-keele\#kutúúyg-a } \\
\text { 'eu estava construindo' }\end{array}$ \\
\hline $\begin{array}{l}2 \text { Passado imperfeito } \\
\text { o-MS- } \theta-\mathrm{VB}-\mathrm{V} \\
o-n d-a ́ \# l a n d-a ́ \\
\text { 'eu comprei' } \\
\text { (e posso comprar novamente) }\end{array}$ & $\begin{array}{l}2 \text { Passado recente } \\
\text { MS-à-BV-IDI } \\
\text { Yà-tùngídï\#énzò } \\
\text { 'eu (recentemente) construí a } \\
\text { casa' }\end{array}$ & $\begin{array}{l}2 \text { Passado recente } \\
\text { MS-na-(MO)-BV-íle } \\
\text { Nji-na\#tuyg-íle } \\
\text { 'Eu tenho construído' }\end{array}$ \\
\hline $\begin{array}{l}3 \text { Passado perfeito } \\
\text { o-MS-à-VB-a } \\
o-n d \text {-a\#lánd-a } \\
\text { 'Eu comprei' } \\
\text { (e comprarei novamente) }\end{array}$ & $\begin{array}{l}3 \text { Passado distante } \\
\text { MS-à-BV-à } \\
Y \text {-à-túng (à) \#énzò } \\
\text { 'eu construí a casa' } \\
\text { (há muito tempo atrás) }\end{array}$ & 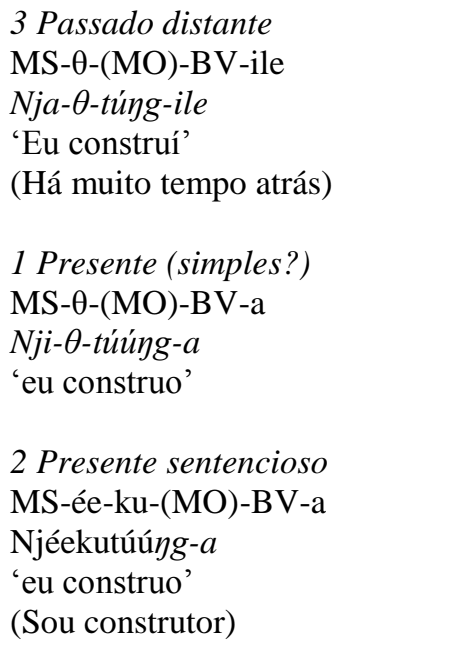 \\
\hline $\begin{array}{l}1 \text { (presente) progressivo } \\
\text { o-ta-MS- } \theta-\mathrm{BV}-\mathrm{VF} \\
\text { o-tá-ndi\#lánd-a } \\
\text { 'Eu estou comprando' }\end{array}$ & & $\begin{array}{l}3 \text { Presente progressivo } \\
\text { MS-li-ku-(MO)-BV-a? } \\
\text { Nji-li-\#kutúúng-a } \\
\text { 'eu estou construindo' }\end{array}$ \\
\hline $\begin{array}{l}2 \text { (presente) habitual } \\
\text { o-ha-MS- } \theta-\mathrm{BV}-\mathrm{VF} \\
\text { o-ha-ndi\#lánd-a } \\
\text { 'eu estou sempre comprando' }\end{array}$ & & $\begin{array}{l}4 \text { Presente durativo } \\
\text { MS-ée-kwa-na-ku(MO)-BV-a } \\
\text { Nj-ée-kwá\#na-kutúúng-a } \\
\text { 'eu tenho construído' }\end{array}$ \\
\hline $\begin{array}{l}1 \text { Futuro simples } \\
\text { o-ta-MS-ka-BV-a } \\
\text { o-tá-ndi-ká\#lánd-a } \\
\text { 'eu comprarei' }\end{array}$ & $\begin{array}{l}\text { 1 Futuro simples } \\
\text { MS- } \theta-\mathrm{BV} \text {-à } \\
\text { Kyà\#lúmíngù\#n- } \theta \text {-túngà\#énzò } \\
\text { 'Amanhã construirei a casa' }\end{array}$ & $\begin{array}{l}1 \text { Futuro indefinido } \\
\text { MS-li-ka-(MO)-BV-a } \\
\text { Nji-li-ka-túúng- } a \\
\text { 'eu construirei' (algum dia) }\end{array}$ \\
\hline $\begin{array}{l}2 \text { Futuro inceptivo } \\
\text { o-ta-MS-ká-kala\#tameka-BV } \\
\text { otándi\#ká\#kala\#nda\#tameka\#okulanda } \\
\text { 'eu estarei começando a comprar' }\end{array}$ & $\begin{array}{l}2 \text { Futuro iminente } \\
\text { sè-MS- } \theta-\mathrm{BV} \text {-à } \\
\text { sè-n- } \theta \text {-tùng(à)\#énzò } \\
\text { 'eu vou construir a casa' }\end{array}$ & $\begin{array}{l}2 \text { Futuro definido } \\
\text { MS-li-áa-ku-(MO)-BV-a } \\
\text { Nji-ly-áa\#ku-túúg-a- } a \\
\text { 'Eu vou construir' (com certeza) }\end{array}$ \\
\hline $\begin{array}{l}3 \text { Futuro habitual } \\
\text { o-ta-MS-ka-kala\#ha-MS-BV-V } \\
\text { o-tándi\#ká\#kalá\#handi\#lánd-a } \\
\text { 'eu estarei sempre comprando' }\end{array}$ & $\begin{array}{l}3 \text { Futuro próximo } \\
\text { sè-MS-(à)BV-à } \\
\text { sè-y-à-túng-(à)\#énzò } \\
\text { '(Logo) eu construirei a casa' }\end{array}$ & $\begin{array}{l}3 \text { Futuro durativo } \\
\text { MS-li-á-na-(MO)-BV-a } \\
\text { Nji\#lyá\#na\#ku\#túúyg- } a \\
\text { 'Eu terei estado a construir' }\end{array}$ \\
\hline
\end{tabular}




\subsubsection{Tempo, aspecto e modo (TAM)}

A Tabela 2.7, na página anterior, foi inspirada também em Sommer (2003, p. 577), mas, enquanto a autora contrastou os tempos verbais de duas línguas, ochindonga e luyana, aqui apresentamos três, além do ochingonda, o quissicongo e o ganguela, cada uma correspondendo às seguintes zonas R, H e K, respectivamente. Felizmente, Ndonga (1995) e Maniacky (2003) apresentam com detalhes os paradigmas verbais dos verbos ku-tunga e kutúúng- $a$, 'construir', em quissicongo e ganguela, o que nos permitiu coligir cada exemplo das duas línguas de modo que fosse possível contrastar as diferenças e nuances da complexidade na marcação de tempo e aspecto nessas línguas (Nurse, 2008). Diferentemente de Sommer (2003), não incluímos as formas negativas, nem todas as distinções de modo discutidas pelos autores.

Seguindo o modelo da tabela encontrada em Sommer (2003), a Tabela 2.7 está organizada da seguinte forma: na primeira coluna copiamos as diversas estratégias na marcação de TAM do ochindonga, conforme apresentado por Sommer para o verbo landa (comprar). A partir daí tentamos posicionar nas duas outras colunas as formas aspectuais, do passado, presente e futuro, em quissicongo e ganguela, numerando cada tipo de passado, presente e futuro conforme a nomenclatura de cada trabalho, que varia de autor para autor. Sendo assim, enquanto Fivaz (2003) classifica o passado em ochindonga em passado completo, perfeito e imperfeito, Ndonga (1995) classifica em imediato, recente e distante. Para o ganguela, Maniacky (2003) enumera além dos passados distante e recente um passado progressivo. Da mesma forma, há distinções para o presente e futuro. Como exemplo, em quissicongo, temos o futuro simples, iminente e próximo, enquanto em ganguela Maniacky denomina futuro indefinido, definido e durativo. A primeira linha vem com um esquema, indicando os diferentes morfemas de TAM das três línguas, além da marca de sujeito (MS) e a base verbal (BV).

A Tabela 2.7 foi organizada apenas como uma forma de visualizar o grau de distinção aspectual das línguas bantas. Não estão enumeradas todas as possíveis nuances de tempo, modo e aspecto das três línguas. Tampouco foi possível localizar para cada língua a correlação exata entre os tempos verbais. Por exemplo, decidimos não incluir a forma do presente em quissicongo por não termos encontrado nenhum exemplo com o verbo tunga (construir), e em ganguela deixamos de incluir muitas outras distinções aspectuais descritas por Maniacky (2003). 


\subsection{Aspectos semânticos e discursivos}

Na apresentação das zonas K e R da savana ocidental, Sommer (2003) dedica os últimos parágrafos do seu texto à negação nas línguas por ela estudadas, porém não trata da predicação não verbal como também não menciona algumas das estratégias de topicalização ou focalização. Achamos necessário fazer uma apresentação desses temas, mesmo que brevemente, porque serão considerados em nossas discussões posteriores sobre possessivos e domínios relacionados. A partir daqui deixaremos de apresentar as estruturas das línguas bantas em forma de tabela para podermos nos concentrar nos aspectos mais semânticos, e para isso, tomaremos a particularidade de algumas das línguas selecionadas por nós. Um outro motivo para isso é a maior dificuldade de encontrar na bibliografia de línguas bantas um tratamento mais detalhado dos temas a seguir. Apenas nas gramáticas de referência foi possível encontrar alguma seção dedicada à predicação não verbal. E as seções sobre tópico e foco são trabalhadas de forma muito breve ao final de teses e gramáticas.

\subsubsection{Cópula e negação}

Os verbos utilizados em construções de cópula são geralmente discutidos pelos autores de uma forma não muito sistemática, o que nos impossibilitou de elaborar uma tabela com as principais formas e funções dessas palavras. Além disso, as diferentes estratégias utilizadas pelas línguas bantas para a expressão da predicação não verbal nos forçariam a ter que interrelacioná-las com os sistemas tonais e aspectuais de cada língua. Como ilustração, vejamos o caso do herero, para o qual uma sentença copulativa é formada sem um morfema de cópula expresso, sendo então um tom alto extra após um tom alto comum que serve para formar uma sentença copulativa (22)b ou um predicado nominal (22)c:

(22) Herero (R31) (Möhlig; Kavari, 2008, p. 237)

Padrão de tom básico sentença copulativa predicado nominal
a. omu-âtjé
b. őmú-âtjé o o mu-néné
c. Omu-âtjé omú-néné.
1-criança
MLP-1-criança 1-grande
1-criança MLP-grande
'uma criança'
'É uma criança grande'
'A criança é grande'

Dessa forma, reservamos algum espaço para mencionar alguns verbos, comumente considerados defectivos ou irregulares, e que são muito comuns nas construções de 
predicados não verbais mais discutidos na literatura (Dryer, 2007; Payne, T., 1997), os predicados nominais, adjetivais e locativos/existenciais, e que, portanto, serão úteis para discussões posteriores sobre possessivos.

Os verbos em questão têm geralmente a forma na (para LCZ; OCH; HRR e YEY), ou $n i$ (para o QMB), poder ser também que tenham a forma li (para YEY; OCH; LCZ) ou ri (para o HRR), outras vezes a forma kala(QCG; NGL; OCH; UMB), ou kara (para HRR) e kasi (para UMB). A distribuição e produtividade de cada um desses itens variam substancialmente de língua para língua, a depender do tempo verbal. Por exemplo, para o presente é utilizada uma forma, enquanto para o futuro e passado outra. Em ganguela, a forma -li é usada para o presente (23)a, e -kala para o passado (23)b:

(23) Ganguela (K12) (Maniacky, 2003, p. 157)
a. nji-li 'eu sou/estou'
b. njina-kééle 'eu era/fui'

Para o umbundo, os verbos -kasi e -li são intercambiáveis para o presente, nas formas afirmativas e negativas (24). Os dois verbos juntamente com la expressa posse predicativa:

(24) Umbundo (R11) (Schadeberg, 1991, p. 49)
a. vá-li (ng'así) v-ónjó
3pl-COP (1sg.-COP) 18-casa
'Eles estão (eu estou) na casa'
b. ó-li-pó/-kó/-mó (ká-kasí-po/-kó/-mó)
3ps-COP-16/-17/-18 (NEG-COP-16/-17/-18)
'Ele está aqui/lá/dentro’ ('Ele não está aqui/lá/dentro')

(25) Umbundo (R11) (Schadeberg, 1991, p. 49)
a. ha-vá-lí
1'-ólombóngo
NEG-3pl-COP COM-10.dinheiro
'Eles não têm dinheiro'
b. onjó í-kasí l'-ápítò ávalí
9.casa MS-COP COM-6.porta NUM
'a casa tem duas portas'


Para o passado, o umbundo usa a forma -kala, como muitas outras línguas bantas.

(26) Umbundo (R11) (Chacusanga, 2006, p. 33) $)^{19}$

Ame ndi-ka-kala

1ps. 1.MS-Fo-COP

'Eu estarei/serei'

Em yeyi existe uma forma de cópula negativa $k h a \sim q h a,(27)$ a com o sentido de "não ser/estar", e -qhu, com sentido "não_ser_com". Esta última pode ser usada em sentenças possessivas negativas (27)b:

(27) Yeyi (R41) (Seidel, 2008, p. 426-7)

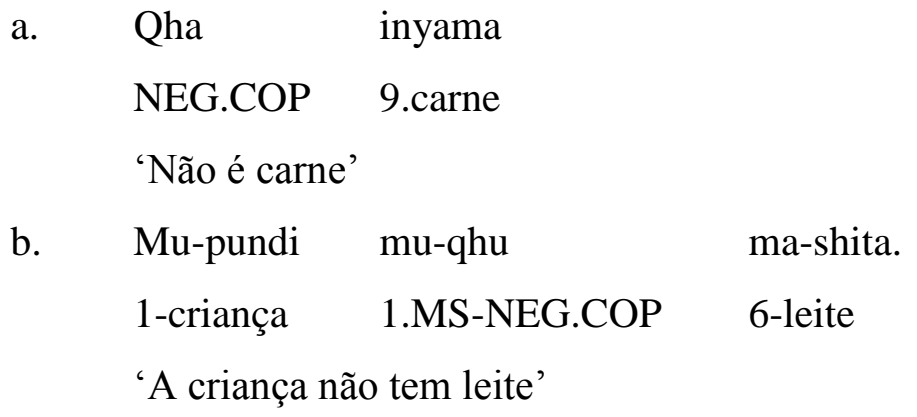

Não nos deteremos muito nas formas negativas, pois, considerando nossos objetivos nesse capítulo e na tese, consideramos suficientes esses exemplos. É válido, ainda, ressaltar a natureza flexional de algumas marcas de negação, o que leva muitos autores a tratar de negação juntamente com o sistema aspectual da língua. Os exemplos (13) e (14), do umbundo e quizombo, respectivamente, demonstram duas das principais estratégias de negação em línguas bantas. A primeira com a marca de negação prefixada ao complexo verbal e a segunda no formato de dupla negação, com os morfemas de negação nas posições pré e pós-verbal.

Por essa rápida explanação sobre cópula e negação, vemos a grande proximidade das estruturas de cópula com possessivos (25) e (27)b. As marcas de negação também exercem papel importante na configuração semântica de definitude, relacionada às construções existenciais, como será discutido no Capítulo 6. Um outro fator importante para a questão de definitude é o foco, para o qual dedicamos algumas palavras.

\footnotetext{
${ }^{19}$ Chacusanga (2006, p. 33) chama o primeiro - $k a$ - de "formativo de gaveta temporal", que serviria de elo de ligação entre a marca do sujeito e o radical verbal, para a formação do futuro imperfeito de qualquer verbo.
} 


\subsubsection{Foco e tópico}

As categorias discursivas de tópico e foco são frequentemente discutidas na literatura, seja de viés formalista ou funcionalista, como relacionadas a diversos fatores semânticos ou pragmáticos, como também a informação velha e nova (Payne, T., 1997). Para os estudos das línguas bantas, a temática é ainda um campo a ser explorado de forma mais aprofundada, conforme atesta o trabalho de Zerbian (2006).

Para nosso trabalho, muitas vezes precisaremos mencionar os fatores relacionados a foco, principalmente nas discussões referentes ao efeito de definitude, o que justifica que dediquemos algumas palavras à temática. Da bibliografia de línguas angolanas, utilizada para a produção de nosso corpus escrito, poucos autores dedicaram alguma seção aos processos de topicalização e focalização nas suas línguas de estudo (Ndonga, 1995; Pedro, 1993; Möhlig; Kavari, 2008). Para o quissicongo, Ndonga atesta pelo menos três mecanismos de focalização na língua: (i) a anteposição do termo a ser focalizado; (ii) o uso de itens focalizadores (kikilù e yì); e (iii) a omissão do pré-prefixo. Desses mecanismos, o último é o que irá requerer alguma atenção quando tratarmos das construções existenciais e o efeito de definitude em línguas bantas. Um exemplo do quissicongo para o último caso seria:

(28) Quissicongo (H16) (Ndonga, 1995, p. 436)
a. ̀̀-mwàn(à)
ò-léèlè
PPF-1.criança
MS-dormir.PERF
'A criança dorme.'
b. $\quad$ mwàn(à) ólè̀è
1.criança MS-dormir.PERF
'É a criança que dorme.' ('uma criança dorme.')

Apesar de nosso interesse recair principalmente sobre foco, mencionamos também a categoria tópico porque os casos de topicalização não raramente estão entrelaçados com os processos de focalização, como se pode observar em quimbundo:

(29) Quimbundo (H21) (Pedro, 1993, p. 338)

a. mùlòjì $\quad$ w-á-fù
bruxo $\quad$ MS- PERF-morrer
'O bruxo morreu.'


$\begin{array}{lll}\text { b. } \quad \text { ò-mùlò:jí } \quad \text { w-á-fú } & \text { mwènè } \\ \text { PPF-bruxo } & \text { MS-PERF-morrer } & \text { FOC } \\ \text { 'Quanto ao bruxo, ele morreu mesmo.' }\end{array}$

Para nosso estudo, então, nos concentraremos nos casos em que os processos de focalização tiverem algo a ver com existenciais e definitude.

\subsection{Tratamento de categorias cognitivas em línguas bantas}

Pelas seções anteriores é possível perceber o quanto as línguas bantas guardam em similaridades morfossintáticas, ao mesmo tempo em que podem apresentar uma grande diversidade em questões semânticas e discursivas, reforçando aqui a sensação de estarmos observando perfeitamente um caleidoscópio. De uma maneira geral, as gramáticas dessas línguas, sejam esboços gramaticais ou gramáticas de referência, são organizadas de uma forma que possibilitam trabalhos de cunho comparativista, mas isso quando a abrangência se mantém dentro das estruturas fonológicas e, até certo ponto, morfossintáticas. Quando o interesse é por temas semânticos ou cognitivos, o cenário encontrado não auxilia muito, devido à exiguidade dos dados.

Uma outra observação é quanto à abrangência de cada tópico tratado. Na bibliografia específica de línguas bantas para este estudo, verificamos que a nomenclatura de cada autor, variando conforme a tradição ou preferências teóricas, não prejudica em muito um trabalho com fins contrastivos. Por outro lado, temas que não estão na ordem do dia podem ser um grande desafio para qualquer tipo de trabalho que necessite coligir dados suficientes para uma análise minimamente baseada em dados empíricos. Isso devido à profundidade em que certos temas são tratados. Por exemplo, questões mais relacionadas à semântica e ao discurso sempre tiveram pouca ou breve apresentação em gramáticas de línguas pouco descritas. No entanto, é evidente que à medida que determinado tema vai se tornando mais conhecido na literatura africanista, e bantuísta em particular, os estudiosos passam a dedicar algumas seções a ele, mesmo que em linhas gerais. Um exemplo disso é a conhecida inversão locativa, que após os primeiros trabalhos, de fundo teórico, gramáticas de referência, como em Möhlig e Kavari (2008) passaram a fazer referência ao fenômeno.

No entanto, nem sempre é fácil pautar-se em trabalhos publicados, pelo menos não quando o assunto tem a ver com fenômenos semânticos. O trabalho de Maho (1999) para as classes nominais em banto é um exemplo. $\mathrm{O}$ autor consegue produzir um trabalho exemplar 
sobre sistemas de classe em línguas bantas, mas aponta como um dos problemas a heterogeneidade das fontes e o acesso ao dado mais consistentes.

Diante de casos como esse reafirmamos que estudos interessados em fatores pragmáticos ou discursivos ensejam que o trabalho com uma determinada língua, ou conjunto de línguas, seja baseado em dados de primeira mão. Em outras palavras, um trabalho de eliciação é geralmente a melhor ferramenta a ser utilizada para uma descrição que busque ser minimamente completa. Mas já discutimos que nem sempre esse é o caso.

Retomamos aqui um ponto crucial para o campo da nossa pesquisa, o de que mesmo diante de todas as dificuldades operacionais, como aqueles discutidos no capítulo anterior, trabalhos que almejam se ocupar de categorias cognitivas, como este que pretendemos atingir nesta tese, devam ser incentivados, mesmo que para isso todos os esforços sejam despendidos, independente de onde sejam conduzidos, se no continente africano ou na Diáspora. Essas considerações se fazem necessárias para que se chame a atenção para a especificidade de um trabalho preocupado com as relações entre domínios conceituais, como o que está sendo descortinado nesta tese. Lidar com categorias cognitivas direciona o estudioso a lançar mão de todos os instrumentos disponíveis para a sua realização. Na impossibilidade de efetivar um trabalho in loco, o que seria o ideal, o estudioso é conduzido a tomar uma postura mais aberta, tanto no caráter teórico como metodológico, na produção de seu trabalho ${ }^{20}$. Para o caso de uma pesquisa sobre possessivos, que em si já demanda um elaborado jogo de conceitos e definições nas diversas nuances e idiossincrasias próprias de um trabalho dessa natureza, os resultados tendem a se tornar mais consistentes à medida que a atenção do pesquisador é voltada para a observação de como categorias cognitivas de difícil delimitação são expressas em um contexto cultural mais amplo, para o que uma descrição nos moldes conhecidos, oferece apenas o começo de um estudo satisfatório.

Queremos defender com isso que trabalhos cognitivistas devem andar juntos com aqueles mais voltados para a descrição das estruturas gramaticais consideradas básicas para o entendimento de estruturas mais complexas, isto é, aquelas na interface da semântica e pragmática.

\footnotetext{
${ }^{20}$ Esse grau de abertura teórica e metodológica será discutido no Capítulo 5, momento em que apresentamos nosso posicionamento epistemológico.
} 


\subsection{Em síntese}

Com esta rápida apresentação de alguns aspectos das gramáticas das línguas bantas, com ênfase nas zonas $\mathrm{H}, \mathrm{K}$ e R, acreditamos ter oferecido uma visão panorâmica de parte da complexidade dessas línguas, permitindo para que nos próximos capítulos nos dediquemos às questões teóricas motivadores deste estudo.

Tentamos tocar, mesmo que de relance, em estruturas básicas das LBs, elegendo alguns tópicos particulares como ilustração, a exemplo da discussão de tom e acento em quimbundo, ou existência de cópula negativa em algumas línguas, como o yeyi e, de modo geral, uma das principais estratégias de marcação de foco por meio da omissão do pré-prefixo. Esperamos que com este capítulo, as discussões possam se desenrolar de uma forma mais natural, tanto nos capítulos teóricos como descritivos, das duas outras partes da tese. 


\section{Parte II QUESTÕES TEÓRICAS E EPISTEMOLÓGICAS}


In my descriptive work, I like to say that the approach I take to formalisms is strictly opportunistic: If a tableau is worth a thousand words, use it! In other words, having a proper command of theory means not only knowing when to use it, but when not to.

So, what is description? [...] I consider description to be another word for analysis [...]

Larry M. Hyman

Why describe African languages?

"Tudo vale."

Paul Feyerabend 


\section{CAPÍTULO 3}

\section{A Expressão de Posse Predicativa}

\subsection{Apresentação}

Qualquer trabalho que se ocupe da semântica ou sintaxe de construções possessivas em determinada língua ou conjunto de línguas encara como primeiro desafio a delimitação do seu universo conceitual. Isso devido ao fato de o domínio das construções possessivas ser incrivelmente amplo e, sem dúvida, controverso quanto à sua natureza. Uma das primeiras tarefas a que cada autor se lança é, então, a de caracterizar o que ele entende por "possessivo". Uma revisão da literatura pertinente é apenas um pequeno e primeiro passo, mas extremamente necessário. Não obstante, essa caracterização inicial é bem mais que um simples protocolo de introdução do leitor à terminologia e aos conceitos operatórios a serem utilizados em cada trabalho. Pela literatura a que tivemos acesso vimos que o conceito de posse é apresentado sempre em função do posicionamento teórico de cada autor, isso quando o estudioso toma a preocupação de definir seus conceitos. Mesmo quando o trabalho se posiciona numa linha mais descritivista é interessante ver como é quase inevitável ter que jogar com termos e conceitos já bem enraizados em certas tradições de descrição gramatical.

Para este trabalho revisamos brevemente alguns pontos discutidos por Stolz et al. (2008), além de uma primeira apresentação de como possessivos são encarados em abordagens cognitivistas (Langacker, 2003). Resenhamos então os dois trabalhos tipológicos principais sobre posse predicativa (Heine, 1997; Stassen, 2009). Sempre que necessário fazemos referência a outros dois volumes dedicados à temática de possessivos (McGregor, 2009, p. 1-12; Baron; Herslund; Sørensen, 2001), além de um capítulo de um livro texto de Creissels (2006a).

Os autores a serem discutidos neste capítulo dedicaram diversos outros trabalhos ao mesmo tema sobre possessivos (Heine, 2001; Stassen, 2005a; 2005b; Stolz, 2001; Creissels, 1996), e todos eles baseados em bibliografias bem diversas, o que torna uma revisão da literatura sobre possessivos um trabalho sempre parcial. Tendo ciência disso, este capítulo servirá muito mais como uma introdução do leitor para os fenômenos que mais interessarão para as discussões posteriores do que de uma revisão da literatura, propriamente dita. Outro motivo não menos importante para esta apresentação é o fato de haver muita confusão 
conceitual e terminológica quanto a possessivos, às vezes de termos básicos como a diferença entre os tipos de possessivos nominais e oracionais, ou de possessivos atributivos e predicativos. Apesar de parecer óbvia tal distinção, em todos os momentos em que apresentamos resultados preliminares de nossa pesquisa, os questionamentos eram frequentemente voltados para a pergunta "o que você entende como um possessivo?", ou os arguidores se detiam mais na natureza de possessivos nominais e não frasais, ou seja, posse atributiva muito mais que predicativa.

O trabalho de Stolz et al. (2008), apesar de orientação tipológico, se restringe às línguas europeias e à questão de classificação de possessivos quanto à (in)alienabilidade, por isso as tipologias de Heine e Stassen merecerão uma resenha mais detalhada nas próximas seções deste capítulo. Como esperado, esses dois trabalhos tipológicos resenhados iniciam com uma discussão detalhada sobre o espectro de fenômenos de que cada autor pretende se ocupar. Os dois trabalhos tratam de temas semelhantes, alguns com maior profundidade, outros com menos detalhes, e apesar dos muitos pontos em comum, os dois autores chegam a resultados que satisfazem às suas preocupações iniciais, sejam elas de fundo teórico e diacrônico, como os de Heine, ou simplesmente a busca de uma classificação tipológica aparentemente desinteressada de objetivos teóricos, como as de Stassen, como veremos mais adiante.

Esta apresentação compreende dois objetivos: (i) contextualizar o leitor sobre a gama de fenômenos abarcados nos estudos sobre possessivos, (ii) e indicar quais dos fenômenos farão parte de nossa descrição e análise para o caso das línguas bantas.

\subsection{O que um possessivo tem?}

Um primeiro passo para o entendimento do que realmente vem a ser um possessivo seria verificar a forma como nossos modelos cognitivos idealizados operam com outros conceitos próximos ao de posse para então distingui-los. O conceito de propriedade legal (do inglês ownership) é apontado como o mais prototípico no conjunto de relações desencadeadas por possessivos (Taylor, 1996).

Heine (1997) oferece vários tipos de posse e a gama de situações em que esses tipos são aplicados. Alguns tipos vão de situações aparentemente mais concretas, como "Tenho uma casa" a outras mais abstratas como "Tenho pra mim que algo vai acontecer". Um dos pontos de discussão sobre a natureza do conceito de posse vem, em parte, dos fatores que estariam em jogo na caracterização desse domínio conceitual, se fatores ditos estritamente 
internos (linguísticos) ou fatores externos (socioculturais). Não há dúvida de que o conceito de posse e a categoria gramatical de possessivos possam ser descritos e analisados em termos linguísticos, sem esquecer que fatores socioculturais frequentemente entram em jogo na configuração de outras distinções, como as de posse alienável e inalienável. ${ }^{1}$ Os traços de (in)alienabilidade de uma construção possessiva são determinados como aquelas em que o objeto possuído (PD) não pode ser expresso sem a indicação do possuidor (PR) ou que PD não pode ser separado do PR. Geralmente os casos de posse inalienável são aqueles para as expressões de parte-todo, como partes do corpo, ou termos de parentesco. Portanto, o traço de (in)alienabilidade é dependente de cada língua.

Ainda dentro dos fatores internos relacionados à expressão de posse, encontramos a distinção entre possessivos com núcleos nominais: posse atributiva ou adnominal, e posse no nível da frase: posse predicativa ou oracional. É comum que se associe o termo "possessivo" às construções possessivas adnominais. Mesmo cientes da estreita relação entre as construções de posse atributiva (carro do José; seu carro) e posse predicativa (José tem um carro; o carro pertence ao José), há uma forte evidência de que aquela forma seja considerada mais prototípica do que esta última. Stolz et al. (2008) apresentam de forma esquemática as possíveis estruturas de possessivos, lembrando que os autores tinham em mente as línguas indo-europeias. A Tabela 3.1 abaixo relaciona as diferentes estruturas que um possessivo pode tomar, em construções possessivas atributivas e predicativas:

Tabela 3.1 - Organização das construções possessivas (Stolz, et al., 2008, p. 11)

\begin{tabular}{ccccc}
\hline & Nível semântico & & Nível sintático & $\begin{array}{c}\text { Estrutura } \\
\text { do possessivo }\end{array}$ \\
\cline { 1 - 3 } Possuidor & Relator & Possuído & & Atributiva: genitival \\
PRO & $\mathrm{X}$ & $\mathrm{N}$ & $\mathrm{NP}$ & Atributiva: pronominal \\
PRO/NP & $\mathrm{X}$ & $\mathrm{N}$ & $\mathrm{NP}$ & Predicativa \\
\hline
\end{tabular}

A tabela acima resume as principais estruturas facilmente encontradas para a expressão de possessivos, que em linhas gerais se constitui da relação entre duas entidades, o possuidor (PR) e um possuído (PD). A relação entre ambos se dá muito comumente com o auxílio de algum morfema, nos termos de Stolz et al. (2008), um relator X que pode ter

\footnotetext{
${ }^{1}$ A partir daqui daremos preferência ao termo "possessivos" em detrimento do de "posse" para nos referir às diferentes expressões reunidas sob a rubrica de possessivos na literatura, como relações de parentesco, partetodo, etc. Com isso intentamos abarcar todos os possíveis espectros incluídos dentro do domínio de coisas que podem ser possuídas e dos elementos que podem atuar como um possuidor.
} 
diversas funções para o caso de possessivos nominais SN X SN (O livro do aluno) ou pronominal (O livro é dele), ou predicativa (o aluno tem um livro), em outras palavras, o relator indicará a relação entre o possuidor e o possuído. Na estrutura atributiva, a expressão de posse pode se dar numa estrutura genitival, como em "John's house", do inglês, onde o morfema 's serve como o relator, ou em uma estrutura pronominal "Meu carro", como em português. Esta tese centra-se, principalmente, nas estruturas predicativas de possessivos " $\mathrm{Eu}$ tinha uma casa", conforme a parte sombreada da tabela 3.1. ${ }^{2}$ É fácil de notar que, em suma, uma construção dita possessiva expressa genericamente uma situação relacional entre dois elementos ou entidades, uma que leva o papel semântico de possuidor (PR) e outra o de possuído (PD). Aparentemente, uma definição como essa esconde outros meandros do que um possessivo pode expressar, ou em outras palavras, o que um possessivo realmente tem.

Dizer que construções possessivas são relacionais caracteriza mais semanticamente a natureza entre um possuidor e um possuído e volta nossa atenção para um processo cognitivo denominado como os pontos de referência cognitivos. Conforme Tribushinina (2008), a noção de pontos de referência cognitivos foi introduzida por Rosch (1975) em seus trabalhos sobre protótipos na categorização de cores. Os pontos de referência foram bastante estudados em Psicologia Cognitiva. Em Linguística temos com Langacker (2009; 2000) diversas aplicações da noção de pontos de referências cognitivos para construções gramaticais, muitas delas de difícil caracterização semântica. Podemos englobar sob a rubrica de Análise de Pontos de Referência os fenômenos gramaticais analisados sob a perspectiva de serem pontos de referências, notadamente as construções possessivas (Langacker, 2003), como também as construções de tópico, dêiticos, metonímia (Langacker, 2000) e anáfora pronominal (Van Hoek, 2007).

Para o caso dos possessivos, Langacker constata que o domínio de possessivos abrange diversas situações relacionais entre duas entidades, um PR e um PD e que tanto nas construções possessivas atributivas como nas predicativas uma entidade mais saliente é evocada com o propósito de estabelecer contato mental com uma entidade alvo menos saliente (Langacker, 2003, p. 4). Nesse caso, a habilidade do ponto de referência seria a operação cognitiva por trás das relações possessivas e que demonstraria de forma mais intuitiva o tipo de relação que acontece entre as entidades PR e PD. A figura abaixo representa a operação de ponto de referência como utilizada em Gramática Cognitiva:

\footnotetext{
${ }^{2}$ Taylor (1996) discute diversas construções possessivas no nível do nome, especificamente para o inglês, a partir de uma linha de análise da Gramática Cognitiva.
} 


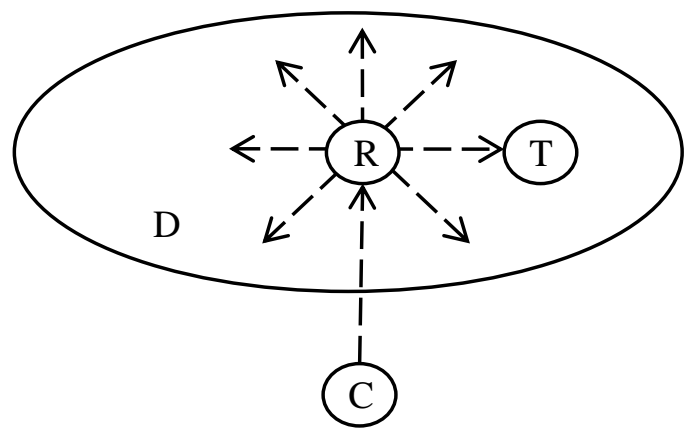

$\mathrm{C}=$ Conceitualizador

$\mathrm{R}=$ Ponto de Referência

$\mathrm{T}=$ Target (alvo)

$\mathrm{D}=$ Domínio

Seta tracejada $=$ Caminho Mental

Figura 3.1 - Análise do Ponto de Referência (Langacker, 2009, p. 82)

Nas palavras do autor:

[...] a habilidade do ponto de referência é nossa capacidade de invocar uma entidade concebida por meio do estabelecimento de contato mental com outra, isto é, acessar mentalmente uma entidade via outra. O Conceitualizador (C) primeiramente direciona sua atenção à entidade servindo como ponto de referência $(R)$. Atingindo $\mathrm{R}$, o Conceitualizador poderá acessar outras entidades associadas, coletivamente chamadas seu domínio (D), e uma delas será seu alvo (T). A relação de ponto de referência é assim uma questão de acesso mental sequenciado, na qual direcionar a atenção a R torna possível direcionar a atenção a T. (Langacker, 2009, p. 82) ${ }^{3}$

Essa é a caracterização esquemática das construções possessivas a partir do que Langacker tem chamado de Análise do Ponto de Referência. Para que se dê conta de todas as outras instanciações que tenham a habilidade do ponto de referência como base conceitual, Langacker demonstra que outros processos cognitivos como a relação assimétrica entre figura e fundo, nos termos técnicos de Langacker, o alinhamento entre Trajetor (TR) e Marco (MR) e o perfilamento decorrente do construal $^{4}$ de uma cena serão também determinantes. Na impossibilidade de apresentar no momento todos os construtos usados em Gramática Cognitiva para representar em diagramas os padrões de uma construção, reservaremos mais algum espaço nesta seção para exemplificar melhor a forma como Langacker trabalha com suas notações para ilustrar as relações de ponto de referência. Para que a demonstração não se torne pesadamente técnica, nos limitaremos a exemplificar melhor como o modelo de Análise

\footnotetext{
3 “"...] the reference point ability is our capacity to invoke one conceived entity as a means of establishing mental contact with another, i.e. mentally accessing one entity via another. The conceptualizer (C) first directs attention to the entity serving as reference point $(\mathrm{R})$. Attending to $\mathrm{R}$ evokes a set of associated entities, collectively called its dominion (D), one of which is the target $(T)$. A reference point relationship is thus a matter of sequenced mental access, where directing attention to R makes it possible to then direct attention to T."

${ }^{4}$ Nem todos os termos da Gramática Cognitiva possuem uma tradução equivalente em português ou já aceita pelos pares brasileiros como o caso de perfilamento para profiling ou Trajetor e Marco para Trajector e Landmark. Decidimos manter o termo construal por não termos indentificado uma tradução aproximada em português. Mantemos também a abreviatura para Alvo como (T) para não haver confusão com outra abreviatura, a de Ator (A) quando formos trabalhar com a categoria Controle.
} 
de Pontos de Referência serve para caracterizar outras relações, como as relações espaciais, codificadas linguisticamente com o uso de adposições. Com essa rápida apresentação, esperamos que possa ser possível seguir intuitivamente o modelo de análise proposto em Gramática Cognitiva que será bastante explorado posteriormente nos próximos capítulos.

Em Gramática Cognitiva, o alinhamento entre Trajetor (TR) e Marco (MR) especifica os elementos de maior e menor proeminência, respectivamente. Numa pergunta como "onde está o livro?" para uma resposta "o livro está em cima, na prateleira", o "livro" é tomado como o elemento de maior proeminência, portanto, considerado o TR, enquanto que a "prateleira", mesmo que esteja presente na cena, tem menor proeminência que o "livro", sendo assim o MR. Nas figuras abaixo, representamos as duas situações em que o livro está localizado na parte de cima de uma prateleira e inserido nela. Os círculos e linhas espessos significam que a atenção do Conceitualizador (C), falante ou ouvinte, está tomando os elementos Ponto de Referência (R) e o Alvo (T) como figura e o Domínio (D) como fundo, na Figura 2(a). Na Figura 2(b) o Ponto de Referência se confunde com o Domínio, dando assim o sentido de inclusão da preposição em do português:

(a) em cima

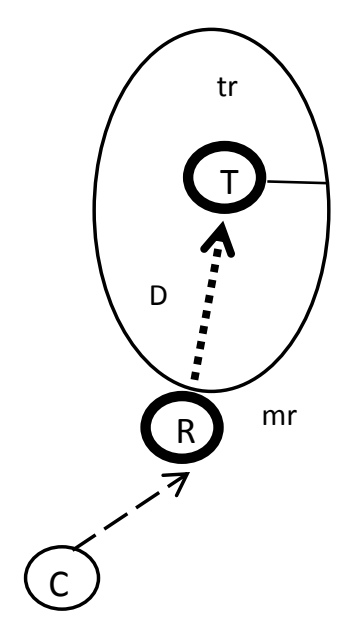

(b) em

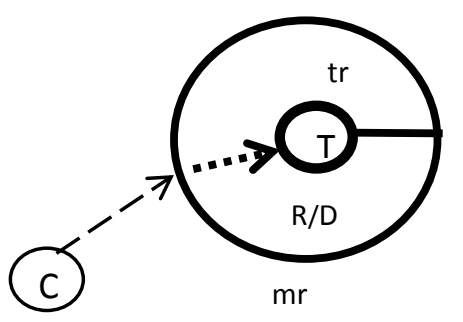

Figura 3.2 - Orientação espacial na análise do ponto de referência

Observa-se que construções locativas tem uma base conceitual também pautada na Análise do Ponto de Referência, apesar desse construto ser, até o momento, usado principalmente para a descrição de construções possessivas (Langacker, 2009; 2003; 2000). A proposta de Langacker, ao eleger a Análise do Ponto de Referência como a caracterização 
esquemática de possessivos, permite que possamos relacionar os mais diferentes subtipos de possessivos possíveis de serem expressos em determinada língua. Nos exemplos abaixo, enumeramos os principais subtipos de possessivos comumente mencionados na literatura, ou seja, os tipos de relação que uma construção possessiva pode expressar:

\section{(1) Propriedade legal}
a. Eu tenho um carro.
b. O pai teve a guarda das crianças.

(2) $\underline{\text { Todo-parte }}$
a. A árvore tem galhos tortos.
b. A mão direita do suspeito tinha um dedo quebrado.

(3) Relações de parentesco
a. Ivan tem três mães diferentes.
b. Ela não tem irmãos, é filha única.

(4) Estados (internos, psicológicos, etc.)
a. O paciente tem dores constantes
b. Quem tem fome tem pressa.

A Análise do Ponto de Referência seria a representação esquemática de um possessivo arquetípico, enquanto todas as outras formas de possessivo como propriedade (posse legal sobre algo), parte-todo (partes do corpo), parentesco (relações sociais), etc. seriam instanciações mais específicas de um esquema relacional de possessivos, digamos, mais abstrato. Em todos os exemplos acima, os possuidores como o "pai" (1b), a "árvore" (2a), "ela" (3b) e o "paciente" (4a) são tomados como o ponto de referência R para chegar mentalmente até os elementos possuídos "a criança", "galhos", "irmãos" e "dores", respectivamente. Em princípio a Análise do Ponto de Referência se mostra bastante geral para agrupar todos os subtipos de possessivos, no entanto, parece faltar ainda algo para uma completa caracterização de possessivos. Esse algo seria o que Doris Payne atesta e com quem concordamos: 
Entretanto, como há múltiplas construções de pontos-de-referência (no tratamento feito por Langacker, por exemplo, para possessivos, construções de tópicocomentário, metonímia), posse envolve mais que apenas identificar um participante com referência a outro participante mais saliente. Eu sugiro que os componentes centrais do significado de posse predicativa sejam (a) a predicação de uma relação íntima entre o ponto de referência primário e o outro participante; e/ou (b) a predicação de controle por parte do participante ponto de referência sobre o outro participante. (Payne, D., 2009, p. 117)

Coincidentemente ou não, a relação íntima e o controle, indicados por Payne para completar a relação com pontos de referência, condizem com os dois parâmetros semânticos usados por Stassen (2009) em seu trabalho tipológico para a delimitação do domínio semântico de possessivos. Para ele, o caso prototípico de posse é caracterizado pela presença de duas entidades (o possuidor (PR) e o possuído(PD) tal que: (i) o possuidor e o possuído estão em uma relação local relativamente duradoura; e (ii) o possuidor exerce controle sobre o possuído. A partir dessa delimitação, o autor apresenta os dois parâmetros para a caracterização do domínio semântico/cognitivo de possessivos: CONTATO PERMANENTE e CONTROLE. ${ }^{6}$ A partir desses dois parâmetros, Stassen acredita ter encontrado uma caracterização para os subdomínios semânticos de posse, geralmente variáveis nas línguas do mundo. Abaixo um quadro proposto pelo autor para os subdomínios:

Tabela 3.2 - Parâmetros semântico/cognitivos de possessivos (Stassen, 2009, p. 17)

SUBTIPOS DE POSSE

Alienável

Inalienável

Temporária

Abstrata
CONTATO PERMANENTE

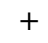

$+$

\section{CONTROLE}

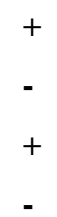

A partir de dois parâmetros e dois valores, Stassen conseguiu delimitar semanticamente a distinção de (in)alienabilidade e a difícil separação entre possessivos temporários e abstratos. Com a Análise do Ponto de Referência, Langacker demonstra a base conceitual comum entre as diversas relações possessivas, enquanto Stassen com os parâmetros semântico/cognitivos de CONTATO PERMANENTE e CONTROLE distingue os

\footnotetext{
5 "However, as there are multiple reference-point constructions (in Langacker's treatment, e.g., possessive constructions, topic-comment constructions, metonymy), possession involves more than just identifying one participant with reference to another salient participant. I suggest that the central meaning components of predicative possession are (a) to predicate an intimate relationship between the primary reference point and another participant; and/or (b) to predicate control by the reference point participant over another participant."

${ }^{6}$ Reservamos ao parâmetro semântico CONTROLE a formatação em caixa alta, enquanto para a categoria cognitiva/gramatical Controle, utilizamos a inicial maiúscula. Para os demais casos, como para a noção geral de controle, deixamos sem nenhuma grafia específica.
} 
subtipos de posse encontrados nas línguas do mundo e não raramente de difícil caracterização. Apesar de todo esse refinamento conceitual empreendido pelos estudiosos, lidar com os domínios conceituais de possessivos em uma determinada língua ainda oferece muito a ser destrinchado. Talvez uma boa forma de começar a tratar de todas as manifestações de possessivos em uma língua ou conjunto de línguas seja o de uma perspectiva up-down, do que é geral nas línguas do mundo para então traçarmos um caminho inverso, bottom-up, tomando emprestado termos da área da Inteligência Artificial. Em outras palavras, podemos partir de perspectivas tipológicas para verificar melhor os casos particulares para depois fazermos o sentido contrário e então averiguar em que as particularidades de alguns possessivos podem contribuir para uma figura mais abrangente da semântica de possessivos.

\subsubsection{Perspectivas tipológicas}

Como nossa preocupação não se restringe a uma questão onomasiológica, ou seja, catalogar as diferentes formas existentes numa mesma língua, ou conjunto de línguas, para exprimir o conceito de possessivos, tais como as diferentes formas lexicalizadas para expressar a relação em que: A “possui” B ou B "pertence” a A, etc., nossa tarefa central é a de verificar as relações entre as construções possessivas, mais especificamente de posse predicativa, com outros domínios conceituais e como esses outros domínios podem ser relacionados. Frente a isso, ao delimitarmos nosso universo de pesquisa às construções de posse predicativa e a relação destas com outras construções, percebemos que se centrássemos nossa atenção apenas sobre o domínio do possessivo, da forma como foi elencado nos exemplos de (1) a (4), deixaríamos de fora aspectos significativos dos fenômenos linguísticos e cognitivos deste estudo.

Em outras palavras, foi a partir de trabalhos de cunho tipológico (Clark, 1978; Heine, 1997; Stassen, 2009) que percebemos que o domínio de possessivos é bem mais abrangente, entrando em intersecção com outros domínios conceituais, notadamente com os de locativos, existenciais e comitativos. Além das relações possessivas básicas, as construções possessivas se relacionam também com outros domínios menos prototípicos, como as construções de possuidor externo (Payne, D.; Barshi, 1999) e o domínio dos sistemas de aspecto e modalidade (Heine, 1997, 4), dentre outros, e que não serão tratados neste trabalho. Frente à imensidade dos domínios conceituais abarcados pela semântica de possessivos, para tornar nossa pesquisa executável foi necessário que restringíssemos o universo da pesquisa. Para isso, elegemos como centro de nossa pesquisa a relação entre possessivos e três outros 
domínios conceituais, arregimentados pelas línguas do mundo para a expressão de posse predicativa, quais sejam: locativos, existenciais e comitativos. E para isso, escolhemos um conjunto de línguas que tem figurado pouco nos debates teóricos sobre possessivos, as línguas do grupo banto. Tal restrição a quatro diferentes construções num grupo determinado de línguas fez com que nossas preocupações sempre girassem em torno das adequações descritiva e explanatória, entendidas como o fim de um bom trabalho em linguística (Dryer, 2006). Essas preocupações nos conduziram, de certa forma, para a necessidade de nos posicionar epistemologicamente quanto ao nosso fazer científico. O que tentaremos fazer brevemente no início do Capítulo 5. Por agora, resta fazermos uma apreciação da literatura tipológica voltada para o fenômeno central desta tese. Nas próximas seções oferecemos as resenhas dos dois trabalhos sobre posse predicativa que, acreditamos, tocam em boa parte dos fenômenos que nos interessarão para a descrição de línguas bantas e para nossas discussões de fundo mais teórico.

\subsection{A tipologia de Heine (1997)}

Fazendo uso de análise translinguística, Heine (1997), sob orientação dos pressupostos da gramaticalização, busca chegar às fontes históricas ou origem das construções utilizadas para a expressão de posse nas línguas do mundo. O raciocínio básico do autor é de que como o conceito de posse constitui um "domínio relativamente abstrato da conceitualização humana" (1997, p. 45), a hipótese é que as construções possessivas derivem historicamente de outras com significado mais concreto.

Para chegar a essas fontes históricas, Heine se vale do construto de Esquemas de Evento (event-schemas). Para o autor, um número pequeno de Esquemas de Evento básicos ofereceria a fonte histórica para as construções possessivas atestadas nas línguas do mundo. Nas palavras de Heine (1997, p. 46): "Um esquema de evento possuiria as propriedades comumente associadas aos esquemas: sintetizam atributos importantes abstraídos de um vasto número de eventos relacionados, tendo a ver com situações estereotipadas com as quais nos deparamos frequentemente.". Francis (2000, p. 89) completa: trata-se de "padrões proposicionais simples que consistem de um predicador mais os seus argumentos e modificadores." Abaixo, reproduzimos o quadro, com algumas modificações, com os oito

\footnotetext{
7، An event schema has the properties commonly associated with schemas: It summarizes important attributes abstracted from a large number of related events, and it has to do with stereotyped situations with which we are constantly confronted..." (p. 91).
} 
esquemas de evento sugeridos por Heine. $\mathrm{O}$ autor segue coerentemente os pressupostos da teoria da gramaticalização por ele advogada, não abrindo mão do caráter da unidirecionalidade.

Tabela 3.3 - Esquemas de Evento para posse predicativa (Heine, 1997)

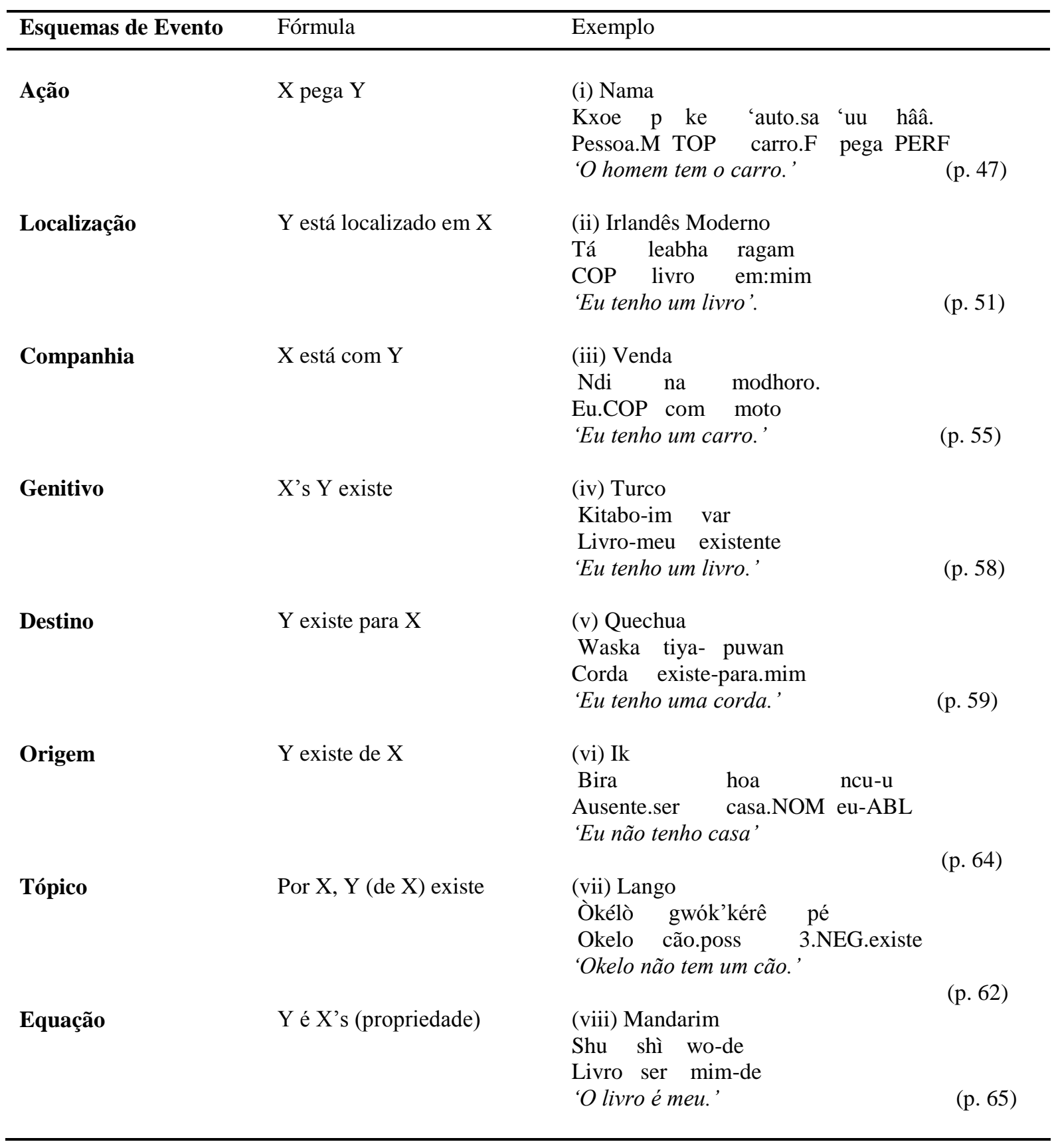

A proposta tipológica de Heine (1997) se apresenta como a primeira a sugerir um número limitado de esquemas a partir dos quais todas as construções de posse predicativa, e mesmo atributiva, nas diversas línguas do mundo pudessem ser classificadas. O suporte de análise é funcionalista e com ênfase na natureza diacrônica das mudanças sintáticas e 
semânticas observadas na evolução das estratégias de posse. Para Heine, deve haver relações estáveis nos processos de "transferência conceptual" entre um "Esquema de Evento" e as construções possessivas a que elas dão origem. Para ele, as construções possessivas resultantes dos Esquemas de Evento não necessariamente refletem os esquemas fontes dos quais a construção é originada (Heine, 1997, p. 92).

O autor também se serve do que ele chama de "explicações funcionais indiretas", para explicar certos casos de mudanças gramaticais, como o caso da evolução do esquema de tópico que faz uso de construções existenciais, consideradas mais básicas por Heine, para então expressar o sentido mais abstrato de posse. O segundo caso é o de verbos de posse utilizados para a expressão de existência, como o caso do francês e do português brasileiro. Francis (2000) critica esse recurso "indireto" de explicação funcional do autor, já que tal postura não oferece explicação convincente baseada nos usos reais das línguas. Para o caso dos dois processos de gramaticalização mencionados acima, Heine afirma que os dois processos não violam o princípio de unidirecionalidade dos processos de gramaticalização pelo fato de os dois processos serem duas etapas diferentes. Mas como afirma Francis, fica a questão de como saber se existem dois tipos de existenciais, um mais básico que o outro. Um que dá origem à expressão de posse e outro que é originado de posse.

O trabalho do africanista continua referência para muitos outros trabalhos sobre posse (Baron; Herslund; Sorensen, 2001) e tem o mérito de ter organizado uma grande variedade na codificação de posse predicativa a partir de um número relativamente reduzido de Esquemas de Evento. Não nos deteremos muito sobre o trabalho de Heine por acreditarmos que o próximo trabalho consegue sintetizar melhor muitos dos insights desta primeira tipologia.

\subsection{A tipologia de Stassen (2009)}

O trabalho de Stassen (2009) é, até o momento, o estudo tipológico mais exaustivo sobre posse predicativa. Após quinze anos de investigação sobre posse, o autor apresenta um estudo detalhado das construções de posse na maioria das famílias linguísticas, em uma amostra de 420 línguas. $\mathrm{O}$ autor propõe uma tipologia de posse predicativa para as línguas do mundo ao mesmo tempo em que acredita ter identificado outros fatores linguísticos intrinsecamente relacionados à forma como as línguas do mundo selecionam suas estratégias para a expressão de posse: sequência temporal e predicação não verbal. Partindo de uma revisão da vasta literatura sobre posse e do seu corpus abrangendo as principais famílias linguísticas, Stassen propõe quatro grandes tipos de estruturas de posse predicativa. 
Os quatro principais tipos de posse predicativa enumerados pelo autor são as que seguem: possessivos locacionais, possessivos comitativos, possessivos de Tópico e possessivos do tipo "ter" (Have-possessive). Para cada tipo de possessivo, o autor apresenta uma definição e uma fórmula.

Tabela 3.4 - Principais Tipos de Construções Possessivas (Stassen, 2009)

\begin{tabular}{|c|c|c|}
\hline $\begin{array}{l}\text { Tipos de Construções } \\
\text { Possessivas }\end{array}$ & Fórmula $^{8}$ & Exemplo \\
\hline $\begin{array}{l}\text { Possessivo Locacional } \\
\text { (Locational Possessive) }\end{array}$ & $\begin{array}{l}\text { Em/para PR, existe um PD } \\
\text { At/to PR, (there) is/exists a PE }\end{array}$ & $\begin{array}{l}\text { (i) Russo } \\
\text { U Ivana byl sinij avtomobil. } \\
\text { Em I. GEN. COP.PASS azul carro } \\
\text { 'Ivan tinha um carro azul.' }\end{array}$ \\
\hline $\begin{array}{l}\text { Possessivo Comitativo } \\
\text { (With-Possessive) }\end{array}$ & $\begin{array}{l}P R \text { está com um } P D \\
P R \text { is/exists with a } P E\end{array}$ & $\begin{array}{l}\text { (ii) Hauçá } \\
\text { Ya-nàa dà kudii } \\
\text { 3sg..PROG COM dinheiro } \\
\text { 'Ele tem dinheiro'. }\end{array}$ \\
\hline $\begin{array}{l}\text { Possessivo de Tópico } \\
\text { (Topic Possessive) }\end{array}$ & $\begin{array}{l}\text { Quanto ao PR, PD existe } \\
\text { As for } P R, P E \text { is/exists }\end{array}$ & $\begin{array}{l}\text { (iii) Tagalog } \\
\text { May relos ang nanay. } \\
\text { Existe relógio TOP mãe } \\
\text { 'A mãe tem um relógio.' }\end{array}$ \\
\hline $\begin{array}{l}\text { Ter-Possessivos } \\
(\text { Have-possessive })\end{array}$ & $\begin{array}{l}P R \text { tem um } P D \\
P R \text { has a } P E\end{array}$ & $\begin{array}{l}\text { (iv) !Xũ } \\
\text { Da'a//om-kx'ao kx'ae peri } \\
\text { Cortador de lenha ter carneiro } \\
\text { 'O lenhador tem carneiros.' }\end{array}$ \\
\hline
\end{tabular}

Além dos quatro grandes tipos de construções possessivas nas línguas do mundo, Stassen (2009, p. 70-106) enumera os seguintes casos de variantes não-padrão: (i) Índice do possuidor no possuído - que pode ocorrer nos quatro tipos de posse predicativa. Nela vai existir algum elemento marcando a posse de PR no PD; (ii) Código zero (zero-encoding) nesta variante, a cópula utilizada para posse não é expressa, o que pode ocasionar em certas condições uma ambiguidade entre construções de identidade e posse; (iii) Possessivos conjuncionais (conjuctional possessives) - são os casos em que a construção de posse

\footnotetext{
${ }^{8}$ Decidimos deixar a fórmula no original em inglês e chamar a atenção para a semelhança das fórmulas entre os Tipos de Possessivos de Stassen com os Esquemas de Evento de Heine.

${ }^{9} \mathrm{O}$ uso que Stassen faz do termo "Tópico" em sua tipologia não deve ser confundido com a categoria Tópico dos trabalhos funcionalistas e discursivos. Nas palavras de Stassen (2009, p. 58): "Um tópico de uma sentence é um item que tem uma função semântica específica, denominada, 'para constituir um enquadre de referência em respeito ao qual a oração principal ou verdadeira (se é uma proposição) ou falsa (se não é uma proposição). No original: "A sentence topic is an item which has a specific semantic function, namely, 'to constitute the frame of reference with respect to which the main clause is either true (if a proposition) or felicitous (if not)'."
} 
predicativa se dá com o uso de partículas coordenativas, como o sentido da conjunção "and" ou outra; (iv) os Possessivos oracionais (clausal possessives) - são alguns casos raros nas línguas do mundo em que a predicação de posse é expressa em duas orações e não apenas em uma como na maioria das línguas do mundo; por fim, o (v) os Tópico-locacionais híbridos (Topic-Locational hybrids) - nos quais há uma certa hibridização entre posse locacional e de tópico. Nessas construções, o PR é marcado como oblíquo e o PD é o sujeito gramatical.

Para Stassen, todas essas variantes não devem ser consideradas como um tipo à parte por se mostrarem fenômenos marginais, que acontecem nos quatro principais tipos de posse predicativa propostos por ele. Para ele, esses "desvios" dos tipos padrão de posse predicativa se devem a processos de gramaticalização. ${ }^{10}$ Para o autor (2009, p. 107-243), pelo menos os seguintes processos de gramaticalização são os responsáveis por criarem as variantes não padrão de posse predicativa, quais sejam: adnominalizacão, predicativizacão e transitivizacão. Iremos nos ocupar deles de forma indireta em outras seções, no entanto, desses três processos, o de transitivização é o que mais nos interessa para o estudo sobre posse predicativa em línguas bantas.

Após apresentar os mais diversos casos de variantes não padrão dos quatro principais tipos de construções de posse nas línguas do mundo, Stassen (2009) propõe dois fatores que seriam determinantes para a escolha que as línguas fazem para a configuração de um ou outro tipo de construção de posse: (i) o sequenciamento temporal; e (ii) predicação não verbal.

O sequenciamento temporal pode ser entendido como a construção que expressa a relação entre dois eventos, A e B, como convergentes (overlapping), precedendo ou seguindo cada um (Traugott, 1975 apud Stassen, 2009). O autor chama a atenção para a possibilidade do Sequenciamento Temporal nas línguas ser convergente, o que será considerado simultâneo, caso contrário, será considerado consecutivo. $\mathrm{O}$ autor faz ainda a distinção entre a sequência com o mesmo sujeito: SS-SEQUÊNCIA (Same-Subject Sequencing) e a sequência com sujeitos diferentes: DS-SEQUÊNCIA (Different-Subject Sequencing). Para a tipologia de posse predicativa, apenas o sequenciamento temporal com sujeitos diferentes e simultânea, ou "DS-Sequência simultânea", será necessário (Stassen, 2009, p. 255). Para esse caso, dois parâmetros serão usados: as línguas serão classificadas como de Codificacão Equilibrada vs. Codificacão "Quebrada" (Balanced vs. Deranked encoding). Stassen (2009, p. 263) alerta para a dificuldade de delimitar uma língua como "Equilibrada" ou "Quebrada". A distinção

\footnotetext{
${ }^{10}$ Vale chamar a atenção para algumas diferenças entre a tipologia apresentada por Stassen (2009) e (2005). Nesta, o autor define seis tipos de posse predicativa, nesse caso, uma posse genitival e a posse conjuncional, o que naquele trabalho são considerados subtipos dos quatro grandes tipos. Conferir Anexo A com mapa retirado de Stassen (2006).
} 
entre Deranking e Balanced languages deve ser vista não como excludente. Uma língua considerada "Equilibrada" pode apresentar construções consideradas "Quebradas" e viceversa, no entanto, a língua exibirá uma preferência entre uma ou outra estratégia de sequenciamento temporal de sujeitos diferentes. ${ }^{11} \mathrm{Em}$ (5a-b), apresentamos exemplos aproximados de como se comportaria uma língua com preferência Equilibrada; e em (5c-d), exemplos aproximados de língua que escolhe uma codificação "quebrada":

Português

a. O João estava atrasado e a Maria ficou preocupada.

b. Quando o João atrasou, a Maria ficou preocupada.

c. (Com) o João estando atrasado, a Maria ficou preocupada.

d. Estando o João atrasado, a Maria se preocupou.

Quanto à predicação não verbal, uma língua é chamada "Compartilhante" (sharedlanguage ou sharer) se a estratégia de codificação para predicado locacional for (ou pude ser) usada também para predicado nominal, e uma língua "Cindida" (Split-language ou splitter) se a estratégia de codificação para as duas construções for diferente. Exemplo de língua compartilhante é o inglês e cindida o português:

(6) Inglês
a. $\mathrm{He}$ is a
teacher.
3sg. COP ART
professor.

'Ele é um professor'
b. $\mathrm{He}$ is at school.
3sg. COP PREP escola
'Ele está na escola'

(7) Português
a. Ele estava na escola.
b. Ele era professor.

\footnotetext{
${ }^{11}$ Stassen (2009) apresenta diversos casos em que determinadas línguas não parecem seguir as previsões de sua tipologia, porém, para o tipólogo, esses podem ser considerados casos marginais para a configuração de uma tipologia de posse predicativa.
} 
3.4.1 Um modelo para a codificação de posse predicativa

Toda essa apresentação se fez necessária para apresentarmos a proposta de Stassen de como as línguas do mundo codificam os quatro principais tipos de posse predicativa. $\mathrm{O}$ modelo do autor é bastante conciso, no entanto, ainda não teve suas reais implicações teóricas e descritivas examinadas, como atestado pelo próprio estudioso. Vejamos como Stassen (2009) acredita ter encontrado a forma como as línguas do mundo "escolhem" uma estratégia ou outra para a expressão de posse predicativa. $\mathrm{O}$ autor apresenta um gráfico que representa os caminhos que as línguas fazem para a codificação de posse predicativa, partindo dos fatores determinantes considerados por ele como decisivos numa das possíveis configurações de construção possessiva:
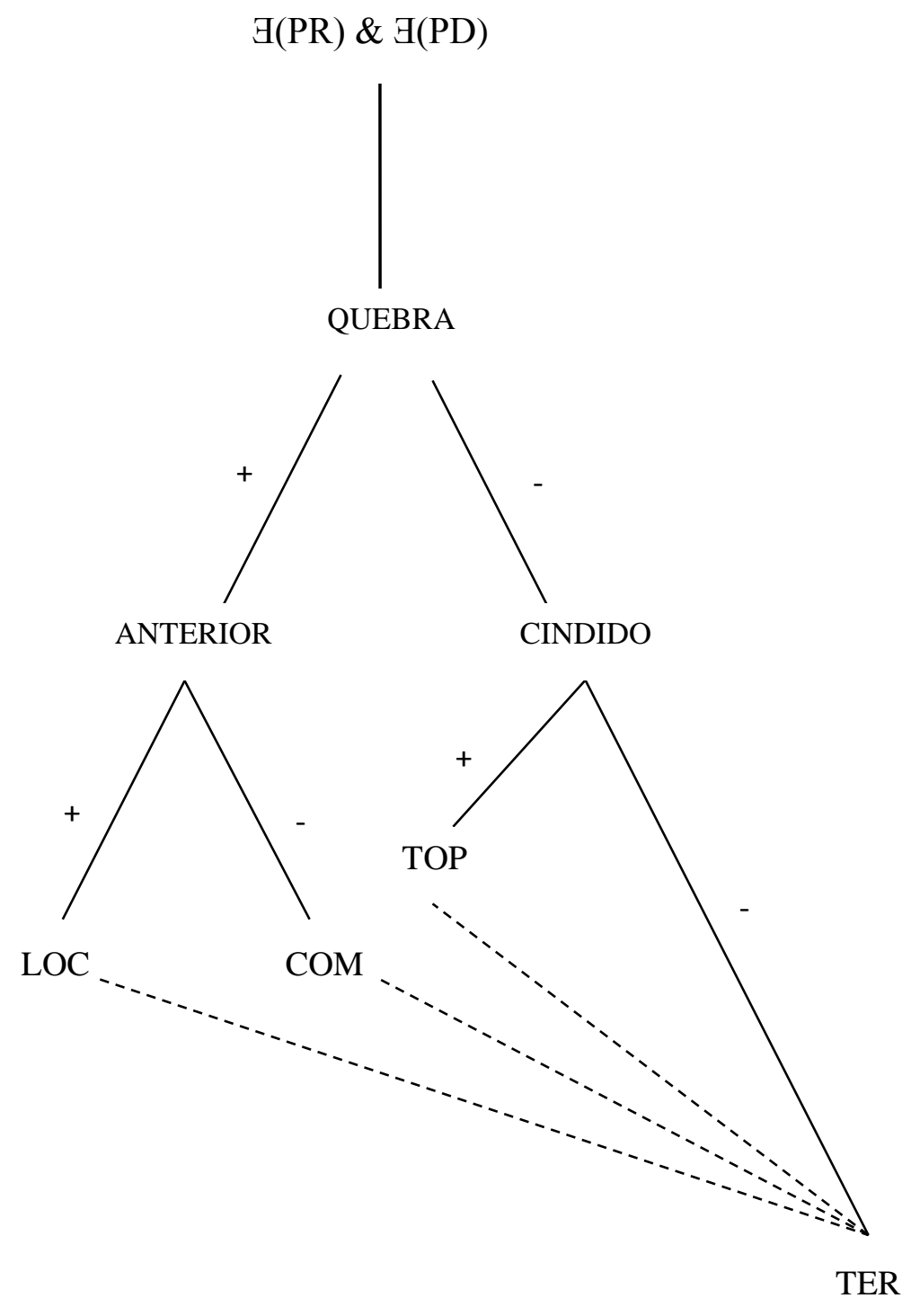

Figura 3.3 - Codificação de posse predicativa (Adaptado de Stassen, 2009, p. 723) 
No Figura 3.3 acima, a partir da expressão da existência de possuidor (PR) e possuído (PD) em dois predicados, as línguas seguem o caminho do Sequenciamento Temporal para configurar suas estruturas de posse. Sendo assim, as línguas irão optar por "quebrar" (derank) ou não um dos predicados no qual a existência de PR ou PD é expressa. Nesse caso, se a língua "quebra" seus predicados, elas ainda terão que selecionar entre uma "quebra" anterior ou por uma "quebra" posterior, dando origem à possibilidade dos possessivos locacionais ou comitativos, respectivamente. Para o caso das línguas que seguem o caminho de não "quebrar", no caso, as línguas equilibradas, elas terão que fazer uso de outro fator para a possibilidade de expressão de posse, sem cair em possíveis ambiguidades estruturais. Nesse caso, a Predicação Não Verbal será crucial para isso. Para o caso das línguas equilibradas, algumas irão fazer um uso "cindido" da cópula, nesse caso, diferenciando nelas as cópulas utilizadas para as construções de predicado nominal e construções para locativo/existência. Nesse caso, a preferência será para a expressão de possessivos de tópico, expresso na forma de um existencial, geralmente. Para outras línguas, resta a alternativa de selecionar entre as possibilidades de expressão de posse uma forma não pautada em uma construção com cópula e de locativo/existência. Essas línguas não farão uso de uma estratégia intransitiva para a expressão de posse, mas terão que arregimentar um verbo pleno para a expressão de posse predicativa, geralmente com o sentido de "to take", "to grasp", etc. É o caso do inglês e diversas outras línguas que utilizam um verbo equivalente a "to have" e que dificilmente pode ter sua origem em algum esquema de locativo/existência, ou nos termos de Heine, em algum evento de esquema pautado nos domínios de locativo ou existência.

Como o autor afirma, as reais implicações teóricas das suas descobertas tipológicas ainda estão por ser exploradas devidamente.

\subsection{Apreciação das propostas tipológicas}

Os trabalhos de Heine (1997) e Stassen (2009) compartilham de uma perspectiva tipológica. Entretanto, Stassen diferencia seu trabalho do de Heine por considerar que este autor faz uso de um viés teórico para construir sua tipologia. No caso, um viés cognitivo/semântico (Stassen, 2009, p. 39), alguns pressupostos da linguística cognitiva e do arcabouço da gramaticalização. Uma diferença básica entre os dois trabalhos é que Heine não acredita haver uma construção comum que reúna todas as construções de posse predicativa nas línguas do mundo, enquanto Stassen acredita ter identificado os processos básicos para a 
possibilidade de expressão de posse nas diferentes línguas, tipologicamente distantes, a partir de uma "estrutura profunda" similar (termo emprestado pelo autor do gerativismo). A posição de Heine se sustenta pela sua convicção teórica de que os processos de gramaticalização que dão origem às formas possessivas nas línguas são unidirecionais, portanto, os oito diferentes Esquemas de Evento propostos por ele dificilmente teriam uma mesma origem histórica no desenvolvimento das construções de posse predicativa.

Os dois autores concordam, no entanto, com a existência de pelo menos quatro formas tipologicamente atestadas na expressão de posse predicativa nas línguas do mundo, quais sejam: (i) línguas que fazem uso de locativos para expressar posse, a partir daqui possessivos locacionais (locational possessive), (ii) línguas que fazem uso do comitativos, possessivos comitativos: (with-possessive), (iii) aquelas que fazem uso de construções de tópico, possessivos de tópico (topic possessive). (estes relacionados ao domínio de existenciais, e (iv) as que fazem uso de uma forma gramaticalizada de verbo equivalente a "to have" do inglês, os possessivos do tipo "ter" ou Ter-posessivos (have-possessive). ${ }^{12}$

Os dois trabalhos tipológicos mostram que a grande parte das línguas bantas utiliza como estratégia principal para a expressão de posse predicativa construções com valor de Comitativo, na tipologia de Stassen, uma "WITH-construction", nos termos de Heine o "Esquema de Companhia", bem exemplificada na fórmula: $\mathrm{X}$ is with Y (X está com Y).

Em síntese, as duas propostas tipológicas resenhadas acima podem ser contrastadas com o último parágrafo do trabalho de Stassen:

\begin{abstract}
Estou ciente de que o argumento que levou à formulação desse gráfico em forma de fluxograma é forte e mais convincente em algumas partes do que em outras. No entanto, sinto que há ampla evidência para assegurar que a variação translinguística na codificação de posse predicativa não é aleatória, e que é restrita por fatores que tem a ver com propriedades estruturais da linguagem humana. No fim do seu livro sobre possessivos, Heine (1997, p. 239) afirma como sua conclusão que 'qualquer tentativa de estabelecer uma estrutura universal única para posse predicativa, de forma que dê conta de toda a variação morfossintática encontrada nas línguas do mundo, está condenada ao fracaso'. O presente trabalho pode ser visto como um argumento a favor de que a posição da afirmação de Heine deve ter sido apenas muito pessimista. (Stassen, 2009, p. 724) ${ }^{13}$
\end{abstract}

12 Os dois trabalhos fazem menção ao português brasileiro como língua que faz uso, nos termos de Heine, do Action Schema e Companion Schema, nos termos de Stassen, de uma Have-construction e de uma Withconstruction, respectivamente, as construções com ter e estar com para a expressão de posse predicativa. Conferir Stolz (2001) e Stolz et al (2008) para um tratamento dessa questão.

13 "I am aware that the argumentation which has led to the formulation of this flow chart is stronger and more convincing in some parts than in others. Nonetheless, I feel that there is ample evidence to hold that the crosslinguistic variation in the encoding of predicative possession is not random, and that it is restricted by factors that have to do with structural properties of human language. At the end of his book on possession, Heine (1997: 239) states as his conclusion that 'any attempt at setting up one single universal structure of predicative possession, to account for all the morphosyntactic variation to be found in the languages of the world, is doomed 
Mesmo se posicionando contra a "Hipótese Localista" que também toma a posição de ter encontrado a estrutura universal para a expressão de posse predicativa nas línguas do mundo, qual seja, a de locativo, Stassen afirma ter chegado a "Universais da Codificação de Posse Predicativa" na elaboração da sua tipologia. Para Heine, a variação na codificação de posse predicativa nas línguas do mundo é explicada da melhor forma a partir dos processos de gramaticalização que podem ser utilizados como "pistas" de como as diversas construções de posse surgem nas línguas.

3.5.1 Para uma tipologia de posse predicativa em línguas faladas e sinalizadas

Seria oportuno mencionar um aspecto dos estudos sobre possessivos a que tivemos acesso, mas que devido à abrangência do tópico não nos será possível dedicar mais do que alguns parágrafos, o dos estudos sobre possessivos e outros domínios em línguas sinalizadas (Zeshan; Perniss, 2008; Quadros; Vasconcelos, 2008; Hendriks, 2008; Cormier; Fenlon, 2009; inter alia). O conjunto desses trabalhos pode permitir uma comparação tipológica entre as modalidades falada e sinalizada de línguas para a expressão de possessivos, da mesma forma que já foi feito quanto à expressão do espaço (Talmy, 2006). Até o momento tem sido uma pequena, mas importante lacuna nos estudos tipológicos sobre posse predicativa não atentar para a modalidade das línguas sinalizadas, conforme crítica de Zeshan e Perniss (2008).

Poderá ser uma área de estudo instigante verificar se as discussões sobre possessivos, até então concentrada em línguas orais, se aplicam para línguas sinalizadas, e se não, quais seriam as diferenças. Tendo tal empreendimento em mente, acreditamos que será de inestimável contribuição o conhecimento sobre línguas sinalizadas da África, campo ainda incipiente até mesmo nos estudos em Linguística Africana. Do corpus utilizado em Zeshan e Perniss (2008), apenas uma língua de sinais africana mereceu atenção: a língua de sinais de Adamorobe, do Gana. A língua de sinais da Tanzânia foi utilizada na pesquisa, mas não recebeu um capítulo naquela publicação.

Queríamos deixar registrado nessa pequena seção, a contribuição que um estudo nesse sentido, focalizando as modalisdades faladas e sinalizadas, para uma tipologia de posse predicativa transmodalidade, lacuna compreensível em Heine (1997) e Stassen (2009), mas que não poderá fazer falta em um próximo trabalho de fôlego sobre o tópico.

to failure'. The present book can be seen as an argument in favour of the position that Heine's assessment of the situation may just be too pessimistic." 


\subsection{Desafios teóricos e descritivos}

Tendo feito estas resenhas detalhadas dos dois trabalhos tipológicos de referência sobre posse predicativa, nossa tarefa poderia ter se restringido ao exame da aplicação ou não dos resultados dos autores, a exemplo de Abdoulaye (2006) para o Hauçá. Por outro lado, resolvemos nos lançar a uma empreitada que poderia ser um pouco mais desafiadora e satisfatória, seguindo nossas intuições.

O tratamento tipológico de Heine (1997a) e Stassen (2009) e a evidência de que pelo menos quatro domínios são os mais recorrentemente utilizados pelas línguas para a expressão de possessivos nos incentivaram a examinar mais seriamente outros estudos que tivessem se ocupado estritamente dessa relação, e isso independentemente da orientação teórica em que o problema seria encarado. Essa pretensa ousadia de lidar com as teorias que se ocuparam de possessivos adveio, de certo modo, de outra constatação. A de que as diferentes teorias arregimentadas para dar conta da relação entre possessivos, locativos e existenciais simplesmente não se cruzavam. A menção a outros trabalhos divergentes dos de cada autor geralmente se dava de forma despretensiosa. ${ }^{14}$ Deixaremos essa discussão para mais adiante, no Capítulo 4 especificamente. Por hora nos ocupamos de explanar o como partimos de trabalhos de cunho tipológicos para então nos envolvermos nas intrincadas propostas que tentaram solucionar o seguinte questionamento de Heine (1997, p. 205) para o problema dos possessivos: “... como se pode explicar o fato de que em muitas línguas, dois, três ou todos os quarto esquemas recebem a mesma codificação?" 15 Neste caso, o autor estava discutindo a relação feita na literatura por ele consultada sobre a relação entre Localização, Posse, Propriedade e Existência e os esquemas que dão origem a essas construções. Como um mesmo verbo usado para possessivos poderia também entrar nas construções de locativos e existenciais, como é o caso do verbo ter no português do Brasil? Nas palavras de Stassen (2009, p. 7):

\footnotetext{
${ }^{14}$ Freeze (2001) em uma publicação posterior ao trabalho de Heine (1997), faz menção a este trabalho, no entanto, sem fazer qualquer réplica às críticas do africanista: "Here we give a structural analysis of existentials, leaving aside pragmatic or funcitional explanations (for the latter type of analysis, see, e.g., Heine 1997)." 15 “... how can the fact be explained that in many languages, two, three, or even all four schemas receive the same encoding?"
} 
Ficará claro que a relação entre possessivos e outros domínios conceituais, assim como os mecanismos diacrônicos que moldam essa relação, constitui-se uma fascinante área de pesquisa. No entanto, ficará claro também que essas questões estão além do escopo da presente investigação [... $]^{16}$

Tomando como questão de pesquisa as motivações das relações entre o domínio dos possessivos com domínios conceituais vizinhos, uma primeira hipótese de trabalho foi a de procurar sistematizar as possíveis relações indicadas na literatura sobre possessivos. Constatamos, porém, como será visto no capítulo 4, que a ênfase das investigações se concentrava não na tentativa de entender como se dão as relações entre cada um dos domínios envolvidos, mas na busca por um denominador comum entre todas as construções. Por fim, mantivemos o objetivo inicial de verificar o funcionamento estrutural da relação de possessivos e seus vizinhos conceituais. Em grande parte, esse seria nosso principal desafio teórico. Como desafio descritivo, percebemos que fora os dois trabalhos tipológicos resenhados neste capítulo, praticamente nenhum outro trabalho se ocupou explicitamente do lugar do domínio do Comitativo na expressão de posse predicativa, exceção o trabalho Stolz (2001) e de Stolz, Stroh e Urdez (2006). Pode parecer contraditória a afirmação de que nenhum outro trabalho tenha se ocupado da questão sendo que as duas referências acima demonstram o contrário. Podemos dizer, de outra forma, que Stolz e associados produziram trabalhos sobre o Comitativo e outros domínios conceituais, porém, a perspectiva dos autores não era a de discutir a problemática como posta por Clark (1978) e Freeze (1992). O trabalho desses autores se classifica na verdade como uma discussão entre o sincretismo do comitativo com o instrumento, entrando a questão do possessivo, existenciais e locativos como fatos das línguas analisadas. Talvez o primeiro trabalho que realmente se posicionou como parte do debate do Paradigma Localista e que tenha tratado do comitativo seja o de Lisa Levinson (2011).

Frente a essa constatação, nos propusemos a verificar em línguas de possessivos comitativos a forma como se dão as relações entre os domínios conceituais de posse predicativa. Com isso, os dois desafios: teórico e descritivo, não necessariamente nessa ordem, ensejam a produção de uma tese de dupla face. Uma que caracterize individualmente os domínios conceituais de locativos, existenciais, comitativos e possessivos e a partir daí quais as implicações para a descrição de línguas bantas. A outra face seria a de examinar em

\footnotetext{
16 "It will be clear that the relationship between possession and other conceptual domains, and the diachronic mechanisms that shape this relationship, constitute a fascinating area of research. However, it will also be evident that these issues are way beyond the scope of the present investigation [...]"
} 
que as particularidades tipológicas das línguas bantas podem contribuir para um reexame das propostas teóricas que buscaram solucionar o problema das construções possessivas.

\subsection{Em síntese}

Considerando a impossibilidade de lidar com todas as questões decorrentes das construções de posse predicativa, decidimos verificar melhor, dentro de um conjunto particular de línguas, a relação entre os três principais domínios conceituais envolvidos na expressão de posse predicativa nas línguas do mundo, segundo os trabalhos tipológicos apresentados, os domínios das construções locativas, existenciais e comitativas.

Propusemos, assim, atuar precisamente onde aqueles trabalhos, deliberadamente ou não, deixaram uma lacuna, as motivações cognitivas que une ao mesmo tempo que distingue as quatro principais estratégias de posse predicativa nas línguas. Para atingir esse propósito, é justo que dediquemos um espaço aos trabalhos que se debruçaram sobre possessivos e domínios relacionados. 


\section{CAPÍTULO 4}

\section{As RelaÇões entre Locativos, Existenciais e PosSessivos ( E Comitativos?)}

\subsection{Apresentação}

Observar que as línguas do mundo empregam locativos, existenciais e comitativos para a expressão de possessivos, conforme os trabalhos tipológicos resenhados no capítulo anterior é apenas o início de uma intrincada relação que já tem sido tema de uma literatura substancial há pelo menos 50 anos. Excluindo-se o comitativo, por razões que iremos discutir oportunamente, linguistas de diversas searas teóricas têm buscado solucionar como se dão as estreitas relações entre locativos e existenciais com a expressão de possessivos. Neste capítulo são apresentados de forma panorâmica os trabalhos considerados representativos dessa literatura, sendo eles os mais comumente citados. Pretendemos dar uma visão, se não do todo, ao menos dos principais tópicos que mereceram a atenção dos estudiosos, e que continuam a intrigar novos entusiastas pela temática.

O capítulo está organizado seguindo as duas principais perspectivas utilizadas para solucionar a problemática em estudo. Uma primeira perspectiva considerada "localista" por defender a ideia de primazia do domínio locativo e que, portanto, todas as construções possessivas e existenciais têm uma estrutura subjacente locativa, e uma segunda proposta, "não localista", contrária à "Hipótese Localista", expressa como a impossibilidade de haver uma única estrutura subjacente a todas as construções de posse e desta com as outras construções inter-relacionadas. Para cada uma dessas propostas, buscamos apresentar desde os primeiros estudos que permitissem esse direcionamento até os desdobramentos e críticas passíveis para cada uma das abordagens. Antes de apresentar esses trabalhos, nos ocupamos de justificar a apresentação dos trabalhos em dois grupos, localistas e não localistas.

\subsubsection{Localizando a problemática}

Nos trabalhos tipológicos de Heine (1997) e Stassen (2009) as construções possessivas e outros domínios conceituais são mencionados, mas os autores tentam não se posicionar sobre a questão: “Se verbos tipo 'ter' ou verbos tipo 'ser' são entidades de estrutura profunda, como alguns têm assumido, ou que devem ser formados via transformações ou outras 
operações, é uma questão que está fora do escopo deste trabalho.” (Heine, 1997, p. 237). ${ }^{1}$ No entanto, Heine (1997, p. 202-207) dedica algumas páginas à questão, além de tecer críticas contundentes à proposta de Freeze.

Frente à vasta literatura sobre os domínios de possessivos, uma primeira tarefa seria a de como classificar todos esses trabalhos a que tivemos acesso. À primeira vista, a velha dicotomia formalismo vs. funcionalismo parecia fazer sentido, aquela capitaneada pelas análises de Freeze, e do lado, oposto aquelas que se opunham ao tratamento formalista. No entanto, o trabalho de Clark (1978) numa busca por explicações funcionais e universais para explicar as construções locativas também, assume uma proposta localista, que como a do "Paradigma Localista" formalista busca uma explicação uniforme para as construções possessivas e existenciais. E mesmo a proposta cognitivista de Langacker (2003) não deixa de ter um quê de uma análise uniforme moderada, ao buscar caracterizar todas as construções possessivas a partir de uma relação básica, a das construções do ponto de referência, guardadas as devidas proporções entre a proposta cognitivista e as formalistas. Frente a tal situação de heterogeneidade teórica, resolvemos seguir a classificação de Doris Payne (2009) para os estudos sobre a relação entre possessivos, existenciais e locativos, classificando-os como "Localistas" e "Não Localistas", mesmo sabendo que uma classificação como esta serviria mais como uma forma de organizar as propostas de cada autor de forma que pudéssemos contrastar cada análise, não traduzindo fielmente as implicações teóricas e descritivas perseguidas para cada posicionamento analítico.

\subsection{As abordagens localistas}

4.2.1 Primeiros estudos (Benveniste, [1966]; Bach, 1967; Lyons, [1967]) ${ }^{2}$

Desde o clássico estudo de Benveniste e sua afirmação de que "ter não é nada mais que um ser de invertido" ('avoir n'est rien autre qu'un être-à inversé') (Benveniste, 1976, p. 215 [1966, p. 197]), a temática sobre a relação entre cópula e verbo de posse tem chamado a atenção de muitos linguistas das mais diferentes searas teóricas. Muitos trabalhos, principalmente de viés formalista, têm sugerido a possibilidade de unir todas as construções

\footnotetext{
1 "Whether 'have'-verbs or 'be'-verbs for that matter, are deep-structural entities, as some have claimed, or else must be introduced as formatives via transformations or any other operations, is an issue that is outside the scope of this work."

${ }^{2}$ Indicamos no título da seção as referências com a data dos trabalhos originais, no entanto, para a tese, consultamos também aqueles que contam com uma tradução para o português (Benveniste, 1976; Lyons, 1979). No corpo do texto, indicamos a data da primeira publicação de trabalhos entre colchetes.
} 
possessivas das línguas do mundo a partir de uma base única, recorrendo facilmente a processos teoricamente direcionados. Na conhecida tríade das relações entre locativos, existenciais e possessivos, o locativo é considerado o melhor candidato para uma unificação, conforme sugerido nos primeiros estudos de Benveniste (1976 [1966]), Bach (1967) e Lyons (1979 [1967]), encontrando em Freeze (1992) uma formalização mais técnica daquelas primeiras propostas. Tal formalização de Freeze chegou a levar a alcunha de "Paradigma Localista”. Não causa surpresa o direcionamento das análises para o locativo considerando que o domínio do locativo é inegavelmente um domínio conceitual básico da estrutura conceitual humana. Enquanto Benveniste enumera alguns exemplos de como se comportam os verbos de cópula e verbos do tipo "ter" em diferentes línguas, Lyons ensaia uma primeira tentativa de formalização de como locativos estão relacionados a possessivos e existenciais. Bach será quem dará um "ponta-pé” inicial, utilizando a terminologia da gramática gerativa em suas primeiras versões e propondo uma forma de resolver o caráter "esquizofrênico" da cópula em algumas línguas.

Esses três trabalhos podem ser indicados como os trabalhos mais influentes para as anáises localistas posteriores. Houve outros trabalhos anteriores a esses, como as gramáticas de caso, baseadas em Anderson (1971), porém, foram esses três trabalhos que elaboraram de uma forma mais direta a possibilidade de enquadrar num mesmo paradigma as construções possessivas e locativas. Para o desenvolvimento, no entanto, da Hipótese Localista de Freeze, o trabalho tipológico de Clark (1978) foi de fundamental importância, como também para outros trabalhos não localistas (Bickerton, 1981), por esse motivo dedicamos a próxima seção a essa primeira tentativa dita tipológica para o exame das construções locativas, existenciais e possessivas (Clark, 1978).

\subsubsection{Abordagem funcionalista e tipológica (Clark, 1978)}

O trabalho de Clark (1978) pode ser considerado como clássico na linha funcionalista, baseado grandemente nas assunções de Lyons (1979 [1967]). A autora examina uma amostra de cerca de 30 a 50 línguas. Apesar das pretensões tipológicas do estudo, suas conclusões se aplicam muito mais a uma generalização parcial entre os quatro tipos de construções examinadas por ela do que a um quadro representativo das línguas do mundo. Se desconsiderarmos alguns pormenores do trabalho de Clark, como ser grandemente baseado em línguas de possessivos locacionais, podemos nos ater aos parâmetros semânticos utilizados por ela para organizar a forma como locativos e existenciais se relacionam. 
Pinheiro e Gerhardt (2004) sintetizam bem a forma como a autora trabalha com os parâmetros de [+/- animacidade] e [+/- definido]. Apresentamos a seguir algumas das conclusões pontuais da análise de Clark (1978), iniciando com as principais construções a serem tratadas por ela:

(1) Inglês (Clark, 1978, p. 87)

a. Existenciais
There's a book on the table.
EXP-ser um livro em ART mesa

'Há um livro na mesa.'

b. Locativas

The book is on the table.

O livro está em.ART mesa

'O livro está na mesa.'

c. Possessivas com Have: possessivas1

John has a book.

João tem um livro

'João tem um livro.'

d. Possessivas com $\mathrm{Be}$ : possessivas2

This book is John's.

Este livro é João-GEN

'Este livro é do João.'

O objetivo da pesquisadora é o de definir os usos das construções acima e a forma como elas podem ser associadas, numa perspectiva, à primeira vista, tipológica. Clark opera basicamente com os traços de animacidade (mais fundamental) e definitude, os dois parâmetros discursivos considerados pela autora como determinadores do cenário geral para os locativos. Seguindo esses parâmetros, ela classifica as construções em existenciais, locativas e possessivas, classificadas abaixo seguindo os dois parâmetros apontados acima:

(i) Se o espaço em questão é animado: o enunciado é possessivo. A existência de duas construções possessivas decorre das condições de definitude do SN possuído:

a) Possessivas1: SN [-definido]: John has a book.

b) Possessivas2: SN [+definido]: The book is John's. 
(ii) Se o espaço for [- animado], há duas possibilidades:

a) para nomes [+definidos]: enunciados locativos;

b) para nomes [- definidos]: enunciados existenciais.

Ainda seguindo a aparente regularidade observada nas diversas línguas, Clark aponta que tais construções são governadas pelas seguintes regras semântico-discursivas: [+definido] precede [-definido] e [+ animado] precede [- animado]. Para Clark, a escolha que as línguas fazem entre os verbos BE e HAVE, dependerá do tema da sentença se o mesmo leva o papel semântico de POSSUIDOR (PR) ou POSSUÍDO (PD) e da definitude do PD. Resumindo abaixo, fica da seguinte forma:

1) Para possessivos com have (possessivas1): POSSUÍDO [-definido] (com SN singular);

2) Para possessivas com be (possessivas 2): com POSSUÍDO [+definido].

Por fim, Clark busca sintetizar suas observações do seguinte modo:

a) Em relação à animacidade dos $\mathrm{SNs}$, as existenciais se relacionam às locativas (LOC [animado]), e as possessivas1 relacionam-se às possessivas2 (LOC [+ definido]);

b) Em relação à definitude dos nomes e ao uso dos verbos, as existenciais estão relacionadas às possessivas1 ( $\mathrm{SN}$ [-definido]), e as locativas relacionam-se às possessivas2 (SN [+definido]).

O interessante na abordagem de Clark é a importância dada aos parâmetros de animacidade e definitude utilizados pela autora como determinantes para a ordem em que aparecem os papéis semânticos de cada construção, no entanto, as particularidades das línguas, tanto do corpus de Clark como outras não estudadas pela autora, podem invalidar suas generalizações, conforme também atestado por Saurí (2008, p. 15). Vale atentar para a forma como Cark (1978) organizou na sua amostra de línguas a forma como esses parâmetros se relacionam, o que servirá como base para outros estudos, como o de Freeze (1992) e Bickerton (1981).

4.2.3 Abordagens formalistas (Freeze, 1992; Kayne, 2000 [1993])

Na linha gerativista, os trabalhos de Freeze (1992; 2001) são já clássicos no empreendimento de análise unitarista para tratar dos domínios de locativos, existenciais e 
possessivos. Freeze parte dos trabalhos de Bach (1967) e Lyons (1968) e acredita ter encontrado uma forma de integrar as construções com verbos "have", ou "have copulas" na terminologia emprestada de Bach, a partir dos pressupostos teóricos da versão de Princípios e Parâmetros, de Chomsky.

Freeze inicia demonstrando a complementaridade entre as construções locativas e existenciais em um punhado de línguas, que basicamente estariam no tipo de possessivos locacionais, na tipologia de Stassen (2009), ou no esquema de locativo, na tipologia de Heine (1997). Para ele, construções como as que seguem, teriam a mesma estrutura profunda, nos termos gerativistas:

(2) Russo (Freeze 2001, p. 945-6)

\begin{tabular}{|c|c|c|c|c|}
\hline \multirow{2}{*}{ a. } & Kniga & byla & $\underline{\text { na } \quad \text { stole. }}$. & (Locativo) \\
\hline & livro.NOM & COP.PASS & PREP mesa.LOC & \\
\hline & \multicolumn{4}{|c|}{ 'O livro estava na mesa.' } \\
\hline \multirow[t]{3}{*}{ b. } & $\underline{\mathrm{Na}} \quad$ stole & byla & kniga. & (Existencial) \\
\hline & PREP mesa.COP & COP.PASS & livro.NOM & \\
\hline & 'Havia/tinha um liv & na mesa’ & & \\
\hline \multirow[t]{2}{*}{ c. } & $\underline{\mathrm{U} \text { menja }}$ & byla & kniga. & (Possessivo) \\
\hline & PREP-PRON & COP.PASS & livro.NOM & \\
\hline
\end{tabular}

Freeze (1992) recorre a diferentes línguas para verificar a variação na ordem de palavras entre línguas SVO, SOV, VSO, etc., tais como francês, hindi e tagalog e atesta que apesar da variação superficial na ordem preferida de palavras de cada língua, há uma regularidade na forma como os papéis semânticos das construções possessivas, existenciais e locativas se comportam. Para Freeze, a regularidade encontrada em tantas línguas entre os constituintes das construções existenciais e locativas pode ser explicada em termos de movimento, seguindo os pressupostos gerativistas, desencadeados pelos traços de [+/definido]. Para as construções possessivas, seguindo na linha de Lyons, Bach e Clark, Freeze acredita que o POSSUIDOR pode ser considerado um locativo.

Abaixo, uma representação de como é entendida a estrutura profunda que daria conta das construções possessivas em relação com as locativas e existenciais: 


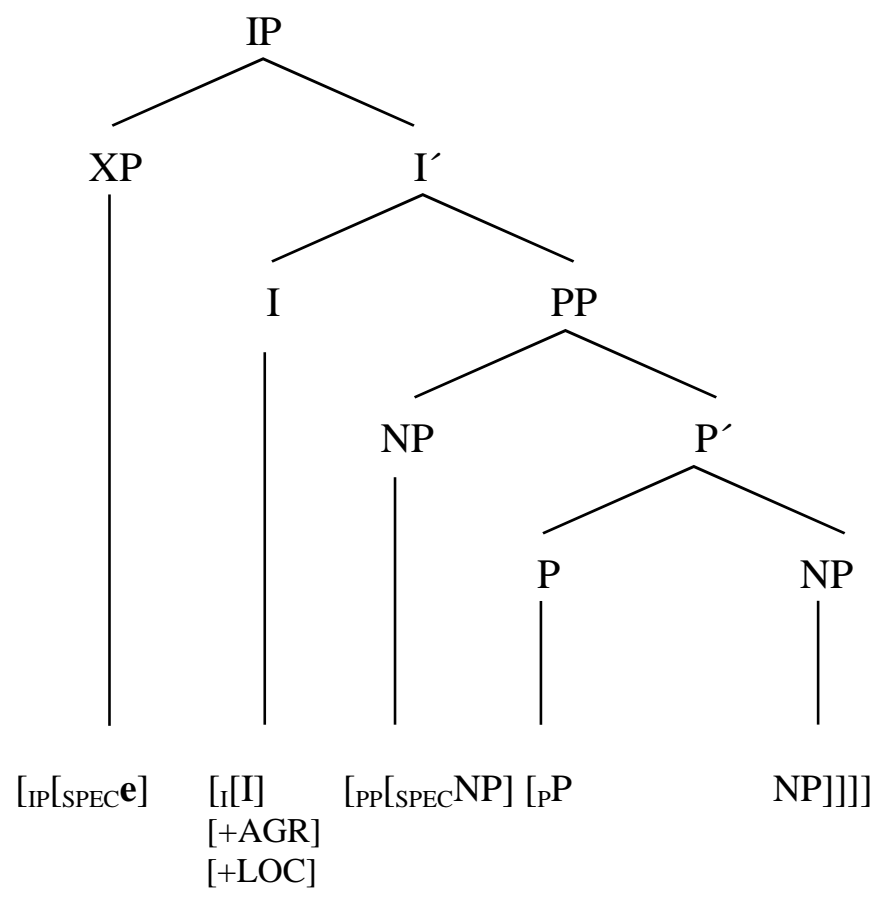

Em síntese, Freeze (1992, p. 559) acredita que o movimento do tema de um locativo é governado pelo traço [+ definido] ou [-definido]: um tema definido é movido para a posição de sujeito decorrendo disso um predicado locativo (exemplo (2a)). Alternativamente, um tema indefinido permanece na posição enquanto o locativo move para a posição de sujeito, decorrendo disso uma construção existencial (exemplo (2b)). Para o caso das construções com "have", Freeze (1992) argumenta que "have copulas" se diferenciam das "be copulas" por aquelas serem "basicamente existenciais com argumentos locativos com o traço [+humano]. Para dar continuidade à sua análise unitarista das construções com have o autor acredita que itens como "have" do inglês não são lexicais, mas traços de categorias funcionais. Em outras palavras, have é nada mais que uma cópula com uma partícula abstrata, geralmente de valor locativo, incorporada, que em predicados possessivos tem como spell-out um item equivalente a "have"3

Uma notação mais intuitiva pode ser verificada abaixo:

A obra de Baker (1988) é ainda bastante influente, apesar das frequentes reformulações das bases teóricas do gerativismo. Para uma resenha crítica dessa obra, baseada em dados empíricos, conferir Van Valin Jr. (1992). 
(4) Blaszczak (2009, p. 3)

a. $\quad \mathrm{HAVE}=\mathrm{BE}+\mathrm{P}$

b. "NP"

Em uma breve explanação, o processo de incorporação é basicamente identificado com o movimento de núcleos (Levinson, L., 2011, p. 377), de acordo com o gerativismo, tendo como obra fundadora o livro de Baker (1988). Em trabalhos descritivos, incorporação é entendido como o processo no qual dois morfemas que em determinado ambiente ocorrem "livremente", em outros eles podem ocorrer como uma unidade sintática. Abaixo, exemplos de dois tipos de incorporação:

(5) Incorporação nominal em mohawk (Baker, 1988, p. 20)
a. ka-rakv ne sawatis hrao-nuhs-a ?
3N-ser.branco DET João 3M-casa-SUF
'A casa do João é branca.'
b. Hrao-nuhs-rakv ne sawatis.
3M-casa-ser.branca DET João

'A casa do João é branca.'

(6) Incorporação de preposição (aplicativo) em chicheua (Baker, 1988, p. 229)
a. Mbdzi zi-na-perek-a msampha kwa nkhandwe.
Zebras MS-PASS-mão-ASP armadilha para raposa
'As zebras entregaram a armadilha para a raposa.'
b. Mbdzi zi-na-perek-er-a nkhandwe msampha.
Zebras MS-PASS-mão-APL-ASP . raposa armadilha

'As zebras entregaram a armadilha para a raposa.'

O processo de incorporação, da forma como Freeze (1992) propõe iniciamente, para os verbos do tipo have, seria o ponto chave que "unificaria" as sentenças locativas, existenciais e 
possessivas. Para línguas como o português brasileiro que permite o uso do mesmo item ter para os três tipos de oração, a relação entre as três sentenças é mais aparente:

(7) Português brasileiro
a. Tem um livro na estante.
(Locativo)
b. Na estante tem um livro.
(Existencial)
c. O Pedro tem um livro.
(Possessivo)

Para muitas línguas, no entanto, aquelas três sentenças são construídas com itens verbais diferentes, apesar da sua similaridade na ordem de palavra e dos traços de definitude dos referentes locativos ou das entidades na relação possessiva, como pode ser verificado em espanhol e inglês, abaixo:

(8) Espanhol (Blaszczak, 2009, p. 5)
a. Pedro es de Berlim.
'Pedro é de Berlim'
b. Pedro está en el parque
'Pedro está no parque.'
c. Pedro tiene un coche.
'Pedro tem um carro'

d. Hay un hombre en el parque.

'Há um homem no parque.'

(9) Freeze (1992, p. 553)

a. The book is on the bench.

'O livro está no banco.'

b. There is a book on the bench.

'Há/tem um livro no banco.'

c. Lupe has a book.

'Lupe tem um livro.'

Foi justamente para lidar com essa diferença "superficial”, mais fácil de verificar no ingês que Freeze recorre ao processo sintático de incorporação, entendido como movimento de núcleos e que se assemelha aos processos morfológicos de incorporação descrito por Baker 
(1988). A fórmula utilizada pelos entusiastas do Paradigma Localista é basicamente esta: "HAVE $=\mathrm{COP}+\mathrm{P}$ ", onde P é uma categoria funcional, nos termos da gramática gerativa, que incorpora em uma cópula produzindo um verbo do tipo have.

O trabalho de Kayne (2000 [1993]) segue as mesmas linhas de Freeze, mas para Kayne a natureza do processo de incorporação ocorre de forma diferente da de Freeze, no que diz respeito à natureza das categorias gramaticais possíveis de incorporação com a cópula de determinada língua. Para ele, as categorias possíveis de incorporação não seriam apenas PP, ou seja, categorias preposicionais e com valor locativo, como também DP, com outros valores possíveis, inclusive comitativo.

A proposta de Freeze (1992), pela sua linha de raciocínio e pelos dados apresentados em uma amostra de línguas relativamente significativa, e por ter sido o primeiro trabalho a sintetizar as intuições dos autores anteriores (Lyons, 1979; Bach, 1967; Clark, 1978) tornouse a principal referência, devido também à sua análise de unir três sentenças a partir de um único processo sintático, o de incorporação, análise esta bastante atraente, que vem recebendo algumas mínimas reformulações e servindo como base para outras análises, como as de den Dikkens (2006). No entanto, o refinamento teórico proposto por Kayne (2000) é atualmente o modelo mais utilizado para análise de diversas línguas, como o egípcio cóptico (Reintges; Lipták, 2009) e o português brasileiro (Avelar, 2004; 2009a; 2009b). Praticamente todos esses últimos trabalhos na esteira da análise de Kayne se valem mais do processo de incorporação para dar conta das construções possessivas. Os traços de [+/-definido], [+/-animado] ou [+/humano] tão importante nas primeiras análises de Clark (1978) e Freeze (1992) deixam de exercer qualquer papel na relação entre as construções locativas, existenciais e possessivas. Para esses autores, a análise de Kayne (2000 [1993]) oferece um leque maior de possibilidades ao permitir que não apenas partículas locativas possam incorporar na cópula, como também qualquer adposição com o valor locativo ou comitativo, a depender da tipologia da língua. Essa é a ideia seguida por Reintges e Lipták (2009) e Avelar (2009a). ${ }^{4}$

Muito tem sido feito nos últimos anos, dentro das particularidades teóricas do gerativismo na sua atual versão do Programa Minismalista. Vejamos alguns das críticas ao Paradigma Localista decorrentes dos desenvolvimentos teóricos do gerativismo.

\footnotetext{
${ }^{4}$ Vale mencionar aqui o estudo de Christie (1970) sobre as expressões de locativos, existência e posse em quissuaíli, talvez primeiro trabalho a tratar da temática em uma língua banta. No entanto, o autor segue fielmente as conclusões dos estudos de Bach (1967), fazendo uso dos dados do quissuáli apenas para comprovar a natureza locativa dos três domínios em questão. Voltaremos a esse texto mais adiante.
} 


\subsection{Críticas e desenvolvimentos das abordagens formalistas}

Heine (1997, p. 218) tece algumas críticas à abordagem de Freeze (1992) que em publicação posterior (Freeze, 2001) cita o trabalho do africanista apenas como uma tentativa de explicar possessivos sob um viés funcionalista, deixando assim a sugestão de que possessivos devem e só podem ser explicados apenas em uma teoria formalista da linguagem. Talvez Blaszczak (2009) seja quem apresente algumas das críticas mais contundentes, dentro da própria abordagem formalista, para a operação sintática base do Paradigma Localista, o processo de incorporação, partindo de dados fundamentados empiricamente, sem deixar, no entanto, de fora questionamentos internos às teorias empregadas. Dentre alguns pontos problemáticos apontados por Blaszcsak (2009) para a abordagem unitarista, temos:

a) nenhuma diferença é feita entre os tipos de cópula (de sentenças de predicado nominal e de sentenças locativo/existenciais, conforme distinção feita por Stassen, para línguas compartilhantes e cindidas.) (Cf. capítulo 3) com a qual as adposições podem incorporar para resultar um verbo do tipo "have" do inglês;

b) nenhuma distinção é feita para o tipo de categoria possível de incorporar com a cópula, além do problema de que em tal abordagem, o possuidor (PR) em uma sentença possessiva seria assinalado caso duplamente, antes e depois de P incorporar em COP.

Esses são apenas alguns dos problemas mencionados por Blaszczak (2009) e que também são apontados de forma direta ou indireta por outros estudiosos como Payne (2009), Lisa Levinson (2011) e Salzmann (2011). Das observações de Blaszczak, aquelas retiradas de dados de línguas eslavas talvez sejam as mais desafiadoras para uma análise unitarista. Vejamos o seguinte caso: de acordo com Freeze (1992), verbos do tipo be e have não são lexicais, mas categorias funcionais. O primeiro coocorre com PPs, enquanto o segundo, decorrente da operação de incorporação, não poderia coocorrer com PPs, da seguinte forma:

(10) Blaszczak (2009, p 10)
a. NP-TER-NP
incorporação $\mathrm{P}=>\mathrm{COP}$
b. PP-COP-NP/NP-COP-NP
sem incorporação $\mathrm{P}=\mathrm{COP}$
c. *PP-TER-NP 
Blaszczak encontra algumas contraevidências para (8) em algumas línguas eslavas, nas quais PP coocorre com ter em construções existenciais/possessivas:

(11) Polonês (Blaszczak, 2009, p. 10)
a. Samochód
ma silnik.
NP-TER-NP
carro.NOM ter motor.ACC
'O/um carro tem um motor'
b. W samochodzie jest silnik.
Em carro.LOC ser motor
PP-COP-NP

'Tem um motor no carro.'
c. W sachomodzie nie ma silnik.
Em carro.LOC NEG ter motor
'Não tem motor no carro.'

(12) Croata (Blaszczak, 2009, p. 10-11)
a. Petar
ima $\operatorname{sir}$
(sira).
NP-TER-NP
Pedro.NOM tem queijo.ACC queijo.GEN
'Pedro tem (algum) queijo.'
b. $\mathrm{Na}$ stolu je bilo sira $\quad$ PP-COP-NP
Em mesa.LOC AUX COP.PASS queijo.GEN

'Tinha (algum) queijo na mesa.'
ima
sira.
Em mesa.LOC ter
queijo.GEN

PP-TER-NP

'Tinha (algum) queijo na mesa.'

(13) Búlgaro (Blaszczak, 2009, p. 11)
a. Petur
ima/imashe
kola.
NP-TER-NP
Pedro
ter/ter.PASS
carro

'Pedro tem/tinha um carro.'
b. $\mathrm{Na}$ masata ima/imashe sirene.
em mesa-ART ter/ter.PASS queijo

PP-TER-NP

'Tem/tinha queijo na mesa.'
c. $\mathrm{Na}$ masata njama/njamashe
Em mesa NEG-ter/NEG-ter.PASS queijo
'Tem/tinha nenhum queijo na mesa.'


Os exemplos em (9c), (10c) e (11b.-c.) mostram que aparentemente não haveria nenhuma restrição ao processo de incorporação, podendo ou não ocorrer, o que reforça os argumentos de Blaszczak de que as línguas têm à sua disposição os dois tipos de verbos, ser e ter, e dependeria de cada língua a necessidade ou não de recorrer ao processo de incorporação. Essa última afirmação é mais ou menos seguida por Jung (2011) que, adotando a versão minimalista de gramática gerativa, ao pautar-se na análise sobre construções possessivas e sua evolução para as expressões auxiliares e modais em russo, considera ser uma questão de parâmetros as línguas expressarem possessivos por meio de verbos do tipo ser/ter. Jung (2011) acredita que os dados daquelas três línguas eslavas nos exemplos (11)(13) não são grande problema para o Paradigma Localista, por observar que a provável violação das regras elaboradas por Freeze (1992) para a não ocorrência de PP-TER-NP, seria motivada sob certas circunstâncias, a depender de dois fatores: o tempo presente e negação (NEG), isso para o caso das línguas eslavas (Jung, 2011, p. 50).

A solução encontrada por Jung (2011) parece bastante atraente, mas por adentrar em uma discussão mais técnica referente às teorias sobre Caso e foco e concentrar-se basicamente em línguas eslavas, podemos dizer que, para a autora, o mecanismo de incorporação não deve ser necessariamente obrigatório, sendo muito mais uma manifestação do Parâmetro be/have, nas línguas do mundo. $\mathrm{O}$ que diferenciaria línguas que fazem uso de cópula para a expressão de possessivos e línguas que fazem uso de verbos do tipo ter seria a necessidade de atribuição de Caso em DP, neste ponto, a autora segue na linha proposta por Kayne (2000 [1993]). Para a autora, línguas do tipo ser seriam desprovidas de traços para Caso, recorrendo a outros mecanismos para a atribuição de caso, por exemplo, a partir de PP ou DP. Já línguas do tipo ter possuem os traços de atribuição de Caso (Jung, 2011, p. 95).

Para não sairmos tanto dos limites de nosso trabalho, mencionamos o trabalho de Lisa Levinson (2011) como outro exemplo de crítica ao modelo formalista. Levinson faz uso de dados do islandês para mostrar que o fenômeno de incorporação tem certas restrições à categoria que pode incorporar e que as construções de posse predicativa em islandês não tem uma base locativa, como defendido por Freeze (1992). Levinson inicia atestando a existência de verbos como hafa e eiga, utilizados restritamente para tempo e propriedade legal em islandês, enquanto que vera með é utilizado para as demais expressões possessivas, como para coisas portáveis, partes do corpo, doenças e acessórios. Abaixo dois exemplos de vera með: 
(14) Islandês (Levinson, L., 2011, p. 360)

$\begin{array}{lllll}\text { a. } & \text { Hún } & \text { er með } & \text { bækumar } & \text { fimm. } \\ \text { ela.NOM } & \text { estar com } & \text { livros-ART.ACC } & \text { cinco } \\ \text { 'Ela tem cinco livros.' } & & \\ \text { b. } & \text { Jón } & \text { er með } & \text { kvef. } & \\ & \text { João.NOM } & \text { estar com } & \text { resfriado.ACC } & \\ & \text { 'João está com/tem gripe'. } & \end{array}$

Para o português brasileiro (PB), Avelar (2009a) segue algumas indicações de Freeze (2001) e apresenta as construções com "estar com" como prova da base comitativa e copular do verbo "ter". O autor demonstra o paralelismo entre construções com "estar com" e "ter" afirmando que a diferença entre as duas construções se dá em termos aspectuais. Enquanto as construções com "ter" teria um valor mais permanente, "estar com" seria usado para aspectos temporários de posse, como nos exemplos:

(15) Português (Avelar, 2009a, p. 141)

a. O Pedro está com dinheiro.

b. O Pedro tem dinheiro.

Não é possível fazer uma comparação entre o islandês e o português, pois as duas línguas diferem consideravelmente no uso da estratégia comitativa para possessivos. Em português o uso de "estar com" é bem mais restrito que "vera með” do islandês, fazendo com que autores considerem o uso de "estar com” como idiomático (Stolz, 2001).

\subsection{As abordagens não localistas}

\subsubsection{Primeiros estudos (Bickerton, 1981; Croft, 1991; Koch, 1999)}

Agrupamos estes três estudos como precursores de abordagens não localistas por encontrarmos neles algumas tentativas de solucionar o "espaço" conceitual entre as três construções bastante discutidas na literatura, de uma forma em que a relação não fosse intermediada por apenas um dos domínios, como o locativo, mas por operações que permeariam a dita relação. O primeiro trabalho, com Bickerton (1981), parte dos resultados tipológicos de Clark (1978) e procura corroborar estudos voltados para a identificação de 
universais. Bickerton (1981) utilizando-se das propostas de Clark (1978) buscou uma explicação considerada universal para as quatro construções, advogando a noção de "Contiguidade" (contiguity), para explicar a estrutura interna entre as construções. Tal noção seria expressa da seguinte forma: “[...] nenhuma língua pode usar o mesmo morfema para expressar duas relações não contínuas (localização e posse ou existência e propriedade (ownership), a menos que o mesmo morfema seja também usado para expressar uma das relações intervenientes (existência e propriedade, para o primeiro caso, e localização e posse para o segundo caso." (Bickerton, 1981, p. 245). ${ }^{5}$

Entretanto, Heine (1997, 204-5) mostra alguns exemplos nos quais a restrição imposta pelo parâmetro da "Contiguidade" não parece valer. O trabalho de Koch (1999) parece ser uma continuação daquele de Bickerton (1981), mas o interesse primário de Koch é diacrônico, muito mais que sincrônico. O interessante, porém, na abordagem desse autor é o refinamento que ele faz para os tipos de locativos e existenciais, na busca de determinar mais apuradamente o espaço de um locativo e de um existencial, tomando os traços discursivos de informação nova e informação dada. À parte a nomenclatura do autor, já em desuso, as ideias de Koch (1999) merecem ser exploradas sob um novo prisma teórico e metodológico, o que, no momento, foge de nossas pretensões. Mencionamos aqui esse trabalho para indicar que diversos outros trabalhos buscavam entender a relação de possessivos com existenciais e locativos sem recorrer a reducionismos.

Dos trabalhos que podemos considerar como precursores das abordagens não localistas, o trabalho de Croft (1991) e seu Modelo de Corrente Causal merece uma maior atenção. O autor, preocupado com modelos tipológicos, trata da questão de papéis semânticos e suas distribuições e restrições nas línguas do mundo. Ele observa então que, a depender da ordem em que aparecem, os papéis semânticos poderiam ser agrupados em Antecendentes e Subsequentes, conforme Tabela 4.1, abaixo:

\footnotetext{
5 " [...] no language can use the same morpheme to express two noncontiguous relationships (i.e., location and possession, or existence and ownership) unless that same morpheme is also used to express on of the intervening relationships (i.e., existence or ownership in the first case, location or possession in the second)."
} 
Tabela 4.1 - Classes de papéis temáticos do Modelo de Corrente Causal (Stolz, 2001, p. 323)

Antecedente

Causa

Agente

Comitativo

Meio

Maneira

Instrumento

\section{Subsequente}

Resultado

Beneficiário

Recipiente
Neutro

Locativo ('Espaço')

Possessivo

Seguindo esse modelo, os papéis semânticos à direita seriam mais propensos a passar por sincrestismo, ou seja, a compartilhar dos mesmos morfemas nas línguas. Um exemplo é o papel do Comitativo, comumente sincretizado com o de Instrumento em grande parte das línguas indo-europeias. O problema para esse modelo era quanto ao papéis de Locativo e Possessivo, para Croft relacionados ao espaço. O autor considera esses dois papéis como Neutro. Mesmo não seguindo uma preocupação localista, Croft abriu caminho para outros trabalhos de maior fôlego sobre a temática, como Stolz (2001), o qual aponta diversos problemas para o Modelo de Corrente Causal de Croft (1991). No entanto, a significância desse modelo, apesar de agrupar os papéis semânticos de Locativo e Possessivo como neutro, é a indicação de que além do domínio do Locativo, os sincretismos nas línguas são mais abrangentes, causando diversas violações e ocorrendo até mesmo onde não seriam esperados. Fora esses três trabalhos, passamos para o exame de duas outras abordagens, não localistas, com uma maior fundamentação teórica e metodológica. O primeiro numa linha mais tipológica e funcionalista, o segunda de acordo com os pressupostos cognitivistas em linguística.

\subsubsection{Abordagem tipológica e funcionalista (Stolz; Stroh; Urdze, 2006)}

Será com o trabalho de Stolz, Stroh e Urdze (2006) que a categoria do comitativo terá seu lugar em um trabalho tipológico de peso. Iniciando com a conhecida Metáfora da Companhia de Lakoff e Johnson (1980), os autores se ocupam da relação entre Comitativo e Instrumento em uma amostra de mais de 300 línguas. As construções locativas, existenciais, comitativas e possessivas são tratadas na tipologia de Stolz e associados em função do que é 
conhecido na literatura tipológica como sincretismo ou "combinação de funções". Nesse caso, além do Comitativo e Instrumento, Possessivo, Espaço, construções coordenativas, e diversos outros papéis semânticos são postos em teste para a identificação das possíveis combinações de cada categoria nas línguas do mundo, tendo como centro o sincretismo entre Comitativo e Instrumento.

Uma das principais contribuições de Stolz (2001) e Stolz, Stroh e Urdze (2006) é a tentativa de demonstrar como se dão as "combinações", nos termos dos autores, entre as partículas e marcas utilizadas para a expressão de Comitativo, Instrumento, Locativo e Possessivos. Stolz (2001) parte da proposta de Croft (1991) para a possibilidade e impossibilidade de sincretismo de casos, assumidos em seu Modelo de Corrente Causal, segundo o qual os padrões de "sincretismo" se dão entre papéis temáticos considerados antecedentes e subsequentes. Em Stolz, Stroh e Urdze (2006) a proposta de papéis semânticos considerada é da "Role and Reference Grammar" (Gramática de Papéis e Referências), que também elege os papéis que podem ou não passar por sincretismo. ${ }^{6}$

Na proposta de Croft, os papéis de Locativo e Possessivo são considerados neutros. Stolz e associados $(2001 ; 2006)$ têm demonstrado que, apesar do bloqueamento defendido por Croft, entre os papéis temáticos antecedentes e subsequentes, alguns desses "bloqueios" são infringidos em diversas línguas, principalmente entre os papéis temáticos antecedentes, Comitativo e Instrumento, com aqueles considerados neutros por Croft, Posse e Locativo. Os estudos de Stolz e associados demonstram que o sincretismo entre micro papéis também se dá fora dos macro papéis defendidos na "Role and Reference Grammar". Nesse caso, os papéis de Comitativo e Instrumento agem fora do Macro Papel de ATOR, sincretizando com o papel de LOCATIVO, sob o Macro papel de AFETADO (UNDERGOER). A questão que fica é se haveria alguma regularidade entre essas infrações.

Para tentar solucionar esse problema, a proposta de Stolz é a de que para haver a possibilidade de combinações entre diferentes "funções", que em tese estariam em "níveis" diferentes e por isso não poderiam "combinar", é a de que um determinado domínio utiliza outro como meio para sincretizar onde, a princípio, não poderia, permitindo assim, em determinados contextos, os sincretismos não previstos. Para que isso aconteça é necessário que haja alguma função que sirva como "Função Ponte" (Bridging Function), que

\footnotetext{
${ }^{6}$ Não nos aprofundaremos na forma como Stolz e associados seguem os pressupostos da "Role and Reference Grammar" e as relações entre os Macro e Micro Papéis, para tanto, sugerimos a leitura de Stolz; Stroh; Urdze (2006, p. 35).
} 
intermediaria a relação, por exemplo, entre Comitativo e Locativo e Instrumento com Possessivo e Locativo. Pelo modelo dos autores, Locativo e Instrumento seriam os detentores de Função Ponte na elaboração de dois tipos de posse: Posse A que seria mais próxima de Locativo (similar ao tipo de possessivos locacionais de Stassen, 2009) e Posse B que seria mais próxima do Comitativo (similar ao tipo de Possessivos de Comitativo de Stassen, 2009). Abaixo a rede conceitual proposta por Stolz (2001, p. 340):

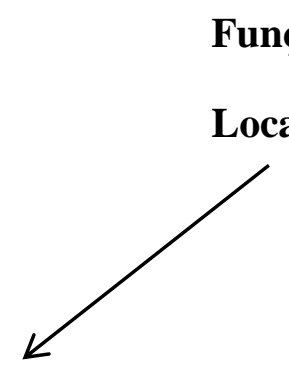

Possessivo A

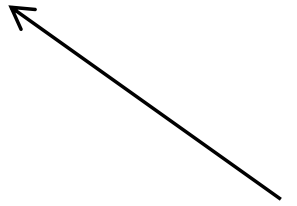

Instrumento

\section{Comitativo}
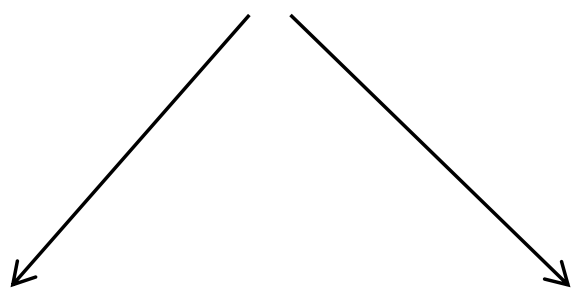

Possessivo B

\section{Função Ponte}

Figura 4.1 - Rede conceitual de "Função Ponte" de Stolz (2001, p. 340)

Um exemplo de como funciona uma Função Ponte é o de línguas que permitem o sincretismo do Comitativo com o Locativo ou de Instrumento com Locativo. Para que isso ocorra é necessário que uma das Funções Pontes esteja agindo, nesse caso, o Instrumento permitiria que Comitativo sincretizasse com Locativo; a função ponte de Locativo permitiria que o Instrumentosincretizasse com Possessivo. ${ }^{7}$

A proposta de Stolz e associados não é a de identificar qual construção seria mais prototípica, o foco são as diversas possibilidades de combinação entre Comitativo e Instrumento com outros papéis semânticos que a princípio não poderiam combinar. Deve ser mencionado que para os trabalhos tipológicos de Stolz e associados, o domínio dos existenciais não recebe a mesma atenção que nos outros trabalhos tipológicos voltados à questão dos possessivos. Os achados tipológicos desses autores têm sido desafiadores para teorias e modelos sobre papéis semânticos, a exemplo de Croft (1991) e da "Role and Reference Grammar” de Van Valin, como também para o caso da Metáfora da Companhia, já

\footnotetext{
${ }^{7}$ Veremos, mais adiante, a possibilidade desses sincretismos no capítulo dedicado à descrição das línguas bantas. Exemplificaremos alguns casos nos quais partículas de comitativo parecem ser usadas em construções espaciais, de mudança de percurso, e que classes nominais locativas parecem também ser usadas na função de Instrumento, quando em frases verbais compostas com aplicativo.
} 
considerada como um universal da conceitualização humana (Lakoff; Johnson, 1980). Será, porém, com Langacker que uma abordagem não localista irá desafiar, de uma forma mais satisfatória, as propostas localistas.

\title{
4.4.3 Abordagem cognitivista (Langacker, 2003; 2009)
}

Com Langacker (2009; 2003) encontramos uma alternativa que demonstra as motivações conceituais da "unificação" das construções possessivas, locativas e existenciais. $\mathrm{O}$ autor se posiciona contra a Hipótese Localista, mas não nega a proximidade conceitual entre as construções locativas e possessivas:

\begin{abstract}
$\mathrm{Eu}$, na verdade, rejeito fortemente a posição localista dos possessivos do tipo TER, os quais são considerados derivarem historicamente de construções de locativo. No entanto, não se deve negar que o locativo é uma noção relevante. Mesmo que não seja só locativo em todos os seus sentidos, os predicados fontes geralmente implicam (em uma construção de locativo) que o sujeito controla (ou ganha controle) da localização do objeto (locado). Além do mais, as estruturas em questão são basicamente agentivas ao invés de locativas. (Langacker, 2003, p. 8) ${ }^{8}$
\end{abstract}

Langacker (2009; 2003) busca, dentro do seu modelo teórico de Gramática Cognitiva, oferecer uma base conceitual para os dois padrões de posse por ele chamado de Have possessive (Construções possessivas do tipo Ter) e Be possessive constructions (construções possessivas do tipo Ser). Fazendo uso de construtos e processos conceituais como alinhamento de trajetor e marco (trajector and landmark allignment), perfilamento (profiling) e mais enfaticamente da Análise do Ponto de Referência (Reference Point Analysis), Langacker acredita ter demonstrado a proximidade conceitual entre os dois principais tipos de construções possessivas nas línguas do mundo, tanto para possessivos no nível nominal (posse atributiva) como no nível oracional (posse predicativa). O autor advoga que todas as relações possessivas podem ser caracterizadas a partir da habilidade do ponto de referência. ${ }^{9}$

Langacker constata inicialmente que o domínio de possessivos abrange diversas situações relacionais entre duas entidades, um possuidor (PR) e um possuído (PD) e que tanto

\footnotetext{
8 "I thus reject a strongly localist account of HAVE-possessives, where they are claimed to derive historically from locative constructions. This is not to deny that location is a relevant notion. Though not primarily locative in any usual sense, the source predicates generally do imply that the subject controls (or gains control of) the object's location. Nonetheless, the structures in question are basically agentive rather than locative."

${ }^{9}$ Por hora não adentramos em detalhes teóricos da Gramática Cognitiva. No capítulo 3 fizemos uma primeira apresentação sobre possessivos e as relações de ponto de referência. No capítulo 5, fazemos uma exposição de alguns construtos da Gramática Cognitiva.
} 
nas construções atributivas como predicativas uma entidade mais saliente é evocada com o propósito de estabelecer contato mental com uma entidade alvo menos saliente. Nesse caso, a habilidade do ponto de referência seria a operação cognitiva por trás das relações possessivas e que demonstraria de forma mais intuitiva o tipo de relação assimétrica que acontece entre as entidades PR e PD. A Análise do Ponto de Referência, entendida aqui como a formalização teórica das relações de pontos de referência cognitivos (Rosch, 1975), explicaria melhor a natureza da relação entre PR e PD por indicar a assimetria da relação entre as duas entidades nas relações de posse, como exemplo: "o pescoço da menina" e a situação assimétrica: "a menina do pescoço"; "o assassinato do presidente" de "o presidente do assassinato", etc. Para Langacker (2003, p. 21): as estratégias de expressões de posse predicativa são alternativas funcionais comparáveis. A equivalência entre um possessivo do tipo TER e um possessivo do tipo SER se reflete no nível estrutural composto (composite structure level), um outro construto da Gramática Cognitiva. As diferenças se dariam pelos processos de conceitualização, como já citados, de perfilamento, alinhamento de trajetor e marco, englobados como processos de construal. Como deixaremos para um momento posterior um detalhamento maior desses construtos, no Capítulo 5, nos limitamos aqui a demonstrar, em alguns poucos gráficos, a forma como Langacker acredita demonstrar que as operações de construal, a partir da Análise do Ponto de Referência, permitem visualizar a alternância conceitual entre línguas que fazem uso de verbos do tipo "ter" e línguas que fazem uso de verbos do tipo "ser" para a expressão de posse predicativa, da seguinte forma:

(a) Possessivo Nominal

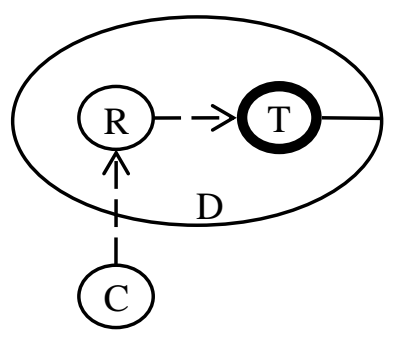

(b) Possessivo TER

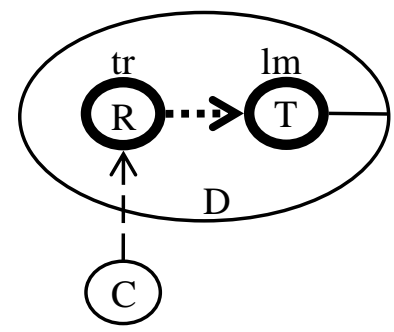

(c) Possessivo SER

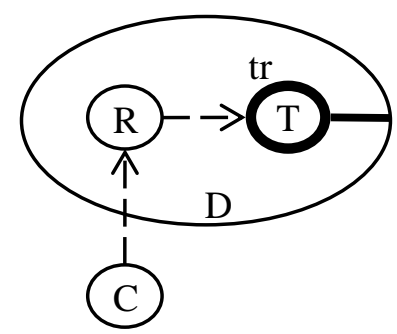

Figura 4.2 - Distinção entre possessivos a partir da Análise do Ponto de Referência

Na Figura 4.2, um possessivo nominal se caracteriza por perfilar uma coisa, enquanto um possessivo oracional perfila um processo, indicado pelos círculos e a seta entre $\mathrm{R}$ e $\mathrm{T}$, mais espessa. A seta tracejada entre R e T nas figuras acima indica o controle de $\mathrm{R}$ sobre $\mathrm{T}$, característica semântica de um possessivo. Uma entidade é possuída quando está sob controle, 
físico, experiencial ou social por outra entidade. Na Figura 4.2(c), as línguas que fazem uso de cópula ou de verbos comitativos para a expressão de posse têm o seu ponto de referência com um papel mais passivo. O Alvo T continua sendo acessado via $\mathrm{R}$, mas este exerce um papel mais tênue, sendo assim T é o elemento perfilado assumindo o estatuto de um trajetor (TR).

De uma representação altamente esquemática das relações de pontos de referênia, conforme apresentado na Figura 3.1, no Capítulo 3, até as diferentes instanciações de possessivos das figuras acima decorrem outros processos cognitivos como arraigamento (entrenchment) e subjetivização da experiência (Langacker, 2009, p. 2-3, 85), ${ }^{10}$ que fogem do escopo desta breve discussão.

Para um resumo de como Langacker encara a possibilidade da relação entre possessivos, locativos e existenciais, transcrevemos abaixo as palavras do autor:

No domínio oracional, possessivos do tipo "TER" e "SER" são distinguidos pela escolha do sujeito. Construções possessivas do tipo "TER" são caracterizadas pelo possuidor (R) funcionando como sujeito, o possuído (T) como objeto. Como descrito em Gramática Cognitiva, os sintagmas nominais de sujeito e objeto codificam respectivamente o trajetor e o marco da relação perfilada, isto é, os participantes focais primário e secundário. Por contraste, o possessivo do tipo "SER" escolhe T como seu sujeito, sem objeto direto. O possuidor é expresso de alguma outra maneira, tipicamente como um objeto indireto ou o objeto de uma adposição [...]. Essas diferenças gramaticais refletem a origem diacrônica das construções de posse predicativa. Os dois tipo básicos de possessivos derivam de construções baseadas em arquétipos conceituais distintos. Suas extensões para usos possessivos mais gerais envolvem processos de gramaticalização e subjetivização. (Langacker, 2003, p. 7) ${ }^{11}$

Portanto, as diferenças entre línguas que fazem uso de verbos derivados historicamente de verbos de ação (no esquema de ação de Heine) e das línguas que fazem uso de cópula para posse (os tipos de possessivos locacionais, existenciais e comitativos de Stassen) estariam em jogo com operações cognitivas que têm como base conceitual comum a habilidade de utilizar um ponto de referência para atingir mentalmente uma outra entidade em um domínio específico. Nas palavras do autor:

\footnotetext{
${ }^{10}$ Para arraigamento "entrenchment" (Lit. entrincheiramento) entende-se como o estabelecimento de unidades linguísticas que se tornam padrões cognitivos ou rotineiros. Subjetivização é um processo similar ao da gramaticalização (Cf. Langacker, 2000).

11 "In the clausal realm, HAVE- and BE-type possessives are distinguished by their choice of subject. HAVEpossessive constructions are characterised by the possessor (R) functioning as subject, the possessed (T) as object. As described in Cognitive Grammar, the subject and object nominals respectively code the trajector and landmark of the profiled relationship, i.e. the primary and secondary focal participants. By contrast, a BEpossessive chooses $\mathrm{T}$ as its subject, with no direct object. The possessor is expressed in some other manner, typically as an indirect object or the object of an adposition [...]. These grammatical differences reflect the diachronic origins of clausal possessive constructions. The two basic types derive from constructions based on distinct conceptual archetypes. Their extension to general possessive use involves grammaticization and subjectification."
} 
Se a afinidade entre construções possessivas e locativas/existenciais não reside em uma origem diacrônica comum, nem em uma estrutura profunda comum, a que então podemos atribuí-la? A resposta já deve ser aparente pela discussão e análises apresentadas: possessivos e locativos compartilham uma caracterização conceitual abstrata baseada na habilidade do ponto de referência. [...] Essa habilidade abstrata em comum é a ligação que permite construções locativas de serem usadas para possessivos e vice-versa. (Langacker, 2009, p. 103) ${ }^{12}$

Por enquanto apresentamos apenas as ideias básicas de como o domínio de possessivos é encarado no arcabouço da Linguística Cognitiva. Mais adiante nos deteremos nos detalhes dos construtos teóricos utilizados por Langacker para a sua análise de possessivos, locativos e existenciais para em seguida, apresentarmos a nossa análise para o comitativo.

\subsection{As diferentes abordagens teórico-metodológicas e uma postura epistemológica}

Os trabalhos resenhados neste capítulo mostram as tentativas de estudiosos de diferentes posicionamentos teóricos e metodológicos de lidar com as relações entre as construções possessivas, locativas e existenciais, enquanto outros focalizaram mais o papel do comitativas. Desde os primeiros trabalhos iniciados nas décadas de 1960 a 1970, as tentativas foram de buscar um denominador comum entre todas as construções que apresentavam similaridades significativas. Fazemos agora uma apreciação do conjunto dos trabalhos apresentados nas seções anteriores, buscando organizar os resultados de cada abordagem de acordo com uma postura epistemológica pluralista (Feyerabend, 2007) e que será tema do Capítulo 5.

4.5.1 Gramaticalização, incorporação e construções de pontos de referência

Dentre as quatro principais estratégias de posse predicativa nas línguas do mundo, três fazem uso de construções intransitivas e uma possui uma configuração transitiva. Do exame da literatura sobre a tipologia das construções possessivas e das relações dessas com locativos e existenciais, verificamos que pelo menos três abordagens teóricas se destacam sobremaneira

\footnotetext{
12 "If the affinity between possessive and locative/existential constructions does not reside in a common diachronic origin, nor in a common underlying structure, to what can we attribute it? The answer should already be apparent from the foregoing discussion and analyses: possessives and locatives share an abstract conceptual characterization based on the reference point ability. (...) This abstract commonality is the link permitting locative constructions to be used for possession, and conversely."
} 
à questão, os estudos sobre gramaticalização, representados por Heine (1997), os da linha gerativista, representado por Freeze (1992), e o arcabouço cognitivista, na figura de Langacker (2003). A abordagem de gramaticalização é capitaneada por Heine (1997) e como foi assunto de outro capítulo, não nos deteremos em pormenores aqui. É necessário, no entanto, recapitular os alcances e limites dessa abordagem. Iniciamos com as observações de Evans e Green (2007, p. 714) que denominam a abordagem de Heine como uma "Abordagem de Extensão Metafórica" (Metaphorical Extension Approaches). Nessa abordagem o processo de gramaticalização é entendido como uma extensão metafórica, um mapeamento de conceitos esquemáticos e imagéticos de formas menos concretas para formas mais abstratas, indo de conceitos-fonte básicos (basic source concepts) para conceitos-alvo (target concepts) mais abstratos. Nesse sentido, o construto de Esquemas de Evento se adéqua bem aos pressupostos da gramaticalização, respeitando o princípio da unidirecionalidade advogado pelo autor. Nessa perspectiva, o domínio de possessivos só comprova ser bastante abstrato, mas não deixa de ter uma origem e uma base corporificada (embodiment) que ao mesmo tempo une os conceitos-fonte.

A abordagem de Heine tem sido bastante influente, pelo menos nos trabalhos funcionalistas e cognitivistas (Baron; Herslund; Sorensen, 2001) e tipológicos voltados para o estudo de línguas sinalizadas (Zeshan; Perniss, 2008). No entanto, a proposta do arcabouço teórico da gramaticalização encara algumas limitações conceituais. Um ponto a ser mencionado é a já clássica hierarquia dos domínios conceituais que servem de fonte para o caminho de gramaticalização encontrada em Heine, Claudi e Hünnemeyer (1991, p. 48). Essa mesma hierarquia é diagramada de forma diferente por Evans e Green (2006, p. 715), reproduzida abaixo: 


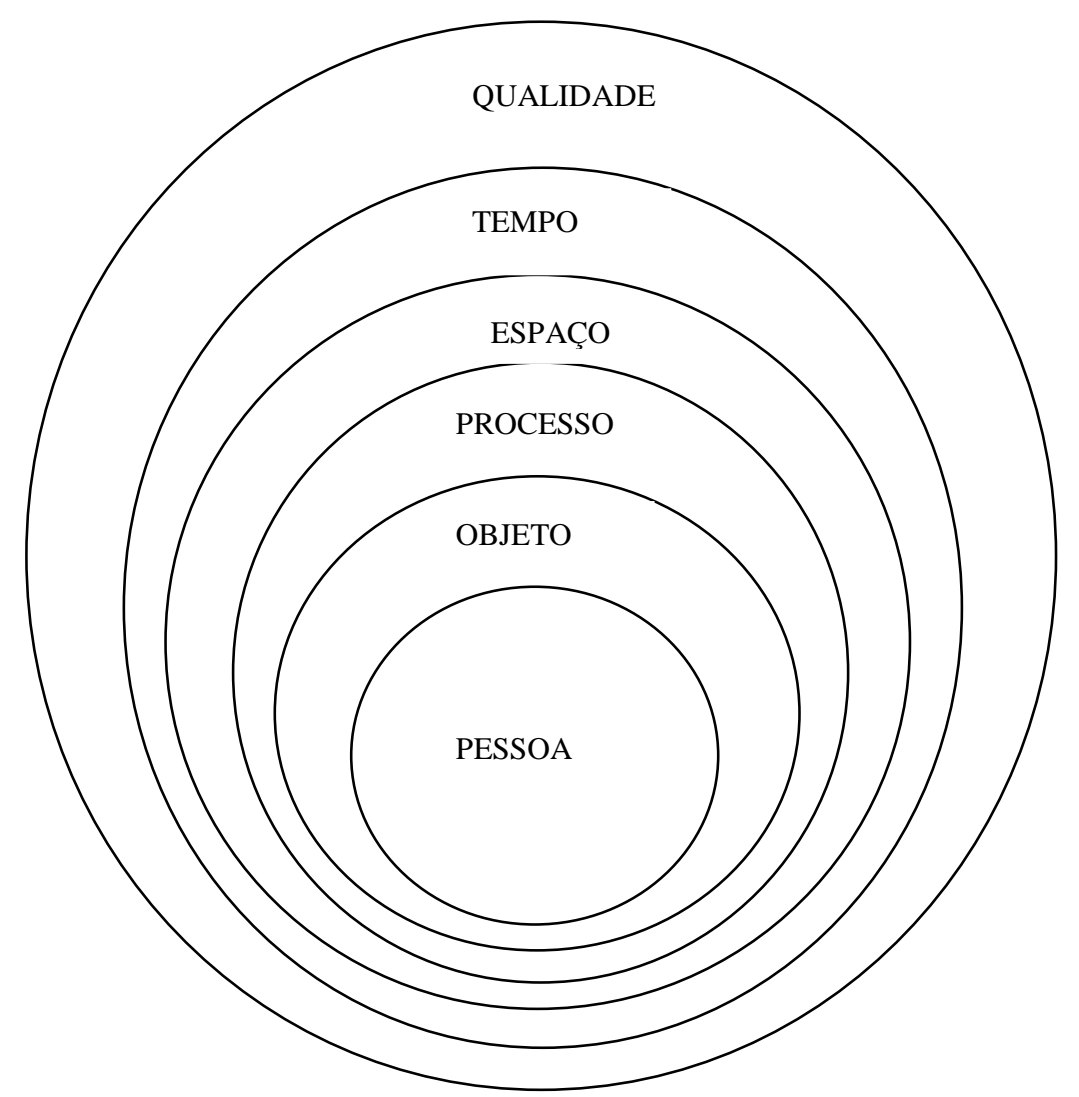

Figura 4.3 - Hierarquia de domínios-fonte (Evans; Green, 2006, p. 715)

Não discutiremos os pormenores da hierarquia proposta pelos autores, mas chamamos a atenção para a observação feita por Evans e Green (2006, p. 715) sobre a dificuldade de localizar na hierarquia de Heine e associados o próprio domínio de POSSE, que para estes autores deveria ficar à direita de ESPAÇO. Com isso, Heine (1997) em seu trabalho tipológico recorre ao construto de Esquemas de Evento, como forma de indicar a não centralidade de um único domínio-fonte. Os Esquemas de Evento têm em comum apenas o caráter mais "concreto" em relação ao de possessivos. Outra observação a ser guardada é a preocupação diacrônica dos trabalhos na linha dos pressupostos da gramaticalização.

Com o uso de um aparato formalista, Freeze (1992) oferece uma proposta simples, mas teoricamente dependente para a complexidade das construções em questão. Talvez o principal problema da abordagem formalista de Freeze seja sua tentativa de generalização tipológica a partir de uma operação sintática, a incorporação, para todos os casos de construções de posse predicativa. Os exemplos das línguas da amostra selecionada por ele têm um sério enviesamento, grande parte das línguas do seu estudo faz uso basicamente da estratégia locativa, ou seja, são línguas de possessivos locacionais, outras de possessivos 
existenciais ou de tópico, na terminologia de Stassen (2009), como demonstrado com os exemplos do russo, hindi, tagalog, etc. A solução encontrada pelas abordagens formalistas para manter o Paradigma Localista, para a qual todas as construções possessivas são na verdade locativas em uma estrutura profunda, acabam por tornar a operação que faz o "casamento" conceitual entre locativos, existenciais e possessivas como o principal ponto de discordância entre os estudiosos. Nesse caso, a operação de incorporação, da forma como proposta inicialmente por Freeze (1992), tem levantado diversos questionamentos sobre até que ponto essa operação pode dar conta de todas as construções possessivas nas línguas do mundo e não só para as línguas de possessivos locacionais.

Olhando sob outro ângulo, o Paradigma Localista gerativista parece cair em uma tautologia: partir da constatação que existenciais são relacionados a locativos, e que da mesma forma possessivos são relacionados a locativos, e para esta última constatação ter que recorrer a processos sintáticos como o de incorporação de $\mathrm{P}=>\mathrm{COP}$ acaba por ensejar o contrário do que deveria ser. Da observação de que línguas de possessivos locacionais podem passar por processos de incorporação, como descrito originalmente por Baker (1988), o processo de incorporação, entendido apenas como movimento de núcleos, faz com que a incorporação seja usada como a única e suficiente justificativa que demonstraria a união conceitual entre possessivos com existenciais e locativos. Resulta disso o fato de tornar a relação entre os domínios conceituais muito dependente de uma operação sintática sem uma base empírica condizente com todos os fenômenos observados nas línguas do mundo, isso para uma proposta que se quer suficientemente geral para ser aplicada a todos os possíveis casos. É, porém, necessário apontar que o processo de incorporação, como proposto por Baker (1988) realmente acontece em algumas línguas. Tal evidência é pautada no fenômeno descrito por Stassen (2009) e chamado por ele de transitivização. Em rápidas palavras, Stassen demonstra que as línguas que utilizam construções intransitivas para possessivos, as de possessivos locacionais, de possessivos de tópico e de possessivos comitatvos, podem vir a criar um verbo com propriedades transitivas, fazendo com que o possuidor nessas línguas ganhe atributo de sujeito, enquanto o possuído ganha traços de um objeto direto, como em uma construção transitiva prototípica. Desses três caminhos de transitivização, interessa por agora o que ocorre para línguas de possessivos locacionais, para as quais Stassen (2009) descreve a possibilidade de categorias funcionais incorporarem na cópula produzindo verbos do tipo “ter”, o que é condizente com o que Freeze (1992) postula para seu Paradigma Localista. Não deixa de ser interessante a forma como Stassen descreve a particularidade da transitivização em línguas de possessivos locacionais: 


\begin{abstract}
Portanto, no curso de uma mudança de um possessivo de tópico-locacional para um Ter-possessivo, o sintagma locacional pronominal é incorporado em um verbo do tipo ser. O resultado final é uma combinação da marca de locativo e o verbo do tipo ser existencial que é reanalisado como um item verbal monomorfêmico. Esse item toma um estatuto transitivo, tomando o possuidor como seu sujeito e o possuído como seu objeto. Em outras palavras, línguas que passaram por esse caminho de gramaticalização até sua conclusão criaram um novo verbo do tipo ter. (Stassen, 2009, p. 232) (Grifo nosso) ${ }^{13}$
\end{abstract}

A semelhança do processo de transitivização descrito por Stassen acima para as línguas de possessivos locacionais é sem dúvida bastante similar ao da análise unitarista de Freeze (1992), guardadas as devidas particularidades. O que os achados tipológicos de Stassen podem indicar é que o Paradigma Localista desenvolvido por Freeze (1992) pode ter sido apenas um pequeno erro de generalização. Tomar como parâmetro os casos de transitivização de línguas de Possessivos Locacionais para todos os demais tipos de possessivos, tanto possessivos comitativos como os de tópico, é desconsiderar as particularidades conceituais e estruturais que as línguas empregam para a expressão de uma mesma relação, mesmo que por meio de domínios conceituais distintos. Pelas evidências apontadas por Stassen (2009), línguas de possessivos locacionais podem, sim, criar um novo verbo do tipo "ter", o problema com esse fenômeno é o de aplicar para outros processos de criação de verbos do tipo "ter", uma mesma operação abstrata de incorporação de $\mathrm{P}=>\mathrm{COP}$. Um ponto crucial a ser discutido com essas últimas observações é de que, dentro de todas as possibilidades, a Hipótese Localista não se mantém caso o domínio do comitativo, exemplificado com as línguas bantas, seja considerado.

Seria interessante traçar uma história do processo de incorporação em teorias linguísticas, desde a sua primeira aplicação por Baker (1988), inicialmente utilizando-a como uma ferramenta para explicar vários fenômenos sintáticos, como causativos, até sua aplicação às construções possessivas com Freeze (1992) e seus desenvolvimentos posteriores e debates. As línguas bantas tiveram um papel importante para a proposta de incorporação de preposição de Baker, mas depois da aplicação para possessivos de Freeze (1992) o termo incorporação passou a ser entendido apenas como um processo sintático, de movimento de núcleos, para o

\footnotetext{
13 "Thus, in the course of the shift from a Topic-Locational Possessive to a Have-Possessive, the pronominal locational phrase gets incorporated into the $b e$-verb. A final result is that the combination of the locational marker and the existential $b e$-verb is reanalyzed as a monomorphemic verbal item. This item then gets transitive status, taking the possessor as its subject and the possessee as its object. In other words, languages which have run this grammaticalization path to its conclusion have created a new have-verb."
} 
qual qualquer contraevidência é deixada às margens. ${ }^{14}$ É possível que nas línguas bantas o processo de incorporação funcione de forma diferente de línguas de possessivos locacionais e existenciais, ou até mesmo nem seja tão necessário,como deve ser o caso também para as línguas que possuem uma estratégia transitiva para a expressão de posse predicativa. Neste caso, um processo de incorporação de $\mathrm{P}=>\mathrm{COP}$ para dar como resultado um spell-out "have" ou "ter"; para o caso do português, torna-se um pouco mais complicado se adotado como uma operação válida para todas as línguas, independente das suas preferências tipológicas. ${ }^{15}$

A abordagem da Gramática Cognitiva de Langacker (2008) busca também em um único construto teórico a ligação entre as diferentes instanciações das construções possessivas. Suas conclusões são as que tomam um posicionamento mais abstrato, pautada grandemente nas relações de pontos de referência (a partir daqui nos referiremos à aplicação de Langacker como Análise do Ponto de Referência, para a diferenciarmos dos mais diferentes tipos de relações de pontos de referências estudados nas ciências cognitivas). Frente à proposta cognitivista de Langacker, seria uma boa pedida uma análise empírica mais fundamentada, considerando os diferentes processos cognitivos de construal, empregados na Gramática Cognitiva. Poderia ser que, de certa forma, achados empíricos como os de Stolz e associados possam aprimorar a análise conceitualista conduzida por Langacker. Como vimos, em Stolz, Stroh e Urdze (2006) o comitativo é parte central do estudo, no entanto, a preocupação dos autores é a de sistematizar os diversos sincretismos encontrados nas línguas, deixando o cerne da questão do porquê esses sincretismos ocorrerem para autores mais (pre)ocupados com essas questões de conceitualização, que seriam então os cognitivistas mais alinhados à linha de anáise de Langacker e Talmy. Para esse caso, os linguistas cognitivistas teriam mais a ganhar se tomassem os resultados de trabalhos tipológicos mais seriamente, fazendo jus ao título de Gramática Cognitiva como teoria baseada no uso.

Boa parte de todas essas considerações delineadas aqui tem como propósito mais específico chamar a atenção dos estudiosos para a importância de uma das estratégias utilizadas pelas línguas para a expressão de possessivos, o domínio conceitual do comitativo.

\footnotetext{
${ }^{14}$ Indicamos o trabalho de Li (2005, p. 45) para uma crítica à proposta de incorporação de preposição de Baker (1988).

${ }^{15}$ Os trabalhos resenhados nas seções anteriores, de Blaszczak (2009), Levinson (2011) e Jung (2011) são bons exemplos do debate sobre a necessidade ou não da operação de incorporação para o caso de línguas que utilizam cópula ou construções intransitivas para possessivos.
} 


\subsection{Um lugar para o comitativo: casando as tipologias com os debates sobre possessivos e domínios relacionados}

Em termos tipológicos, a estratégia prototípica para a expressão de posse predicativa nas línguas bantas é a construção de cópula associada ao uso de uma partícula de valor comitativo, conforme bem atestado pelos trabalhos de Heine (1997) e Stassen (2009). Na terminologia de cada autor, diríamos que a maioria das línguas bantas segue o Esquema de Evento de companhia, nas palavras de Heine, ou que são línguas de possessivos comitativos, na terminologia de Stassen. Uma rápida olhada nos títulos dos trabalhos voltados para a relação entre os domínios conceituais relacionados a possessivos demonstra sem grandes dificuldades a quase que total ausência do comitativo nos debates sobre a base conceitual de posse predicativa (Clark, 1978; Freeze, 1992; Kayne, 2000; Langacker, 2009), excetuando o trabalho tipológico de Stolz, Stroh e Urdze (2006) que é voltado justamente para o domínio do comitativo. Ainda assim, o trabalho desses autores é dedicado quase que exclusivamente às línguas da Europa. Sem dúvida, parte do motivo da ausência do comitativo nos debates sobre possessivos se dá pela preferência de utilização de línguas de possessivos locativos, ou possessivos de tópico para tentar explicar as línguas que usam verbos (semi)transitivos, equivalentes a ter do português ou have do inglês para a expressão de posse predicativa. Línguas que utilizam a estratégia de possessivos comitativos são marginalmente citadas ou analisadas. Esse cenário se mostra intrigante se levarmos em conta que o domínio do comitativo está intimamente relacionado ao de possessivos, sendo mesmo bastante expressivo nas duas principais tipologias de posse predicativa, discutidas no capítulo 3 (Heine, 1997; Stassen, 2009).

Fora alguns poucos trabalhos como os de linha tipológica de Stolz (2001) e Stolz, Stroh e Urdze (2006), o comitativo não parece representar um bom candidato a dividir as descrições e análises sobre a relação entre possessivos com locativos e existenciais. Mesmo quando o comitativo é identificado entre as estratégias para posse predicativa, como é o caso da estratégia comitativa em português (estar com), os autores tratam do valor semântico de comitativos como uma espécie de locativo (Avelar, 2009a considera a preposição com do português como PP locativo). O trabalho do cognitivista Langacker (2009, p. 103) não é diferente. O autor inclui a preposição with do inglês como uma das alternativas "locativas" para possessivos locacionais (Langacker, 2009 , p. 103). Tal posicionamento não deixa de ter reflexo até mesmo em manuais de linguística voltados para trabalhos de campo, como em Thomas Payne: 
Pode parecer estranho o possuidor em uma oração possessiva ser considerado um locativo, mas quando você pensa sobre isso, é o que um possessivo é: quando você possui algo, ela está literalmente ou figurativamente localizada "sobre", “em” ou "com" você. [...] muitas línguas prestam atenção gramaticalmente para essa similaridade cognitiva tal qual os possuidores são tratados formalmente da mesma forma que locativos. (Payne, T., 1997, p. 122) ${ }^{16}$

Talvez o trabalho mais próximo do que está sendo pretendido aqui seja o de Lisa Levinson (2011), que parte de dados do islandês e sua estratégia comitativa para possessivos. No entanto, a crítica da autora se dirige mais precisamente à caracterização da categoria $\mathrm{P}$ nos trabalhos formalistas e a natureza dos processos de incorporação. Vale citar a seguinte constatação da autora: "Línguas que têm possessivos de companhia envolvendo preposição têm sido pouco discutidas na literatura sobre TER, apesar do fato de que essas construções se assemelharam muito mais as de TER.” (Levinson, L. 2011, p. 363). ${ }^{17}$

Tal constatação torna-se mais curiosa se considerarmos que a estratégia comitativa é uma das mais representativas estatisticamente nas tipologias de posse predicativa (Heine, 1992; Stassen, 2009), depois da estratégia locativa, tendo no grupo das línguas bantas suas maiores representantes. Basicamente, uma área geográfica significativa do continente africano tem no comitativo a principal estratégia para construções possessivas, no entanto, os trabalhos voltados para a relação entre possessivos e outros domínios conceituais se restringem aos domínios dos locativos e existenciais. Os trabalhos tipológicos de Stolz (2001) e Stolz, Stroh e Urdze (2006) tomam o comitativo como foco da análise, mas também se restringem ao papel semântico do Comitativo principalmente em relação ao de Instrumento. Até mesmo na discussão sobre possessivos e outros domínios, Heine (1997, 4.4) se restringe àqueles discutidos na literatura e nada menciona sobre a significância do comitativo. A questão óbvia a que se pode chegar com essas constatações é a de como seriam os resultados ou direcionamentos dos debates sobre possessivos se o comitativo fosse levado em conta mais seriamente? Nesta tese, essa é uma das principais questões, trazer para o palco de debates sobre possessivos o papel do comitativo na sua relação com possessivos, locativos e existenciais, e com ele a contribuição das línguas bantas para o refinamento dessas discussões. Produzimos assim, um casamento dos resultados tipológicos sobre possessivos com os

\footnotetext{
16 "It may seem odd that the possessor in a possessive clause is considered to be a location, but when you think about it, that is what possession is: when you posses something it is literally or figuratively located "on", "at", or "with" you. [...] many languages pay attention grammaticaly to this cognitive similarity in that possessors are treated formally the same as locations."

17 "Languages that have companion possession involving prepositions have been little discussed in the literature on HAVE, despite the fact that these constructions much more closely resemble HAVE."
} 
resultados dos debates teóricos sobre a relação entre as construções possessivas com locativas e existenciais.

Uma primeira mudança a ser produzida nessa nova perspectiva seria que não mais apenas a tríade Locativos-Existenciais-Possessivos deveria ser considerada, mas o quarteto Locativos-Existenciais-Comitativos-Possessivos, atentando para as quatro principais estratégias para a expressão de posse predicativa nas línguas do mundo. Heine (1997, p. 222) refere-se justamente a essas quatro "formas elementares de expressão da experiência". Outra mudança esperada seria o que Lisa Levinson (2011) demonstra com os dados de uma língua que usa uma estratégia comitativa para possessivos, a de que os dados do islandês vão contra um paradigma localista forte, nas linhas de Freeze (1992). Nesse caso, mesmo que os autores continuem adeptos de algum tipo de "unitarismo" formalista, mesmo o mais flexível, como o que segue nas linhas de análise de Kayne (2000), atentar para o comitativo, de certa forma, tira a centralidade do locativo/existencial nas análises sobre possessivos e seus domínios conceituais. A esse respeito, as línguas bantas tornam-se um terreno fértil para testar os limites do paradigma localista, pautado principalmente no processo de incorporação.

Podemos apontar como uma diferença básica entre nosso trabalho e os demais que se ocuparam das construções possessivas em relação com as construções locativas e existenciais, o papel primordial do domínio conceitual do comitativo no conjunto das principais estratégias utilizadas pelas línguas naturais para a expressão de posse predicativa. Acreditamos que um melhor entendimento da relação entre possessivos, existenciais e locativos só se dará com a participação do comitativo, completando assim o quadro dos domínios conceituais de possessivos.

\subsection{Em síntese}

Frente a essa diversidade de abordagens sobre o mesmo tema, acabamos por encarar alguns questionamentos epistemológicos sobre o posicionamento teórico a que deveríamos adotar. Tendo em mente os objetivos de descrever as construções locativas, existenciais, e possessivas em línguas bantas sem esquecer a importância do comitativo para essas línguas, e o caráter conceitual das relações existentes entre essas construções, uma primeira alternativa seria a de abordar as construções focalizadas a partir de uma base conceitualista de linguagem.

A abordagem cognitivista nos pareceu mais adequada para tal empreendimento, por compartilharmos de alguns dos seus pressupostos como a base simbólica da linguagem e a 
abordagem da língua baseada no uso (usage-based approach). A abordagem cognitivista se coaduna bem com o posicionamento de Heine (1997, p. 205) para quem: "[... ] posse, da forma como encontramos no discurso linguístico, não é um domínio independente e autocontido, mas sim um domínio que exibe um número de relações sistemáticas com outros domínios da conceitualização humana." (Heine, 1997, p. 234). ${ }^{18}$ Concordando com essa afirmação, decidimos enfatizar o caráter cognitivo das relações entre possessivos e os demais domínios conceituais, o que nos levou a buscar em uma abordagem cognitivista de gramática os dos processos de conceitualização que serão úteis para uma analise conjunta dos quatro domínios em questão, foco do Capítulo que segue.

18 “... possession, as we encounter it in linguistic discourse, is not an independent and self-contained domain, but rather exhibits a number of systematic relationships with other domains of human conceptualization." 


\section{CAPÍtulo 5}

\section{Domínios Conceituais de possessivos e a Análise do Ponto de REFERÊNCIA}

\subsection{Apresentação}

Trataremos neste capítulo, com mais detalhes, dos quatro domínios conceituais foco de nosso estudo, os de localização, existência, companhia e posse para então buscarmos as suas relações com as construções existenciais, locativas, comitativas e possessivas. Uma motivação para um capítulo voltado para uma caracterização conceitual mais refinada para cada domínio se deve ao fato de que os estudos que trataram das relações entre locativos, existenciais e possessivos (Cf. Capítulo 4) tomam as categorias semânticas como dadas e nenhuma tentativa de refinamento descritivo ou explicativo é perseguido. O objetivo então é o de examinar cada domínio conceitual individualmente para que depois sejam verificadas como se dão as ligações conceituais existentes entre elas e os processos cognitivos envolvidos nessas relações.

No capítulo anterior, apresentamos algumas abordagens teóricas que se ocuparam das construções possessivas em sua relação com as construções locativas e existenciais, e de certa forma com as construções comitativas. Para cada construto teórico adotado pelos estudiosos, em seus argumentos e hipóteses, a problemática da relação de possessivos com outros domínios conceituais foi considerada como solucionada e, para cada solução, o arcabouço teórico escolhido por seus proponentes foi advogado como a melhor alternativa para o quadro de fenômenos em estudo. Adotar quaisquer daquelas orientações teóricas poderia nos levar possivelmente a resultados semelhantes, mesmo incluindo um quarto domínio conceitual nos debates anteriormente já concluídos, nesse caso, o do comitativo. Cada arcabouço teórico, no entanto, tem suas limitações e cientes disso foi que tentamos solucionar nossos questionamentos epistemológicos, como já mencionado algumas vezes. Este capítulo servirá para apresentarmos nosso posicionamento na forma como encaramos o estudo dos domínios conceituais de posse predicativa. Acreditamos que para tratar da relação de possessivos com outros domínios conceituais é necessário que se faça uma análise atenta de cada domínio conceitual em particular, a fim de que a análise não fique tão enviesada por se focalizar apenas alguns detalhes de um quadro mais amplo e complexo. Partindo desta justificativa, um leque bem maior de fenômenos relacionados às quatro construções estudadas pode se abrir, 
apontando para outras construções que aparentemente não teriam nenhuma relação com possessivos, como o caso das construções de localização, origem e destino de um percurso ou o papel semântico de Instrumento. O fio condutor para a análise cognitiva dos domínios serão os construtos propostos na Gramática Cognitiva de Langacker (1987; 1991; 2000; 2002; 2008; 2009).

Devemos enfatizar que mesmo tomando uma teoria em particular, adotamos uma postura epistemológica que, acreditamos, se coaduna bem com a perspectiva desejada para este trabalho, postura essa que exemplificaremos com um capítulo da linguística brasileira que ficou conhecido como o debate do "linguista-camaleão", pano de fundo que utilizaremos para exemplificar nosso posicionamento epistemológico, tema das próximas seções.

\subsection{Construtos teóricos, metodologias e anarquismo epistemológico}

\subsubsection{Um linguista-camaleão feyerabendiano}

Incluir na tese uma parte voltada para assuntos epistemológicos merece alguns esclarecimentos. Conforme já mencionado, a divisão desta tese em três partes buscou seguir os principais questionamentos que acompanharam os desenvolvimentos e (re)direcionamentos desta pesquisa. Para realizar os objetivos de descrição linguística para a qual nos propusemos, encaramos a necessidade de nos posicionar criticamente em relação aos arcabouços teóricos e suas metodologias para lidar com os possessivos. Uma alternativa a qual poderíamos seguir seria a postura deliberada de não recorrer, a priori, a nenhuma orientação teórica dentre as diversas opções no mercado de teorias linguísticas. ${ }^{1}$ Para este último caso, os linguistas geralmente se identificam como descritivistas, optando por um direcionamento tipológico ou em outras situações se dizem seguidores dos pressupostos da "Teoria Linguística Básica" (Basic LinguisticTheory), como advogada por Dixon e outros (Dryer, 2006).

Talvez o posicionamento mais radical seja o de Haspelmath (2010) que acredita ser possível produzir descrições linguísticas livres de quaisquer arcabouços teóricos, sem o uso de conceitos pré-operatórios, uma "Teoria gramatical livre de enquadramentos" (Framework-free gramatical theory). Para ele, tal atitude é bem mais comum entre os linguistas do que se imagina. Uma postura livre de enquadramentos teóricos apriorísticos ofereceria menores riscos de enviesar a visão do linguista diante de qualquer fenômeno linguístico a ser estudado.

\footnotetext{
${ }^{1}$ A apropriação aqui do termo "mercado de teorias linguísticas" não tem nenhum sentido pejorativo, como poderia soar a princípio (Conferir as introduções dos dois volumes de Foundations of Cognitive Grammar (Langacker, 1987; 1991), mas na mesma perspectiva usada por Heine e Narrog (2010).
} 
Para Haspelmath, faz parte do conjunto de enquadramentos apriorísticos até mesmo a conclamada Teoria Linguística Básica. O autor chega a mencionar que a sua postura se aproxima à da Gramática de Construções Radical (Radical ConstructionGrammar) de Croft (2001), sobre a qual não entraremos em detalhes aqui. Os argumentos de Haspelmath podem até ser aplicáveis num contexto estritamente epistemológico, no entanto, em termos de política acadêmica é cada vez mais difícil ser totalmente isento de qualquer posicionamento teórico, mesmo que o posicionamento pretendido seja considerado ateórico².

Para o caso de nosso trabalho, que desde o início teve uma motivação de cunho teórico, ignorar os resultados e esforços empreendidos por outros pesquisadores que trataram das construções possessivas seria no mínimo ingênuo, portanto, não poderíamos desconsiderar os alcances e limites do que já havia sido feito antes por diversos estudiosos. Diante dessa situação, encaramos frequentemente a necessidade de justificar nossas escolhas teóricas, ao invés de simplesmente adotar uma postura dita mais neutra, e com isso, dita mais descritivistas, já que havíamos selecionado línguas bantas, línguas que contam com uma tradição de estudos descritivistas. Para um empreendimento de descrever as relações conceituais entre possessivos e domínios relacionados nessas línguas, víamos a toda hora a necessidade de justificar determinada teoria para a descrição e análise.

Frente a esses questionamentos e dilemas, tivemos uma boa surpresa de ver que essas mesmas questões já haviam sido o tema de um debate no cenário da linguística brasileira. $\mathrm{Na}$ década de 1980, a linguística brasileira se deparou com um debate que ficou conhecido como a do "linguista-camaleão", protagonizado de um lado por Fernando Tarallo (1986) e de outro por Borges Neto e Müller (1987). Tal debate, em síntese, apresentava a sugestão de Tarallo para um certo "descompromisso" por parte do linguista com a teoria ou modelo a que o mesmo se atém para desenvolver suas pesquisas linguísticas. Contrariamente, Borges Neto e Müller (1987) se opõem a esse "camaleão" que parece ser desnecessariamente "eclético", sem uma “fundamentação epistemológica mínima”. Em rápidas palavras, Tarallo queria demonstrar que o não comprometimento dogmático com determinada teoria permitiria ao linguista "ver mais" do que as lentes do seu arcabouço teórico permitiriam. A maior flexibilidade do linguista-camaleão não quer dizer que o mesmo seja perniciosamente

\footnotetext{
${ }^{2}$ Poderíamos iniciar neste ponto algumas considerações sobre como as decisões teóricas de estudiosos não deixam de ser, stricto sensu, decisões políticas, determinadas não raramente pelas exigências de instituições de fomento ou das teorias alinhadas como mainstream. Quanto a isso, apenas reiteramos que a linguística possui elementos interessantes para discussões epistemológicas, principalmente as feyerabendianas, que até o momento não mereceram a atenção de estudiosos da filosofia da linguística. Alguns desses pontos polêmicos podem ser encontrados em Borges Neto (2004).
} 
eclético, apenas o fato de não se deixar amarrar pelos dogmas teóricos de uma única teoria poderia permitir ao linguista olhar para fenômenos que possivelmente um comprometimento exacerbado com uma única visão obscureceria em certos pontos. Frequentemente as análises gerativistas são usadas como exemplo desse tipo de visão unilateral. Deve-se ter em mente que o inverso também pode funcionar. Às vezes, utilizar determinado construto teórico auxilia também a atentar para certas frações de um fenômeno que um olhar "descompromissado" demais possivelmente deixaria de considerar mais seriamente.

Frente a esse debate, percebemos que o linguista-camaleão de Tarallo era feyerabendiano, conscientemente ou não seguia alguns pressupostos do Anarquismo Epistemológico, conforme defendido pelo filósofo da ciência Paul Feyerabend, sistematizado na sua obra principal, "Contra o método" (2007 [1975]). A proposta de Tarallo, seguindo intuitivamente os insights da epistemologia feyerabendiana, apontou para a possibilidade de superar, numa certa medida, os dilemas que tivemos sobre a que teoria ou metodologia aderir para a realização da pesquisa. Se ligarmos a proposta do linguista-camaleão ao anarquismo epistemológico feyerabendiano, vemos que a proposta ousada de Tarallo não era tão sem uma “fundamentação epistemológica mínima”, como o acusaram Borges Neto e Müller. Levando a proposta de Tarallo um pouco mais longe, diríamos que uma postura epistemológica anarquista seria uma terceira via para o dilema de adotar ou não uma teoria ou assumir uma total isenção de escolhas teóricas apriorísticas. ${ }^{3}$ É possível, assim, adotar uma determinada teoria sem necessariamente ser dogmático.

Como já foi observado anteriormente, a forte tendência cognitivista desta pesquisa poderia entrar em contradição com a indicação de um anarquismo epistemológico. Deixamos explícito, porém que, mesmo que nossa orientação siga uma linha cognitivista, ainda assim buscaremos uma postura condizente com os pressupostos da epistemologia feyerabendiana, de acordo com o posicionamento do "camaleão-linguista" de Tarallo (1986) que aqui chamaremos de "linguista-camaleão". 4

\footnotetext{
${ }^{3}$ Para não ficarmos apenas com um caso brasileiro de linguista-camaleão, podemos considerar o posicionamento de Haspelmath (2010) tão radical quanto o de Tarallo, porém, no sentido diferente, mas não oposto. Diríamos que, continuando com as metáforas de répteis, para Haspelmath, os estudiosos da linguagem deveriam ser "linguistas-tiranossaurus rex", nas palavras de Pagotto (2000), ou seja, seriam predadores independentes de quaisquer teorias. Esse linguista seria então o maior de todos os predadores das teorias linguísticas concebíveis.

4 Argumentamos que tal postura seja possível apenas com outros ingredientes epistemológicos pouco mencionados nas ciências de estudos da linguagem, a "vigilância epistemológica", da forma como foi advogada para a Sociologia e outras ciências humanas (Bourdieu; Chamboredon. Passeron, 2000), no entanto, não nos deteremos a fundo sobre essas questões aqui.
} 
É preciso ressaltar que acreditamos que os pressupostos da linguística cognitiva permitem uma abertura maior com outras abordagens teóricas, tornando possível, assim, que reafirmemos nossa postura epistemológica desejada. Para tanto, trazemos a afirmação de Taylor ao tratar da relação da linguística cognitiva com outros ramos da linguística, notadamente com a linguística autônoma ou gerativista:

\begin{abstract}
À medida que a Linguística Cognitiva entra no mainstream (..) tornará-se cada vez mais anacrônico para ela mesma se enquadrar em termos de opositora para outras abordagens. Diálogo - e ouso sugerir, integração - com outras abordagens devem bem se tornar a ordem do dia. (Tayor, 2007, p. 283)
\end{abstract}

Guardando a especificidade do caráter convergente do empreendimento cognitivo em linguística, reafirmamos que tratar de construções como possessivos, locativos, existenciais e comitativos, em busca de suas relações conceituais, os pressupostos fundadores da linguística cognitiva oferecem um instrumental teórico mais atento aos aspectos semânticos e de conceitualização, inegavelmente envolvidos no significado de construções gramaticais, e que nem por isso deveremos deixar o diálogo com outras abordagens que se dedicaram às mesmas problemáticas.

\title{
5.2.2 Gramáticas cognitivas, descrição e análises linguísticas ${ }^{6}$
}

Após a justificativa de nosso posicionamento epistemológico, reiteramos que as abordagens cognitivas de gramática serão o carro chefe de nossa análise, porém, seguindo o espírito feyerabendiano indicado na figura do linguista-camaleão defendido por Tarallo (1986). Utilizar os construtos da Gramática Cognitiva (CG), extrapolando seus limites epistemológicos ao atentarmos para as mais diversas abordagens teóricas que se ocuparam das construções possessivas poderá trazer ganhos teóricos e descritivos. Podemos apontar algumas possibilidades a seguir.

\footnotetext{
5 “As Cognitive Linguistics enters the mainstream (...) it will become increasingly anachronistic for Cognitive Linguistics to frame itself in term of opposition to other approaches. Dialogue - and dare I suggest, integration with other approaches may well become the order of the day."

${ }^{6}$ Utilizamos "gramáticas cognitivas" (no plural) para indicar a possibilidade de desenvolvimento de outros modelos de gramáticas cognitivas nas quais a cognição tenha um papel crucial, da mesma forma que há diversos modelos de gramáticas de construção (Goldberg, 1995; Croft, 2001; Östman; Fried, 2004). Gramática Cognitiva (com inicial maiúscula) refere-se ao modelo de gramática desenvolvido por Langacker por cerca de quatro décadas, boa parte dela pautada nos construtos da semântica cognitiva (Talmy, 2000a; 2000b; Fauconnier; Turner, 2002; Lakoff; Johnson, 1980; Lakoff, 1987) e parte naquelas gramáticas de construção, notadamente na de Goldberg (1995).
} 
Tendo sido elaborada por mais de quatro décadas, a Gramática Cognitiva (GC), inicialmente chamada de Space Grammar, conta atualmente com um livro introdutório básico (Langacker, 2008) e diversas coletâneas (Langacker, 2009; 2002; 2000), mas teve com os dois volumes Foundations of Cognitive Grammar (Langacker, 1987; 1991) sua primeira apresentação mais refinada e formalizada. Nosso intuito aqui não é, porém, o de apresentar todos os construtos utilizados em GC. Restringimos nossa apresentação aos princípios básicos das teorias e suas estreitas aplicações para a caracterização conceitual das construções focalizadas por nós neste trabalho. O poder descritivo e explicativo da Gramática Cognitiva tem se mostrado em diversas áreas dos estudos linguísticos com categorias gramaticais que têm recebido uma caracterização conceitual que outras abordagens teóricas não puderam explorar em todas as possibilidades, e em parte por não estarem tão comprometidas com os fenômenos cognitivos em si. A CG tem obtido sucesso no cenário teórico em linguística justamente por isso, pelo fato de compartilhar de resultados obtidos em outras áreas das ciências cognitivas. Quanto à sua adequação descritiva, encontramos em Tuggy (2008) e Radden e Dirven (2007) dois exemplos da utilização do arcabouço teórico da CG para a descrição de uma língua indígena norte-americana e para o inglês, respectivamente ${ }^{7}$. Em linhas gerais, a GC compartilha com as gramáticas de construção a assunção de que a descrição linguística deve partir das unidades construcionais, entendidas em GC como uma unidade simbólica decorrente de dois polos, um polo fonológico e um polo semântico, ou do modo como são entendidas nas diversas gramáticas de construção, o pareamento formafunção (Langacker, 2009; 2008; Goldberg, 1995).

Na concepção da GC, a língua é um inventário estruturado de unidades linguísticas convencionais (Langacker, 2000; 1987; 2008), mais especificamente de unidades simbólicas, portanto, a gramática de uma língua é simbólica e é significado. Em última instância, a gramática é conceitualização (Langacker, 2008). Sendo conceitualização, as estruturas linguísticas compartilham de diversas operações cognitivas mais gerais da estrutura conceitual humana. Para darmos continuidade, nos ocupamos agora de alguns dos construtos teóricos da Gramática Cognitiva e suas implicações para a descrição de línguas bantas. Faremos algumas considerações quanto ao poder descritivo e explicativo dessa teoria ${ }^{8}$.

\footnotetext{
${ }^{7}$ O professor Ataliba de Castilho (c. p.) em diversas oportunidades tem demonstrado o interesse de ver uma primeira publicação de uma 'gramática cognitiva do português', a exemplo do trabalho de Radden e Dirven (2007) para o inglês. Em um relatório técnico ao Fundo de Amparo à Pesquisa de São Paulo-FAPESP, Castilho (Manuscrito) aponta algumas possibilidades para esse projeto.

${ }^{8}$ Nos primeiros cursos sobre gramática cognitiva dos quais participamos, não raramente ficávamos intrigados com a possibilidade de utilizar uma abordagem teórica tão voltada para questões semânticas e cognitivas para descrever estruturas gramaticais de difícil caracterização semântica, como fonemas e morfemas, estes geralmente
} 


\subsubsection{A base conceitual da gramática}

Dos diversos construtos teóricos desenvolvidos por Langacker, o da Análise do Ponto de Referência é apenas um primeiro passo que nos permitirá analisar os domínios conceituais de nosso estudo. A Análise do Ponto de Referênca de Langacker (2009) se mostra como a melhor caracterização, em termos conceituais, para caracterizar possessivos, locativos, dentre outras operações básicas.

Um bom começo para lidar com a conceitualização de locativos (LOC), existenciais (EXIST), comitativos (COM) e possessivos (POSS) é caracterizá-los em suas bases experienciais. Para isso, a noção de "domínio", como desenvolvida em Gramática Cognitiva (Langacker, 1987, cap. 4; Langacker, 2008, p. 44-54), nos dá uma primeira pista de como definir melhor o que estamos chamando de domínios conceituais. Nas palavras de Langacker (2008, p. 44-5): "Neles e por eles mesmos, domínios básicos não são conceitos ou conceitualizações. Eles são entendidos melhor como esferas de experiência em potencial, dentro das quais a conceitualização pode ocorrer e conceitos específicos emergem." ${ }^{\text {9 }}$ Quando pensamos em um domínio, automaticamente nosso conhecimento de mundo nos direciona a subdomínios ou outros domínios relacionados. Por exemplo, pensar em casamento é relacionar essa instituição social a diversos subdomínios como questões comportamentais, festas, vestido branco, igreja, etc. Esses tipos de relações são também chamados de Modelos Cognitivos Idealizados (Lakoff, 1987). Grande parte dos domínios conceituais são nãobásicos, constituindo-se assim como uma matriz de domínios. Para o caso do conceito de possessivos, dizemos que é uma matriz de domínios na qual entram outros subdomínios, ESPAÇO, TEMPO, FORÇA, CONTROLE. Nesta tese, quando nos referimos ao domínio conceitual de possessivos estamos reforçando a ideia de que esse domínio conceitual para ser tal como ele é vale-se de todo o corpo de conhecimento que temos a partir de uma base experiencial de outros domínios. Para o caso de possessivos, os outros domínios seriam os de locativos, existenciais e comitativos.

descritos como 'as menores unidades desprovidas de significado'. Com o passar do tempo, temos percebido a força heurística das orientações cognitivas nos estudos das línguas. Como um exemplo, citamos o trabalho de Nathan (2008) para uma primeira abordagem em fonologia sob os pressupostos da gramática cognitiva. Ungerer (2007) oferece um quadro de questões abordadas pela Gramática Cognitiva em áreas da morfologia.

9 "In and of themselves, basic domains are not concepts or conceptualizations. They are better thought of as realms of experiential potential, within which conceptualization can occur and specific concepts can emerge." 
Em Gramática Cognitiva, o conceito de domínio conceitual é um pressuposto básico a partir do qual os subsistemas gramaticais são codificados como também relacionados aos domínios básicos como ESPAÇO, TEMPO e DINÂMICA DE FORÇAS. Para tanto, processos cognitivos como a atenção e perspectivização são apontados como operações básicas para a elaboração e extensão de categorias gramaticais. Podemos reunir boa parte das operações cognitivas responsáveis pela estruturação do sistema linguístico no que Langacker chama de Construal, ou seja, a habilidade de conceber e representar uma mesma situação em maneiras alternativas (Langacker, 2008, p. 43). As operações de construal são geralmente classificadas com seguem (Langacker, 2008, Cap. 3; Verhagen, 2007, p. 53):

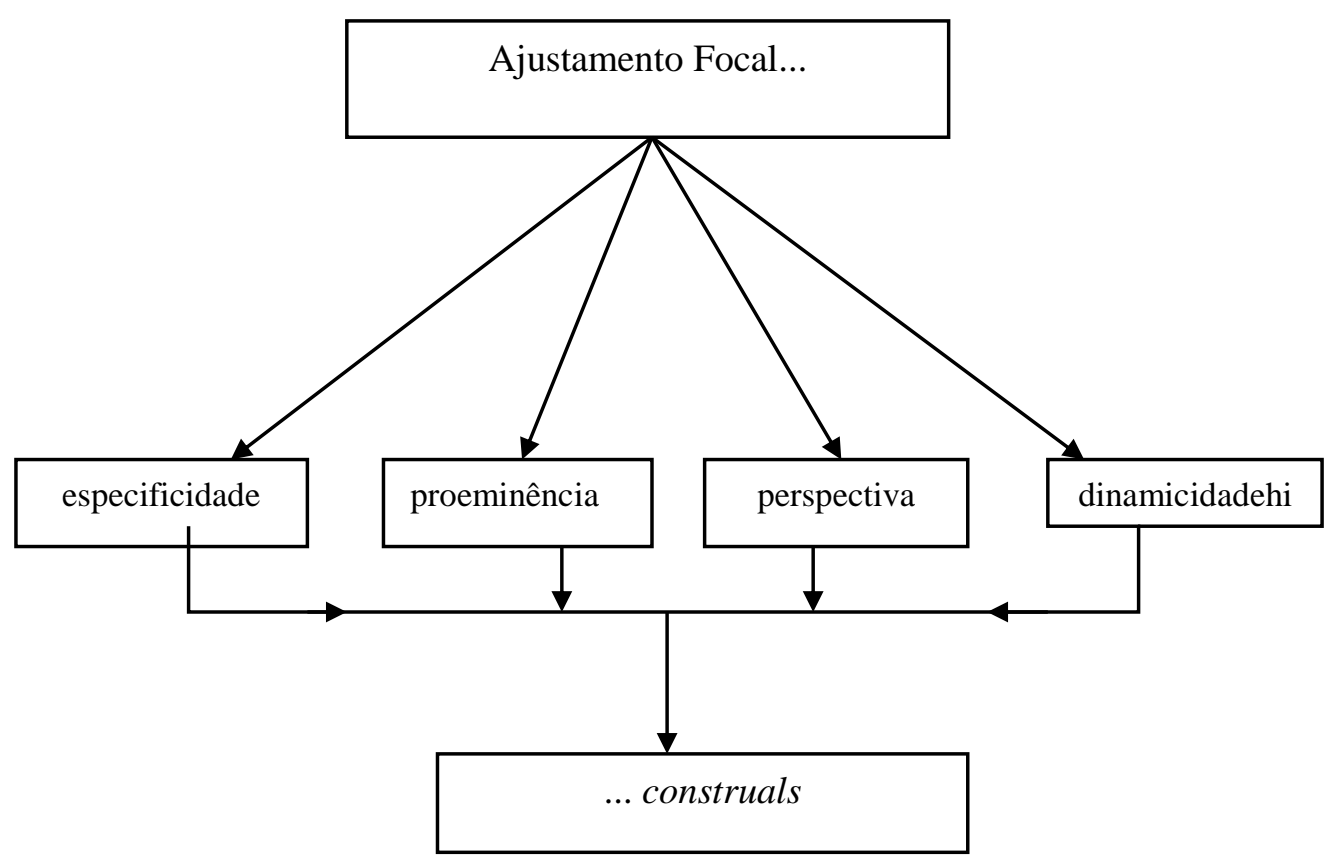

Figura 5.1 - Relação entre ajustamento focal e construal (Evans; Green, 2006, p. 537)

Em rápidas palavras, Especificidade é relacionada à categorização, a forma como operamos com nossas abstrações, de conceitos esquemáticos para conceitos mais específicos. Por exemplo, o conceito de [MAMÍFERO] é esquemático em relação ao de [GATO]. Proeminência compreende especialmente as operações pautadas nos fenômenos de Figura/Fundo, que em Gramática Cognitiva serve como base das operações de alinhamento entre um trajetor (TR), a entidade de foco primária, e o marco (MR), a entidade de foco secundário. Por exemplo, a proeminência dada ao TR é a razão da pouca aceitabilidade de certas expressões: 
(1) Alinhamento entre TR e MR (Langacker, 2008, p. 71)

a. Onde está a luminária?

(i) A luminária (TR) está em cima da mesa (MR).

(ii) *A mesa (TR) está em baixo da luminária (MR).

b. Onde está a mesa?

(i) A mesa (TR) está em baixo da luminária (MR).

(ii) A luminária (TR) está em cima da mesa (MR).

As operações de perspectivização têm a ver com o arranjo visual (viewing arrangement) realizado pelos conceitualizadores. Por exemplo, o falante conceitualizador pode escolher entre as expressões "o rio está localizado logo depois das casas" ou "as casas estão bem antes do rio". A Dinamicidade engloba o caráter temporal no desenvolvimento da conceitualização. A forma como as entidades de conceitualização são ordenadas é imprescindível para a distinção de certos conteúdos semânticos. Todas essas operações de construal auxiliam na determinação da organização cognitiva dos domínios conceituais e o modo como esses domínios servem como base para categorias gramaticais. Uma rápida explanação como essa apenas aponta para a complexidade das operações cognitivas subjacentes e inerentes de construções gramaticais, ao mesmo tempo em que se observa a arbitrariedade na classificação dessas operações (Croft; Cruse, 2004, p. 43-46) ${ }^{10}$.

\subsubsection{Caracterização conceitual de categorias relacionadas a possessivos}

Muitos dos construtos da Gramática Cognitiva podem oferecer parte da resposta dos processos cognitivos apontados por Heine como necessários para entender como se dão as relações entre domínios conceituais vizinhos. Nas palavras do autor: "Uma resposta significativa para esta questão (como se dá a relação entre possessivos e outros domínios), argumentamos, não é possível sem levar em conta os processos cognitivos em consideração

${ }^{10}$ Talmy, por exemplo, classifica em quatro subsistemas o seu Modelo de Sistemas de Estruturação Conceitual:

a. Sistema de configuração estrutural

b. Sistema atencional

c. Sistema perspectival

d. Dinâmica de forças

O Modelo de Talmy tem muitos pontos em comum com as operações de construal da Gramática Cognitiva, no entanto, para não tornarmos esta apresentação muito mais demorada, indicamos as discussões sobre o assunto em Croft e Cruse (2004, Cap. 3); Evans e Green (2006, Cap. 15) e Verhagen (2007). 
que são responsáveis por tal situação.” (Heine, 1997, p. 205) (grifo nosso) ${ }^{11}$. Mesmo que nessa citação o autor esteja se referindo aos processos cognitivos presentes nos processos de transferência conceitual entre Esquemas de Evento, é possível extrapolar o alcance desses processos cognitivos e trazer para a presente discussão diversos outros mecanismos de conceitualização na linguagem humana.

O interesse passa agora a ser não mais apenas a busca das motivações que permitem que possessivos se relacionem conceitualmente com locativos, existenciais e comitativos, como também o porquê de os falantes distinguirem muito bem essas construções entre si, apesar da grande semelhança entre elas. Em outras palavras, o que faz com que um falante de uma língua de possessivo locacional possa distinguir um locativo de um possessivo, ou para o caso de línguas bantas que usam a estratégia comitativa, a distinção entre uma construção comitativa de uma possessiva. Para encontrarmos as ligações é preciso que sejam observados os pontos de distinção, seguindo o posicionamento de Kemmer:

\begin{abstract}
Ao usar esta metodologia básica de comparar a relação forma-significado nas línguas do mundo para as muitas diferentes categorias gramaticais, nos permite examinar quais tipos de situações os seres humanos são mais propensos a juntar e quais eles são mais propensos a distinguir. Dessa forma, podemos ganhar um insight para quais tipos de propriedades de coisas e situações são significantes para a mente humana e então construir a base de categorias conceituais. Além disso, isso nos permite, por meio de análises semânticas, trabalhar precisamente as relações entre as categorias distinguidas. O resultado de tal investigação é uma rede de relações entre as categorias, um tipo de 'mapa semântico' dos domínios conceituais investigados (...). (Kemmer, 2002, p. 92) ${ }^{12}$
\end{abstract}

Sob essa perspectiva apontada por Kemmer, acreditamos que, para lidar com os domínios conceituais das construções locativas, existenciais, comitativas e possessivas, advogando uma postura cognitivista, é quase impossível não relacionar essas construções com os domínios de localização, existência, companhia e posse. Desse modo, pretendemos levar a cabo uma tentativa anterior de Pinheiro e Gerhardt (2004) e Pinheiro (2010a; 2010b), de apresentar uma base experiencialista e conceitual para a "representação semântica subjacente aos conceitos-chave" de "Posse", "Existência" e "Locação", nas palavras dos autores.

\footnotetext{
11 "A meaninful answer to this question, we argue, is not possible without taking the cognitive processes into consideration that are responsible for such situations."

12 "Using this basic methodology of comparing form-meaning relationships in the languages of the world for many different gramatical categories allows us to examine which kinds of situations human beings are likeliest to group together, and which they are likeliest to distinguish. In this way we can gain an insight into what kinds and properties of things and situations are significant for the human mind, and hence made the basis of conceptual categories. Futher, it allows us, through semantic analysis, to work out the precise relations between the categories distinguished. The result of such an investigation is a network of relations among categories, a kind of 'semantic map' of the conceptual domains investigated (...)."
} 
Conforme já antecipamos, junto a esses três conceitos, trataremos, também, do de "Companhia", para incluirmos as línguas de possessivos comitativos de nossa análise, as línguas bantas.

Nosso objetivo, nesta tese, toma um direcionamento distinto, mas não oposto, do da maioria dos autores que se ocuparam com o estudo sobre relações entre categorias cognitivas (Croft, 1991; Koch, 1999; Stolz, Stroh e Urdez, 2006; Freeze, 1992; Langacker, 2003). Para entendermos como domínios conceituais são agrupados e conceitualmente inter-relacionados é preciso também entender como eles são distinguidos entre si. Nossa proposta inicial é a de que os domínios conceituais de locativos, existenciais, comitativos e possessivos compartilham de uma mesma estrutura conceitual, os quatro domínios são "relações de pontos de referência”. Dizendo isso, afirmamos que a razão da proximidade conceitual entre possessivos e outros domínios conceituais é a possibilidade de relacionarmos duas entidades de forma que uma serve como um ponto de acesso para uma segunda entidade, dentro de um espaço conceitual ou domínio dos conceitualizadores (Na seção 3.2 fizemos uma primeira apresentação das relações de pontos de referência). Mesmo sugerindo que as relações de pontos de referência como operação da capacidade humana de conceitualização que possibilita de certo modo a integração entre diferentes domínios conceituais ainda assim elas não são suficientes para possibilitar que os falantes possam individualizar esses mesmos domínios em construções gramaticais diferentes, ou seja, em diferentes categorias. Falta identificar outras forças cognitivas em jogo para que a distinção entre as categorias aconteça. Dito isso, reafirmamos que cada um desses domínios se apresenta como categorias cognitivas distintas, nenhum falante se mostra incapaz de discernir uma construção possessiva de uma construção locativa, mesmo que locativos sejam usados para expressar posse.

Atentaremos, no restante deste capítulo, para esses aspectos que relacionam domínios conceituais, para posteriormente nos ocuparmos, preliminarmente, daquilo que pode ser responsável por distingui-los, a categoria semântico-cognitiva Controle. Adotar o construto da Análise do Ponto de Referência, elaborado em Gramática Cognitiva, como um construto teórico que descreva os elementos e processos das relações de pontos de referência, irá trazer para este trabalho uma caracterização mais condizente com os tipos de fenômenos gramaticais e cognitivos em jogo no emaranhado conceitual com o qual estamos lidando, ao mesmo tempo em que delineamos melhor a forma como iremos nos apropriar de uma teoria em 
particular, a Gramática Cognitiva, para buscarmos uma visão mais completa do nosso tópico de pesquisa. $^{13}$

\subsection{Análise do Ponto de Referência em domínios conceituais}

\subsubsection{Posse e possessivos}

Iniciamos com os possessivos justamente por ser esse o domínio conceitual central de nossa tese, a partir do qual os outros domínios conceituais estão relacionados. E, claro, por ser ele um domínio matriz de difícil caracterização, toma parte de locativos, existenciais e comitativos para a realização de sua expressão linguística (Heine, 1997, p. 222). As relações possessivas são bastante complexas, abarcando outras variedades de relações, por exemplo: de parentesco, todo-parte, estados, etc., conforme já apresentamos anteriormente, no Capítulo 3. As línguas selecionam então diferentes estratégias para a expressão de possessivos, a depender de parâmetros estruturais como o sequenciamento temporal e a predicação não verbal, como defende Stassen (2009) no seu modelo de codificação de posse predicativa (Cf. Figura 3.3).

Segundo esse modelo, as línguas fazem uso de três tipos de construções intransitivas para a expressão de posse predicativa: construções locativas, construções existenciais e construções comitativas, além, claro de construções transitivas, geralmente com verbos gramaticalizados com o sentido original de "pegar", "agarrar", "segurar", etc. Diante de todas essas diferentes estratégias para possessivos e a grande proximidade conceitual entre elas, nosso objetivo nesta seção e nas que seguem será o de demonstrar que todas elas podem ser caracterizadas como construções de pontos de referência. E para isso, lançaremos mão de alguns processos cognitivos eleitos em Gramática Cognitiva como fundamentais para indicar as similaridades e as distinções entre esses quatro diferentes domínios conceituais. Em dois momentos diferentes já tivemos a oportunidade de examinar as relações possessivas sob a lente da Gramática Cognitiva. No Capítulo 3 introduzimos a noção da Análise do Ponto de Referência e no Capítulo 4 esboçamos em linhas gerais como a Gramática Cognitiva encara as diferentes estratégias nas línguas do mundo para construções possessivas do tipo TER e SER, ou seja, as construções transitivas e intransitivas para a expressão de posse predicativa. Resta agora apresentar de forma mais minuciosa a estrutura de possessivos na arquitetura da

\footnotetext{
${ }^{13}$ Reservamos o título, com iniciais maiúsculas, Análise do Ponto de Referência, à formalização realizada por Langacker (2009) em Linguística dos processos de pontos de referência cognitivos utilizados em Psicologia Cognitiva (Rosch, 1975).
} 
Gramática Cognitiva e, concomitantemente, propor como processos de conceitualização ou de construal se aplicam para uma possível delimitação entre esses domínios.

Para tornar essa delimitação minimamente possível, iremos nos ater no que autores como Langacker (2003), Heine (1997), Taylor (1996)inter alia, concordam ser a noção mais prototípica de um possessivo, a de propriedade legal (em inglês ownership). Contudo, essa prototipicidade vem, com certeza, de nossos modelos cognitivos idealizados sobre as relações de posse, o que pode tornar tal prototipicidade dependente de fatores culturais. Vejamos como Langacker representa os dois principais tipos de possessivo, os possessivos de tipo "ter" e possessivos do tipo "ser", numa construção predicativa, a partir de dois exemplos:

(2) Hopi (Langacker, 2009, p. 91)

Pam kii-'yta

2PS casa-ter

'Ele tem uma casa'

(3) Japonês (Langacker, 2009, p. 99)

Watashi-ni-wa mago-ga iru

1PS-para-TOP neto-SUJ COP

'Eu tenho um neto' (Lit. 'O neto, para mim é que existe.')

O primeiro exemplo, do hopi, é também um caso de incorporação nominal, no qual o morfema - 'yta quecarrega a semântica de posse, junta-se a kii produzindo um composto verbal com o sentido de 'casa.ter'. A sentença seria basicamente um caso de uma construção intransitiva, específica do hopi, língua com a disponibilidade do processo de incorporação nominal para exprimir posse predicativa. Escolhemos, porém, esse exemplo do hopi justamente para enfatizar a noção de que o importante numa relação de posse é o processo em si, muito mais do que a simples distinção entre construções transitivas e intransitivas para posse predicativa. O exemplo do japonês, no exemplo (3), é um caso de construção possessiva do tipo SER, portanto, intransitiva. Porém, guarda com a construção do hopi a mesma relação de ponto de referência. Na primeira é expressa a posse legal de uma pessoa sobre um bem imóvel, uma casa; no segundo caso o possessivo é o de uma relação de parentesco.

Para ilustrar melhor a afirmação de que o importante para os dois casos é a relação esquemática de possessivo em si, apesar dos diferentes subtipos de possessivos e a utilização de verbos do tipo "ter" ou "ser", contrastamos os dois exemplos acima na forma de 
diagramas, conforme as notações em Gramática Cognitiva, mas de forma simplificada. Vejamos os diagramas e a explicação em seguida:

Pam kii-'yta

'Ele tem uma casa'

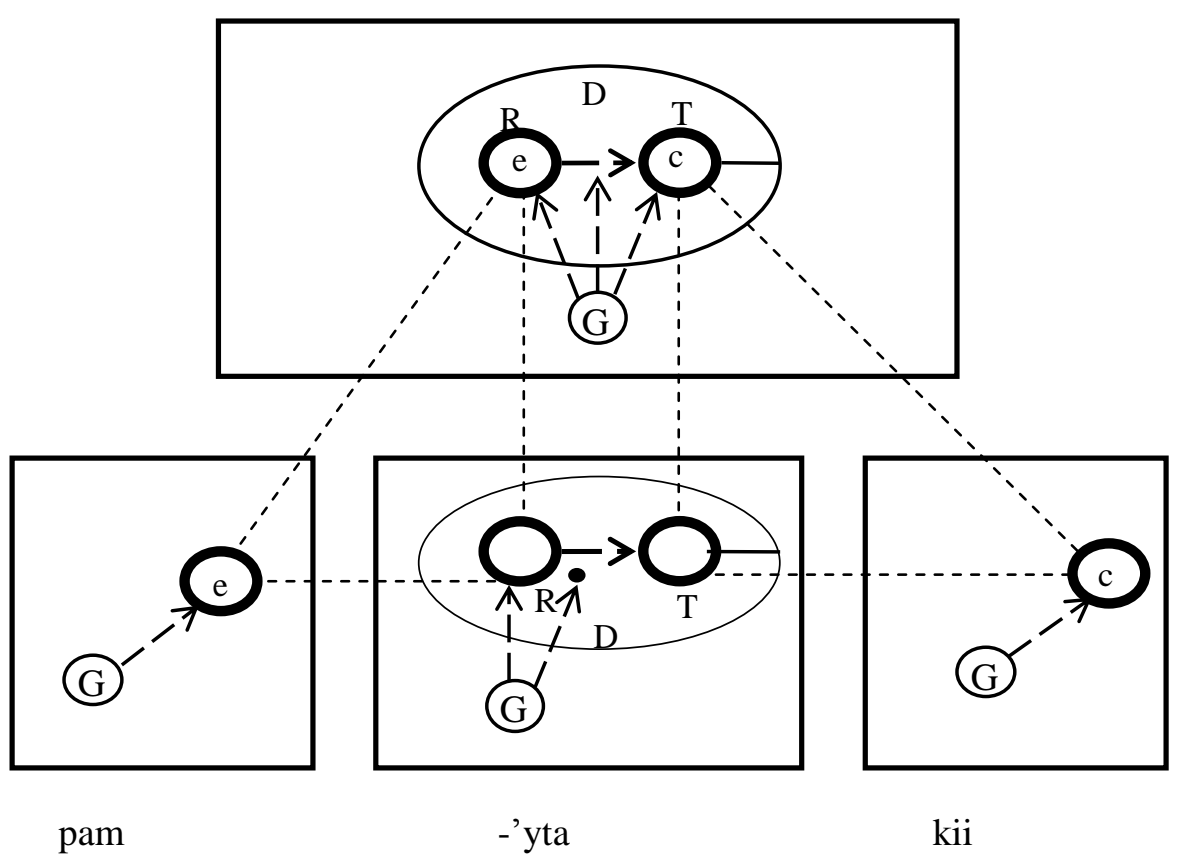

Figura 5.2 - Possessivo do tipo “ter” na APR (Langacker, 2009, p. 92)

Watashi-ni-wamago-ga iru

'O neto, para mim é que existe.'

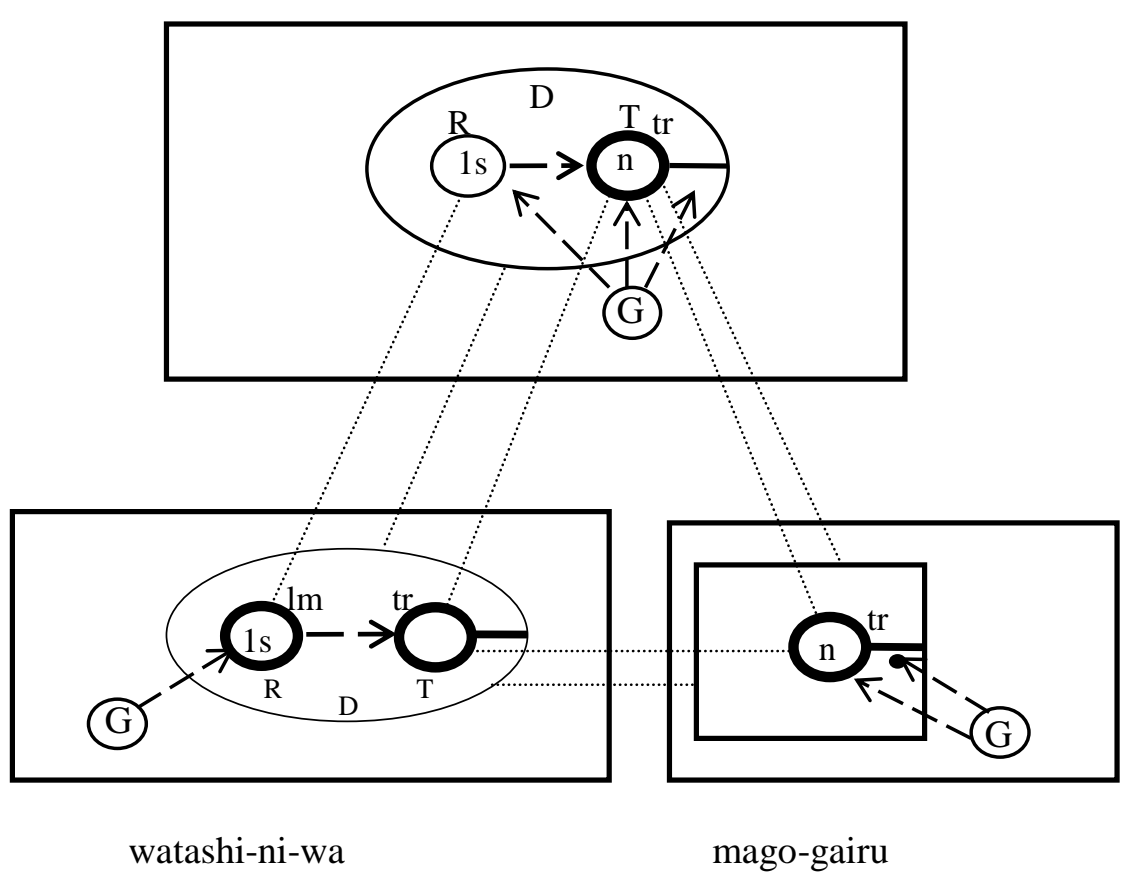

Figura 5.3 Possessivo do tipo “ser” na APR (Langacker, 2009, p. 100) 
Deixamos de lado, propositadamente, especificações que não serão, neste ponto, necessárias, como a caracterização do grounding dos possessivos $(\mathrm{G})$, a diferença entre "tipo" e "instanciações", etc. o que interessa no momento é a arquitetura da Gramática Cognitiva, especificamente a da "estrutura do nível composto".

Para os dois tipos de possessivos, a diferença acontece na estrutura de nível composto representada pelos retângulos superiores, mas para essa diferença acontecer as demais estruturas componenciais menos complexas, os retângulos inferiores, são integrados por meio de correspondências. Na arquitetura da Gramática Cognitiva, para a qual a língua é uma "montagem de unidades simbólicas", a superimposição de cada unidade simbólica carrega o significado que é obtido após os processos de construal, ou seja, o resultado obtido é uma unidade simbólica mais complexa, mas que guarda a estrutura esquemática produtora, de certo modo, do sentido. Para o caso dos dois diagramas na página anterior, a operação cognitiva é a da Análise do Ponto de Referência, diagramado em um dos retângulos inferiores. Acontece que, com a integração do esquema de ponto de referência com a estratégia utilizada na construção para possessivo, na Figura 5.1 um verbo do tipo "ter", transitivo, e na Figura 5.2 um verbo do tipo "ser", intransitivo, a diferença produzida será na proeminência dada a um dos elementos do domínio conceitual. Na Figura 5.1, as duas entidades são perfiladas, na Figura 5.2, apenas o alvo (T) recebe maior proeminência.

O que torna as duas construções possessivas é a característica em comum entre as duas, a de um conceitualizador tomar um ponto de referência como caminho mental para atingir um alvo, reforçando para isso o caminho mental, Fig. 5.1, ou o alvo, Fig. 5.2.

Reiteramos aqui que não temos a pretensão de nos aprofundar em todos os pormenores de todos os casos de possessivos, mas somente indicar que uma relação possessiva é basicamente uma relação de pontos de referência cognitivos que, ao mesmo tempo que aproxima domínios conceituais, também permite que haja formas de distingui-los.Passamos agora a tratar da forma como outros domínios conceituais podem ser incluídos na mesma linha de análise de possessivos.

\subsubsection{Companhia e comitativos}

Inicialmente, vejamos como o Comitativo poderia ser definido. Arkhipov apresenta a seguinte definição para uma construção comitativa: 
Em resumo, o comitativo é definido como um tipo particular de construção usado para 'pluralizar' um participante - isto é, predicar o mesmo estado de coisas de dois participantes individuais, tal que o predicado principal não é repetido e os dois participantes não são iguais em seus estatutos sintáticos. (Arkhipov, 2009, p. 223) ${ }^{14}$

Um exemplo em português seria:

(4) João saiu com a Maria = 'Eles (João + Maria) saíram = João e Maria saíram.

Em linhas gerais, Arkhipov considera o comitativo como uma construção usada para "pluralizar" um conjunto numa situação assimétrica de forma que os participantes compartilhem da mesma asserção no evento descrito. Os dois participantes podem ser denominados aqui como "acompanhado" (CD) e a "companhia $(\mathrm{CN})$ ". À primeira vista, a definição apresentada parece fazer sentido se temos em mente que o principal objetivo de Arkhipov é o de distinguir a categoria Comitativo de outras categorias gramaticais, de forma que um trabalho tipológico, aos moldes de Stassen (2000 e 2009), possa ser realizado. Sendo assim, Arkhipov tenta distinguir o comitativo de outras categorias como: acompanhamento, associativo, participantes poliádicos, verbos comitativos, coordenação de NPs, construções inclusionárias, etc. Essas últimas categorias são consideradas por ele como quase-comitativas. Numa outra perspectiva, Stolz, Stroh e Urdze (2006) se concentram na natureza polissêmica dos morfemas de comitativo, enquanto Heine e Kuteva (2002, p. 79-90) enumeram pelo menos dez principais caminhos de gramaticalização possíveis, tendo as partículas com valor de comitativo como origem.

O trabalho tipológico de Stolz, Stroh e Urdez (2006) tenta elaborar um mapa semântico do sincretismo existente entre o comitativo e as funções gramaticais comumente associadas a ele, dentre elas as construções de agentividade, coordenação, relações espaciais, possessivos e instrumento. O trabalho dos autores se concentra muito mais na relação entre comitativo e instrumento, mas dedica uma boa parte para a relação do comitativo com o possessivo.

As marcas de comitativo também exercem um papel importante em outras construções gramaticais, como no domínio da coordenação entre sentenças ou entre sintagmas nominais. Stassen (2000) sugere uma primeira tipologia para as construções coordenativas entre NPs denominadas por ele como NP-conjuctions. Para línguas que fazem uso de marcas diferentes

\footnotetext{
14،'In a nutshell, comitative is defined as a particular construction type used to 'pluralize' a participant - that is, to predicate the same state of affairs of two individual participants, such that the main predicate itself is not repeated and the two participants are not equal in their syntactic status."
} 
para construções como em "A e B" e "A com B", como é o caso do inglês, são denominadas como AND-languages. Para as línguas que fazem uso da mesma marca para as construções coordenativas e comitativas, como em "A com/e B", o autor denomina como WITHlanguages, conforme exemplos abaixo ${ }^{15}$ :

(5)

Inglês

a. John and Mary are married.

João e Maria ser casados

'João e Maria são casados'

b. John went out with Mary.

João com Maria saíram.

'João saiu com a Maria'

(6) Hauçá (Abdoulaye, 2004, p 171, 174)

a. naa gàmu dà Boolà bàaki-n kàasuwaa.

1sg.PVF encontrar COM Bola perto-de mercado

'Eu encontrei com Bola perto do mercado.'

b. Abdù dà Feemì sun ga juunaa kàasuwaa.

Abdu CONJ Femi 3pl.PFV ver REF mercado

'Abdu e Femi se encontraram no mercado.'

O último caso, de WITH-languages, é o prototípico para a maioria das línguas bantas.

Em concordância com as definições de Stassen apresentadas acima, encontramos em Haspelmath $(2007$; 2004) alguns argumentos para a distinção do valor coordenativo em WITH-languages, considerando que apenas a marca do comitativo é utilizada para os dois tipos de construções. O parâmetro para tal distinção seria em termos semânticos. Enquanto em "João e Maria comeram" a partícula coordenativa daria uma ideia simétrica entre os dois participantes, a de que os dois participantes comeram, em "João comeu com Maria", há uma assimetria na qual possivelmente Maria não comeu, apenas acompanhava João enquanto este comia (Haspelmath, 2007, p. 29). Nos termos da Gramática Cognitiva, um dos participantes

\footnotetext{
${ }^{15}$ Para Stassen (2000), essas seriam apenas as duas estratégias mais salientes, já que em muitas línguas pode haver a combinação do uso das duas estratégias, fato mais comum de acontecer nas línguas que fazem uso da estratégia comitativa. Arkhipov (2009) sugere uma complementação à tipologia de Stassen (2000) ao propor que além das duas estratégias reportadas por Stassen, as línguas deveriam ser classificadas "cardinalmente" pelo número de distinções possíveis. Como Arkhipov dedica apenas um parágrafo para essa classificação, torna-se difícil uma apreciação mais plausível da sua proposta.
} 
seria o foco da atenção, sendo assim o TR, enquanto o outro serviria como o marco, MR. A observação de Haspelmath aproxima a delimitação do comitativo com a de possessivo no ponto em que as duas construções compartilham de uma diferença no perfilamento dos participantes. O que contribuiria, de certa maneira, para a possibilidade de o domínio do comitativo compartilhar cenas semelhantes com o de possessivo seriam novamente nossos modelos cognitivos idealizados, geralmente conceitualizamos um possuidor como acompanhado de suas posses sugerindo uma proximidade "intrínseca" entre possuidor e possuído; em outras palavras, os parâmetros semânticos CONTATO PERMANENTE apontado por Stassen (2009) ou a esfera pessoal de um indivíduo, proposta por Creissels (2013) indicariam que a relação entre os dois participantes se dá pela ideia de proximidade.

Fica relativamente fácil de observar a grande similaridade de uma relação comitativa com a de possessivos a partir da Análise do Ponto de Referência. Apesar de Langacker em nenhum momento considerar o valor do comitativo numa relação de pontos de referência cognitivos, decidimos elaborar uma possível convenção para o domínio do comitativo na notação da APR:

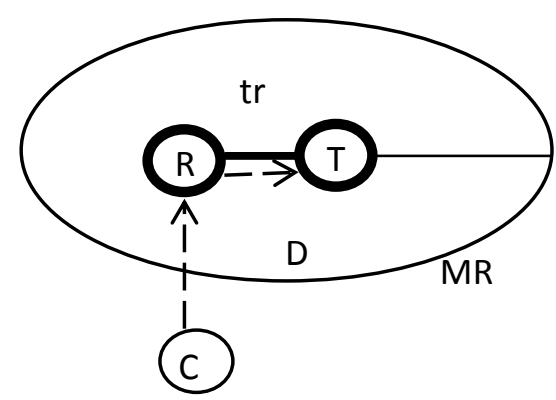

Figura 5.4- Comitativo na Análise do Ponto de Referência

A linha espessa entre $\mathrm{R}$ e $\mathrm{T}$ daria a ideia de que duas entidades podem ser conceitualizadas como um único participante, tendo a relação de pontos de referência ainda como a representação esquemática. O Conceitualizador perfila as duas entidades como um único TR, enquanto o Domínio serve como o MR. À primeira vista, a Análise do Ponto de Referência se adéqua bem ao que Arkhipov chama de construção comitativa (genuína).

Poderíamos considerar que uma relação prototípica para o comitativo, em que A está perto e acompanhado por B, conforme Figura 5.4, guarda a mesma relação daquela dos possessivos. Grosso modo, como já afirmamos, uma entidade a ser acompanhada serve como um ponto de referência $\mathrm{R}$ para que se acesse a entidade que será a companhia, neste caso, o alvo $\mathrm{T}$ da relação de companhia. Relação similar à de possessivo. Há outras nuances na 
relação comitativa que precisam ser consideradas, mas reservamos um outro momento mais adiante para tratar disso.

\subsubsection{Existência e existenciais}

O domínio de existenciais mostra-se um pouco mais problemático para uma caracterização conceitual devido à sua grande proximidade com o domínio de localivos. Stassen (2009, p. 49) em nota de rodapé atesta que a diferença entre locativos e existenciais dá-se em termos discursivos e pragmáticos. Sentenças locativas possuem o elemento locado como tópico, sendo marcado como definido, em línguas que possuem tal marcação. Por outro lado, o elemento locado em sentenças existenciais seria visto como informação nova, sendo marcado como indefinido. Esse modo de distinguir sentenças existenciais de locativas tem sido a mais utilizada pelos estudiosos, pautando-se quase que exclusivamente nos parâmetros de [+/- definido]. Alguns autores chegam a afirmar que o domínio da existência é essencialmente locativa (se algo existe, existe em algum lugar. Cf. Lyons, 1979).

Em Gramática Cognitiva, Langacker sugere uma forma mais intuitiva para uma possível distinção entre localização e existência, também baseada na Análise do Ponto de Referência. Os gráficos abaixo representam os dois domínios:

a) Localização

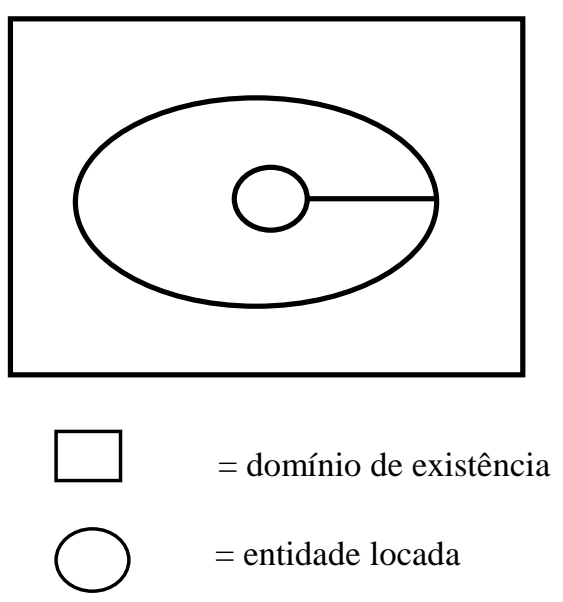

b) Existência

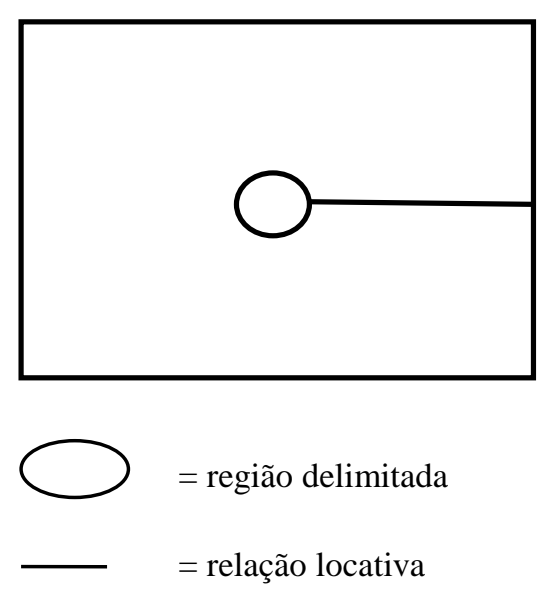

Figura 5.5 - Distinção entre localização e existência (Langacker, 2003)

Para o autor (2003, p. 9): "Mesmo que haja mais elementos envolvidos, uma diferença primária entre as expressões de locativo e existencial é que aquela indica uma localização que 
de alguma forma é delimitada e identificável, enquanto esta deixa a localização implicada totalmente sem especificação"16.

Apesar dessa diferença, há ainda uma grande semelhança na configuração dos dois domínios, e devido a essa grande semelhança na conceitualização de localização e existência, é tão comum que as construções existenciais sejam associadas a locativos. Pinheiro (2010a; 2010b) trata boa parte da semântica de "ter" no português do Brasil, demonstrando que uma parte significativa dos sentidos desse verbo é relacionada a locativos ou existenciais, como é possível verificar na Tabela 5.1 retirada de Pinheiro (2010a) (os exemplos em itálico foram acrescidos na Tabela abaixo):

Tabela 5.1 Usos e sentidos de "ter" pleno no português brasileiro (Adaptado de Pinheiro, 2010a)

\begin{tabular}{|c|c|c|}
\hline $\begin{array}{l}\text { 1. LOCATIVO/ } \\
\text { EXISTENCIAL }\end{array}$ & $\begin{array}{l}\text { - CONCRETO } \\
\text { - ABSTRATO } \\
\text { - ETD } \\
17\end{array}$ & $\begin{array}{l}\text { (i) Só tem um shopping na minha cidade. } \\
\text { (ii) Tem gente na sala. } \\
\text { (iii)Tem uma falha na sua argumentação. } \\
\text { (iv) Tem dez anos que acabou a guerra. }\end{array}$ \\
\hline 2. POSSESSIVO & $\begin{array}{l}\text { - CONTINÊNCIACONCRETA } \\
\text { - CONTINÊNCIA ABSTRATA } \\
\text { - PROPRIEDADE } \\
\text { - RELAÇÃO INTERPESSOAL } \\
\text { - PARTE -TODO } \\
\text { - EXPERIÊNCIA } \\
\text { - Outros }\end{array}$ & $\begin{array}{l}\text { (v) Minha cidade só tem um shopping. } \\
\text { (vi) Sua argumentação tem uma falha. } \\
\text { (vii) João tem dois carros. } \\
\text { (viii) Ele tem duas irmãs. } \\
\text { (ix) Ela tem um nariz bonito. } \\
\text { (x) Tenho saudades da minha infância. }\end{array}$ \\
\hline $\begin{array}{l}\text { 3. POSSESSIVO- } \\
\text { LOCATIVO }\end{array}$ & $\begin{array}{l}\text { - CONCRETO } \\
\text { - ABSTRATO }\end{array}$ & $\begin{array}{l}\text { (xi) Ele deve ter uns mil livros naquela } \\
\text { biblioteca. } \\
\text { (xii) Ele teve poucas oportunidades na vida. }\end{array}$ \\
\hline 4. QUALIFICATIVO & & (xiii) Lula tem Sarney como um aliado. \\
\hline
\end{tabular}

Dos exemplos de (i) a (vi) e os exemplos (xi) e (xii) há a expressão de algum predicado locativo acompanhando os diferentes sentidos do verbo ter. Observando-se agora os diagramas na Figura 5.4 torna-se mais fácil visualizar a proximidade tão grande entre

\footnotetext{
16، Though more is surely involved, a primary difference between locative and existential expressions is that the former indicate a location which is to some extent delimited or identified, whereas the latter leave the implied location wholly unspecified."

${ }^{17}$ Expressão de Tempo Decorrente, conforme discutido em Avelar (2012).
} 
locativos e existenciais, o que não impossibilita a expressão de existenciais sem a menção a locativos:

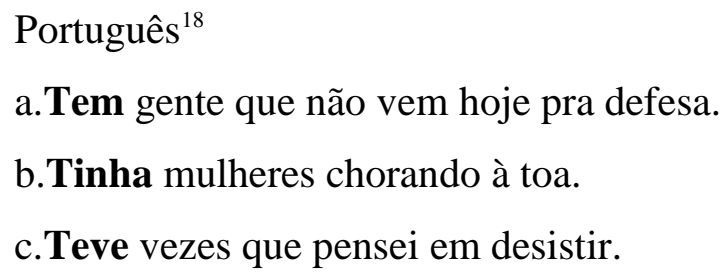

\subsubsection{Localização e locativos}

O domínio dos locativos é um campo controverso e de difícil classificação tipológica, por lidar com a categorização do espaço e consequentemente com a forma como expressamos linguisticamente as categorias espaciais. Uma rápida consulta da literatura voltada para as construções locativas mostra que a variação encontrada nas línguas do mundo é imensa (Levinson; Wilkins, 2006), indo de línguas que não fazem uso de um verbo básico para a expressão de um locativo a línguas que fazem distinções sutis de posições para determinados locativos. Uma das formas de se tentar tornar válida uma tipologia dos predicados locativos seria o uso de uma construção básica ou da "Construção Locativa Básica", adotado por Levinson e Wilkins (2006, p. 15-17) e outros estudiosos como Grinevald (2006).

Mesmo com toda a complexidade de caracterizar o domínio conceitual de locativos, os estudiosos não discordam de tratá-lo como um domínio básico da conceitualização humana (Langacker, 2008, p. 47). Mas quando se trata de considerar locativos como a base ou a origem de determinada construção não se especifica que tipo de locativo está sendo considerado. Para o caso de uma Construção Locativa Básica, que seria a resposta a uma pergunta do tipo “onde está A?", compondo-se de um tema, o verbo utilizado para a codificação do sentido de localização e o predicado locativo. Uma esquematização para os elementos de construções locativas poderia ser a seguinte:

$$
\text { TEMA + COP + Y.LOC.X }
$$

\footnotetext{
18 Para Avelar (2009b), a emergência de ter existencial em português brasileiro está relacionada ao "empobrecimento" do paradigma flexional do português brasileiro (com consequências para restrições sobre sujeitos nulos) e a realização de PP locativos na posição de sujeito (inversão locativa) de sentenças transitivas.
} 
Onde $\mathrm{Y}$ e $\mathrm{X}$ se referem a alguma adposição ou marca de caso indicando uma localização estática ou dinâmica. Construções de localização estática são geralmente consideradas como mais prototípicas. ${ }^{19} \mathrm{Na}$ Figura 5.5 já esquematizamos como diferenciar um existencial de um locativo a partir da Análise do Ponto de Referência, resta agora concentrar nossa análise sobre a proximidade de locativos com possessivos. Na tipologia de Heine (1997), dos oito esquemas de evento propostos como origem para possessivos, três são locativos, estritamente falando. $\mathrm{O}$ esquema de locativo configura-se como um locativo estático, e os esquemas de origem e o de destino como locativos dinâmicos. Ainda assim, não fica bem explícito qual a configuração esse locativo precisa ter para ser conceitualizado como um possessivo. Em outras palavras, elementos como a configuração espacial, a dinâmica de forças envolvidas entre os elementos constituintes de um locativo não são levados em conta quando o domínio conceitual do locativo é eleito como o domínio básico para quaisquer outros domínios. Sendo um domínio básico da estrutura conceitual humana, torna-se tentador e quase uma armadilha conceitual reduzir quaisquer outros domínios ao de locativo.

Na Gramática Cognitiva, o domínio do locativo é representado conforme a Figura 5.5 abaixo, onde o alvo T seria o TEMA, a entidade de maior proeminência, portanto, servindo como o trajetor:

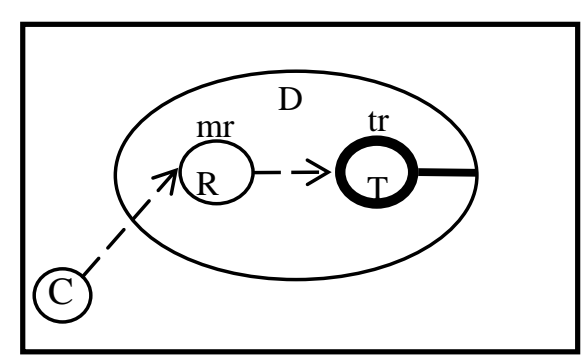

Figura 5.6 Localização na Análise do Ponto de Referência

Tendo argumentado que os quatro domínios de interesse da tese podem ser considerados como pontos de referência, na próxima seção nos ocupamos com a discussão de como podemos diferenciar um domínio do outro a partir das operações de construal.

\footnotetext{
${ }^{19}$ Chamamos a atenção para a dificuldade de diferenciar, em termos absolutos, locativos estáticos de locativos dinâmicos (Cf. Dewell, 2005).
} 


\subsection{Delimitando domínios conceituais}

À primeira vista, por nosso trabalho se concentrar bastante sobre locativos, existenciais, comitativos e possessivos, uma impressão possível é a de que estamos simplesmente seguindo os quatro principais tipos de possessivos da tipologia de Stassen(2009) e que, assim, nosso trabalho é grandemente baseado naquela tipologia. Embora seja indiscutível tal direcionamento, a decisão de tratar dos quatro domínios é, na verdade, resultado da análise de toda a literatura que passou por nosso escrutínio (Cf. Caps. 3 e 4 ), inserindo este trabalho assim na linha da discussão da conhecida literatura sobre a relação de possessivos com locativos e existenciais (Clark, 1978; Freeze, 1992; Kayne, 1993; Langacker, 2003).

Chamamos ainda a atenção para o fato de Heine (1997, p. 45) ter sugerido primeiramente esses quatro domínios como fontes universais para o desenvolvimento de construções de posse predicativa: o que alguém faz (Ação), onde alguém está (Localização), quem é acompanhado (Companhia), e o que ou quem existe (Existência). O diferencial do nosso trabalho é justamente o de trazer para o palco dessas discussões o domínio conceitual do comitativo, tão importante para entender as construções de posse predicativa em línguas bantas, mas ausente nos principais debates sobre possessivos. Não podemos afirmar qualquer originalidade nesse sentido, lembrando que Stolz (2001) já havia atentado para essa questão. Com Lisa Levinson (2011) temos um primeiro trabalho que utiliza o comitativo como contra evidência da influente "Hipótese Localista" dos estudos gerativista (Cf. Cap. 4). O que diferencia nosso objetivo do de Lisa Levinson é tomar um conjunto de línguas que fazem uso marcadamente do comitativo para as construções de posse predicativa como foco de nossa análise e descrição. Com isso, voltamos a afirmar que para um entendimento mais completo sobre as relações entre domínios conceituais de possessivos, esses quatro domínios devem ser considerados em conjunto. Na seção anterior, elegemos a APR como a base conceitual comum desses quatro domínios, torna-se necessário agora apontar quais operações são utilizadas para a diferenciação dos domínios conceituais.

$\mathrm{Na}$ figura 5.7, agrupamos em um mesmo espaço os quatro domínios conceituais, de existenciais, locativos, comitativos e possessivos, como forma de fazer uma comparação entre cada um. Tentamos seguir a mesma sequência da Figura 3.3, onde Stassen (2009) sugere o caminho que as línguas trilham para escolher que tipo de possessivo irá utilizar. Dessa forma, o primeiro retângulo, no alto da página, representa a estratégia existencial ou os possessivos de tópico. O próximo retângulo, à esquerda, representa os possessivos locacionais. Ao lado 
dele, temos o retângulo que representa os possessivos comitativos. Por fim, o retângulo do fim da página representa as línguas que fazem uso de algum verbo semitransitivo para possessivos. Para as quatro situações, o conceitualizador irá dar proeminência a uma área específica do domínio conceitual, permitindo assim a diferenciação entre os quatro a partir de uma base comum, a da relação de ponto de referência, diagramado em cada retângulo.

EXIST

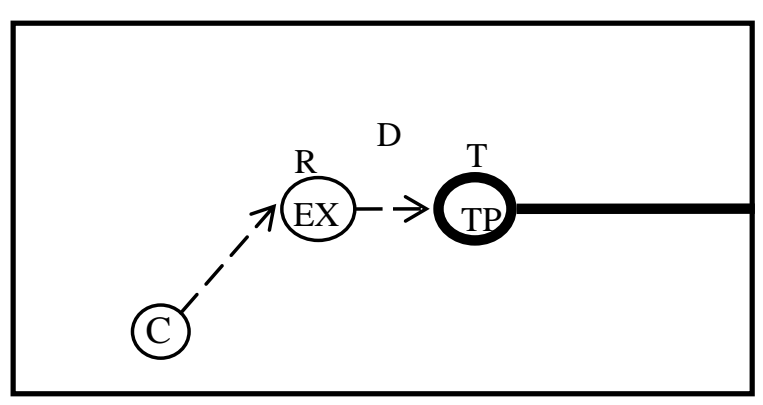

LOC

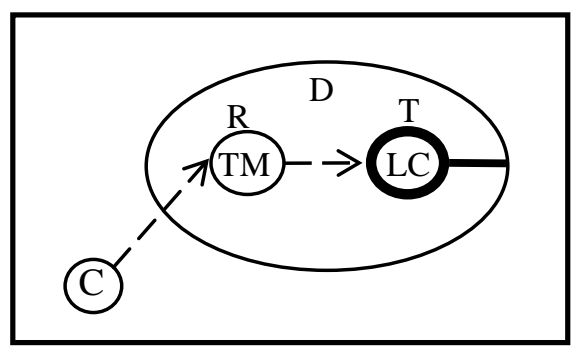

$\mathrm{COM}$

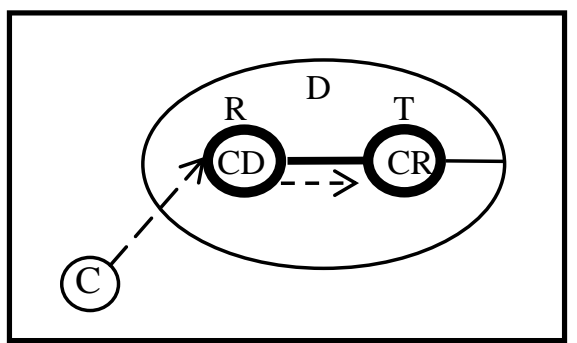

POSS

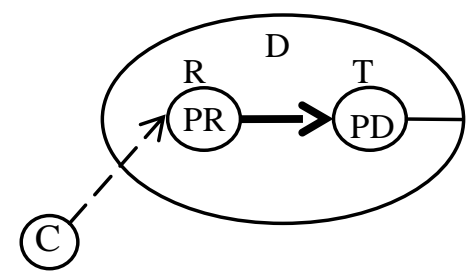

Figura 5.7 - Relação entre domínios conceituais de EXIST, LOC, COM e POSS 
Diversas operações de construal como proeminência e perspectivização contribuem para a delimitação de um domínio conceitual em relação a outro. Atentando para os retângulos que representam o locativo e existencial, vemos que a proeminência é dada ao alvo T, representados pelo segundo círculo dentro do Domínio D. Com isso, conforme já atestado, esses dois domínios são bastante próximos, o que é confirmado por ter o alvo T focalizado. $\mathrm{O}$ retângulo que representa o comitativo, à direita, mostra que a proeminência é para os dois participantes, que são perfilados como um conjunto pluralizado, o que é indicado pela reta que une os dois. Por fim, o retângulo de baixo representa os possessivos baseados em verbos de ação ou semitransitivos. Em resumo, os quatro domínios conceituais do nosso estudo são diferenciados na Análise do Ponto de Referência a partir do elemento que é perfilado. Isso mostra a relação de cada construção com seu domínio: "Existência, "Locativo", "Companhia" e "Posse". No último retângulo da Figura 5.7, resolvemos não representar os dois círculos de $\mathrm{R}$ e $\mathrm{T}$ com linhas espessas para darmos ênfase à seta entre os dois, representando assim o caráter mais agentivo ou ativo desses tipos de construção, e que a relação de possessivos tem o processo em si como perfilado pelos conceitualizadores.

Agora que fizemos a distinção de cada domínio a partir da Análise do Ponto de Referência, tentaremos enfatizar na Figura 5.8, a tendência que os três primeiros domínios, de existenciais, locativos e comitativos, têm para serem recrutados pelas línguas para expressar posse predicativa. Deixamos cada domínio, novamente, na disposição que está na Figura 5.7, desta vez, procuramos manter os fatores estruturais apontados por Stassen como responsáveis pela escolha que as línguas fazem para posse predicativa: sequenciamento temporal e predicação não verbal. Assim, no alto da figura indicamos a existência dos dois elementos em uma relação possessiva, o possuidor (PR) e possuído (PD), que irão ser expressos no domínio de existenciais (EXIST), como tópico (TOP) e o elemento que existe (EX); no domínio de locativos (LOC), como locativo (LC) e o elemento locado ou tema (TM); e no domínio de companhia (COM), com os elementos: acompanhado (CD) e companhia (CA). Esses três elementos são conceitualizados como possuidor (PR) e possuído (PD), passando posteriormente por processos de gramaticalização de forma que a estrutura de uma construção intransitiva, nos possessivos de tópico, locacionais e comitativos, passa a ser uma construção transitiva de um possessivo expresso como um verbo do tipo "ter". A questão que permanece é: como distinguir um TP, um LC e um CD de um PR e um EX, um TM e um CA de um $\mathrm{PD} ?^{20}$

\footnotetext{
${ }^{20}$ Os processos de gramaticalização são representados na Figura 3.3 pelas linhas tracejadas. Na Figura 5.8, alinhamos cada elemento aos papéis de PR, sujeito e PD, objeto direto .
} 

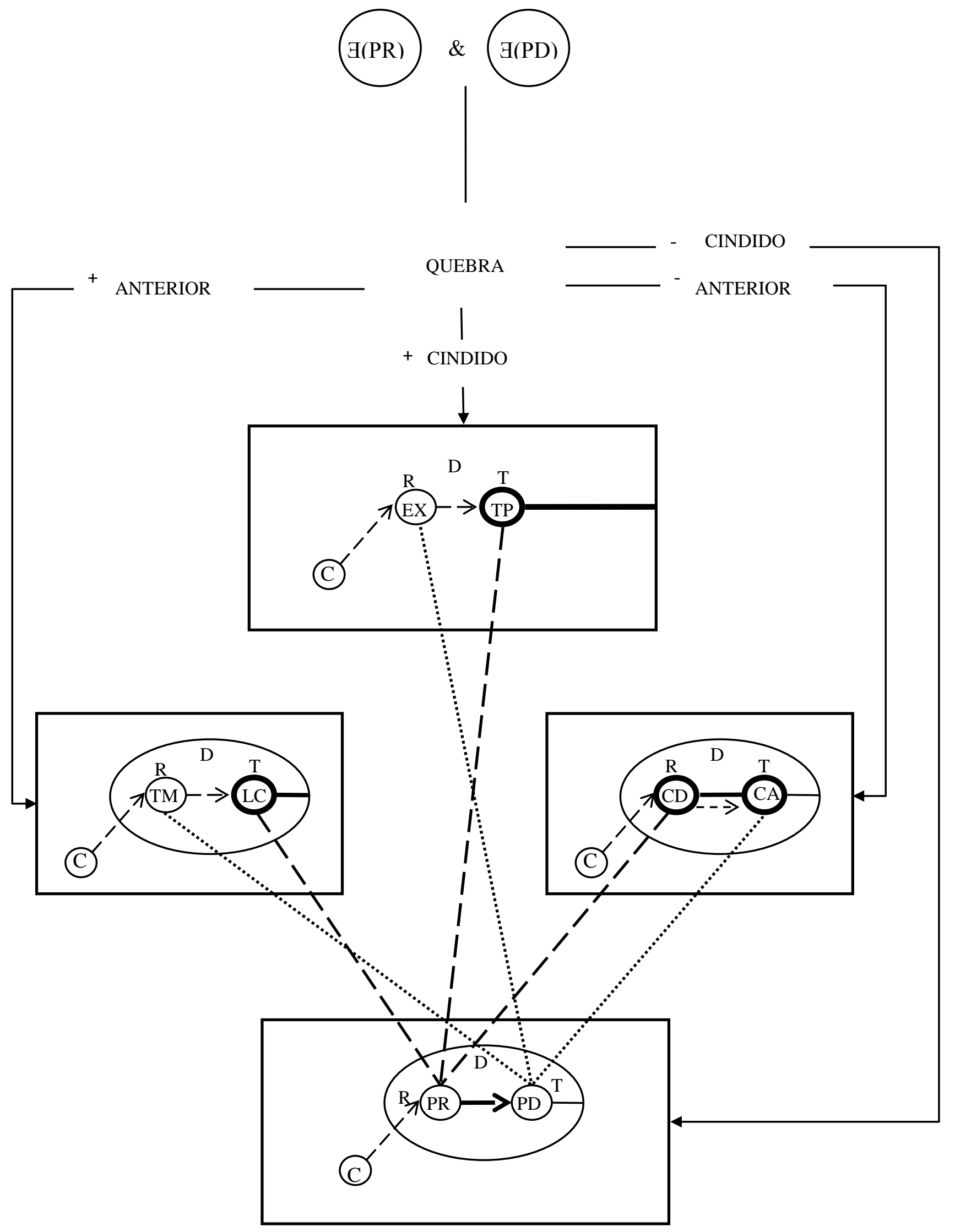

Figura 5.8 - Codificação de posse predicativa e domínios conceituais 
Para esse tipo de demarcação de domínios conceituais reside o mérito de uma teoria de gramática preocupada com a faceta imagética da linguagem, da forma como faz a Gramática Cognitiva. Acreditamos firmemente que a Análise do Ponto de Referência, pautada na habilidade humana de utilizar pontos de referência em diversos níveis cognitivos, caracteriza bem os quatro domínios conceituais de possessivos. De qualquer forma, ainda falta conseguir caracterizar, conceitualmente, como possessivos são distinguidos de outros domínios. Como já adiantamos por diversas vezes, voltamos a ressaltar que a categoria semântico-gramatical Controle deve exercer parte significativa desse papel, na conceitualização de possessivos. Assunto a ser explorado com mais detalhes no Capítulo 7.

Por agora resta demonstrar com mais cuidado que a base conceitual comum desses quatro domínios na Análise do Ponto de Referência ainda não é suficiente. Pela literatura consultada no Capítulo 4 verificamos que existe um leque bem maior de outras construções relacionadas a possessivos que poderíamos classificar como subdomínios.

\subsection{Subdomínios e subconstruções}

Podemos considerar como uma especificidade do nosso trabalho a preocupação de caracterizar a particularidade de cada uma das quatro construções desta tese, digamos, em seus próprios termos, e com isso atentar para subdomínios dessas principais construções nem sempre considerados pelos autores. Dizer simplesmente que possessivos têm sua base em locativos, seguindo o "Paradigma Localista" (Freeze, 1992), é não dizer muito se não se sabe a que locativo se está referindo. Uma observação mais atenta para o domínio das construções locativas pode demonstrar que as operações e configurações de localização não são suficientes para caracterizar um locativo como possessivo nas línguas do tipo de possessivos locacionais.

Podemos resumir em rápidas palavras alguns desses subdomínios e subconstruções.

Para o domínio do comitativo temos a questão do sincretismo com o domínio do Instrumento. Stolz, Stroh e Urdze (2006) têm demonstrado que para a maior parte das línguas indo-europeias as marcas para o comitativo (COM) e instrumento (INST) são as mesmas, o que levou Lakoff e Johnson (1980) a postularem a Metáfora da Companhia como universal. Esse universal perdeu seu estatuto depois dos trabalhos tipológicos desses autores, que mostraram com dados suficientes que a maioria das línguas do mundo faz uso de marcas distintas para marcar instrumento e companhia. 
Em uma amostra de cerca de 300 línguas, os autores constataram que a maior parte delas não apresentava sincretismo entre as marcas de comitativo e instrumento, enquanto uma mínima parte delas apresentava a possibilidade de tal sincretismo. Um número ainda menor de línguas, além de duas marcas diferentes para comitativo e instrumento, também apresentava formas alternativas para um daqueles papéis semânticos (Stolz, Stroh e Urdze, 2006, p. 103-4). Partindo desses fatos, os autores classificam as línguas em 3 tipos:

(9) Classificação das línguas quanto ao sincretismo entre COM e INST

Tipo A, aquelas que distinguem COM e INST;

Tipo B, as que usam a mesma marca para os dois;

Tipo $\mathrm{C}$ as que fazem uso de um tipo misto entre os dois primeiros, uma partícula específica para o COM enquanto outra sincretiza INST e COM ou uma partícula específica para INST enquanto outra partícula sincretiza COM e INST em outros contextos.

Podemos então encarar o subdomínio de instrumento como merecedor de atenção, em um estudos sobre domínios conceituais de possessivos.

Para o domínio de existenciais, não é difícil perceber que as propostas de distinção entre locativos e existenciais de muitos autores recorrem basicamente ao chamado efeito de definitude (ED), sendo considerado como um universal por autores como Freeze (1992), e servindo como um traço semântico imprescindível para a tipologia de Clark (1978). Freeze considerava que em construções existenciais apenas SN indefinidos seriam permitidos, como exemplo do inglês. Uma forma mais esquemática de visualizar a relação entre esses fatores seria:

(10) Freeze (2001, p. 946)
a. O TEMA
está em
um LOCATIVO
[+ definido]
[+/- humano]
?[- definido]
b. No LOCATIVO está
um TEMA
[-humano]
[-definido]
c. O LOCATIVO está/tem
[+ humano]
um/o TEMA
[+/- definido] 
O traço [+/- humano] pertence ao predicado locativo enquanto o traço [+/- definido] pertence ao argumento do tema (Freeze, 2001, p. 946). No entanto, esses parâmetros não são simples como podem parecer; por exemplo, o que dizer de línguas em que esses dois parâmetros não parecem ser tão comportados? Para o português, Avelar (2009b) e Viotti (2002) demonstram que o ED não é tão obrigatório assim. Esse parece ser o caso para muitas línguas africanas ${ }^{21}$.

Para o caso dos locativos, as línguas do mundo dispõem de estratégias as mais variadas para a sua expressão. Na Figura 5.5, a relação de ponto de referência se aplica sem grandes problemas, mas o tipo de locativo, se estático ou dinâmico, não é explicitado. Faltam nessa caracterização as dinâmicas de força aplicadas para o caso dos locativos (Talmy, 2000) e a forma como conceitualizamos locativos, pautados no esquema imagético de CONTÊINER (Dewell, 2005). Para o caso de como as línguas codificam locativos estáticos e dinâmicos, Creissels $(2006 b)^{22}$ apresenta um esboço de tipologia. O autor propõe uma classificação na qual são relacionadas as formas como as línguas do mundo fazem uso de adposições e afixos de caso para a distinção entre as construções locativas, de origem e destino de um percurso, nos termos do autor, os sentidos de essivo, ablativo e alativo. $\mathrm{O}$ autor apresenta as seguintes estratégias possíveis de serem empregadas pelas línguas para codificar tais distinções:

Padrão 1 - os três sentidos - essivo, ablativo e alativo - aparecem sem ambiguidade na escolha que as línguas fazem no uso de adposições e afixos de caso;

Padrão 2a-c - o uso de adposições e afixos de caso expressam sem ambiguidade um desses sentidos e os outros dois convergem, nos seguintes casos: (a) ablativo vs. essivo-alativo, (b) alativo vs. essivo-ablativo, (c) essivo vs. alativo-ablativo;

Padrão 3 - o uso de adposições e afixos de caso não é sensível à distinção entre os três sentidos.

Para o caso das línguas indo-europeias, das cinco estratégias possíveis, são utilizadas principalmente duas: o Padrão 1 e 2(a), enquanto em boa parte das línguas africanas, principalmente da família nigero-congolesa, o padrão 3 é mais comum. Creissels (2006b, p.22) chama a atenção para a quase que total inexistência de línguas que apresentam o Padrão

\footnotetext{
${ }^{21}$ Em diversas línguas do mundo o efeito de definitude não parece ser categórico como se acredita. Zeitoun et al (1999) demonstra isso para línguas austronésias. E o mesmo parece se aplicar para as línguas bantas (Zerbian; Krifka, 2008).

${ }^{22}$ Creissels baseia-se em parte nos trabalhos em Shay e Seibert (2003).
} 
2(b), e afirma não ter ciência de nenhuma língua que empregue o Padrão 2(c). No total, de cinco possibilidades, apenas três são empregadas, as duas primeiras exemplificadas abaixo:

(11) Espanhol (Padrão 1) (Creissels, 2006b, p. 20)

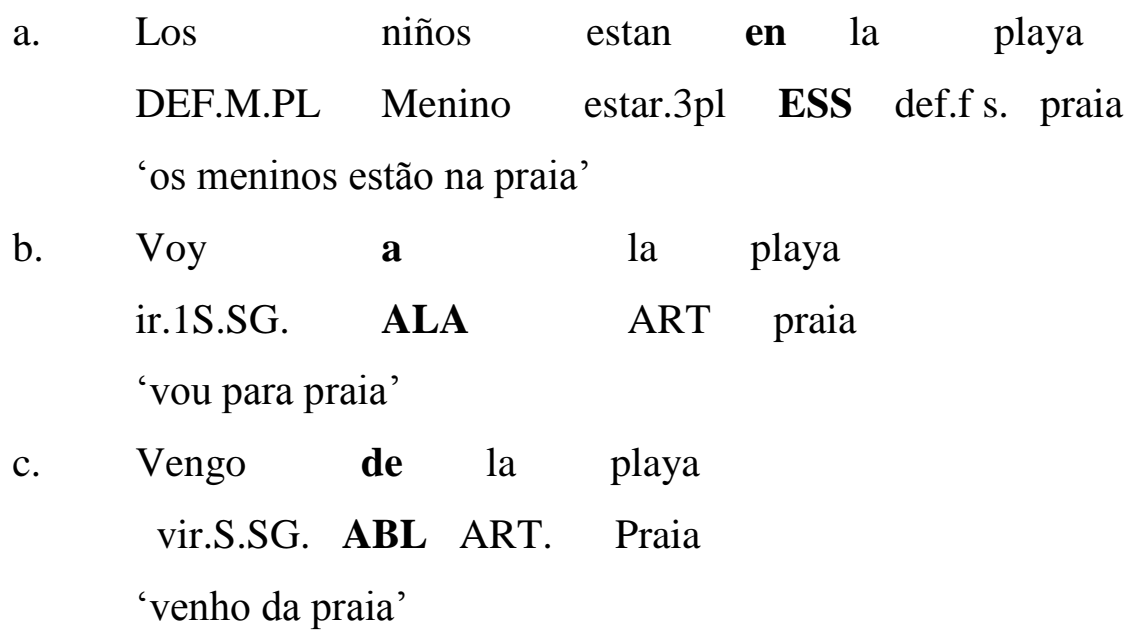

(12) Catalão (Padrão 2(a))(Creissels, 2006b, p. 20)
a. Els hem trobat a la botiga
3pl. Aux.1pl. encontrar ESS ART mercearia
'nós encontramos eles na mercearia'
b. Els hem enviat a la botiga
3pl. Aux. Enviar ESS/ALA ART mercearia
'nós enviamos eles para a mercearia'
c. Vénem de la botiga.
vir.3pl ABL ART mercearia
'eles vêm da mercearia'

Em Araújo e Rocha (2011), uma explicação cognitiva e funcional foi proposta para explicar o porquê de tal configuração da tipologia de Creissels. $O$ que nos interessa na tipologia em questão é a observação feita por Creissels de que mesmo tendo logicamente cinco possibilidades para expressar locativos, destino e origem de um percurso, as línguas na verdade utilizam três estratégias principais. Essas mesmas estratégias são as que são comumente "arregimentadas" para a expressão de posse predicativa em línguas de possessivos locacionais, de acordo com a tipologia de Stassen (2009).

Uma observação óbvia é a de que o construto da APR pode ser bastante esquemático a ponto de poder representar todos esses tipos de construções e subconstruções ou domínios e 
seus subdomínios. No entanto, abarcar todos esses possíveis subdomínios dentro da mesma base conceitual das construções de pontos de referência seria cair no mesmo tipo de reducionismo praticado pelos autores adeptos do Paradigma Localista. Como também indicar que as operações de construal são as únicas responsáveis pelas diferenças existentes entre esses subdomínios seria seguir a linha dos unitaristas de juntar todas as construções possessivas a partir da operação de incorporação. Nesse ponto, parece que chegamos a um beco sem saída, para o qual não ousamos dar uma solução, mas indicar uma possível linha de investigação.

\subsection{Para além da Análise do Ponto de Referência}

Para diminuir os problemas levantados na seção anterior, chamamos novamente a figura do nosso linguista-camaleão. Para nosso estudo sobre a relação de possessivos com outros domínios conceituais, refutar ou abandonar o Paradigma Localista pela Análise do Ponto de Referência não condiziria com a sugestão do início deste capítulo, de uma epistemologia anarquista em Linguística. A primeira constatação de um linguista-camaleão anarquista é a de que os modelos teóricos ditos racionais ou autocontidos guardam já em si seus próprios limites. Restaria então, para tal anarquista, o transitar pelas fronteiras teóricas procurando sempre novos horizontes na borda dos limites impostos por essas mesmas teorias. O que esse nosso tímido ensaio de anarquismo epistemológico tem apontado é para a tentativa de evitar um comprometimento exacerbado com determinada teoria de forma que possamos considerar todos os possíveis desdobramentos de um conjunto de fenômenos.

Temos trabalhado até aqui com a hipótese de que, apesar da grande proximidade conceitual entre os domínios de locativos, existenciais, comitativos e possessivos, deve haver fatores cognitivos que contribuem para a distinção de cada domínio nos contextos esperados. A Análise do Ponto de Referência consegue mostrar onde esses quatro domínios se irmanam e ao mesmo tempo, como eles se diferenciam, contando para isso a especificação das operações de construal, ou seja, a partir de capacidades cognitivas mais gerais torna-se possível verificar o que é comum entre esses domínios e o que os tornam distintos. No entanto, verificamos que apesar de identificar como esses quatro domínios se relacionam ainda há processos que precisam ser suficientemente descritos e explicados. De uma forma mais sucinta, queremos dizer que ainda falta explicar como existenciais, locativos e comitativos são "arregimentados" para o sentido de possessivo, e isso sem desconsiderar o variado leque de subdomínios que esses domínios abarcam. 


\subsection{Em síntese}

Voltamos aqui a assumir a sugestão de que para empreitadas como essa é necessário tomar uma boa dose de anarquismo epistemológico, o que pode nos permitir a ousadia de buscar a formalização de categorias até então não exploradas ou não destrinchadas para a solução de parte de novos questionamentos. Perseguiremos esse fim nos dois últimos capítulos que se aproximam, pondo em prática o que temos frequentemente proposto, a inclusão de línguas de possessivos comitativos nos debates sobre as relações conceituais entre possessivos e outros domínios e o argumento de que é sim, possível, identificar um fator responsável pela caracterização de locativos, existenciais e comitativos como possessivos. A última parte do Capítulo 7 será dedicada a essa última ideia, a de que a categoria. Controle deve ser tomada como o fator que faz um possessivo, possessivo. 


\section{Parte III QUESTÕES DE DESCRIÇÃO E ANÁLISE}


"De manière générale et habituelle, les langues bantu forment le verbe <<avoir〉> au moyen du verbe <<être〉> suivi de $n a, n e, n i, l a, y a,\langle<$ avec〉>. Mais la copule est souvent absente, sous-entendue dans la plupart des cas, et il ne reste plus que na, ne, ni, la, ya..." (Obenga, 1985, p. 184)

Wasema waimba

"Quem cantar desafinado cantou também" (Máxima umbundo coletada por Gociante Patissa,

Disponível em: <http://ombembwa.blogspot.com.br/> Acesso em: 22 de maio de 2012) 


\section{CAPÍtulo 6}

\section{Construções locativas, Existenciais, Comitativas e Possessivas EM LÍNGUAS BANTAS}

\subsection{Apresentação}

Neste capítulo, voltamos a atenção para as construções de interesse da tese nas línguas bantas, centrando a descrição e análise sobre os tópicos gramaticiais discutidos nos capítulos anteriores, especificamente os capítulos 4 e 5. ${ }^{1}$ Tomamos do capítulo 4 os principais fatores indicados como responsáveis pelas relações entre possessivos e os demais domínios conceituais, como o efeito de definitude, a inversão locativa, incorporação, etc. Do capítulo 5, consideramos as construções gramaticais pouco discutidas nos debates sobre possessivos, como a tipologia de locativos estáticos e dinâmicos e o papel semântico de Instrumento.

Não pretendemos aqui uma descrição exaustiva de cada construção, mas apontar as possibilidades de análise ao expandir o rol de construções a serem descritas, contribuindo assim para uma descrição mais refinada das construções relacionadas a possessivos em línguas bantas. Quando questões teóricas, como aquelas discutidas nos capítulos anteriores, passam a fazer parte das preocupações descritivas, alguns fenômenos linguísticos tomados como dados ou quase nunca discutidos podem revelar uma complexidade bem maior, indicando a necessidade de considerá-los para um trabalho que se ocupe da semântica de possessivos e domínios relacionados. Um exemplo seria o efeito de definitude, visto como geral para a maioria das línguas, mas que não se aplica categoricamente para as línguas bantas. Um segundo exemplo seria o domínio do comitativo, visto como um papel semântico sem grande importância, mas não para línguas de possessivos comitativos.

Coletamos as diversas alternativas encontradas em nosso corpus, escrito e eliciado, para uma apresentação organizada a partir dos principais tópicos relacionados na literatura. Sempre que possível apresentamos dados eliciados juntamente com aqueles retirados do corpus escrito. Voltamos a ressaltar que os dados a serem apresentados e as discussões serão apenas apontamentos para questões a serem aprofundadas em momentos oportunos. Não esquecendo que cada uma das construções aqui estudadas mereceriam um capítulo

\footnotetext{
1 Vale ressaltar que grande parte dos temas a serem tratados neste capítulo foi discutida sob um prisma cognitivista no capítulo anterior. Remetemos o leitor às seções que tratam mais especificamente dos tópicos a serem retomados nas próximas seções deste capítulo. Desta vez, partindo de uma perspectiva mais descritivista, tendo como referências as questões teóricas discutidas no capítulo 5.
} 
individualmente. Como tal empreitada foge de nossos objetivos, procuramos pontuar certos aspectos que podem ser interessantes para futuras descrições.

Nas próximas seções trataremos das construções locativas, existenciais, comitativas e possessivas de forma separada, chamando a atenção para os principais fenômenos relacionados a cada construção particular, sejam eles mais gerais na literatura tipológica ou mais específica na linguística bantuísta. Por exemplo, para as construções locativas apresentamos uma visão panorâmica sobre inversão locativa; para as construções existenciais, as discussões se direcionam para a questão do efeito de definitude. Quanto às construções comitativas a relação destas com o papel semântico de Instrumento e a coordenação entre NPs. Por fim, sobre as construções possessivas, enumeramos as diferentes formas que as línguas bantas do nosso estudo apresentam para as construções de posse predicativa. Ainda para as construções possessivas, detalhamos o processo de gramaticalização denominado transitivização por Stassen (2009), processo este considerado como responsável por alguns fenômenos no que diz respeito a possessivos comitativos.

\subsection{Construções locativas}

Na seção 5.3.4 apresentamos o que seria a base conceitual de locativos na Análise do Ponto de Referência, e vimos que a delimitação conceitual de locativos é uma tarefa bastante complexa. Parte dessa complexidade é verificada quando se atenta para tipologias como a que foi sugerida por Creissels (2006b) para locativos estáticos e dinâmicos. Nessa tipologia, o autor busca caracterizar de uma forma mais detalhada as configurações do que comumente chamamos de locativos. Destrinchar com mais cuidado as nuances de um locativo permite verificar que o rótulo de locativo esconde não raramente diferenças de conceitualização espacial que podem variar drasticamente de língua para língua. Para as línguas bantas, parte dessa complexidade de situações e distinções semânticas e espaciais possui algumas particularidades, as quais buscaremos explicitar nas seções que seguem.

\subsubsection{Localização}

Numa Construção Locativa Básica, a resposta para uma pergunta to tipo "Onde está X?", encontramos geralmente os seguintes elementos: um TEMA, um predicado locativo (LOC) e uma cópula (COP). A depender das preferências de cada língua, esses elementos serão ordenados diferentemente ou pode também não ocorrer a cópula. Abaixo apresentamos 
exemplos de Construções Locativas Básicas para o quizombo e umbundo. No exemplo (1), do quizombo, língua SVO, a preferência é posicionar a cópula ao final da sentença, tornando agramatical a sentença se o predicado locativo for posicionado ao final, conforme exemplo (1c). Para o umbundo, também língua SVO, a ordem canônica não difere em uma construção locativa (3). ${ }^{2}$

Quizombo (H 16h) $)^{3}$
a. à-ntù
mù-nzó
è-nà
2-pessoas
18-9.casa
MS-COP
'As pessoas estão em casa'
b. nkàndà và-mèsà
mì-nà
10.livros 16-mesa MS-COP
'Os livros estão na mesa'

$\begin{array}{llll}\text { c. } & \text { *antu } & \text { e-na } & \text { mu-nzo } \\ & \text { 2-pessoas } & \text { MS-COP } & \text { 18-9.casa }\end{array}$

(2) Umbundo (R11)
a. omanu
va-kasi
v'onjo
2.pessoas
MS-COP
18-9.casa

'As pessoas estão na casa'
b. a-livulu
a-kasi
k'-omesa
6-livro
6.MS-COP
17-9.mesa

'O livro está na mesa.'

Como vemos, os predicados locativos são marcados nas línguas bantas pelas classes nominais locativas, numeradas com 16, 17 e 18, exercendo um papel na configuração dos locativos que geralmente é realizado por adposições. Para línguas bantas que não possuem as classes nominais locativas, como o lingala ou o lembaama (B62) (Okoudowa, 2010), certas partículas são

\footnotetext{
${ }^{2}$ Vale mencionar que outras variedades do quicongo podem seguir uma ordem diferente para a Construção Locativa Básica, conforme foi possível atestar com falantes de outras variedades faladas na República Democrática do Congo, quando de nossa viagem de pesquisa para Lisboa. Agradecemos a Bienvenu Lukala por algumas informações sobre outras variedades do quicongo e do quituba.

${ }^{3}$ As sentenças retiradas da literatura estão todas identificadas ao lado de cada exemplo. Todos os outros exemplos, em negrito e sem referência, são do nosso corpus.
} 
gramaticalizadas e passam a funcionar como preposições ou posposições. No lingala, a partícula na é utilizada nos contextos locativos comumente produzidos por preposições:

(3) Lingala (C36d) (Meeuwis, 1998, p. 24) ${ }^{4}$

$$
\begin{array}{lll}
\text { Ba-yán-di } & \boldsymbol{n a} & \text { mésa } \\
\text { 3pl.AN-sentar-PRES } & \text { PREP.COM } & \text { mesa }
\end{array}
$$

'Eles estão sentados na mesa'

Os usos das cópulas nas construções locativas demonstram também a complexidade das línguas bantas. Nos exemplos acima (1) e (2), em sentenças no presente, as cópulas são na e kasi, para o quizombo e umbundo, respectivamente. No entanto, para o passado, as duas línguas irão usar uma cópula na forma -kala, conforme exemplos em (4) e (5):

(4) Quizombo $(\mathrm{H} 16 \mathrm{~h})^{5}$
a. nkéntò
kù-mbánzà kà-kà-kálà
1.mulher
17-9.cidade MS-Fo-COP
'A mulher estava na cidade'
b. nkéntò kù-nkókò kà-kà-kálà
1.mulher 17-9.rio MS-Fo-COP
'A mulher estava no rio'

(5) Umbundo (R11)
a. Ukãi
w-a-kala
vo-lupale
1.mulher
MS-TAM-COP
18-11.cidade
'A mulher estava na cidade.'
b. Ukãi w-a-kala vo-lwi
1.mulher MS-TAM-COP 18-11.rio
'A mulher estava no rio.'

A diferença fica então na configuração do locativo estático. Para o quizombo, os locativos "cidade" e "rio" levam a classe locativa 17, com o sentido de direção, enquanto em umbundo a classe locativa é a 18, com uma ideia de interioridade. O interessante desses exemplos é o de

\footnotetext{
${ }_{5}^{4} \mathrm{Na}$ seção 6.4 tratamos com mais detalhes da partícula $n a$.

${ }^{5}$ Consideramos esse segundo $\mathrm{ka}$ - como um formativo de tempo, conforme caso similar para o umbundo (Chacusanga, 2006, p. 33).
} 
demonstrar que mesmo sendo bastante aceita na literatura bantuísta a distinção semântica entre as três classes nominais locativas dessas línguas, cada língua tem formas diferentes de conceitualização do espaço. Um trabalho contrastivo entre essas três classes nominais em um conjunto de línguas de diferentes ou mesma zona linguística poderia ser bastante elucidativo quanto à diversidade de conceitualização espacial por bantófonos. Fora as expressões de localização estática ou de Construção Locativa Básica, são nas construções locativas dinâmicas que o comportamento das classes nominais locativas revelam suas verdadeiras complexidades na configuração espacial, ou seja, são nas construções de mudança de localização, mais especificamente de uma origem para o destino de um movimento, que podemos perceber algumas particularidades nas línguas do nigero-congolês, como atestado por Creissels (2006b).

\subsubsection{Origem e destino de um percurso}

Para as construções de origem e destino de um percurso, faremos uso da terminologia empregada por Creissels (2006b), a qual o autor identifica como a codificação dos sentidos de ablativo e alativo, aquele entendido como o sentido de origem de um percurso e este como o de sentido destino de um percurso. O sentido de essivo é empregado para o de localização ou inclusão. Conforme a tipologia de Creissels (2006b) apresentada na seção 5.5, as línguas bantas seriam classificadas como de Padrão 3, línguas para as quais a distinção entre esses três sentidos, essivo, ablativo e alativo, não seria codificada em adposições ou marcas de caso. A semântica das classes nominais locativas podem ser a explicação para esse fato. Nos exemplos eliciados abaixo, organizamos dois exemplos para o quizombo, umbundo e lingala indicando nos exemplos (6a), (7a) e (8a) o sentido de destino de um percurso e nos exemplos (6b), (7b) e (8b) o de origem de um percurso. Os morfemas das classes nominais locativas foram glosados de acordo com o sentido espacial expresso e não a numeração comumente utilizada, ou seja, os sentidos de alativo e ablativo, respectivamente:

Quizombo (H16h)
a. nkéntó
w-élè
kù-mbànzà
1.mulher
MS-ir.PERF
ALA-9.cidade
'a mulher foi para a cidade'
b. nkéntò
tùk-ìdì
kù-mbànzà
1.mulher vir-PERF
ABL-9.cidade
'a mulher veio da cidade' 
Umbundo (R11)
a. ukãi
w-a-ind-a
1.mulher
MS- PERF -ir-VF
v-olupale
'A mulher foi para a cidade.'
b. ukãi
w-a-tund-il-il-a
1.mulher
MS-PERF-sair de. APL-REV-VF
k-olupale
'A mulher veio da cidade.'

(8)

Lingala (C 36d)

$\begin{array}{lllll}\text { a. } & \text { mwásì } & \text { a-keyi } & \text { nà } & \text { èbàlé } \\ & \text { 1.mulher } & \text { MS-ir.PASD } & \text { ALA } & \text { cidade } \\ \text { 'A mulher foi para cidade' } & \\ \text { b. } & \text { mwásì } & \text { à-wítí } & \text { nà } & \text { mbókà } \\ & \text { 1mulher } & \text { MS-vir.PASD ABL } & \text { rio } \\ & \text { 'A mulher veio do rio' }\end{array}$

Dos exemplos das três línguas, observamos que o quizombo usa a mesma classe nominal locativa, a classe $17-k u$, para codificar os dois sentidos, alativo e ablativo. Nos exemplos em (7) o umbundo usa as classes nominais locativas 16 para o alativo e 17 para o ablativo, por outro lado, o umbundo faz também uso da extensão do aplicativo para dar o sentido de origem de um percurso (Creissels, 2006b). Os exemplos em (8), do lingala, mostram como uma língua banta sem as classes nominais locativas expressa os dois sentidos citados acima. A partícula na é usada nos dois casos, função que a classe locativa 17 do quizombo parece preencher. $\mathrm{O}$ fato a ser verificado mais de perto nesses exemplos é o da utilização da mesma marca para a codificação de dois sentidos espaciais considerados assimétricos, o de origem e destino de um percurso (Papafragou, 2010), o que levou possivelmente Araújo e Rocha (2011) a considerarem tal assimetria como a explicação cognitiva para a não existência de línguas em que convirjam os sentidos de ablativo com alativo e essivo, os Padrões $2 b$ e 2 c da tipologia de Creissels (2006b). Apenas com um exame mais minucioso como esse será possível verificar que a conceitualização espacial de qualquer língua pode e deve ser considerada com mais cuidado, fato desconsiderado, com motivos até certo ponto justificáveis, pelos trabalhos que relacionam locativos a possessivos. Os fenômenos espaciais passam a se tornar mais complexos se juntarmos as duas configurações espaciais, uma trajetória com mudança de 
percurso, o que descortina ainda mais as diferentes estratégias das línguas para a conceitualizar objetos num espaço.

6.2.3 Mudança de um percurso

Seguindo o mesmo esquema de apresentação dos dados para as três línguas eliciadas, abaixo enumeramos os exemplos de mudança de um percurso:

(9) Quizombo (H16h)

\begin{tabular}{|c|c|c|c|c|}
\hline a-lékè & à-túk-ìdì & kù-nzó & è-lè & ku-nkókò \\
\hline 2-moleques & MS-sair-PERF & 17-9.casa & MS-ir.PERF & 17-9.rio \\
\hline
\end{tabular}

'Os moleques foram de casa para o rio'
b. a-lékè
à-túk-ìdì
kù-nkókò
é-zídì
kù-nzó
2-moleques
MS-sair-PERF
17-9.rio
MS-ir-PERF 17-9.casa

'Os moleques vieram do rio para casa'

(10) Umbundo (R11)

a. Omãlã v-atund-a k-onjo on-kw-end-el-a k-olwi

2.criança MS-sair-VF 17-9.casa MS-INF-ir-APL-VF 17-9.rio

'As crianças foram de casa para o rio.'

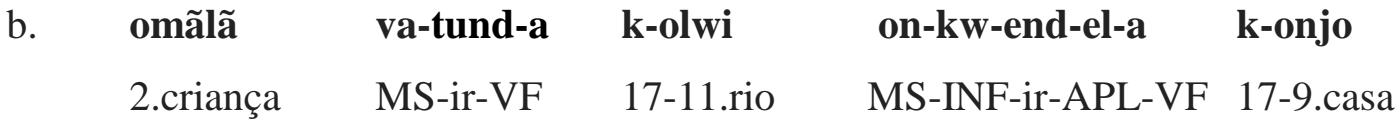

'as crianças vieram do rio para casa.'

(11) Lingala (C36d)

$\begin{array}{lllll}\text { a. b-ana } & \text { ba-kéyi } & \text { nà } & \text { èbàlé } & \text { útà ndákò } \\ \text { 2-criança } & \text { MS-ir } & \mathrm{ABL} & \text { casa } & \mathrm{ALA}\end{array}$

'As crianças foram de casa para o rio'

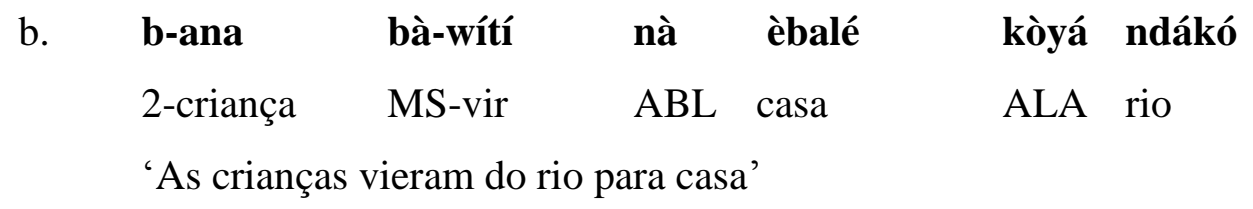

Nos exemplos acima é que a proposta tipológica de Creissels (2006b) parece se aplicar melhor para o caso das línguas bantas. Em (9) e (10), o quizombo e umbundo marcam os dois 
locativos "casa" e "rio" com a mesma classe locativa, 17, recorrendo ao verbo e suas extensões juntamente com a ordem dos predicados locativos para a codificação do abativo e alativo. O lingala usa a partícula $n a$, que sincretiza com o sentido de comitativo, para suprir a codificação dos sentidos de ablativo, e para o alativo faz uso de diferentes preposições, uta e koya. O suposto sincretismo da partícula na em lingala poderia ser apontada como um caso de sincretismo entre marcas de possessivo e instrumento com o sentido de locativos, fato considerado raro nas línguas do mundo, de acordo com o trabalho tipológico de Stolz, Stroh e Urdze (2006). É necessário um trabaho mais detalhado sobre a semântica de na do lingala e seu vasto leque de usos e sentidos, para que se possa especificar o real estatuto de sincretismo de comitativo com locativo e outros domínios, já que esse morfema nessa língua abrange praticamente todos os usos comumente esperado para as preposições de línguas indoeuropeias. Procuramos verificar o mesmo fato para outras línguas do nosso estudo e identificamos num contexto em que há uma escala definida de espaço e um tempo transcorrido, exemplos do quizombo que parecem indicar um tipo de sincretismo da marca de comitativo com expressões espaciais, a partir dos seguintes dados eliciados:

Quizombo (H16h)

$\begin{array}{llllllll}\text { túkà } & \text { kù-nzó } & \text { yé } & \text { kùnà } & \text { kókò } & \mathbf{1 5} & \text { mìnùtì } & \text { mù-màlù }^{6} \\ \text { Desde } & 17-9 . c a s a & \mathrm{COM}(\text { até }) & \text { LOC } & \text { 9.rio } & 15 & \text { minuto } & \text { 18-12.pé }\end{array}$

'De casa para o rio são 15 minutos a pé' (Lit. 'De casa com o rio são 15 min. a pé.')

Interessante notar que a partícula "yé" usada com o valor de comitativo em quicongo é aqui utilizada no sentido de "até". Em português, a preposição "até" tem muito mais um valor escalar do que de espaço propriamente dito, mas se considerarmos que nas línguas bantas a configuração de uma construção do tipo "IR de X até Y" codifica realmente uma mudança de localização, o ye nesse caso seria um dos raros casos nas línguas do mundo do sincretismo entre a partícula de comitativo com expressões de espaço (Stolz, Urdez, Stroh, 2006), fato a ser esclarecido com um estudo mais aprofundado. Ainda relacionada à questão de locativos, temos o conhecido fenômeno de inversão locativa, discutido na próxima seção.

\footnotetext{
${ }^{6}$ Nosso colaborador de quizombo deu a seguinte sentença como alternativa para (13):

.(i) túkà kù nzó (nàté) yé kùnà nkókò 15 mù málù.

Com o uso de "nàté" antes de yé, também com o seguinte de "até", possivelmente um decalque de "até" do português.
} 


\subsubsection{Inversão locativa}

Inversão locativa (IL) é uma das construções bastante discutidas na literatura bantuísta (cf. Salzmann 2011 para uma revisão da literatura). Nela, há uma inversão do sujeito e de um locativo seguido de uma inversão das funções gramaticais: o locativo passa a ser o sujeito, enquanto o tema perde suas propriedades de sujeito. Desde as primeiras propostas de Bresnan e Kanerva (1989) e a primeira tentativa de classificação tipológica por Demuth e Mmusi (1997), novos dados de diferentes línguas bantas têm enriquecido as análises, tornando uma classificação tipológica cada vez mais difícil (Cf. Buel, 2007 e Marten, 2006, 2010). ${ }^{7}$

Como exemplo, abaixo temos inversão locativa em herero (R31) e chicheua (N31):

(13) Herero (R31) (Marten, 2007, p. 98)
a. òvà-ndù
v-á-hìtí
mó-ngándá
2-pessoas MS2-PASD-entrar
18-9-casa
'os convidados entraram na casa'
b. mò-ngàndá mw-á-hìtí òvá-ndù
18-9-casa MS18-PASD-entrar 2-pessoa

'na casa entraram os convidados'

(14) Chicheua (N31) (Bresnan, 1994, p. 77)
a. Chi-tsime chi-li ku mu-dzi.
7-poço 7.MS-COP 17 3-vila
'O poço está na vila.'
b. Ku mu-dzi ku-li chi-tsime.
17 3-vila 17.MS-COP 7-poço

'Na vila está o poço.'

Dentre as principais propriedades discutidas nas línguas bantas para as construções de inversão locativas, encontramos as restrições temáticas propostas inicialmente por Bresnan e Kanerva (1989) para os quais a IL seria restrita aos verbos inacusativos, sendo isso possivelmente uma propriedade universal da IL. Demuth e Mmusi (1997) demonstram que outras línguas bantas permitem construções de IL com diferentes tipos de verbos: intransitivos

\footnotetext{
${ }^{7}$ Para uma discussão da tentativa de expandir a análise de línguas bantas para outras línguas não africanas, conferir Salzmann (2004, 2011).
} 
passivizados, bitransitivos passivisados e inergativos ativos. Marten (2006), a partir de exemplos do herero (R31) mostra que há uma maior flexibilidade quanto a tal restrição proposta por Bresnan e Kanerva. A Tabela 6.1 abaixo sintetiza as restrições para os tipos de verbos apontadas pelos autores nas línguas bantas analisadas até o momento:

Tabela 6.1 - Tipo de verbo em IL Marten (2007)

\begin{tabular}{llllllll}
\hline Tipo de verbo & & Chichewa & Kichaga & Chishona & Setsuana & Sesotho & Ochiherero \\
\multirow{2}{*}{ Inacusativo } & Ativo & OK & OK & OK & OK & OK & OK \\
& Passivo & - & - & OK & OK & OK & OK \\
\multirow{2}{*}{ Inergativo } & Ativo & - & - & - & OK & OK & OK \\
& Passivo & - & - & OK & OK & OK & OK \\
\multirow{2}{*}{ Transitivo } & Ativo & - & - & - & - & - & OK \\
& Passivo & OK & OK & OK & OK & OK & OK \\
Bitransitivo & Ativo & - & - & - & - & - & - \\
& Passivo & - & - & OK & OK & OK & OK \\
\hline
\end{tabular}

Pela Tabela, vê-se que do chicheua ao herero tem-se uma variação significativa quanto ao tipo de verbo que permite as construções de IL em línguas bantas. Outro tipo de variação bastante discutida na literatura é quanto à morfologia locativa. A partir dessa variação, os autores têm tentando classificar os tipos de IL.

Buell (2007) sugere os termos "Inversão Locativa Formal" para as línguas que apresentam morfologia locativa na concordância dos locativos sujeitos e "Inversão Locativa Semântica" para as línguas que não apresentam concordância morfológica para o locativo sujeito, em outras palavras, as línguas seriam classificadas de acordo com alguns padrões formais "padrão concordante" (agreeing pattern), enquanto outras com o padrão não concordante (non-agreeing pattern). Línguas como o chicheua, exemplo (15), seguem um padrão concordante, enquanto línguas como o setsuana (16) seguem um padrão não concordante:

(15) Chicheua (N31) (Bresnan; Kanerva, 1989, p. 15-6)

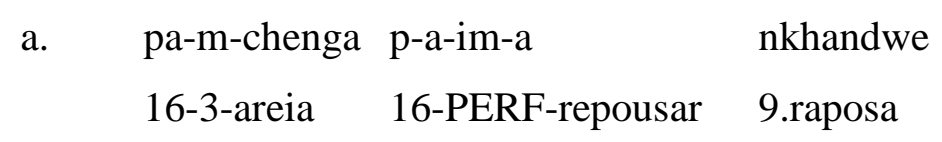

'Na areia repousa a raposa.'

b. ku-um-dzi ku-na-bwérá a-lendo-wo

17-3-vila 17-PASD-vir-VF 2-visitantes-aqueles

' $\mathrm{Na}$ /para a vila vieram aqueles visitantes.' 
$\begin{array}{lll}\text { c. m-mi-tengo } & \text { mw-a-khal-a } & \text { a-nyani } \\ \text { 18-4-árvore } & \text { 18-PERF-sentar-VF } & \text { 2-babuínos }\end{array}$

Nas árvores estão sentados os babuínos

(16) Setsuana (S31) (Demuth; Mmusi, 1997, p. 5)

a. fá-se-tlharé-ng gó-émé ba-símané

16-7-árvore-LOC 17-ficar parado 2-garoto

'Pelas árvores ficam parados os garotos.'

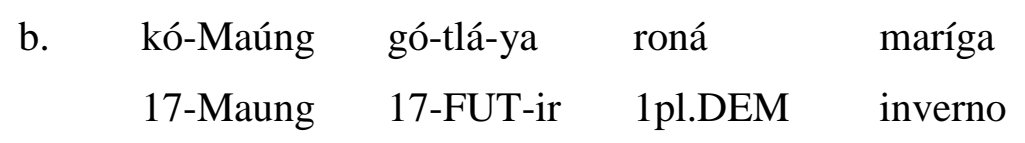

'Para Maung nós devemos ir no inverno.'

c. mó-lefátshé-ng gó-fúla di-kgomo

18-5-campo 17-pastar 10-gado

'No campo está pastando o gado.'

Para Demuth e Mmusi (1997), a concordância no verbo se dá com o sujeito locativo, mas não estritamente com a classe de concordância. Enquanto o verbo concorda com as classes locativas 16, 17 e 18 em chicheua (15), em setsuana, apenas a classe nominal locativa 17 concorda em todas as situações. Se o sujeito locativo for retirado, a marca de concordância locativa permanece no verbo, mas na verdade, acaba tendo muito mais um valor de expletivo do que locativo, segundo as autoras.

(17) Setsuana (S31) (Demuth; Mmusi, 1997, p. 9)

gó-fúla di-kgomo

17-pastar 10-gado

'é o gado que está pastando/Há/tem gado pastando'

Classificações como esta de Buell (2007) têm levado autores a buscar nas línguas bantas explicações para o mesmo fenômeno em outras línguas, como o português brasileiro (Avelar; Cyrino; Galves, 2009), posição criticada por Salzmann (2011). Para a nossa discussão sobre possessivos, interessa mostrar que uma análise mais detalhada sobre esse fenômeno sintático demonstra que Freeze (1992) não estava muito preocupado com todas as implicações de sua proposta, como pode ser visto em seu argumento contra Carol Georgopoulos, quem chamou a atenção do formalista para a necessidade de verificar todas as 
implicações de uma anáise unitarista para possessivos se se afirma que uma construção possessiva é um sujeito locativo com traços [+ humano] (Freeze, 1992, p. 561-2), portanto, tendo a ver com construções de inversão locativa. Salzmann (2004) segue na mesma linha de crítica de Georgopoulos.

A Tabela 6.2 sintetiza os padrões de variação na concordância locativa no verbo, encontrados em 8 línguas bantas que mereceram estudos sobre IL até o momento:

Tabela 6.2 - Categoria do locativo e marcação do sujeito em IL (Marten, 2007)

\begin{tabular}{lllll}
\hline Língua & $\begin{array}{l}\text { Categoria do } \\
\text { locativo }\end{array}$ & $\begin{array}{l}\text { Morfologia } \\
\text { nominal }\end{array}$ & $\begin{array}{l}\text { Morfologia } \\
\text { verbal }\end{array}$ & $\begin{array}{l}\text { Interpretação da marca do } \\
\text { sujeito }\end{array}$ \\
\hline Chichewa & $\mathrm{N}$ & $16 / 17 / 18$ & $16 / 17 / 18$ & Locativo \\
Suaíli & $\mathrm{N}$ & - & $16 / 17 / 18$ & $\begin{array}{l}\text { Locativo? } \\
\text { Kichaga }\end{array}$ \\
Chishona & $\mathrm{N}$ & - & 17 & Expletivo \\
& $\mathrm{N}$ & $16 / 17 / 18$ & $17 / 18$ & Locativo \\
Setsuana & $?$ & & $16 / 17 / 18$ & Locativo \\
Sesoto & $\mathrm{N}(?)$ & $16 / 17 / 18$ & 17 & Expletivo \\
siSwati/Zulu & $\mathrm{P}$ & - & 17 & Expletivo \\
Ochiherero & $\mathrm{N}(?)$ & - & 17 & Expletivo \\
& & $16 / 17 / 18$ & $16 / 17 / 18$ & Expletivo \\
& & 16 & Locativo \\
\end{tabular}

Mesmo em um conjunto relativamente restrito de línguas bantas é possível verificar um certo grau de diversidade entre os valores das classes nominais locativas. As línguas que não apresentam uma morfologia rica de concordância na marca de sujeito para a inversão locativa teria o seu índice concordante considerado como tendo um valor expletivo. No entanto, Buell (2007, p. 109) se mostra cético quanto ao valor expletivo das classes locativas de algumas línguas.

A semântica e a sintaxe da inversão locativa, se estudadas a fundo tanto no grupo das línguas bantas como em outras famílias linguísticas, apontam para a necessidade de um enfraquecimento do Paradigma Localista extremado da forma que é proposto por Freeze (1992). A inversão locativa em línguas bantas mostra que um locativo com as funções de sujeito pode sim apresentar a semântica de existenciais, como veremos em exemplos mais adiante, mas forçar a semântica de possessivos em locativos com os traços [+ humano] na posição de sujeito não parece ser tão plausível como é o caso para línguas de possessivos locacionais, das quais Freeze faz bastante uso. Para as línguas bantas, de possessivos comitativos, a inversão locativa, com locativos sujeitos com traços [+/- humano], enseja apenas e unicamente uma inversão locativa, nada que se assemelhe a possessivos. 
Para as línguas angolanas de nosso estudo, decidimos não adentrar na questão de como classificá-las seguindo os parâmetros discutidos pelos autores apresentados nesta seção, primeiramente por não termos tido tempo suficiente para a eliciação de dados nesse sentido, segundo por acreditarmos que os trabalhos produzidos até o momento sobre inversão locativa estão se pautando em casos muito específicos de línguas bem específicas. Uma tipologia, nos moldes conhecidos e esperados, necessita de uma amostra mais condizente com a natureza e abrangência do fenômeno, concordando assim com as críticas de Salzmann (2011). Um conjunto de estudos com algumas dúzias de línguas não preenchem todos os requisitos para uma proposta convincente de tipologia, apesar de ser esse o caminho para se chegar a uma classificação tipológica mais satisfatória, pelo menos para o caso das línguas bantas. No entanto, tais argumentos não nos redimem de apresentar alguns fatos com os quais teremos que lidar em futuros estudos sobre a temática em línguas angolanas, como os exemplos abaixo do quizombo:

(18) Quizombo (H16h) (Araújo; Teca; Fernando, em preparação)

$\begin{array}{llllll}\text { a. Vànà } & \text { mfúlù } & \text { sí } & \text { và-lèká } & \text { ànà } \\ & \text { 16.LOC } & 9 . \text { cama } & \text { FUT } & \text { 16-dormir } & \text { 2.crianças }\end{array}$

'Na cama dormirão as crianças.'

$\begin{array}{lllll}\text { b. } & \text { kùnà } & \text { mbánzà } & \text { kù-kòt-èlè } & \text { má-tókò } \\ \text { 17.LOC } & \text { 9.cidade } & \text { 17-entrar-PERF } & \text { 6-jovens }\end{array}$

'Na cidade entraram os jovens.'

\begin{tabular}{|c|c|c|c|}
\hline mùná & nzó & 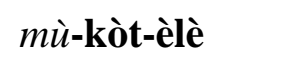 & mìvì \\
\hline 18.LOC & 9.casa & 18-entrar-PERF & 4.ladrões \\
\hline
\end{tabular}

'Na casa entraram ladrões.'

Nesses exemplos, identificamos no quizombo o padrão dito concordante, as três classes locativas, 16-18, são retomadas no verbo como marcas de sujeito, perfeitamente. Acontece que o prefixo locativo não se afixa diretamente ao nome na posição de sujeito, como acontece nos outros exemplos. Antes, compõem-se com o morfema $n a$, que em outras construções do quizombo é usado como cópula. A dúvida que fica é se, devido ao atual grau de gramaticalização dessas partículas, devemos encará-las como palavras locativas com estatuto de preposição, ou se para os três casos estaríamos lidando na verdade com a junção da classe locativa com a cópula do presente. Esse não é um grande problema descritivo, como 
pode parecer, mas a configuração da inversão locativa, da forma como está nos exemplos em (18), demonstra que a diversidade na produção desse fenômeno sintático está ainda longe de uma classificação satisfatória.

\subsection{Construções existenciais}

Quanto às estratégias utilizadas para a expressão de existenciais, grande parte das línguas bantas dispõe de cópulas. Nos exemplos abaixo, no quizombo a cópula leva a marca do sujeito, enquanto no umbundo é o morfema da classe nominal locativa, 17:

(19) Quizombo (H 16)

$\begin{array}{ll}\text { Nzámbì } & \text { wè-na } \\ \text { 9-Deus } & \text { MS-COP }\end{array}$

'Deus é (existe)'

(20) Umbundo (R 11)

$\begin{array}{ll}\text { Ku-li } & \text { Suku } \\ \text { 17-COP } & 1 . \text { Deus } \\ \text { 'Deus é (existe)' }\end{array}$

Exemplos como em (20), do umbundo, são indicados pelo africanista Heine (1997) como uma possível evolução da marca de locativo para um expletivo, comum em construções existenciais, a exemplo de there to be do inglês e il y a do francês. Para tanto, o africanista considera o seguinte exemplo de construção existencial como um expletivo:

(21) Suaíli (G42) (Heine, 1997, p. 206) ${ }^{8}$

$\begin{array}{llcc}\text { Pa- } & \text { na } & \text { wa-tu } & \text { w-engi } \\ \text { 16.LOC- } & \text { ter } & \text { 2-pessoa } & \text { 2-muito } \\ \text { 'Há muitas pessoas.' (Lit. 'Lá tem muitas pessoas.') }\end{array}$

Construção com classes locativas e cópula semelhante é encontrada também em herero:

\footnotetext{
${ }^{8}$ Neste exemplo, Heine glosa a partícula na como 'ter', o que em outros momentos a mesma partícula é glosada como 'com' ou 'estar_com'.
} 
(22) Herero (R31) (Möhlig; Kavari, 2008, p. 206)

$\begin{array}{lll}\text { P-ondjúwó } & \text { pa-rí } & \text { n-ombépérá. } \\ \text { LOC-casa } & \text { LOC-COP } & \text { COM-frio }\end{array}$

'Na casa estava frio.' ('Na casa tinha frio.')

Nesse caso, a cópula ri é acompanhada do locativo $p a$, da mesma forma que em suaíli. O que nos interessaria, porém, seria a possibilidade de expressar existenciais com a cópula seguida da partícula de comitativo, o que verificamos com os seguintes dados do yeyi:

(23) Yeyi (R41) (Seidel, 2008, p. 422)
a. Mu-na u-ndavu mu-mu-tara.
18-ser_com 1a-leão 18-3-interior
'Há/tem leões no interior (do país)'
b. Kwa-ra-na uwara kw-inda
17-COP.PASS-ser_com 14-cerveja 16-7-mercado

'Havia/tinha cerveja no mercado'

Em consulta ao nosso corpus escrito não encontramos nenhum outro exemplo como esse acima. Em kwanyama (R21) encontramos um exemplo de existencial negativo:

(24) Kwanyama (R21) (Halme, 2004, p. 46)

'Omushití ke_kó.

1.Criador NEG.1_17

'Não há Criador.' (Lit. O Criador não está lá.')

Uma observação a ser feita tem a ver com o exemplo anterior do herero, também um caso de inversão locativa. Relembrando a análise de Freeze (1992) e Clark (1978), verifica-se que quase sempre a leitura que se faz de inversão locativa é a de um existencial. Os exemplos abaixo do umbundo, sem glosas no original, retirados de Schadeberg e Valente, demonstram perfeitamente isso: ${ }^{10}$

\footnotetext{
9 A partícula na está glosada da forma que a maioria dos autores costuma fazer, ora com o traço ('ser/estar_com'), ora com o ponto ('ser/estar.com').

${ }^{10}$ As glosas são nossas, nos originais os autores dão apenas a tradução.
} 
(25) Umbundo (R11) (Schadeberg, 1986, p. 432; 434)
a. k-òlwi
kú-li óvi-ti
17-11.rio
17-COP
4.-árvores

'Há/tem árvores pelo rio.'
b. v-òmbénje mú-ĩi óv-éva
16-9.cabaça 18-COP 4-água

'Há água na cabaça.'

(26) Umbundo (R11) (Valente, 1964, p. 105)

$\begin{array}{llll}\text { k'onjo } & \text { ku-tate } & \text { ku-li } & \text { o-wuya } \\ \text { 17-casa } & \text { 17-pai } & \text { 17-COP } & \text { 3-calor }\end{array}$

'Na casa do pai está quente.' (Lit.' Na casa do pai há/tem calor.')

Dos exemplos acima, sem dúvida, a interpretação de existencial é bastante adequada, o que corrobora as análises sobre existenciais. É fácil, também, notar que em cada exemplo, o TEMA é acompanhado do pré-prefixo, comumente relacionado à determinação em línguas bantas. Pelas análises dos autores (Clark, 1978; Freeze, 1992), o TEMA, em uma construção existencial, deve ser indefinido, carregando o traço [- definido]. Vejamos um pouco mais sobre a semântica do pré-prefixo, para em seguida discutirmos algo sobre o efeito de definitude, inegavelmente relacionado a esses casos.

\subsubsection{O pré-prefixo}

O pré-prefixo, conhecido na tradição bantuísta como aumento (de Blois, 1970), é geralmente relacionado à determinação de SN ou à definitude, o que levou alguns estudiosos a considerá-lo como equivalente a algum tipo de artigo, à semelhança das línguas indoeuropeias (Katamba, 2003). Essa perspectiva, no entanto, simplifica bastante a questão dos usos e distribuição do pré-prefixo em línguas bantas. De Blois (1970, p. 152) já havia notado que o pré-prefixo passava por algumas restrições, notadamente no uso de nomes próprios, termos de parentesco, vocativos e nomes precedidos por marcas de negação. ${ }^{11}$

\footnotetext{
${ }^{11}$ Em herero, o pré-prefixo é usado antes de classes nominais locativas, tendo a função de presentativo (Möhlig; Marten; Kavari, 2002, p. 33). Para uma visão geral sobre o pré-prefixo na área norte-oeste do domínio banto, conferir Grégoire e Janssens (1999).
} 
Para Hyman e Katamba (1993) nem um tratamento estritamente sintático nem puramente semântico/pragmático podem dar conta dos fenômenos relacionados ao préprefixo, sendo necessário recorrer à sintaxe para entender melhor o comportamento desses morfemas, que na verdade estão relacionados não apenas à definitude, como também à especificidade e foco. Para os autores, mesmo com a complexidade encontrada para uma classificação dos usos do pré-prefixo, algumas generalizações são possíveis, como o caso das formas nominais sem o pré-prefixo que são licenciadas por dois operadores sintáticos, negação (NEG) e foco (FOC).

Os exemplos abaixo demonstram isso, em (27a) o nome "livro", bìtábó, está sem préprefixo, mesmo que em luganda o uso do pré-prefixo seja obrigatório numa oração relativa, independentemente da definitude do NP, e em (27b), o primeiro objeto, báànà, está focalizado, portanto, aparece sem o pré-prefixo, mesmo sendo definido, enquanto o segundo objeto, è-bítábó, aparece com o pré-prefixo, mesmo sendo indefinido:

(27) Luganda (E15) (Hyman; Katamba, 1993, p. 224, 229)
a. Tè-báálàbà
báágùlà
bìtábó
NEG-ver.PASS
REL2.comprar.PASS
livros
'Eles não viram aqueles que compraram os livros.'
b. yàgúlìrà
báànà
è-bítábó
ele-comprar.PASS
crianças
PPF-livros
'ele comprou livros para as crianças.'

$\mathrm{O}$ fator NEG apontando pelos autores parece atuar em quizombo, conforme exemplos abaixo em que em (28a) o uso do pré-prefixo em "nzo" (casa) pede uma leitura definida e, em (28b), para que haja uma leitura definida, o pré-prefixo deixa de ser utilizado:

(28) Quizombo (H16h) (Araújo; Teca; Fernando, em preparação)

$\begin{array}{llllll}\text { a. mùnà } & \text { yínà } & \text { nzílà } & \text { mù-kálà } & \text { é-nzó } & \text { yínà } \\ \text { LOC } & \text { DEM } & \text { 9.rua } & \text { LOC-COP } & \text { PPF-9.casa } & \text { DEM } \\ \text { wà-mu-èn-è } & & & \\ \text { MS-ver.PERF-VF } & & & \\ \text { 'Naquela rua havia/tinha a casa que você viu' } & \end{array}$




\section{b. mùnà yínà nzílà kà mù-á-kàlà nzó kó yínà ngèyé \\ LOC DEM rua NEG1 LOC-MS-COP casa NEG2 DEM 2PRON \\ wà-muèn-è \\ MS.ver.PERF-VF \\ 'Naquela rua não havia/tinha a casa que você viu'}

Entretanto, em quissolongo, dialeto do quicongo, temos um exemplo do uso do préprefixo para um SN definido em um possível contexto de foco e negação em (29b):

(29) Quissolongo (H16) (Diarra, 1989, p. 10)
a. kì-mwén-é nzò kó
NEG1-ver.PERF-VF 9.casa NEG2
'Não vi casa nenhuma'
b. è-nzò ki-mwnéné-yò kò
PPF-9casa NEG1.ver.PERF-MO NEG2
'a casa, não a vi'

Diante de exemplos como esses, faz-se necessário ainda um trabalho de fôlego para a semântica e sintaxe do pré-prefixo em línguas bantas. Todos os autores concordam que o préprefixo está relacionado à definitude, mas até o momento não contamos com nenhuma tipologia voltada para a questão do pré-prefixo em línguas bantas, relacionado ao efeito de definitude. Como está fora dos limites desta tese um tratamento mais adequado, tentamos verificar alguns aspectos do que tem sido discutido como efeito de definitude, para as línguas bantas, na próxima seção.

\subsubsection{Efeito de definitude}

Nas línguas bantas, a definitude é indicada por diferentes meios morfossintáticos como usos adicionais de pronomes demonstrativos ou marcas de concordância no verbo. Um exemplo é o suaíli que faz uso de demonstrativos antes de SNs para indicar definitude (Zerbian; Krifka, 2008). Conforme já afirmado várias vezes, outro meio utilizado pelas línguas bantas é o uso do pré-prefixo. Desde o primeiro trabalho comparativo de de Blois (1970), pouco tem se discutido sobre a semântica e o papel do pré-prefixo nas línguas bantas.

\footnotetext{
${ }^{12}$ Sem glosas no original. Indicamos a segmentação da forma que foi possível identificar cada segmento.
} 
Mesmo com trabalhos mais recentes, como os de Hyman e Katamba (1993) e Progovac (1993) e Petzell (2003), ainda parece bastante controverso o verdadeiro estatuto do préprefixo e os fatores morfossintáticos, semântico/pragmáticos e discursivos que afetam a distribuição deles nas línguas bantas.

Em nosso trabalho de elicitação de dados com um dialeto do quicongo, nos deparamos com a seguinte situação. Ao pedir ao nosso colaborador de pesquisa que apresentasse em quizombo a sentença: "Há/tem açúcar no café" obtivemos o exemplo em (30a), evidentemente a preferência foi a de uma construção de posse no lugar da construção existencial. Insistimos para a configuração espacial de um existencial/locativo em que "havia/tinha açúcar no café, desta vez com a cópula no passado, e obtivemos (30b), construída como um locativo. Para a terceira tentativa, obtivemos o equivalente a uma construção existencial iniciada com a cópula seguida da partícula comitativa yé (COM), no entanto, como ressaltado pelo colaborador, essa construção não é tão "natural", sendo que nela é obrigatório o uso do pré-prefixo sem o qual a sentença se torna agramatical. Pela tradução do colaborador, a sentença em (30c) seria melhor traduzida como "é no café que havia/tinha açúcar" ou "havia/tinha açúcar era no café" com o SN "café" focalizado. Porém, tal construção iria contra as generalizações de Hyman e Katamba (1993) de que o fator FOC desfavorece o uso do pré-prefixo. Em (22d) tentamos o uso de um demonstrativo para tornarmos "café" [+ definido] e [+ específico] e obtemos novamente um locativo, desta vez com o uso de um locativo enfático no final da sentença "mó":

(30) Quizombo (H16h) (Araújo; Teca; Fernando, em preparação)

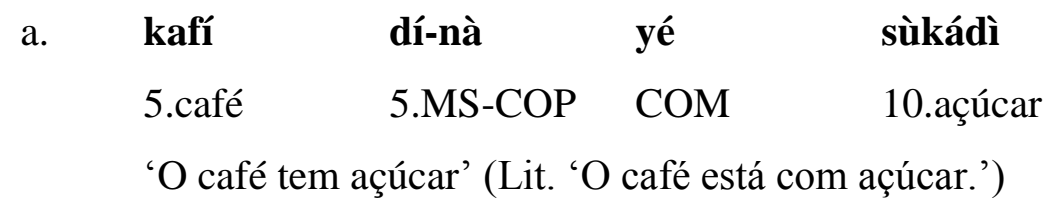
b. Sùkádì ká-zí-kàlá mùnà kàfî
10.açúcar PERF-10.MS-COP 18.LOC 5.café
'O açúcar estava no café'

$\begin{array}{llll}\text { c. díenà } & \text { yé } & \text { sùkádí } & \text { é-káfì } \\ \text { 5.COP } & \mathrm{COM} & \text { 10.açúcar } & \text { PPF-5.café }\end{array}$

'Havia/tinha açúcar no café'
d. Mùnà
dínà kàfî
sùkádì
zé-nà
mó
18.LOC
5.DET 5.café
10.açúcar
10.MS-COP LOC (Enf)

'Naquele café açúcar há/tem lá.' 
Os exemplos acima são apenas uma pequena demonstração da complexidade a ser encontrada nas línguas bantas concernente ao chamado efeito de definitude, inegavelmente relacionado a foco e outros mecanismos sintáticos.

\subsection{Construções comitativas}

Uma construção comitativa, retomando a definição de Arkhipov (2009), seria aquela utilizada para pluralizar um conjunto no qual os participantes teriam um papel assimétrico. Nas línguas do mundo, as partículas ou morfemas com valor comitativo são bastante polissêmicos (Strolz, Stroh e Urdze, 2006), o que torna qualquer trabalho tipológico para comitativos uma tarefa árdua. Conforme classificação tipológica desses autores, as línguas bantas, pelo menos as do nosso estudo, são do Tipo B, usando a mesma marca para o valor de comitativo e instrumento, como também para a coordenação entre NPs, o que pode ser verificado pela tradução para o português do exemplo abaixo, em quimbundo:

(31) Quimbundo (H21) (Pedro, 1993, p. 188) ${ }^{13}$

$\begin{array}{lllll}\text { Ngá-súmb-ú } & \text { mbíjì } & \text { nì xítú } & \text { nì } & \text { kítàdì } \\ \text { 1ps-PERF-comprar-VF } & \text { peixe } & \text { CONJ carne } & \text { COM/INST } & \text { dinheiro }\end{array}$

'Eu comprei peixe e carne com dinheiro.'

Abaixo, provérbio em quimbundo com a partícula comitativa:

(32) Quimbundo (H21) (Xavier, 2010, p. 131)

ù- $\theta$-énd-à nì mù-zúmbù kì-ù-á-zímbà-él-él-è

3sg-PRE-andar-VF COM 3-beiço NEG-REM-3sg-esquecer- APL-PERF-VF

'Quem tem boca vai a Roma.' (Lit. 'Ele anda com beiço, ele não (se) perdeu.')

Das línguas angolanas a que tivemos acesso às gramáticas ou com as quais trabalhamos com eliciação, o luchazi, ochindonga, herero e yeyi têm partículas com valor comitaitvo na forma $n a$, além de outras variantes, como é comum para muitas outras línguas bantas (Nurse, 2008). Para o quimbundo, ni. Para as demais línguas, a marca do comitativo apresenta uma certa variação, com

\footnotetext{
${ }^{13}$ No original o autor não especifica o número das classes nominais.
} 
as seguintes: para o quicongo, yé, para o umbundo, la, e Em quizombo, encontramos o uso da partícula yé com na formando o composto yéna, de acordo com o exemplo abaixo:

Quizombo (H16h) (Araújo; Teca; Fernando, em preparação)

$\begin{array}{llll}\text { Kópò } & \text { yénà } & \text { mázà } & \text { yì-bùdík-ídí } \\ \text { 7.copo } & \text { COM } & \text { 6.água } & \text { 7.MS-quebrar-PERF }\end{array}$

'O copo com água quebrou.'

Nurse dedica algumas palavras à partícula na:

\begin{abstract}
As línguas bantas têm apenas um $n a$ 'e, com' comitativo bastante alastrado. A conjunção $n a$ liga não apenas nomes, mas também orações e assim vem a se tornar um marcador de narrativas; 'estar+com (+ nome verbal)' dá 'ter'; 'estar com' ou 'ter' produz o progressivo, o qual pode se tornar marca de imperfectivo; 'não estar com agora' ou 'não ter agora' pode produzir 'ainda não'; e 'estava com' e 'estará com' forma a base para o passado e futuro. (Nurse, 2008, p. 250-1) ${ }^{14}$
\end{abstract}

Creissels (2013) também faz algumas considerações a cerca dessa partícula comitativa ao tratar do estatuto dela em tsuana:

Historicamente, a variante $n a$ - (a qual tem uma distribuição bastante limitada e nunca é obrigatória no tsuana) é reflexo da preposição comitativa do protobanto $* n a$, sendo que a variante produtiva le tem obviamente cognatos em outras línguas bantas do sudoeste apenas, e sua etimologia continua um mistério. (Creissels, 2013, p. $468)^{15}$

Essa citação foi retirada da discussão que o autor faz ao constatar o uso de na e le em tsuana para construções comitativas e possessivas. Voltaremos a essa questão mais adiante. $\mathrm{O}$ que é necessário manter em mente agora é a natureza sincrética das partículas de comitativo (Heine; Kuteva, 2002). No entanto, da mesma forma que para possessivos, o comitativo parece exibir uma prototipicidade quanto à relação entre NPs, o que Arkhipov (2009) chama de construção comitativa genuína. Vejamos o caso do quicongo e sua partícula comitativa yé que cobre grande parte das situações esperadas para uma construção comitativa:

\footnotetext{
14 “'Bantu has only one widespread 'comitative', na 'and', 'with'. The conjuction na links not just nouns but also verbs in clauses and so comes to be a narrative marker; 'be+with(+ verbal noun)' gives 'have'; 'be with' or 'have' give progressives, which may become imperfectives; 'not be with now' or 'not have now' may give 'not yet'; and 'was with' and 'will be with' form the basis for past and futures."

15 "Historically, the variant $n a$ - (which has a very limited distribution and is never obligatory) is a reflex of the Proto-Bantu comitative preposition *na, whereas the productive variant $l e$ has obvious cognates in the other Southern Bantu languages only, and its etymology remains a mystery."
} 
(34) Quizombo (H16h) (Araújo; Teca; Fernando, em preparação)
a. sé váyík-ìdí
mù-nsúkà
pai sair-REC
COM 1-criança
18-9.manhã
yé mwàná
'O pai saiu com o filho de manhã.'
b. sé yé
nkúdì
à-vàyìk-ídì
yé mwànà
pai $\mathrm{COM}$
9.mãe
MS-sair.REC
COM 1.criança
'O pai e a mãe saíram com o filho.'

\begin{tabular}{|c|c|c|c|c|}
\hline sé, & nkúdì & yé & mwànà & à-vàk-ídì. \\
\hline pai & 9-mãe & $\mathrm{COM}$ & 1.criança & MS-sair-PERF \\
\hline
\end{tabular}
'O pai, a mãe e o filho saíram.'

Nos exemplos acima, os participantes são distribuídos de várias formas, a depender de como participam da cena, e isso decorrente do uso da preposição yé. Os três participantes, o "pai", a "mãe" e o "filho", estão em uma relação assimétrica. No primeiro caso, o pai executa a ação de sair, tendo a companhia do filho. Na segunda (34b), o pai e a mãe saem em companhia do filho. Por fim, na terceira, os três participantes tomam a ação juntos. Nas três cenas, apenas na última o verbo apresenta uma forma diferente, mas não foi possível verificar com nosso colaborador o motivo dessa mudança, ensejando mais trabalhos de eliciação nesse sentido.

No quissicongo, dialeto do quicongo, a mesma partícula ye, chamada por Ndonga de relator associativo, participa da coordenação entre orações:

Quissicongo (H16) (Ndonga, 1995, p. 452)

$\begin{array}{lcll}\text { Wà-yímb }(\grave{a}) & \text { ò-mwànà } & \text { yè } & \text { wà-m'-vóndà } \\ \text { 3ps.pegar.PERF } & \text { PPF-criança } & \text { COORD } & \text { 3ps.MO-matar.PERF } \\ \text { 'Ele pegou a criança e a matou.' } & & \end{array}$

Para a nossa apresentação do comitativo em línguas bantas, nos ocuparemos principalmente com a relação entre o comitativo e as estratégias de coordenação, bem como do papel semântico do instrumento. Para a relação do comitativo com possessivos dedicamos a seção 7.5 do Capítulo 7. 


\subsubsection{Coordenação comitativa}

Retomando aqui a tipologia de Stassen (2000), lembramos que as línguas bantas são WITH-languages, de acordo com aquela tipologia, indicando que a mesma partícula usada para o comitativo é também utilizada para a coordenação entre SNs, em oposição às línguas que dispõem de duas unidades lexicais para a expressão de companhia e de coordenação entre nomes. A particularidade dessas línguas, de coordenação comitativa, é a possibilidade de algumas ambiguidades, como atestado no exemplo (36b) no qual o sentido pretendido seria “O pai comeu arroz e feijão, com o filho", porém, para que a sentença seja aceitável é preciso que se use a palavra "kumosi” (junto), em (36a):

(36) Quizombo (H 16h) (Araújo; Teca; Fernando, em preparação)
a. Yándì
dìdì
lòsò
yé
màdésò
3 sg.
comer.PERF
arroz
COM feijão

$\begin{array}{lll}\text { kùmósì } & \text { yé } & \text { mwànà } \\ \text { junto } & \text { COM } & \text { criança }\end{array}$
'Ele comeu arroz e feijão com o filho'
b. *Yándì dìdì lòsò yé màdésò yé mwànà
3sg. comer.PERF arroz COM feijão $\quad \mathrm{COM}$ criança

Em AND-languages, essa ambiguidade seria resolvida com um item lexical diferente, específico para a coordenação entre NPs, no caso do português seriam $\boldsymbol{e}$, diferenciando o comitativo de com. Em uma construção na qual os dois participantes compartilham a posição de sujeito, a ambiguidade não existe:

(37) Quizombo (H16h) (Araújo; Teca; Fernando, em preparação)

$\begin{array}{lllllll}\text { yándì } & \text { yé } & \text { mwànà } & \text { á-dìdì } & \text { lòsò } & \boldsymbol{y} \text { é } & \text { mádésò } \\ 3 \mathrm{sg} & \mathrm{COM} & \text { criança } & \text { MS-comer.PERF } & \text { arroz } & \mathrm{COM} & \text { feijão }\end{array}$

'Ele e o filho comeram arroz e feijão'

Parte dessa ambiguidade pode ser entendida pela relação assimétrica típica de uma relação comitativa. Pelos exemplos acima, pode parecer que seja apenas uma questão de ordenação dos SNs. Em (36b), o filho está no final da sentença, sendo incluído com os elementos que foram comidos pelo pai, o que demanda a indicação por outro item lexical da 
relação de companhia com o primeiro participante. Já no exemplo em (37), o filho está logo no começo da sentença, permitindo ser entendido também como participante da ação de comer. Na terminologia da Gramática Cognitiva, a partícula yé não permite alinhar o filho como TR juntamente com o pai, em (36b), precisando fazer uso da palavra "kumosi". Em (37), porém, pelo fato de o filho estar juntamente com o pai numa posição de sujeito, ambos são perfilados como um mesmo trajetor (TR) na sentença, enquanto que o MR, arroz e feijão, são menos proeminentes, carregando a função de objeto direto.

Conforme a tipologia de Stassen (2000), as línguas buscam desenvolver alternativas para a distinção entre uma construção comitativa de uma coordenação de NPs, a partir de verbos, numerais ou outro determinante. Dentre as línguas do nosso estudo, o umbundo parece ser um exemplo de língua banta que está desenvolvendo uma partícula de coordenação de NPs. Para o umbundo, a partícula do comitativo é la, sendo usada também para a coordenação entre NPs:

Umbundo (R11)

$\begin{array}{llll}\text { ise } & \text { l'-omola } & \text { v-atund-a } & \text { l'-omeĩe } \\ \text { pai } & \text { COM-1.criança } & \text { MS-sair-VF } & \text { COM-manhã } \\ \text { 'O pai e o filho saíram de manhã.' } & \end{array}$

Acontece que, além da partícula la, a língua parece ter recrutado outra estratégia para partícula coordenativa, possivelmente gramaticalizada do verbo "ir", oku-kwenda, enquanto em quicongo, apenas ye é utilizado para os dois sentidos:

(39) Umbundo (R 11)

omoĩa wa-kala l'onjala, l'enyona kwenda otulo

1-criança MS-COP COM-9.fome COM-5.sede CONJ 13.sono

'A criança tinha/estava com fome, sede e sono.'

(40) Quizombo (H16h) (Araújo; Teca; Fernando, em preparação)

$\begin{array}{llllllll}\text { mwànà } & \text { wà-kàlà } & y e ́ & \text { nzálà } & y e ́ & \text { vwìnà } & y e ́ & \text { túlò } \\ \text { 1.criança } & \text { MS-COP } & \mathrm{COM} & \text { 9.fome } & \mathrm{COM} & \text { 5.sede } & \mathrm{COM} & \text { 13.sono } \\ \text { 'O filho tinha/estava com fome, } & \text { com sede e com sono.' }\end{array}$


O uso de kwenda é ainda restrito ao último elemento de uma lista, como em (39), não sendo possível substituir la em la onjala e la enyona, por kwenda, o que indica que o processo de gramaticalização ainda está em progresso. Ainda é cedo para prever se kwenda irá tomar o lugar de la em todos os contextos de coordenação entre NPs ou se continuará restrito a esse uso. Em yeyi, identificamos um caso similar, mas na impossibilidade de verificar em outros contextos, selecionamos o exemplo abaixo no qual aparecem justamente a partícula do comitativo na e o item coordenativo indu:

(41) Yeyi (R41) (Seidel, 2008, p. 220)

\begin{tabular}{|c|c|c|c|}
\hline kwa-ra-na & u-nshuru & indu & ruwawa \\
\hline 17-PAST-COM & 1a.-lebre & COORD & 1a-chacal \\
\hline
\end{tabular}

'Lá vivia uma lebre e um chacal.'

As línguas que estão seguindo esse caminho de gramaticalização podem oferecer boas evidências para as generalizações tipológicas de Stassen (2000).

Na próxima seção, tratamos do papel semântico de Instrumento.

\subsubsection{Instrumento}

Stolz, Stroh e Urdze (2006) indicam três tipos principais na forma como as línguas sincretizam as marcas de Comitativo e Instrumento. Segundo a tipologia dos autores, o Continente africano parece seguir a mesma tendência das línguas indo-europeias, sendo a preferência pelo Tipo B, a do sincretismo entre as referidas marcas. Tal sincretismo, como já mencionado, ensejou a elaboração da Metáfora da Companhia de Lakoff e Johnson (1980). No entanto, existem casos de não sincretismo entre as marcas de Comitativo e Instrumento, conforme podemos verificar neste exemplo do yeyi, no qual a marca do comitativo na difere da de Instrumento sha:

(42) Yeyi (Seidel, 2008, p. 173)
a. Nda-y-a
$n a$-tjo
sha $=$ ma-kondo
1s-(Ant-)vir-a
COM-Subs(7)
INST=6-pé

'Eu vim com isso (comida) a pé.' (Lit. 'Eu vim com isso com (usando) o pé.') 
Atentar para isso nos faz acreditar que descrições mais detalhadas de línguas bantas podem revelar um outro quadro para a tipologia de Stolz e associados. Estamos inclinados a afirmar que um exame mais detalhado sobre o domínio do Instrumento em línguas bantas pode reforçar o apelo de Arkhipov (2009) por uma tipologia do Comitativo mais refinada.

Abaixo, coligimos exemplos de línguas do nosso estudo:

(43) Quizombo (H16h) (Araújo; Teca; Fernando, em preparação)

sé wà-bàkà zìnzónzì yé ndóbù yìmòsì

pai 5.MS-pescar 10.peixe INST 9.anzol 9.NUM

'O pai pescou os peixes com um anzol.'

(44) Umbundo (R11)

$\begin{array}{llll}\text { isya } & \text { wa-tamba } & \text { olombisi } & \text { l'onjolo } \\ \text { pai } & \text { MS-pescar } & \text { 10.peixe } & \text { INST-9.anzol }\end{array}$

'O pai pescou os peixes com um anzol.'

(45) Herero (Möhlig; Kavari, 2008, p. 221) ${ }^{16}$

Má-ve-tjangá ombapíra n-õpéna.

1.pl-AUX-escrever carta INST-caneta

'Eles estão escrevendo com uma caneta.'

(46) Quimbundo (Pedro, 1993, p. 59)

Dìyálá ú-dìmà nì mákù

5.homem 1.MS-cultivar-IMPERF INST 6.mãos

'O homem cultiva com as mãos.'

Percebemos que para o quizombo, durante nosso trabalho de eliciação, que além da utilização da marca de comitativo para instrumento, havia também a preferência para a expressão de instrumento a partir do uso da classe nominal locativa 18. Poderíamos sugerir que esses casos seriam algum tipo de sincretismo entre marcas de locativos com o papel semântico de instrumento, conforme indicado por Stolz (2001). Stolz sugere que certos sincretismos são mais raros de acontecer, nesse caso o autor estava discutindo o caso em que

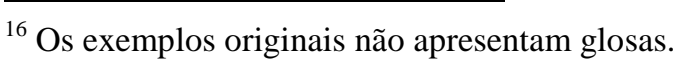


marcas de comitativo são usadas em expressões locativas. Para o quizombo, encontramos a situação contrária. Fica a dúvida, no entanto, se realmente a classe nominal locativa 18, mu-, é um morfema locativo sincretizando com o instrumento ou se o instrumento é expresso por algum tipo de construção idiomática, para o caso do português brasileiro. Os dois exemplos abaixo mostram como acontece em quizombo. Em português é possível uma tradução quase literal para os exemplos:

(47) Quizombo (H 16h) (Araújo; Teca; Fernando, em preparação)
a. Lùzòlò vó-nd-èlè
mèmè
mù-mbélè
Luzolo
MS-matar-PERF
carneiro
18-faca
'Luzolo matou o carneiro com a faca' (Lit. Luzolo matou o carneiro na faca)
b. sé vwètè mvwátù mù-nzákì
pai vestir.REC 3.roupa 18-pressa
'O pai vestiu a roupa com pressa.' (Lit. 'O pai vestiu a roupa na pressa.')

Para o caso do umbundo não foi possível verificar nas sessões de eliciação a existência do mesmo sincretismo, mas tudo indica que o sincretismo entre INST e LOC não é possível em umbundo (48) da mesma forma que acontece em quizombo (49):

Umbundo (R11)

isya $l$ '-omõla

waye

va-lya

l'-ovoko

1.pai COM-1.criança

POSS

2.MS-comer.REC

COM-6.mão

'O pai e o seu filho comeram com as mãos.'

(49) Quizombo (H16) (Araújo; Teca; Fernando, em preparação)

$\begin{array}{lllll}\text { sé } & \boldsymbol{y e ́} & \mathbf{1 . m w a ̀ n a ̀ ~} & \text { à-día } & \text { mù-mòkò } \\ \text { pai } & \mathrm{COM} & \text { criança } & \text { MS-comer.VF } & \text { 18-6.mão }\end{array}$

'O pai e o filho comeram com as mãos.'

Os fatos possíveis de identificar em estudos que deem atenção ao instrumento podem levar estudiosos a demonstrar uma ligação ainda maior entre os domínios de possessivos e instrumento. Da mesma forma que temos argumentado em favor da inclusão do domínio conceitual do comitativo nos estudos sobre possessivos e locativos e existenciais, o instrumento tem se mostrado relativamente próximo a possessivos e locativos quando é dada 
a ele a devida atenção. Nossas observações na seção 5.5, são corroboradas com o instrumento, confirmando assim a necessidade de considerar também os subdomínios (conceituais) envolvidos nas construções relacionadas a posse predicativa.

\subsection{Construções possessivas}

Para a apresentação das construções possessivas em línguas bantas resolvemos não nos determos nos subdomínios ou subtipos de possessivos, da forma como discutimos no Capítulo 3. Pelo corpus escrito e pelos dados eliciados não nos foi possível coligir e examinar as diferentes nuances na expressão das relações possessivas, nos contextos de propriedade, parte-todo (juntamente com o traço semântico de (in)alienabilidade), relações de parentesco, etc. Já mencionamos, no entanto, que a análise desses aspectos semânticos são desejados, mas como não interferem diretamente nos fenômenos de relações conceituais de nosso interesse, decidimos nos ater apenas ao caráter estrutural das estratégias de posse predicativa das línguas bantas desta tese. Enquanto para as construções locativas, existenciais e comitativas, nos centramos muito mais sobre os subdomínios, de locativos estáticos e dinâmicos, inversão locativa, efeito de definitude, coordenação comitativa e instrumento, para os possessivos iremos verificar melhor as diferentes estratégias predicativas. O que não nos exime de um trabalho futuro com o fim de analisar comparativamente os diversos subtipos de possessivos.

Verificamos pelo menos quatro estratégias de construções de posse predicativa nas línguas bantas a que tivemos acesso. Dentre elas, o umbundo é a única a apresentar um verbo equivalente a "ter", além da construção prototípica em línguas bantas, numa construção com verbos de cópula mais a partícula de valor comitativo. Encontramos também, em quicongo, uma construção de posse predicativa que parece seguir o esquema de evento de equação, conforme proposta por Heine (1997). Nesta e nas próximas páginas apresentamos as principais construções de posse predicativa identificadas em nosso corpus.

\subsubsection{Construções com cópula e comitativo [PR $\quad(\mathrm{COP})+\mathrm{COM} \quad \mathrm{PD}]$}

A primeira estratégia é a mais prototípica para as línguas bantas, como já mencionado, o uso da cópula com as partículas de comitativo. No entanto, temos algumas particularidades na forma como cada língua utiliza o comitativo juntamente com as cópulas. Em boa parte das línguas de nosso estudo, no tempo presente, sem marcas de negação, é comum que a partícula 
de comitativo apareça como único item lexical responsável pela relação de possessivo. Para o caso do herero, ochindonga e yeyi, é a partícula na:

(50) Herero (R31) (Möhlig; Kavari, 2008, p. 205) ${ }^{17}$
a. Ú
ná
omútímá
omuwá
3 ps.sg
$\mathrm{COM}$
cl.3-coração
3-bom
'ela/ele tem um bom coração'
b. Ondjou í-n-omása.
Elefante 9-COM-força
'Um elefante tem força.'

(51) Yeyi (R41) (Seidel, 2008, p. 423)
a. Ni-na ba-mankisi
2p-COM 2a-pares
'Vocês todos têm pares'

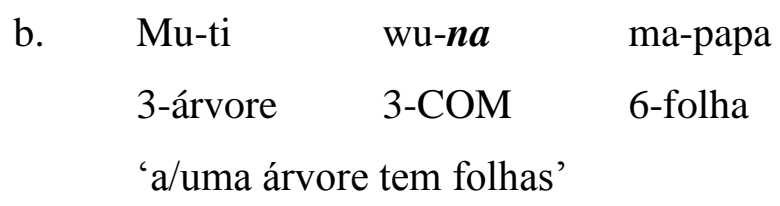

(52) Ochindonga (R22) (Fivaz, 2003, p. 131)

Ngame ondi-na-óshihautó óshipe

1PS MS-COM-carro novo

'Eu tenho um carro novo.'

Casos como esses são vistos como evidência de que as línguas estão passando pelo processo de transitivização, ou de criação de um verbo do tipo "ter", como veremos na seção 6.6 .

Da mesma forma que acontece com outras línguas bantas, como o suaíli, se a sentença estiver no passado um outro verbo, comumente denominado de defectivo, é utilizado. Para o herero é o verbo ri:

\footnotetext{
${ }^{17}$ Os exemplos originais não apresentam glosas, portanto, não foi possível identificar a função de todas as unidades na sentença, como o clíticos $i$ do exemplo (44b). Em outros momentos, os autores traduzem na como verbo "ter".
} 
(53) Herero (R31) (Möhlig; Kavari, 2008, p. 206)
a. Wa rí n-omútímá omuwá
3ps.sg COP COM-3-coração bom
'ela/ele tinha um bom coração'
b. Ondjou yá-rí n-omása.
Elefante $\quad$ 9-COP $\quad \mathrm{COM-força}$
'Um elefante tinha força (hoje).'

No lingala, o presente é construído com a cópula e o comitativo:

(54) Lingala (C 36d)

$\begin{array}{llll}\text { ò-bà-tó } & \text { bà-zálì } & \text { nà } & \text { bà-ndàkó } \\ \text { PPF-2-pessoas } & \text { 2-COP } & \mathrm{COM} & \text { 2-casas } \\ \text { 'as pessoas têm casas' } & & \end{array}$

Tudo indica que a forma como as partículas de comitativo ocorrem em construções de posse predicativa está fortemente relacionada ao sitema de TAM de cada língua. Por outro lado, o caminho de gramaticalização das partículas comitativas pode ser uma variável importante para o comportamento das construções possessivas. Na falta de traços de marcação de TAM nas partículas comitativas, as línguas precisam recorrer a outros mecanismos morfofonológicos:

(55) Quimbundo (H 21) ${ }^{18}$
a. ò̀ mù-hátù ù-ál-à kì-tádì DET 1-mulher 1-PRS-COP-VF COM 7-dinheiro 'a mulher tem dinheiro'
b. éì̀ ù- $\varnothing$-ál-à $\quad$ à à-ánà kì-ádì, étù tù- $\varnothing$-ál-à nì mù-ánà ùmófî P2' 1-PRS-estar-VF COM 2-filho 7-dois, P1" 1-PRS-estar-VF COM 1-filho 'você tem dois filhos, nós temos um filho'

\footnotetext{
${ }^{18}$ Os exemplos do quimbundo foram gentilmente cedidos por Xavier e fazem parte do corpus utilizado em sua tese de doutorado (2010). Xavier glosa o pré-prefixo como DET, enfatizando o papel de determinante do préprefixo em muitas línguas bantas.
} 
Para o passado remoto, a cópula kala tem uma ligeira modificação:

Quimbundo (H21) (Xavier, 2010, p. 127)

ò mánì-ù-á-étù ì- á- èf-él DET 9-mãe-1-GEN-P1' 9-REM-estar-PERF-VF COM 6-dor 6-GEN-15-nascer 'Minha mãe teve dores do parto'

Línguas como o quicongo e o umbundo, que possuem estratégias bem diferentes para posse predicativa (Cf. 6.4.3 e 6.4.4), não permitem o uso da partícula comitativa sozinha para a expressão de possessivo. Neste ponto, uma questão que deve ser perseguida, com o fim de entender as diferentes possibilidades em construções de posse predicativa em línguas bantas, é o grau de gramaticalização e o estatuto dos morfemas do comitativo para cada língua. Um exemplo de como pode ser produtivo um trabalho sobre a relação entre cópulas e partículas de comitativo é um fato curioso discutido por Creissels (2013), nesse caso, para o tsuana. Mesmo que esses fenômenos não se tenham verificado em línguas angolanas, dedicamos a próxima seção para essa discussão, pois as questões levantadas pelo autor podem ser úteis para investigações posteriores.

\subsubsection{O estatuto de COP e COM [PR (NEG) COP.COM (+ COM) PD $]$}

É comum uma interação entre a cópula e o morfema que carrega o valor de comitativo, para a expressão de possessivos. Uma boa exemplificação disso é dada por Creissels para o caso do tsuana:

(57) Tsuana (S31) (Creissels, 2013, p. 469)
a. Ke le Katso.
1SG ser_com com 1.Kitso
'Eu estou com o Kitso.'
b. Ke na le ma-di.
1SG ser_com com 6-dinheiro
'Eu tenho dinheiro'
c. *Ke na madi.
1SG ser_com dinheiro 
Nas sentenças acima, Creissels observa que o verbo defectivo na é usado juntamente com a partícula comitativa le, tanto para companhia como para possessivos. No entanto, o verbo na sozinho não carrega a noção de possessivo, como ocorre com outras línguas bantas como o herero, yeyi, etc. (Cf. 6.4.1). O fato de na, co-ocorrer com le deixa dúvidas quanto ao valor de comitativo dessa partícula, para Creissels (2013, p. 469), Porém, em sentenças negativas acontece o seguinte:

(58) Tsuana (S31) (Creissels, 2013, p. 469-470)
a. $G a$ ke na le Kitso.
NEG 1SG ser_com com 1.Kitso
'Eu não estou com o Kitso.'
b. $\quad$ Ga ke ma-di.
NEG 1SG ser_com 6-dinheiro
'Eu não tenho dinheiro.'
c. $\quad$ Ga ke na na-o.
NEG 1SG ser_com com-6
'Eu não tenho nenhum (dinheiro).'

Em sentenças negativas, $n a$ ocorre sozinho como um verbo comitativo.

Em sentenças de polaridade negativa (52), le é opcional, determinando se a sentença será comitativa (52a) ou possessiva (52b). Infelizmente não foi possível verificar com dados eliciados como se comportariam as línguas bantas do nosso estudo. Até antes de ter conhecimento do trabalho de Creissels (2013) não foi dada tanta atenção para o papel da negação para a semântica do comitativo e do possessivo. Em exemplos retirados do nosso corpus escrito, também não foi possível localizar nenhuma situação similar àquela do tsuana. Vejamos alguns exemplos do herero, nos quais o verbo defectivo ri combina com na em sentença negativas: 
(59) Herero (Möhlig; Kavari, 2008, p. 205) ${ }^{19}$
a. été ka-twá-rí n-ënyándó.
3pl NEG-ms-COP COM-felicidade
'Nós não estamos felizes.' (não estamos com felicidade)
b. ovikuryá mbí kaví rí n-äwa.
comida ? NEG? COP COM-bom
'Esta comida não é boa.' (não com bom)

Os casos anteriores envolvem o tipo de construção que temos considerado prototípica para a expressão de posse predicativa em línguas bantas. observamos, no entanto, em duas das línguas de nosso estudo que a expressão prototípica fugia um pouco daquelas da maioria das línguas bantas. As duas seções seguintes se concentram sobre o quizombo e umbundo, respectivamente.

\subsubsection{Construções com esquema [PR $\quad$ PD $\quad$ COP + POSS $]$}

Nos trabalhos de eliciação com o quizombo, além do material bibliográfico, vimos que a expressão de posse predicativa preferida, no presente, parece ser, grosso modo, próxima do evento de esquema de equação, da tipologia de Heine (1997):

(60) Quizombo (H16h)
a. a-ntú
nzó
é-nà
z-áu
2-pessoas
10.casas
2.MS-COP
10-POSS
'As pessoas têm casas' (Lit. 'As pessoas, as casas são delas')
b. muntú
nzó (ymósì)
ké-nà
y-áu.
1-pessoa
9.casa (NUM)
1.MS-COP 9-POSS
'O homem tem (uma) casa' (Lit. 'O homem, a casa é dele')

\section{c. à-lóngókí}
nkándà
è-nà
mí-au
2-estudantes
10.livros
2.MS-COP
2-POSS

'Os estudantes têm livros' (Lit. 'Os estudantes, os livros são deles')

\footnotetext{
${ }^{19}$ Os exemplos no original não apresentam glosas.
} 
Nessas construções, o quizombo segue a fórmula PR PD COP POSS, o possuidor (PR) vem no início da sentença, seguido do possuído (PD), para então a cópula juntamente com o pronome possesivo. As traduções entre parênteses indicam melhor o esquema para posse predicativa do quizombo. Dereau (1955) já indicava tal estratégia para o quicongo:

(61) Quicongo (H16) (Dereau, 1955, p. 30, 31)

$\begin{array}{lll}\text { a. mwâna } & \text { u-na } & \text { yâme } \\ \text { 1.criança } & \text { MS-COP } & \text { POSS }\end{array}$

'Eu tenho um filho' ('A criança, ela está comigo’)

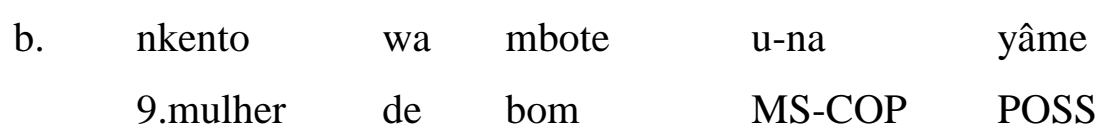

'Eu tenho uma boa esposa' ('Uma esposa boa, ela está comigo')

A diferença dos nossos exemplos eliciados daqueles de Dereau é quanto ao PR que não aparece na posição de tópico, nos exemplos em (55), o que faz com que Dereau considere o PD como sujeito da sentença. Segundo nosso colaborador falantes de quizombo, as sentenças em (54) são preferidas para a expressão de posse predicativa, no presente, no entanto, Dereau (1955, p. 31) atesta que a forma em (55a) era a mais corrente, sendo que o uso da cópula na com a preposição yé daria um sentido mais forte para possessivo, e já indicava que ye não raramente deixava de ser utilizado:

(62) Quicongo (H16) (Dereau, 1955, p. 31)

$\begin{array}{llllll}\text { Nzo } & \text { ya } & \text { yi, } & \text { nêla } & \text { zôle } & \text { i-na } \\ \text { Casa } & \text { DEM } & ? & \text { janela } & \text { duas } & \text { MS-COP }\end{array}$

'Aquela casa tem duas janelas.'

Novamente, os dados em Dereau diferem dos nossos:

(63) Quicongo (H16)

$\begin{array}{llll}\text { Zì-nzó } & \text { zí-ná } & \boldsymbol{y} \text { é } & \text { zi-nela } \\ \text { 10-casa } & \text { MS-COP } & \text { COM } & \text { 10-janelas }\end{array}$

'As casas têm janelas.'

Da mesma forma que para as outras línguas bantas, para outros tempos verbais outras 
cópulas são empregadas e o uso de ye torna-se obrigatório:

(64) Quizombo (H16h) ${ }^{20}$
a. a-ntú
á-kálà
yé
zì-nzó
2-pessoas MS-COP
COM 10-casa
'As pessoas tinham casas.'
$\begin{array}{lll}\text { b. } & \text { a-ntú } & \text { sí } \\ & \text { 2-pessoas } & \text { FUT }\end{array}$
à-kálà
$\boldsymbol{y} e ́$
zí-nzó
COM 10-casa

'As pessoas terão casas.'

Uma outra língua, classificada como da zona B, que usa uma partícula de comitativo semelhante à do quicongo é o Nzadi:

(65) Nzadi (B865) (Crane; Hyman; Tukumu, 2011, p. 145)

$\begin{array}{llllll}\text { a. } & \text { bo } & \text { a } & \text { mán } & \text { ye } & \text { ndzaa } \\ 3 p 1 & ? & \mathrm{COP} & \mathrm{COM} & \text { fome }\end{array}$

'Eles têm/estão com fome.'

$\begin{array}{lcccccc}\text { b. } & \text { mi } & \text { a } & \text { máy } & \text { ye } & \text { mbvel } & \text { dzum. } \\ \text { 1sg } & ? & \text { COP } & \text { COM } & \text { anos } & \text { NUM } \\ \text { 'Tenho/Estou com } 10 \text { anos.' } & & \end{array}$

6.5.4 Construções transitivas $[\mathrm{PR}+\mathrm{V}+\mathrm{PD}]$

Outro caminho de gramaticaização para a criação de um verbo "ter" na maioria das línguas é a reanálise de um verbo transitivo, geralmente significando "pegar", "levar" ou “segurar" para a expressão de possessivos (Heine, 1997), dentre outros nem tanto comuns como "ganhar" (Creissels, 1996). Em umbundo, além da estratégia comitativa, mais prototípica para as línguas bantas, “vakasi la = 'eles estão com = eles têm' (Schadeberg, 1990, p. 19), o verbo "kwete", originalmente com o sentido de segurar (Alves, 1951, p. 449), é usado para a maioria das construções possessivas. Em Valente (1967, p. 187) já encontramos uma primeira discussão sobre a relação entre os verbos $l i$, kasi e kwete, traduzidos pelo padre como "ser", "haver" e "ter". Alguns exemplos do umbundo:

\footnotetext{
${ }^{20}$ Carter e Makoondekwa (1987) explicam em seu curso de conversação em quizombo diversas situações no uso possessivos dentre os discutidos nesta seção.
} 
(66) Umbundo (R11)
a. Om-anu
va-kwete olondjo
2-pessoa
MS-ter 10.casa
'As pessoas têm casas.'
b. Olondonge vi-kwete alivulu
10.estudantes MS-ter 6.livros
'Os estudantes têm livros.'
c. olonjo vi-kwete ocivanjelo
10.casas MS-ter 7.janelas
'As casas têm janelas.'

A preferência em umbundo para posse predicativa é sem dúvida esta com o verbo kwete. No entanto, a estratégia comitativa é ainda usada em umbundo:

\begin{tabular}{|c|c|c|c|c|}
\hline \multicolumn{5}{|c|}{ Umbundo (Schadeberg, 1990, p. 56) ${ }^{21}$} \\
\hline óco & ókalè & l'úlóng'o, & kú-ka-kále & l'úsyayi. \\
\hline para que & $\mathrm{COP}$ & $C O M$-cérebro & 2PS-NEG-COP & COM-preguiça \\
\hline
\end{tabular}

Podemos considerar o umbundo como uma língua de Ter-possessivos, com o verbo kwete em processo de gramaticalização avançada. No Dicionário Etimológico de Alves é possível encontrar o seguinte sobre esse verbo:

(68) Umbundo (R11) (Alves, 1951, p. 449-5)

KWESA, KWESE, KWETE

(otji) Ver KWEKA (2), KWEKWEÑE (otji).

I. De kwata = segurar

II. V. A. Segurar. Ter. possuir, tomar a peito, agarrar com força. III. 1 .

- NOTA. 1) Este verbo usa-se geralmente só no indicativo, sendo os demais tempos substituídos pelos do verbo kala. 2)

\footnotetext{
${ }^{21}$ Exemplo do umbundo sem glosas no original, significando: 'Para serdes sábio, não podes ser preguiçoso' .
} 
Chegamos a pensar na hipótese de que talvez o umbundo estivesse se comportando como o português, tendo à sua disposição as estratégias comitativas e transitivas para posse predicativa, sendo que a primeira é geralmente usada para posse temporária ou estados. Consultamos um curso de conversação mais atual do umbundo (Chacusanga, 2006) e verificamos que, apesar da preferência por kwete, a estratégia comitativa é ainda utilizada praticamente nos mesmos contextos de posse temporária ou para estado:

(69) Umbundo (R11) (Chacusanga 2006, p. 45)
a. ame ndi-kwete oñgi
1PS 1sg-ter 9.desejo sexual

'Eu tenho desejo sexual'

\section{b. Ndi-kasi l'-ongeva \\ 1PS-COP COM-9.saudade}

'Eu tenho saudades'

Pode ser que o umbundo e o quicongo estejam trilhando caminhos diferentes para as suas construções de posse predicativa, conforme exemplos abaixo:

(70) Quizombo (H16)

$\begin{array}{llll}\text { mvu } & \text { makumatatu } & \text { ngi-na } & \text { miau } \\ \text { ano } & \text { trinta } & 1 \text { sg-COP } & \text { POSS }\end{array}$

'Tenho trinta anos.'

(71) Umbundo (R. 11) (Chacusanga 2006, p. 41)

Ndi-kwete akwi atatu k-alima

1sg-ter trinta 18-ano

'Eu tenho trinta anos.'

(72) Quimbundo (Xavier, 2010, p. 126)
Nì-ál-à
nì
mà-kúnìà-tánù à-á-mí-vù nì úvùà
1sg.PRS-estar-IPF CONJ 6-dez-6-GEN-cinco 6-GEN-3-ano CONJ 5-nove 'Tenho 59 anos.' 
Com essas duas línguas angolanas, o umbundo e o quicongo, tomamos ciência de que as línguas bantas, apesar da grande semelhança entre elas, guardam também grandes diferenças. Ficam os questionamentos sobre como lidar com essas diferenças que de alguma forma é o que também reúne essas línguas pertencentes à mesma família, além, é claro, da necessidade de descrições mais detalhadas para cada estratégia de posse predicativa.

\subsection{Transitivização: 'deriva de ter' de possessivos comitativos}

Transitivização é um processo de gramaticalização descrito por Stassen (2009, p. 209) o qual provoca o fenômeno de "Have-drift" (Ter-deriva), de acordo com a denominação do mesmo autor. Nele, línguas que apresentam as estratégias locativas, comitativas e de tópico para posse podem desenvolver construções equivalentes a um possessivo com verbos do tipo "have" ou "ter" (Have-possessive). Em outras palavras, é um processo de reanálise que torna transitiva uma construção intransitiva. Nesse processo, o PR é, ou vem a ser, o sujeito da sentença e o PD passa a ter traços de objeto direto.

Stassen acredita que o processo de transitivização se configuraria como o fim de um processo, a "Deriva de Ter" (Have-drift), nas palavras do autor:

[...] se uma língua tem, ou passa a ter, um possessive do tipo "ter", uma reanálise posterior parece ser bloqueada: possessivos do tipo "ter" nunca mudam para algo mais. Assim, temos que concluir, por alguma razão, que possessivos do tipo "ter" representa algum tipo de 'zona terminal' no desenvolvimento diacrônico das construções possessivas. Dado essa direcionalidade marcante, podemos rotular esse processo de gramaticalização como deriva de "ter". (Stassen, 2009, p. 209) ${ }^{22}$

Para as línguas que usam a estratégia comitativa para possessivos, Stassen aponta três possibilidades no caminho de gramaticalização, das quais duas se aplicam mais especificamente às línguas bantas. Uma terceira é atestada apenas em línguas indígenas norteamericanas (Stassen, 2009, p. 218-9) e seria a fusão da partícula comitativa com um classificador. Os dois outros processos de transitivização que interessa para nossa discussão são os que seguem: o Tipo I no qual o verbo “ter” surge da fusão da cópula e da partícula do comitativo, seguindo o seguinte caminho:

\footnotetext{
22 "[...] if a language has, or has acquired, a Have-Possessive, further reanalysis seems to be blocked: HavePossessives never change into something else. Thus, we have to conclude that, for some reason, the HavePossessive represents some sort of 'terminal zone' in the diachronic development of possession constructions. Given this remarkable directionality, we can label the grammaticalization process at issue as have-drift."
} 
(73) Fusão de BE-WITH ${ }^{23}$

PR $x-B E+$ WITH-PD $=>$

$\Rightarrow$ PR $x[$ BE-WITH $]+$ PD $=>$

$=>P R \times[H A V E]+P D$

O exemplo dado por Stassen de língua que apresenta o Tipo I de deriva de "ter" é o luganda. Para ele, a língua em um primeiro exemplo (73a), exibe a cópula locativa/existencial $l i$ e o "elemento associativo" na, indicando que o complexo li-na funcionando como um verbo simples transitivo, com o sentido de "estar.com":

(74) Luganda (E15) (Stassen, 2009, p. 211)
a. O-li-na ekitabo
2SG-COP-COM livro
'Você tem um livro'
b. ekiwwugulu ki-ri-na ebyoya
coruja cl.MS-COP-COM penas
'Uma coruja tem penas.'

Antes de fazermos qualquer comentário sobre esse primeiro processo, vejamos em seguida o segundo tipo de deriva de "ter". Para o Tipo II, a partícula comitativa recebe propriedades de verbo transitivo ou, como Stassen denomina, ocorre uma "verbalização" de "COM", seguindo o seguinte caminho:
Verbalização de COM
PR WITH PD $=>$
$=>$ PR HAVE PD

\footnotetext{
${ }^{23}$ Não é raro, como já deve ter sido notado, que os autores frequentemente glosam a partícula como "be.with" ou "estar_com", ou mesmo "ter", demonstrando a dificuldade de identificar os verbos comitativos como verbo ou preposição.
} 
Para o Tipo II, Stassen dá como exemplos o suaíli e o chona:

(76) Suaíli (G42) (Stassen, 2009, p. 216)
a. Ni-na kisu
1SG-COM faca
'Eu tenho uma faca'
b. A-li-kuwa na watoto wengo
3SG.COP COM crianças muitos
'Ele tem muitos filhos.'

(77) Chona (S10) (Stassen, 2009, p. 216)
a. Ndi-ne murowo
$1 \mathrm{ps}-\mathrm{COM}$ vegetais

'Eu tenho vegetais.'
b. Ndi-ca-va ne-mbga
1sg-FUT-tornar COM-cachorro

'Eu deverei ter um cachorro.'

O que diferenciaria o Tipo I do Tipo II do processo de transitivização para as línguas bantas seria a presença ou não da cópula nas construções de posse predicativa, parâmetro um pouco duvidoso para o caso das línguas bantas, devido aos pontos a seguir. Primeiramente, como temos demonstrado nas seções anteriores, boa parte das línguas da nossa amostra tem como preferência o uso da partícula comitativa sem a cópula expressa para as construções possessivas no presente. Sempre que o tempo tem referência ao passado ou futuro, a língua faz uso de uma forma da cópula. Mesmo com algumas exceções, como o lingala e o quimbundo, que expressam a cópula juntamente com o comitativo para possessivos no presente, ainda não é bem claro se realmente está acontecendo um amálgama ou fusão da cópula com a partícula do comitativo. Quanto ao processo de verbalização da partícula do comitativo, permanecem as mesmas questões. Os dois exemplos utilizados por Stassen não diferem em muito dos exemplos do luganda.

Ainda não foi provado o estatuto real dos verbos possessivos-comitativos nesse processo de gramaticalização proposto por Stassen, pelo menos não para o caso das línguas bantas. Stassen aponta o mesmo processo de gramaticalização para o caso de outras línguas de famílias genéticas diversas, mas para o caso das línguas bantas um exame mais detalhado 
pode mostrar que tal processo de gramaticalização não parece chegar à sua completude, ou seja, nenhum verbo comitativo é usado somente para posse predicativa, em todos os possíveis contextos.

À primeira vista é intrigante notar a similaridade do processo de transitivização com aquele de incorporação. A fusão de BE-WITH e o processo sintático P-to-BE poderiam ser encarados como o mesmo fenômeno, mas descritos por lentes teóricas diferentes. Porém, é preciso manter em mente que cada arcabouço teórico trata dos seus objetos não só com lentes diferentes como também disseca os fenômenos com suas próprias pinças, modelando-o à sua maneira. A fusão de BE-WITH é um processo de gramaticalização, portanto, uma mudança histórica, enquanto a incorporação de $\mathrm{P}($ reposição) em COP é um processo sintático e, digamos, abstrato, em termos sincrônicos.

Apesar da similaridade com o processo de incorporação de cópula e preposição, $\mathrm{BE}+$ $\mathrm{P}$ proposto na abordagem gerativista, deve-se ter em mente que este processo proposto por Stassen é diacrônico, seguindo um caminho de gramaticalização, enquanto que o BE + P é um processo derivacional em termos gerativistas. Mesmo com a especificidade dos dois processos, acreditamos que alguma confusão é feita na literatura justamente por essa semelhança, entre um "have-drift" do Tipo I com as análises derivacionais. Um exemplo disso seria a análise feita por Reintges e Lipták (2009) para o egípcio cóptico. Em resumo, desconfiamos que o processo de transitivização para línguas de possessivos comitativos não produzem o mesmo tipo de incorporação que pode ocorrer em línguas de possessivos locacionais (veja-se para isso a discussão levantada na seção 4.5.1 e a citação de Stassen, 2009, p. 232, ali).

\subsection{Em síntese}

Muito mais que tentar exaurir as possibilidades de descrição das quatro construções focalizadas neste capítulo, seja para o caso particular das línguas bantas ou para as línguas de modo geral, buscamos demonstrar, neste capítulo, parte da complexidade das construções focalizadas neste estudo. Uma análise mais extensa e pormenorizada deve ser ainda realizada, tomando, para isso, que todos os aspectos tipológicos das línguas bantas mencionados aqui, em relação a locativos, existenciais, comitativos e possessivos, além das diversas subconstruções também referidas, sejam considerados. Tal estudo pode produzir uma rede construcional mais completa, auxiliando a entender melhor o conjunto de fenômenos 
observados entre essas construções. Tal empreendimento, no entanto, está além do que podemos realizar com este trabalho.

Podemos enumerar alguns pontos vistos panoramicamente neste capítulo. Para as contruções locativas: (i) as línguas bantas, como quaisquer outras línguas, exibem estratégias variadas para a expressão de locativos estáticos; (ii) quanto a locativos dinâmicos, as LBs exibem um traço tipológico curioso que foi apontado por Creissels (2006b), a não distinção por meio de afixos de caso ou adposições entre ablativo e alativo. Para as construções existenciais: (i) indica-se que o efeito de definitude não tem o mesmo peso que tem para outras línguas, como o inglês; (ii) o pré-prefixo merece um estudo atualizado, sobre suas mais diversas funções. Para as construções comitativas: (i) as línguas bantas são consideradas em sua maioria WITH-languages; (ii) verbos comitativos são utilizados para posse predicativa.

Da descrição das construções locativas, existenciais, comitativas e possessivas de línguas bantas, verifica-se que cada construção guarda um leque de relação com outras subconstruções, tornando um mapeamento semântico das relações entre essas subconstruções uma tarefa extremamente complexa, mas necessária. 


\section{CAPÍTULO 7}

\section{Domínios Conceituais de Posse Predicativa em Línguas Bantas e a Categoria Controle}

\subsection{Apresentação}

O capítulo anterior foi dedicado às construções objeto de nosso estudo separadamente, focalizando a particularidade das línguas bantas analisadas, atentando também para subconstruções que guardam estreita relação com aquelas. Dessa forma, nos ocupamos de aspectos das construções locativas, existenciais, comitativas e possessivas de modo que pudéssemos ter uma ideia mais geral sobre os limites e alcances de cada construção.

Chegamos neste ponto ao cerne de nossa discussão e das nossas perspectivas para que a análise a ser apresentada neste capítulo possibilite uma convergência entre as diferentes propostas teóricas para explicar como locativos, existenciais, comitativos e possessivos se relacionam, e isso em decorrência da nossa preocupação na descrição das línguas bantas. Temos enfatizado continuamente que o domínio do comitativo deve ser considerado como domínio distinto e fundamental para a expressão de posse predicativa na literatura dedicada a essas construções e domínios relacionados, para que se faça jus às particularidades tipológicas das línguas bantas (Heine, 1997; Stassen, 2009). Como foi visto, no trabalho de Freeze (1992) nenhuma língua de estratégia comitativa para possessivos foi mencionada, a não ser para comprovar a existência de processo de incorporação. Se tomamos a posição de que o comitativo é um domínio conceitual distinto dos domínios de locativo, existencial e possessivo, uma análise unitarista para possessivos não poderá ser admissível. Mesmo que cada um deles tenha uma base conceitual comum, as relações de pontos de referência.

Neste capítulo buscamos avançar com algumas conclusões, considerando todo o espectro possível de relações entre os domínios conceituais de posse predicativa em línguas bantas. para chegarmos a esse fim, propomos uma linha de investigação direcionada para uma melhor caracterização da categoria Controle como forma de nos apontar uma solução satisfatória para as relações entre possessivos, locativos, existenciais e comitativos. Perseguimos, então, neste capítulo, o questionamento: o que faz de um comitativo possessivo em línguas bantas? E dessa questão, como se daria a relação de uma construção possessiva com as construções locativas e existenciais, tão bem discutida na literatura? Por fim, 
propomos que a categoria semântico-gramatical Controle seja o fator primordial para que se faça uma distinção entre possessivos e os demais domínios conceituais.

\subsection{Descrição de línguas bantas e implicações para os debates sobre possessivos e domínios relacionados}

No capítulo 4 discutimos a necessidade de incluir nos debates sobre as construções possessivas o domínio do comitativo, pautados nos resultados de trabalhos tipológicos sobre posse predicativa (Heine, 1997; Stassen, 2009). Tomamos como exemplo o primeiro trabalho que se ocupou do tema para uma língua banta específica, o artigo de Christie (1970) para o suaíli. Nesse trabalho, diversos aspectos das construções locativas, existenciais e possessivas são considerados pelo autor, no entanto, nada é falado sobre o comitativo, por possíveis razões já mencionadas na seção 6.6. Christie segue as propostas de Bach (1967) e aplica para o suaíli os mesmos resultados numa linha gerativista deste autor. Ao observar que em suaíli as sentenças locativas e possessivas fazem uso da mesma partícula $n a$, traduzida pelo autor como have (Christie, 1970, p. 167), Christie acredita que a mesma análise de Bach (1967) e Lyons (1968) poderia ser aplicada a uma língua banta, advogando uma estrutura profunda locativa como a melhor resposta para explicar as sentenças possessivas em suaíli. Repetimos abaixo algumas das sentenças discutidas por Christie: ${ }^{1}$

(1) Suaíli (G42) (Christie 1970, p. 166-7)²
a. Pa-na
watu
nyumba-ni
LOC-COP pessoas
casa-LOC
'Tem pessoas na casa.'
b. watu wa-na nyumba
Pessoas MS-COP casas

'As pessoas têm casas.'

Dentre as línguas bantas com as quais procedemos com algum trabalho de eliciação, prouramos aplicar os procedimentos de descrição e análise, conforme verificado na literatura, para comparar as construções locativas, existenciais e possessivas. Repetimos diversas vezes

\footnotetext{
${ }^{1}$ A análise de Christie para o suaíli pode ser apontada como um exemplo de como as lentes teóricas direcionam a atenção do pesquisador para aspectos dos fenômenos linguísticos que, ao mesmo tempo, podem obscurecer detalhes simples, mas primordiais como da mesma maneira podem contribuir para destrinchar aspectos que somente os dados em si não seriam suficientes para uma descrição mais completa. Essas considerações nos levaram a discutir com mais vagar sobre esse ponto no capítulo 5.

${ }^{2}$ Sem glosas no original.
} 
que as discussões dos autores se concentram sobre locativos, existenciais e locativos. Se levarmos em conta todos os fatos linguísticos discutidos nos capítulos anteriores, acreditamos que a forma mais adequada de tratar da questão de possessivos e domínios relacionados em línguas bantas deve ser da forma como apresentamos abaixo, onde além daquelas três construções tão bem discutidas na literatura, o domínio do comitativo deve ser considerado, da mesma forma:

(2) Quizombo (H16h) (Araújo; Teca; Fernando, em preparação)
a. á-ntù
mu-nzó
è-na.
(Locativo)
2-pessoas
18.LOC-9.casa
2.MS-COP

'As pessoas estão na casa.'
b. vèná yé ndíngà záyìngí mù-Angola (Existencial)
16.COP COM 10.línguas 10.muitas 18-Angola

'Tem muitas línguas em Angola.'
c. a-ntú
nzó
é-nà
záu
(Possessivo)
2-pessoa
10.casas
2.MS-COP
10.POSS
'As pessoas têm casas'
d. a-ntú á-kálà yé zìnzó. (Possessivo/Comitativo)
2-Pessoas 2.SM-COP COM 10.casas
'As pessoas tiveram casas' (recentemente)

(3) Umbudu (R11)
a. Omanu
va-kasi
v'onjo.
2.Pessoas
2.MS-COP 16-casa
(Locativo)
'As pessoas estão na casa.'
alimi
alwa.
18-Angola
18.MS-COP
6.línguas
6.muitas
(Existencial)
'Tem muitas línguas em Angola.'
c. Omanu va-kwete olo-njo.
2.pessoa 2.MS-ter 10.casa
(Possessivo)
'As pessoas têm casas.'

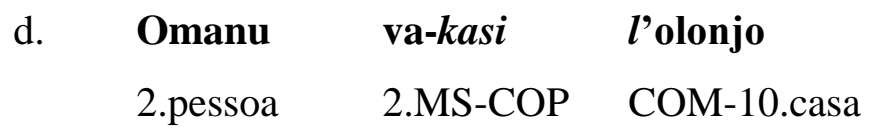
'As pessoas têm casas' 
Se seguimos a linha de análise dos autores que advogam o Paradigma Localista (Freeze, 1992; Clark, 1978), as construções locativas são aquelas nas quais um tema definido está na posição de sujeito (2a) e (3a). Até esse ponto, independente da preferência pela ordem das palavras, os predicados locativos em línguas bantas são facilmente identificados, geralmente marcados com as classes nominais locativas, para as línguas que as tenham. Para uma sentença existencial, o tema será indefinido e o locativo é que irá preencher a posição de sujeito. O exemplo (2b) não parece se adequar tanto com as descrições e análises dos seguidores do Paradigma Locaista, já que nem sempre os SNs são distinguidos com o parâmetro [+/- definido]. Em (3b) temos um exemplo de inversão locativa, no qual o locativo é o sujeito. Por fim, as análises unitaristas identificariam no exemplo (2c) um pequeno desafio, já que o esquema de predicação de posse predicativa nesse exemplo foge ligeiramente das construções prototípicas analisadas pelos autores. Já em (3c) temos a situação na qual entraria em jogo o processo de incorporação, mecanismo ao qual os autores recorrem para fazer o "casamento" entre as construções locativas, existenciais e possessivas (Cf. 4.2.3 e 4.5.1). O verbo kwete do umbundo em (3c) seria encarado como resultado de um movimento de uma categoria funcional abstrata para a cópula (qual delas?) do umbundo, produzindo como resultado o verbo do tipo "ter", e o possuidor (PR), na posição de sujeito, seria um locativo com o traço [+ humano], reafirmando assim o caráter locativo das construções possessivas.

À parte essas duas estratégias para posse predicativa em quizombo e umbundo, a maioria das línguas bantas dispõem de construções comitativas para possessivos. Em (2d) e (3d), para o passado, o quizombo e o umbundo fazem uso preferencialmente do comitativo para expressar posse predicativa. Para as análises unitaristas, as sentenças possessivas nos dois casos seriam casos em que não ocorre incorporação, permitindo que as categorias funcionais dessas línguas, nesse caso as partículas de comitativo ye e la, não incorporem nas cópulas kala e kasi, do quizombo e umbundo, respectivamente. Enquanto para o exemplo do umbundo, o verbo kwete seria o resultado de um processo de incorporação, a construção em (3d) com kasi + la não teria a obrigatoriedade de passar por esse processo sintático. Não seria preciso ir muito longe para perceber que uma anáise unitarista como esta padece de um forte reducionismo. Reducionismo este já identificado e discutido por nós na seção 4.5.1. A análise unitarista de Freeze (1992) se aplica muito bem para o caso das línguas de possessivos locacionais, no entanto, para as línguas de possessivos comitativos, como as línguas bantas, seria forçado demais considerar kwete como resultado da incorporação de kasi + la. Forçado 
ou não, a análise unitarista continua bastante influente. É o caso de autores como Avelar (2009a) que argumenta que o verbo ter do português brasileiro apresenta traços abstratos da cópula estar e da preposição comitativa com. Lisa Levinson (2011), apesar de se posicionar de uma forma mais crítica quanto ao processo de incorporação, acaba por adotar a mesma linha de análise para vera með (ser com) do islandês, mas mostra, no entanto, que a operação sintática de incorporação não dá conta de todas as variações dos verbos possessivos.

As línguas bantas não parecem se comportar diferentemente das demais línguas do mundo, no que diz respeito à relação entre possessivos, locativos e existenciais. Como já foi repetido diversas vezes nesta tese, a particularidade das línguas bantas reside no valor comitativo de suas construções possessivas, sendo assim, se nosso objetivo inicial era trazer as línguas bantas para o debate sobre possessivos nas línguas do mundo, não poderíamos forçar uma análise de possessivos para as línguas bantas, de possessivos comitativos, dentro das análises para línguas de possessivos locacionais.

Para embasar melhor nossas afirmações, nas próximas seções nos ocupamos da relação entre possessivos com locativos, em seguida de possessivos com existenciais e por fim de possessivos com comitativos, para então apresentar a nossa proposta de análise para os debates da literatura apresentados no capítulo 4. Basicamente, defendemos que a característica tipológica de como as línguas bantas expressam posse predicativa aponta para uma terceira via de análise, que diminui o peso dos processos de de incorporação (ainda importante em processos de gramaticalização em línguas de possessivos locacionais), conforme advogado pelo Hipótese Localista; e que complementa a abordagem da Análise do Ponto de Referência. ${ }^{3}$

Apresentamos nas próximas seções, basicamente o nosso percurso de descrição e análise até chegarmos à categoria semântico-gramatical de Controle.

\subsection{Possessivos e locativos}

Não iremos nos deter muito na relação entre possessivos e locativos para as línguas bantas por pensarmos que não restam dúvidas de que, por serem línguas de possessivos comitativos, o domínio do locativo não exerce o mesmo papel para a expressão de possessivos como é o caso de línguas de possessivos locacionais ou de possessivos de tópico.

\footnotetext{
${ }^{3}$ Heine (1997, p. 222) já havia observado que as análises unitaristas se aplicavam bem para o caso das línguas que tiveram suas construções possessivas decorrentes diacronicamente de construções locativas. Esse é justamente o problema do enviesamento descritivo dos autores do Paradigma Localista, por terem se pautado muito mais em línguas de possessivos locacionais. Vale lembrar que nem todas as línguas de possessivos locacionais se adéquam ao Paradigma Localista (Cf. Blaszczak, 2009 para o caso de algumas línguas eslavas).
} 
Verificamos, em nossas descrições no Capítulo 6, que as línguas bantas (LBs) possuem diversas possibilidades para a expressão de um predicado locativo, dispondo de diferentes cópulas locativas e existenciais para isso. Se seguíssemos as linhas de análise do Paradigma Localista, teríamos que procurar alguma relação entre as unidades lexicais que codificam os sentidos de locativos em línguas bantas para a sua relação com as relações possessivas.

Verificamos na seção 6.2 alguns aspectos dos locativos de LBs, fortemente relacionados às classes nominais locativas, geralmente numeradas como 16, 17 e 18, na tradição bantuísta. Nos dados que foi possível descrever, as construções de origem e destino de um percurso, nas LBs, não ensejam qualquer possibilidade de expressão de posse predicativa, como é o caso das línguas de possessivos locacionais. Numa versão mais forte da Hipótese Localista, seria esperado que ao menos houvesse algum indício de que as cópulas das línguas africanas chegassem a passar por algum processo de justaposição com as classes nominais locativas, ensejando que por processos de gramaticalização viabilizassem uma junção entre cópula e morfemas locativos, decorrendo daí a incorporação que produziria um verbo do tipo "ter", e não apenas com a partícula de comitativo, e isso devido ao fato de que o parâmetro do efeito de definitude não exerce o mesmo papel para locativos e existenciais, como acreditado por Freeze (1992).

Neste ponto, é interessante retomar uma das críticas de Blaszczak (2009), a de que os estudos formalistas não fazem qualquer diferenciação entre os tipos de cópulas existentes. Em qual tipo de cópula as categorias funcionais precisam incorporar para que dê como resultado um verbo do tipo "ter"? No capítulo 2, de apresentação de aspectos gramaticais de línguas angolanas, demonstramos rapidamente a complexidade do sistema de predicação não verbal de LBs, com diferentes formas de cópula a depender do sistema de TAM, havendo até mesmo interação com o sistema tonal de cada língua.

Apesar de todas as contraevidências, ainda tentamos proceder com eliciações de dados em contextos locativos e possessivos para então lançarmos um olhar sobre os detalhes estruturais das LBs e se haveria algum indício da proximidade entre locativos e possessivos, seguindo o exemplo de Doris Payne (2009).

Os exemplos abaixo foram dispostos de acordo com a organização utilizada pelos autores aderentes do Paradigma Localista. Em (4a) solicitamos ao nosso colaborador para expressar um locativo, "duas pernas estavam na mesa". O sentido pretendido era o de que alguém estaria com as pernas sobre uma mesa. No entanto, nosso colaborador deu como sentença preferida o que na análise de Freeze (1992) seria uma sentença existencial, com um locativo na posição de sujeito e o tema após a cópula, porém, com o traço [+ definido], o que 
não seria esperado para uma sentença existencial. Reforçamos o pedido ao nosso colaborador, de que queríamos duas sentenças, uma que expressasse mais o locativo e outra a existência da coisa localizada. Como alternativa, tivemos o exemplo (4b), com o uso de um locativo enfático ao fim da sentença, vá. Por fim, em (4c) obtivemos uma sentença possessiva com cópula e partícula de comitativo:

(4) Quizombo (H16h)

$\begin{array}{llllll}\text { a. } & \text { Vànà } & \text { mèsà } & \text { vá-kàlà } & \text { màlù } & \text { mòlè } \\ & \text { 16.LOC } & \text { 6.mesa } & \text { 16.MS-COP } & \text { 6.perna } & \text { 6.NUM }\end{array}$

'Na mesa estavam duas pernas' (Pretendido: 'Duas pernas estavam na mesa')

b. Vànà mèsà màlù mòlè mà-kàlà vá

16.LOC 6.mesa 6.perna 6.NUM 6.MS-COP LOC (Enf.)

'Tinha duas pernas na mesa' (Lit. 'Na mesa, duas pernas estavam lá')

\begin{tabular}{|c|c|c|c|}
\hline E-mésà & mà-kálá & $y e ́$ & màlù \\
\hline PrP-6.mesa & 6.pl-COP & $\mathrm{COM}$ & 6.perna \\
\hline
\end{tabular}

'A mesa tinha duas pernas' (Lit. 'A mesa estava com duas pernas' pro caso de uma mesa quebrada)

$\mathrm{Na}$ análise localista, estas três sentenças compartilhariam a estrutura de locativo, sendo na construção possessiva, o papel do possuidor (PR) seria a de um locativo com os traços [+humano] ou de [+ animacidade], e nas construções de locativos e existenciais seriam os traços de [+/- definitude] que determinaria quando uma sentença seria locativa ou existencial.

Por mais óbvio que pareça, a relação entre o PR em (4c), mesa com o PD malu operada pela cópula e pela partícula de comitativo kala ye, é encarada como um locativo, na visão do Paradigma Localista, reduzindo o domínio conceitual do comitativo ao de localivo. É inegável que a relação comitativa enseja a proximidade entre as entidades (estar na companhia de alguém é estar próximo a ela), no entanto, reduzir a localização à relação comitativa não resolve a questão do porquê as LBs, em certos contextos, dão preferência ao comitativo para posse ao invés de simplesmente incorporar a categoria funcional de comitativo com a cópula, produzindo um verbo do tipo "ter".

Talvez o fenômeno de inversão locativa pudesse apontar para uma relação maior entre possessivos e locativos, no entanto, o verdadeiro estatuto de inversão locativa é ainda um tópico controverso (Cf. Salzmann, 2011), e para o caso das LBs, mesmo que um locativo adquira as propriedades de sujeito de uma setença, o que pelas generalizações de Freeze 
(1992) tornaria a sentença existencial para então ser relacionada a possessivos, a proximidade entre locativos e possessivos não se dá de uma maneira direta. As críticas de Salzmann (2004, p. 287-292) para a asserção de que possessivos são locativos na posição de sujeito com traços de animacidade diz pouco da complexidade que é a inversão locativa em línguas bantas.

Voltamos a ressaltar que não negamos que locativos são intimamente relacionados a possessivos, segundo a análise unitarista de Freeze (1992), guardando a devida ressalva de que essa afirmativa é verdadeira e aplicável para o caso das línguas de possessivos locacionais, como o russo e outras línguas eslavas. Querer forçar as línguas bantas, de possessivos comitativos, para a análise unitarista de Freeze seria equivalente a querer trazer as línguas de possessivos locacionais para o mesmo esquema de possessivo das LBs, inversão que pareceria inaceitável para os localistas. Acreditamos que possessivos possam ser caracterizados como locativos com o traço [+ humano], pelo menos no nível da estrutura conceitual. $\mathrm{Na}$ estrutura linguística, as línguas recorrem a diferentes expedientes para a expressão de posse predicativa. Não é ideia estranha a de que comitativos têm alguma relação com locativos, considerando que para uma entidade ser acompanhada por outra as duas devem compartilhar um espaço de proximidade, prototipicamente, mas há inegavelmente uma distinção. Vejamos um exemplo do yeyi, onde a marca de comitativo é substituída pela a de locativo:

Yeyi (R41) (Seidel, 2008, p. 214)
a. ma-li ma-qhu ku-ba ni=mu-nyana.
6-dinheiro 6-não_estar_com Inf-ser COM=1-homem
'Por esse tempo, dinheiro não estará com o homem.'
b. ma-li ma-qhu ku-ba ku-mu-nyana.
'Por esse tempo, dinheiro não estará no homem.'
6-dinheiro 6-não_estar_com Inf-ser 17=1-homem

Fazemos uma ressalva, no entanto, de que nem sempre a distinção é fácil. O domínio conceitual de locativo é um domínio básico na conceitualização humana, por isso, participa de diversas relações. Lembrando que além do parâmetro de Controle, o de Contato Permanente ou "esfera pessoal de um indivíduo" é chamado como necessário em uma construção possessiva. Surgem, assim, situações de difícil delimitação, como o exemplo abaixo do lingala, que deixa uma certa ambiguidade quanto ao sentido de locativo: 
(6) Lingala $(\mathrm{C} 36 \mathrm{~d})^{4}$

$\begin{array}{llll}\text { a. Mwásì } & \text { à-zálák-ì } & \text { nà } & \text { mbókà } \\ \text { Mulher } & \text { MS-COP-PASD } & \text { PREP } & \text { cidade } \\ \text { 'A mulher estava na cidade' } & & \end{array}$

A estrutura é a mesma de um possessivo, mas ao invés de expressar que a mulher "tinha" uma cidade, expressa a localização da mulher "na cidade". E isso é possível em parte devido ao grande sincretismo da partícula na do lingala, que abarca os usos e sentidos comumente associados às preposições de línguas indo-europeias. A questão que fica é: o que permite ao falante conceitualizar a construção acima como um locativo e não um possessivo?

\subsection{Possessivos e existenciais}

Ainda nas análises unitaristas, possessivos e existenciais compartilhariam dos mesmos argumentos nas mesmas posições, quais sejam, predicados locativos (LOC) na posição de sujeito e o tema seguido de verbos de cópula, sejam eles cópulas do tipo "ser" ou do tipo "ter". O que distinguiria uma construção de outra seria o traço de [+/- humano]. Se o predicado locativo apresenta o traço [- humano] será um existencial, se for [+ humano] será um possessivo. Novamente, reafirmamos que tal análise pode ser aplicada para as línguas de possessivos locacionais ou de tópico, mas para outros casos é bem mais complicado. O que interessaria no momento seria muito mais o traço de [+/- definitude] do tema, considerado como o fator determinante na caracterização de uma ou outra construção, seja ela possessiva ou existencial. Como já foi discutido na seção 6.3.2, o efeito de definitude em LBs não se configura da mesma forma que em línguas indo-europeias. Mesmo para línguas como o português brasileiro, o efeito de definitude não é tão determinante para as construções existenciais (Viotti, 2002).

Da mesma forma que fizemos para a relação de locativos com possessivos, tentamos verificar a relação entre as duas construções com algumas línguas. Abaixo temos uma sentença iniciada com a combinação da cópula com a partícula do comitativo do quizombo kala ye, obtida com trabalhos de eliciação:

\footnotetext{
${ }^{4} \mathrm{Na}$ seção 6.4 tratamos com mais detalhes do estatuto da partícula na.
} 
Quizombo (H 16)

$\begin{array}{lllll}\text { vá-kálá } & \boldsymbol{y e ́} & \text { à-lèké } & \text { à-sàkánen-ángà } & \text { vávà } \\ \text { 16-COP } & \mathrm{COM} & \text { 2-jovens } & \text { 2.MS-brincar-HAB } & \text { 16.aqui }\end{array}$

'havia/tinha crianças bricando aqui' (Lit.: 'Estava com jovens brincando aqui)

O mesmo pode ser verificado em português brasileiro, com exemplos adaptados de Avelar (2009):

(8) Português brasileiro (Avelar, 2012, p. 78)

a. Na hora do assalto tava com/tinha mais de dez policiais dentro do banco.

a. Tá com um engarrafamento enorme na cidade.

b. Tá com filmes ótimos em promoção na locadora.

Os exemplos em (8) são encarados como semelhantes àquele em (7), possível em LBs. Mas Avelar se mostra cético quanto às reais motivações para essas semelhanças. Os argumentos do autor continuam na linha de análise para os verbos possessivos. "Estar com" ocorre em sentenças existenciais por compartilhar de traços possessivos, caindo assim na circularidade dos argumentos do Paradigma Localista já apontados na seção 4.5. Talvez esses sejam casos menos prototípicos para comitativo, os das construções existenciais/locativas, porque nelas as partículas de comitativo parecem perder basicamente o sentido de Companhia para serem usados como marcas de relações espaciais ou de estruturação de evento, no entanto, a Análise do Ponto de Referência demonstra perfeitamente essa proximidade conceitual. Novamente afirmamos que todas elas são construções que têm como base pontos de referência. A habilidade de ponto de referência se mantém latente nessas construções, mesmo que elas sejam instanciações menos prototípicas. Em todas as construções, a proeminência dada a um ou outro elemento numa relação de ponto de referência é determinante para a forma como os itens lexicais podem integrar distintas construções gramaticais de acordo com o a opção de perfilamento feita pelo Conceptualizador, falante/ouvinte.

\footnotetext{
${ }^{5}$ Exemplos adaptados de Avelar (2012).
} 
Não nos determos tanto na distinção entre possessivos e existenciais, por acharmos que parte dos pontos discutidos para a relação com locativos são válidos para o caso das sentenças existenciais. Vejamos com mais detalhe a relação de possessivos com comitativos.

\subsection{Possessivos e comitativos}

Com o comitativo e possessivo, chegamos finalmente aos dois domínios conceituais mais próximos para as LBs. Sem dúvida alguma, o domínio do comitativo é o que guarda uma relação mais íntima com o de possessivos, o que não deixa de ter também alguma relação com de locativos e existenciais, conforme demonstramos nas seções anteriores deste capítulo. Nossa insistência durante toda a realização deste trabalho foi justamente a de oferecer ao comitativo a atenção que nos debates sobre possessivos em outras famílias linguísticas era devotada somente a locativos e existenciais.

Da mesma forma que fizemos com a relação de possessivos com locativos e existenciais, procuramos identificar nas LBs, de possessivos comitativos, o que transformaria em possessiva uma construção, inicialmente, de companhia. Buscamos agrupar as sentenças com os dois sentidos, como nos exemplos que seguem:

Quizombo (H16h)

a. ákentó ènà 2.mulher 2.COP COM 10.mãe $\begin{array}{lll}\text { awu } & \text { lúmbú } & \text { kía wónsò } \\ 2 . P O S S & 7 \text { dia } & \text { 7.de todo }\end{array}$

'As mulheres estão com as mães o dia todo'

$\begin{array}{llllll}\text { b. akento } & \text { kíntwádì } & \text { ngúdí } & \text { zau } & \text { lúmbú } & \text { kía wónsó } \\ \text { 2.mulhere } & \text { possuir } & \text { 10.mães } & \text { 10.delas } & \text { 7.dia } & \text { 7.de todo }\end{array}$

'As mulheres tinham suas mães o dia todo' (Pretendido: 'As mulheres tinham suas mães o dia todo consigo')

Solicitamos uma sentença que expressasse companhia, e outra expressando possessivo. O exemplo em (9b) foi produzido com o verbo "possuir" do quizombo, indicada pelo nosso colaborador como um pouco estranha. $\mathrm{Na}$ dificuldade de especificar que queríamos as duas sentenças com a mesma construção, mas com a distinção entre posse e companhia, elaboramos sentenças nas quais os falantes teriam que expressar posse e companhia numa mesma situação para que então pudéssemos verificar alguma modificação na escolha dos verbos ou diferenças na forma de conceitualizar o que seria próprio de posse e 
o que seria próprio para companhia. Os próximos exemplos são os mais próximos do que intentamos fazer:

(10) Quizombo (H16h)

\begin{tabular}{|c|c|c|c|c|c|}
\hline mwánà & wà-kálà & $y e ́$ & mókò mólè mà-kálà & $y e ́$ & nlémbó \\
\hline 1.criança & MS-COP & $\mathrm{COM}$ & 6.mão 6.duas 6.MS-COP & $\mathrm{COM}$ & 4.dedo \\
\hline nsámbánò & mùnà & kònsó & kókò & & \\
\hline 4.seis & 18.LOC & cada & mão & & \\
\hline
\end{tabular}

Para as duas situações, a de que a criança tinha duas mãos (no caso de alguma outra deformidade, poderia ter mais de duas mãos) e cada mão apresentava seis dedos, a estratégia para as duas situações foi a de possessivo, com o uso da cópula e do comitativo kala ye. A sentença em português utilizada como estímulo para a eliciação não funcionou tão bem. Pela tradução, esperávamos que um possessivo fosse usado e depois um comitativo.

Tentamos elaborar desta vez sentenças com os sentidos de posse e companhia bem mais específicos, como em "tenho X mas não está comigo", o que procedemos com eliciação com o quizombo e lingala:

(11) Quizombo (H16h)

\begin{tabular}{|c|c|c|c|c|c|}
\hline mònó mvwídí & mvéló, & kansì & ká & wè-ná & yámè \\
\hline 1P.sg possuir & 3.bicicleta & mas & NEG & 3.MS-COP & PRON \\
\hline
\end{tabular}

(12) Lingala (C36d)

$\begin{array}{llllllll}\text { Ngáí } & \text { nà-zàlì } & \text { nà } & \text { vélò } & \text { kási } & \text { è-zàlì } & \text { nà } & \text { ngáí te. } \\ \text { 1P.sg } & \text { 1.MS-COP } & \text { COM } & \text { bicicleta } & \text { mas } & \text { MS-COP } & \text { COM } & \text { PRON NEG } \\ \text { 'Tenho bicicleta, mas ela não está comigo.' } & & & \end{array}$

Para os dois casos, obtivemos duas situações. Para o quizombo foi utilizado o verbo equivalente a "possuir" - $v w a ́$ (Carter; Makondekwa, 1987, p. 173) para o possessivo e para a companhia a estratégia esperada, com cópula e o pronome. Para o ligala, as duas situações foram construídas com a estratégia comitativa, tanto para posse como para a situação de companhia. 
Para uma nova tentativa, utilizamos a estória do pescador e do filho (Cf. Apêndice A) e obtivemos os seguintes dados para o quizombo e umbundo:

(13) Quizombo (H16h)

\begin{tabular}{|c|c|c|c|c|c|c|c|}
\hline mwa-ànà & wà-kàlà & $y e ́$ & lámbà & kànsì & kà & kà-kàlà & $y e ́$ \\
\hline 1.criança & 1.MS-COP & $\mathrm{COM}$ & 7.bolsa & mas & NEG1 & MS-COP & $\mathrm{COM}$ \\
\hline u-nkàbù & mùnà & & zí-b-ùl-à & & & kío. & \\
\hline 14.coragem & NEG2 18.LOC & & 10.MS-f & $-R E V-$ & & LOC (Enf) & \\
\hline
\end{tabular}

(14) Umbundo (R11)

\begin{tabular}{|c|c|c|c|c|c|}
\hline Omõla & wa-kala & $l$ 'okulava & okohamba, & pwãi & ka-kwate-le \\
\hline 1.criança & 1.MS-COP & COM-bolsa & consigo & mas & NEG-ter-? \\
\hline epandi & $\mathbf{k u}-\mathbf{y}$ & ik-ul-a. & & & \\
\hline 5.coragem & 5.de & MO-fechar-RE & I-VF & & \\
\hline
\end{tabular}

Desta vez obtivemos o uso da estratégia comitativa para as duas situações, de posse e companhia, em quizombo, enquanto para o umbundo foram utilizadas as estratégias de comitativo e de verbo do tipo "ter" para possessivo.

Parte da dificuldade na delimitação do que pode ser um possessivo ou um comitativo é a grande semelhança na configuração dos participantes nas duas construções. Como vimos nas figuras que representam as relações possessivas e comitativas a partir do ponto de referência, no capítulo 5, os dois participantes são perfilados pelos conceitualizadores, enquanto que nas construções locativas e existenciais, o alvo (T) é a entidade perfilada. No processo de transitivização descrito por Stassen (2009), o autor afirma que a criação de verbos do tipo "ter" de línguas de possessivos comitativos seria menos problemática devido ao fato de que nas construções comitativas o participante que leva o papel semântico de acompanhado (CD) já possui quase todas as propriedades de sujeito, prototípicas de construções (semi)transitivas onde há um PR e PD.

Queremos enfatizar com isso que, diferentemente das análises localistas, a relação de comitativo com possessivos é pautada em outros fatores semânticos diferentes daqueles usados para locativos/existenciais: [+/- definido] e [+/- humano]. O fator principal para esses dois domínios é melhor caracterizado por [+/- controle]. 


\subsection{Controle: uma categoria gramatical necessária, mas não suficiente?}

As dificuldades de distinguir o que seria um comitativo de um possessivo, conforme foi demonstrado para o caso dos exemplos das línguas bantas nas seções anteriores também podem ser verificadas com o português brasileiro e sua estratégia comitativa para possessivos:

(15) Português brasileiro
a. Tô com uma casa pra alugar.
b. Tenho uma casa pra alugar.
c. Tô com o carro do meu irmão este fim de semana.
d. $\quad$ ?Tenho o carro do meu irmão este fim de semana.

Apesar da possibilidade de alternância entre estar com e ter em português, há a diferença aspectual entre as duas expressões, aquela mais temporária e esta mais permanente. As sentenças em (15d), apesar de ser aceitável, é menos adequada se proferida fora de um contexto específico em que o verbo "ter" adiquira o sentido de que a posse é temporária. Em português essa diferença é mais fácil de perceber com a expressão de estados mentais ou físicos, como abaixo:

(16) Português brasileiro
a. Ele esteve com febre.
b. Ele teve febre.

No primeiro caso, a sentença poderia ser proferida na situação em que uma pessoa teve febre por um breve momento, como durante uma noite, enquanto a segunda seria mais apropriada para alguém que sofre de alguma doença crônica e que por isso tem febre constantemente. Em resumo, nosso trabalho de eliciação executado com o fim de distinguir possessivos de comitativos teve que encarar grandes dificuldades. Percebemos que devíamos seguir um outro caminho de análise, não enviesado pelas propostas localistas, como estávamos procedendo desde o início. Frente a essas dificuldades, passamos a recorrer aos parâmetros semânticos que realmente pareciam importar para as línguas bantas: CONTATO PERMANENTE e CONTROLE. 
O africanista Creissels (1979) em sua tese, nos idos das décadas de forte análise localista (Bach, 1967; Lyons, 1968), vale-se da ideia de que línguas que usam majoritariamente comitativos para construções possessivas demonstram uma relação de grande proximidade com a coisa possuída, decorrendo disso que para caracterizar adequadamente onde começa um possessivo a partir de um comitativo deve-se recorrer ao que o autor chama de "esfera pessoal de um indivíduo". Em trabalho mais recente, Creissels (2013) volta a fazer uso dessa ideia, juntamente com a de que na evolução entre as várias estratégias para possessivos, o papel do Controle, enquanto categoria semântica, é crucial. O africanista não aprofunda a sugestão, deixando em aberto como essa categoria semântica resolveria a distinção e a proximidade entre possessivos com os domínios conceituais que dão origem a construções de posse predicativa. Essa sugestão relembra bem a caracterização dos subdomínios de possessivos de Stassen (2009, p. 17) reproduzidos em nossa Tabela 3.2. Os parâmetros semânticos de CONTATO PERMANENTE e CONTROLE podem ser comparados com os da sugestão de Creissels. A “esfera pessoal de um indivíduo" pode muito bem ser caracterizado pelo CONTATO PERMANENTE de Stassen. Quanto ao CONTROLE, fica a dúvida sobre a melhor forma de utilizar esse parâmetro. Dos trabalhos a que tivemos acesso, de nossa bibliografia sobre possessivos, apenas Lisa Levinson (2011) parece ter se aventurado a utilizar o parâmetro CONTROLE como uma categoria semântica capaz de diferenciar duas construções em islandês. Já havíamos mencionado em outro momento que a construção com vera með em islandês comporta os sentidos de comitativo e possessivo, conforme exemplos abaixo:

(17) Islandês (Levinson, L., 2011, p. 360-1)
a. Jón
er með barnið
sitt.
João
estar com criança-ART.ACC dele
'João tem a seu filho' ${ }^{6}$ (tem a guarda legal do filho?)

\footnotetext{
${ }^{6}$ Optamos pela tradução do exemplo acima do islandês como o uso do verbo ter com a preposição $a$ para indicarmos um certo grau de transitividade. Fato semelhante é discutido por Creissels (2013) para o espanhol:

(i) Espanhol Creissels (2013, p. 461)

Para Creissels, o uso da preposição $a$ indica um grau de transitividade maior em (ib) do que em (ia).
} 


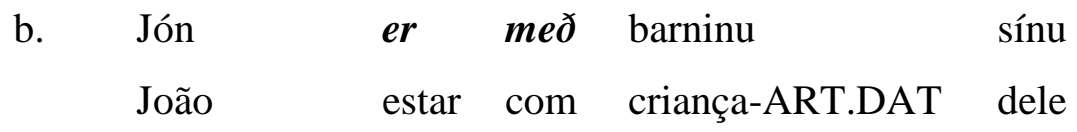

'João está junto com o seu filho' (a criança o acompanha por livre vontade)

As duas construções diferem apenas na marcação de caso, em (17a) a criança recebe o caso de acusativo, enquanto em (17b) recebe o de dativo. A primeira expressa mais claramente uma relação de posse, a segunda apenas a de companhia. Partindo da forma como Stassen (2009) discute o parâmetro semântico de CONTROLE, a autora encontrou uma forma de caracterizar o que faz um comitativo ser usado como possessivo, para o islandês. Lisa Levinson (2011, p. 380) propõe o seguinte:

$\begin{array}{lll}\text { Núcleo } & \text { traço de Caso } & \text { realização argumental } \\ \mathrm{P}_{\text {Controle }} & \text { Acusativo } & \text { Controle/Possessivo temporário } \\ \mathrm{P}_{\text {Simetria }} & \text { Dativo } & \text { Simetria/Acompanhamento }\end{array}$

Seguindo esse esquema da autora, na terminologia gerativista, $\mathrm{P}$ é o núcleo de uma frase preposicional licenciadora de Caso em islandês. Com isso, se o Caso for o de acusativo, o parâmetro semântico de Controle atua, permitindo uma caracterização de posse temporária ou de [+controle]. Se o núcleo $\mathrm{P}$ licencia o Caso de dativo, a interpretação passa a ser simétrica entre os participantes da construção, decorrendo uma expressão comitativa com o traço de [-controle].

Como em português, e na maioria das línguas bantas, não dispomos de marcas de Caso explícitas para caracterizarmos a relação entre os participantes de uma construção, resta-nos uma melhor caracterização da categoria Controle $^{7}$ e a expectativa de que um refinamento conceitual como esse possa contribuir para uma caracterização entre os domínios conceituais em questão. A ideia subjacente a essa constatação é indicada pela contraparte em português, das expressões comitativas de posse. "Ter" e "Estar com" em português poderiam ser entendidas como estratégias diferentes para a expressão de posse. "Estar com" seria preferido quando o possuidor não exerce total controle sobre a coisa possuída, com o traço de [controle], sendo assim o seu uso tão amplo parra estados mentais e físicos em português. O uso de “Ter' seria preferido se há o traço [+ controle]. Acontece que essa distinção não é marcada explicitamente em português, como deve ser o caso para as LBs.

\footnotetext{
${ }^{7}$ Relembramos aqui a convenção que decidimos adotar para diferenciar o parâmetro semântico CONTROLE (em caixa alta) da categoria Controle (com inicial maiúscula) da noção geral de controle.
} 
Partimos então para a segunda parte deste capítulo, dedicada à discussão de como a formulação da categoria semântica CONTROLE pode lançar nova luz sobre os debates sobre possessivos.

Praticamente todos os estudos e propostas teóricas elaborados para solucionar a questão de como possessivos são relacionados a outros domínios conceituais apontam para parâmetros semânticos. Para Stassen (2009) seria CONTATO PERMANENTE e CONTROLE (Cf. Tabela 3.2); para Creissels (2013) seria a "esfera pessoal de um indivíduo" e Controle (Creissels, 2013), como também para Heine (1997). Controle é mencionado frequentemente na caracterização de possessivos e de outras categorias gramaticais. No entanto, tal categoria não recebeu ainda o devido aprofundamento teórico, ou melhor, ainda não foi adequadamente formalizada, até o momento.

Se pegarmos a noção de controle como um parâmetro semântico (CONTROLE), é possível pensarmos nessa noção como uma categoria conceitual (Controle), que poderia ser identificada em construções gramaticais. Essa é relativamente a ideia que temos ao analisar os trabalhos funcionalistas/tipológicos ocupados com a semântica ou sintaxe de possessivos. ${ }^{8}$ Uma observação constante em todos os trabalhos consultados sobre posse predicativa é a indicação de que Controle seria uma categoria necessária e primordial para caracterizar uma expressão como possessiva. Heine (1997, p. 38) menciona o Controle como um dos parâmetros para a caracterização dos diversos subtipos de possessivos. Stassen (2009, p. 14), em nota de rodapé, enumera diversos trabalhos funcionalistas/tipológicos que elaboraram de alguma forma a noção de controle para analisar fenômenos como agentividade (Langacker, 2002); transitividade (Hopper; Thompson, 1980), sistemas de voz (Klaiman, 1991), papéis semânticos e causativos (Comrie, 1981), entre outros. ${ }^{9}$

A situação continua sempre na indicação da categoria semântico-cognitiva de Controle como responsável pelas propriedades de uma construção como possessiva, mas nenhum esforço é dispendido para uma melhor caracterização de que tipo de relação de controle está sendo discutida. Até mesmo na esteira de trabalhos formalistas (Levinson, L., 2011), essa categoria é indicada como o traço que distingue uma sentença possessiva de uma comitativa,

\footnotetext{
${ }^{8}$ Vale mencionar a tese de doutorado de Storto (2003) que embora voltado mais para a semântica formal, emprega a noção de controle para a distinção de possessivos, no nível da frase e da oração.

${ }^{9}$ Castilho (2000) menciona que Dik em sua gramática functional faz bastante uso do parâmetro [ +/- Controle] para a classificação de predicados:

[+ Dinâmico] [+ Controle] $=$ Evento de ação.

[+Dinâmico] [ - Controle $]=$ Evento de processo.

[-Dinâmico] [+ Controle] = Situação de posição.

[-Dinâmico][-Controle] = Situação de estado.
} 
para o caso do islandês. Langacker (2003, p. 10) atesta que os arquétipos de possessivos advêm da concepção de um ponto de referência (R) "controlando" um alvo (T), a partir das diversas relações possíveis entre um PR e um PD. A questão que permanece é: que tipos de relações de controle são essas? A sensação é a de estarmos procurando por uma categoria cognitiva bastante disseminadas nas línguas do mundo, mas que não encontra facilmente um meio de expressão específico para cada língua, em particular. A melhor forma de descrever essa situação é a de estarmos procurando por uma categoria gramatical necessária, mas não suficiente. Comrie (1981) descreve da seguinte forma essa sensação, ao discutir sobre uma forma de classificar os diferentes papéis semânticos das línguas, como agente, instrumento, etc.:

\begin{abstract}
O ponto mais importante que nós queremos fazer, referente as relações entre agente, força, instrumento e paciente é que isso não é tanto um conjunto de relações semânticas discretas, mas muito mais um continuum, sendo os rótulos representando diferentes pontos ao longo desse continuum. O continuum como um todo pode ser encarado como um continuum de controle, e devemos usar esse termo ao invés de rótulos discretos, exceto informalmente. Nossa tarefa é então, nos certificarmos se a distinção em termos de controle encontra reflexo linguístico formal em uma ou mais línguas, correlacionando com a distinção conceitual que pode ser identificada entre iniciadores conscientes [...] (Grifo nosso) (Comrie, 1981, p. 59) ${ }^{10}$
\end{abstract}

Após essa citação, o autor mostra alguns casos em que certas línguas se valem da noção do grau de controle marcado gramaticalmente para distinções semânticas, a partir da escolha de 'caso:

(19) Tsova-Tush (Comrie, 1981, p. 59)

a. So voz-en-so

1sg. ABS.cair-AORIST-1sg:ABS

'Eu caí'

b. As vuiz-n-as

1sg. ERG.cair-AORIST-1sg.:AORIST

'Eu caí'

\footnotetext{
10 "The most important point that we want to make concerning the relations among agent, force, instrument, and patient is that this is not so much a set of discrete semantic relations, but rather a continuum, the labels representing different points along this continuum. The continuum as a whole can be regarded as a continuum of control, and we shall use this term rather than the set of discrete labels, except informally. Our task is therefor to ascertain wether distinction in terms of control find formal linguistic refletion in one or more languages, correlating with the conceptual distinction that can be drawn among conscious initiator [...]"
} 
Nesses exemplos, (19b) implica maior controle sobre a ação da queda (caí deliberadamente) e que tal construção não poderia ser usada se fosse usada numa situação em que a pessoa não controla a queda. Mas como o próprio Comrie atesta: essas distinções de grau de controle "são encontradas esporadicamente nas línguas do mundo" e não há ciência se esse tipo de distinção é "completamente generalizada a esse respeito" (1981, p. 60).

Por um bom tempo ponderamos como seria elaborar uma forma de representar a maneira em que a categoria Controle exerce um papel importante na configuração de uma construção possessiva. Lembramos então de um caso bem sucedido de formalização de uma categoria semântica que tem servido para a caracterização de diversas construções gramaticais, a categoria Dinâmicas de Forças, conforme produzida por Talmy (2000, p. 409470).

A categoria semântica das dinâmicas de uma força também não recebe nas línguas do mundo uma expressão específica. Nenhuma língua conhecida oferece um morfema específico para expressar o sentido de uma força, no entanto, a formalização da categoria Dinâmicas de Força tornou possível "visualizar" conceitualmente as relações entre duas entidades e o modo como essas relações são mapeadas em construções gramaticais. Com o fim de ilustrar melhor como Talmy procedeu na sua formalização e alguns dos resultados obtidos, apresentamos os diagramas utilizados pelo cognitivista:

a

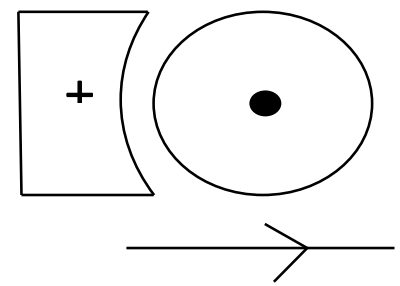

c
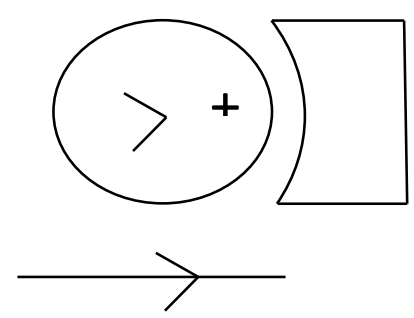

b

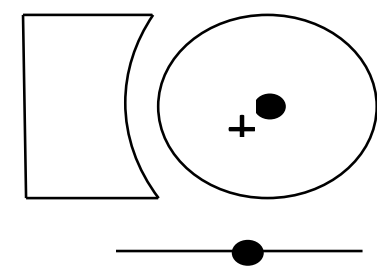

d

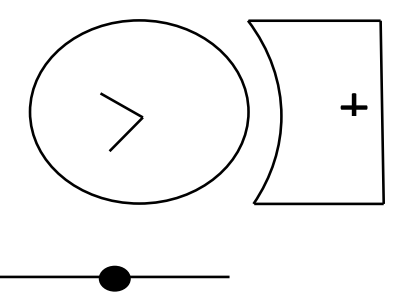

Figura 7.1 - Padrões básicos das Dinâmicas de Força (Talmy, 2000, p. 415)

A ideia básica é a dos dois elementos na interação de uma força, um "agonista" (círculo), elemento focal, exerce uma força sobre um "antagonista" (quadrado com a concavidade), que pode bloquear ou não a força exercida. Da interação entre agonista e 
antagonista, quadro padrões são possíveis: a) o agonista é levado a ter movimento pelo antagonista; b) o agonista se mantém em repouso apesar da força exercida pelo antagonista; c) o agonista mantém movimento apesar da oposição do antagonista; d) o agonista tem tendência para movimento, mas o antagonista é mais forte e o bloqueia. Dessa interação, a semântica de construções como estas abaixo seriam caracterizadas de uma forma mais refinada:

(20) Exemplos linguísticos das Dinâmicas de Força (Talmy, 2000, p. 416) ${ }^{11}$

a. A bola continou rolando por causa do vento soprando nela.

b. O galpão continuou de pé, apesar do vendaval soprando contra ele.

c. A bola continou rolando, apesar da grama áspera.

d. A tora continuou deitada na inclinação por causa das bordas nela.

O modo como Talmy formalizou as operações entre dois elementos em uma interação de forças teve tanto êxito que tem sido utilizada até mesmo em abordagens formalistas, a exemplo da semântica conceitual de Jackendoff (1990). Diversos autores têm utilizado esse construto para a operacionalização de diversas construções gramaticais, de causativos a verbos modais (Cf. Mulder, 2007 para uma revisão e apreciação desses trabalhos).

Uma questão óbvia seria se se poderia aplicar à categoria Controle o mesmo tipo de formalização desenvolvido para a categoria Dinâmicas de Força. Considerando que o construto de Dinâmicas de Força foi uma generalização sobre os estudos de Talmy para as construções causativas (Mulder, 2007, p. 294; Croft; Cruse, 2004, p. 66), não seria difícil de imaginar que as construções possessivas ensejariam uma formalização da categoria Controle. Sabemos, porém, que tal empreitada demandaria um trabalho mais longo e voltado especificamente para a elaboração dessa categoria, trabalho esse que foge dos limites da nossa tese. Por outro lado, uma contribuição do nosso trabalho poderia ser uma sugestão inicial de como dar os primeiros passos, nesse sentido. Sendo assim, dedicamos as últimas seções desta tese para demonstrar a necessidade de formalização da categoria semântico-gramatical Controle de modo que a mesma seja operacionalizada e mais presente nos estudos sobre possessivos, da mesma forma que passamos boa parte desta tese argumentando a favor de uma presença mais significativa das línguas bantas nos debates sobre possessivos.

\footnotetext{
${ }^{11}$ Possíveis traduções para:

a. The ball kept rolling because of the wind blowing on it.

b. The shed kept standing despite the gale wind blowing against it.

c. The ball kept rolling despite the stiff grass.

d. The log kept lying on the incline because of the ridge there.
} 


\subsubsection{Formalização para a validade de uma categoria gramatical}

Pode parecer um tanto pretensioso, a princípio, dedicar os momentos finais de uma tese para apontar algumas possibilidades de formalização de uma categoria tão complexa como Controle. A razão para isso é justamente o fato de que durante todo nosso percurso de investigação, desde a primeira constatação da proximidade entre companhia e posse com as construções com estar com do português até a descoberta de que posse predicativa na maioria das línguas bantas é realizada com verbos comitativos, fomos sempre conduzidos para textos teóricos ou descritivos que apontavam para o papel do Controle como imprescindível em uma construção possessiva. Quando finalmente nos deparamos com a grande proximidade conceitual entre possessivos e comitativos, particularmente nas línguas bantas, estávamos certos de que deveria haver algo que poderia ser apontado como o responsável pela grande proximidade entre aqueles domínios, juntamente com os de existenciais e locativos, ao mesmo tempo em que esses mesmos domínios conceituais pudessem ser distinguidos pelos falantes conceitualizadores. Para isso, reiteramos a ideia de que a formalização de uma categoria semântica pode contribuir para a sua validade como tal, vide, por exemplo, a formalização das Dinâmicas de Força com Talmy (2000), ou dito de outra maneira, uma categoria semântica ou gramatical por ser válida é que é passível de ser formalizada. Acreditamos firmemente que esse seja o caso da categoria Controle.

No Capítulo 5 apresentamos uma tentativa de caracterização dos quatro domínios conceituais de nosso estudo a partir da Análise do Ponto de Referência, da forma como é entendido em Gramática Cognitiva. Nossa primeira pista, de como aqueles domínios se relacionam, era a de que todos compartilham de uma mesma base conceitual, são relações de pontos de referência. As operações de perfilamento e os construtos de trajetor (TR) e marco (MR) da Gramática Cognitiva indicariam em que os quatro domínios se diferenciam, a partir de operações de construal. Acreditamos que havíamos chegado a alguns mecanismos básicos que auxiliam a distinguir possessivos, locativos, existenciais e comitativos, porém, ficou claro que faltava um segundo fator para outro nível de distinção: o fator que distinguiria possessivos de locativos, existenciais e comitativos.

A Figura 5.6 buscou uma primeira tentativa de distinguir aqueles domínios. Segundo nossa figura, a proeminência dada pelos falantes para relação em si entre o ponto de referência $\mathrm{R}$ e o alvo T é que seria determinaria uma semântica possessiva no lugar das outras, ou seja, a seta que direciona o ponto de referênca $\mathrm{R}$ até seu alvo $\mathrm{T}$ que indica mais 
especificamente o que é um possessivo, no entanto, logo percebemos que apenas essa proeminência não era suficiente.

Por um bom tempo não soubemos como poderíamos visualizar em um gráfico ou figura a forma como uma entidade controla outra, seguindo o exemplo de Talmy (2000) para caracterizar formalmente o construto de Dinâmicas de Força, conforme a Figura 7.1 acima, até que nos deparamos com um construto da Gramática Cognitiva utilizado para tratar de construções impessoais em Langacker (2009, cap. 5). O construto em questão é o do Ciclo do Controle (Control Cycle) reproduzido abaixo:

Base

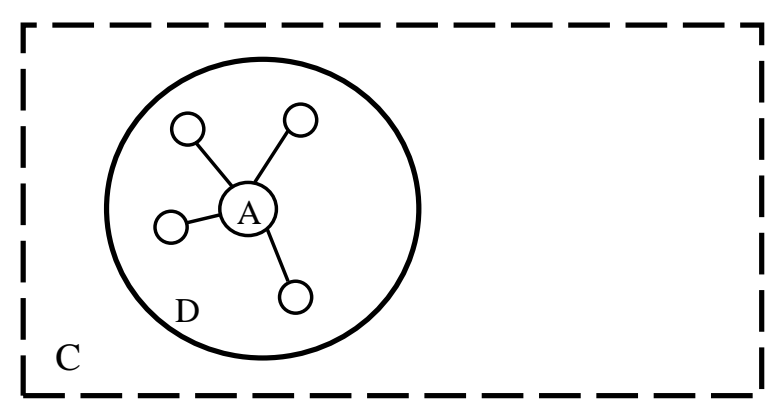

<estático>

Ação
Potencial

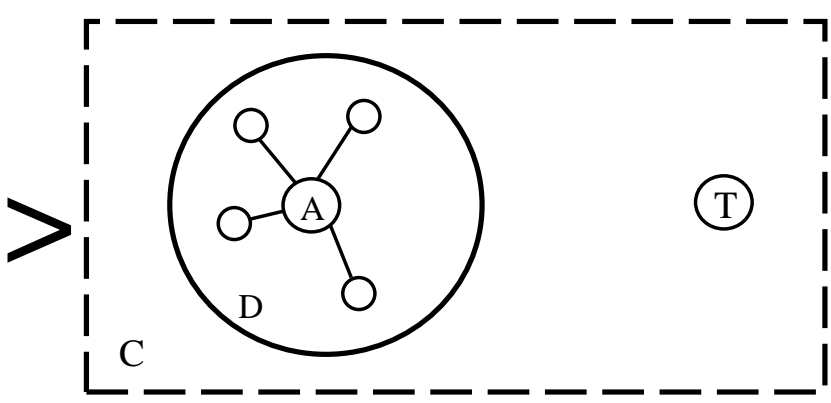

$\langle$ tensão>

Resultado
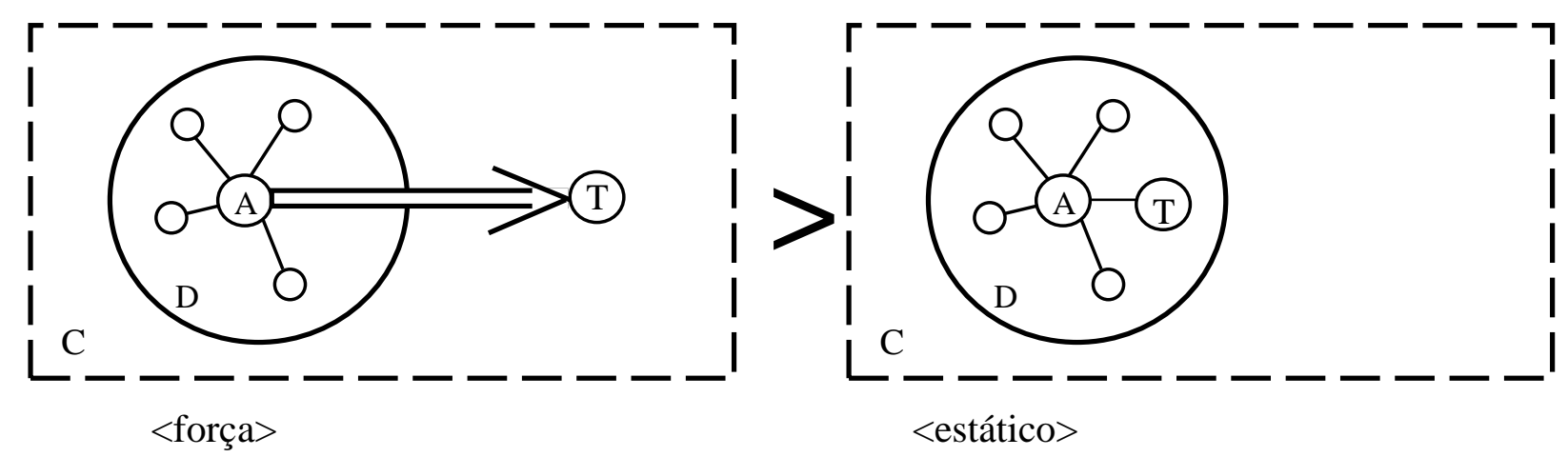

$\mathrm{A}=$ ator $\mathrm{D}=$ domínio $\quad \mathrm{C}=$ campo/conceitualizador $\quad \mathrm{T}=\mathrm{Alvo}$

Figura 7.2 Ciclo do Controle (Langacker, 2009, p. 130)

Os diagramas acima podem ser descritos da seguinte forma: Langacker divide o Cliclo do Controle em quatro estágios. No estágio Base, um ator (A) (em sentido genérico) tem controle sobre um conjunto de entidades, representadas pelos círculos menores, constituindo o domínio (D) de A. Na segunda fase, um alvo (T) entra no campo (C) de A, em outras 
palavras, entra no campo de interação. A possibilidade de interação entre A e T causa uma tensão, pois A precisa lidar com o T de alguma forma. O meio encontrado para lidar com T no campo de interação de A é trazê-lo para sua zona de controle, decorrendo disso a aplicação de uma força que traz T para a zona de controle de A. a terceira fase é a da aplicação da força que resulta em um novo estágio de estabilidade ou relaxamento (Langacker, 2009, p. 130). Por mais simples que pareçam essas quatro fases, Langacker acredita que esse modelo cognitivo de ciclo de controle pode representa a sequência de diversos aspectos da experiência humana, desde o nível físico até os níveis mental, social e conceitual.

Desse modelo geral, é possível fazer pelo menos duas comparações. Uma primeira com o próprio construto de Análise do Ponto de Referência (Cf. capítulo 5). Temos basicamente os mesmos elementos das relações de pontos de referência, sempre o escaneamento de um conceitualizador de um ponto que serve como referência para atingir contato com um alvo T. A diferença entre o construto de Análise do Ponto de Referência e o Ciclo do Controle é a presença do construto Dinâmicas de Força, esquematizado, grosso modo, na terceira fase. É justamente com a aplicação da força que o alvo T passa a fazer parte do domínio de A. Se quisermos ir um pouco mais longe com as similaridades entre os construtos, podemos relacionar a segunda fase do Ciclo do Controle com o esquema de existenciais na Análise do Ponto de Referencia. Se adicionássemos uma reta entre $\mathrm{T}$ e o campo $\mathrm{C}$, teríamos esquematicamente a representação de existenciais. A terceira fase, com a aplicação de um esquema de força, lembra perfeitamente a figura para possessivos transitivos, com verbos do tipo "ter". A última fase do Ciclo do Controle poderia caracterizar os pontos de referência de locativos, caso adicionássemos uma reta entre T e o domínio de A. Por fim, para chegarmos à representação de comitativo, a seta que liga $\mathrm{A}$ a $\mathrm{T}$ deve representar o mesmo sistema de força representado na terceira fase, demonstrando assim o caráter quase transitivo de uma construção comitativa aplicada para possessivo. Nesses termos, é mais visível a proximidade entre possessivos e comitativos.

Conseguimos, em parte, representar por meio de gráfico o que Levinson (2011) propôs para o islandês. A diferença entre uma construção comitativa e uma possessiva é a de que na relação entre as duas entidades envolvidas na relação de ponto de referência, se a duas são perfiladas como um mesmo conjunto individual, mas pluralizado, apesar da relação levemente assimétrica entre as entidades, temos uma relação comitativa. Mas se na relação entre as entidades, uma se sobrepõe à outra, exercendo sobre a segunda um controle maior, teríamos uma relação na qual há uma transferência de energia entre as entidades (o que lembra o modelo de transitividade da Gramática Cognitiva, o modelo da bola de bilhar) ou a aplicação 
de uma força sobre a outra, temos uma situação característica de possessivo. Dentro do modelo de Ciclo do Controle temos a categoria de Dinâmicas de Força, a qual são representadas duas forças opostas e o resultado de suas forças antagônicas. Para o caso das construções possessivas existem duas entidades onde uma, exercendo uma interação de força sobre a outra passa a "controlar" uma segunda entidade, em rápidas paavras diríamos que onde há controle, há posse.

Logicamente, uma apresentação em linhas gerais como esta não será satisfatória. É preciso um pouco mais de refinamento. Mas para tal empreitada é também necessário um novo trabalho dedicado exclusivamente a esse fim. Queremos apenas, no momento, abrir caminho para uma primeira tentativa de formalização da categoria que modo que possa ter êxito na aplicação de construções gramaticais. Sabemos que outras alternativas poderão ser consideradas para a formalização da categoria Controle e, possivelmente, até em detrimento da proposta que ora apresentamos neste trabalho. De qualquer forma, produzindo frutos ou não, o construto de Ciclo do Controle de Langacker demonstra ser, pelo menos intuitivamente, condizente com os fenômenos caracterizadores de possessivos.

Para tornar mais ilustrativo o Ciclo do Controle, Langacker (2009, p. 131) considera que predicados possam ser semanticamente caracterizados em termos das relações perfiladas no Ciclo de Controle, mesmo que a caracterização seja parcial. O autor enumera pelo menos quatro mapeamentos típicos dos estágios do Ciclo do Controle, o que lembra também os quatro padrões das Dinâmicas de Forças:

(a)

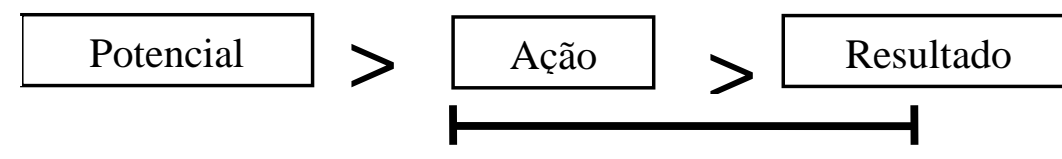

agarrar, pegar

(b)

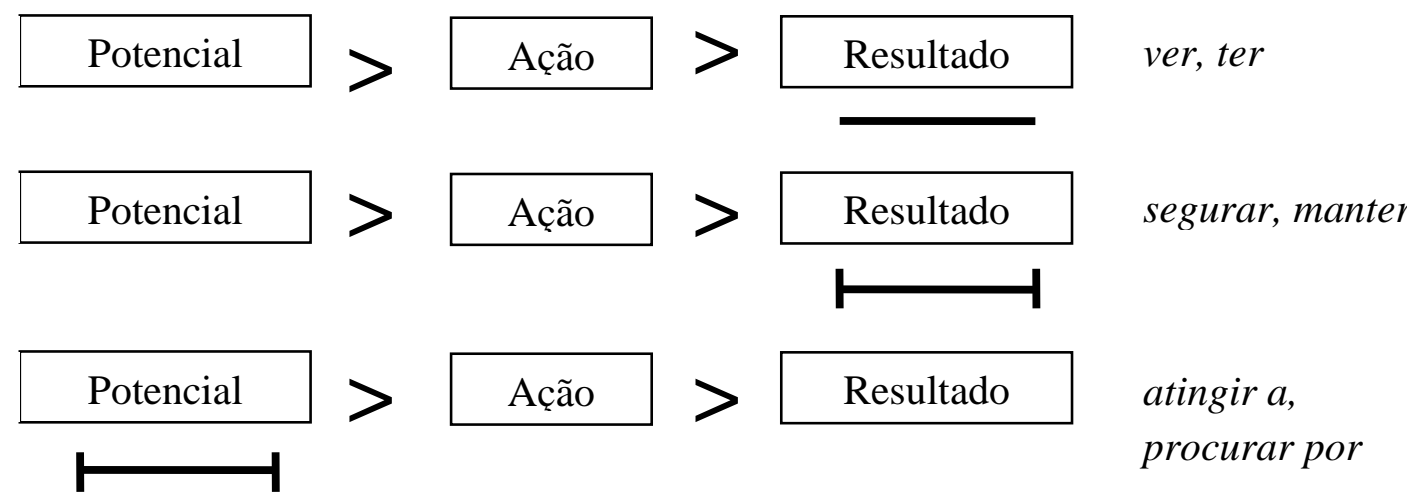

Figura 7.3 - Mapeamentos perfilados no Ciclo do Controle (Langacker, 2009, p. 131) 
Na relação perfilada em 7.3(a), há uma ação delimitada na qual o Ator estabelece controle sobre um Alvo T. A relação seguinte, em 7.3(b) é do perfilamento de uma situação estável, decorrente de uma ação. Outros predicados designam a atividade de "manter" o controle, uma vez que ele tenha sido atingido, em 7.3(c). E, reiniciando o ciclo, há os predicados que perfilam atividades preparatórias para o ator de adiquirir controle sobre algo, representado em 7.3(d). Abaixo, buscamos exemplificar as etapas perfiladas no Ciclo do Controle a partir dos verbos sugeridos na Figura 7.3 acima: ${ }^{12}$

(21) a. A criança pegou o gato.

b. A criança tem um gato com ela.

c. A criança segura o gato nos braços o tempo todo.

d. A criança porcura por outra gato pela sala.

É interessante notar que Langacker considera o verbo "ter" como um "resultado perfilado" no Ciclo do Controle. De certo modo, "ter" algo é justamente o resultado da aplicação de controle sobre o algo possuído. Posse, como entendemos, se inicia entre o terceiro e último estágio do Cico do Controle (Figura 7.3). A relação de controle pode ser distinguida ainda mais, com os tipos de controle que o Ator pode exercer, ativo ou passivo, etc., onde R controla T, mas em graus diferentes de controle:

(a)

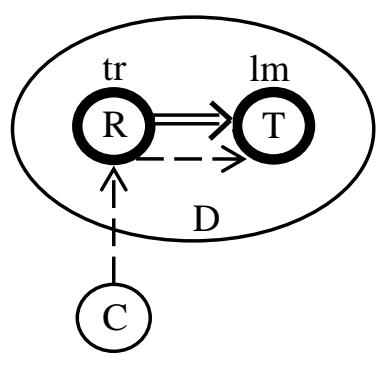

Controle agentivo

- Evento físico específico

- Força realmente exercida

Verbo perfectivo

- Fonte possessiva (b)

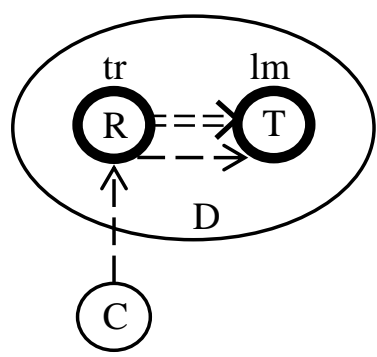

Controle ativo

- Acesso privilegiado

- Potencial para interação

verbo imperfectivo

- Possessivo prototípico (c)

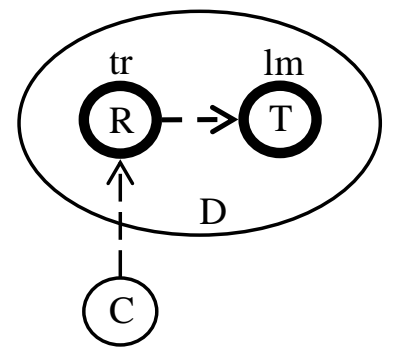

Controle passivo

- Ponto de referência passivo

- Acesso mental por C

verbo imperfectivo

- Possessivo esquemático

Figura 7.4 - Controle na APR (Langacker, 2009, p. 104)

${ }^{12}$ Clancy (2010, p. 30-33) apresenta ideia similar ao Ciclo do Controle de Langacker, mas decidimos não adentrar na proposta do autor. Fica aqui a menção ao trabalho e a sugestão da similaridade entre as propostas. 
Com essa brevíssima apresentação, demonstramos que a categoria Controle pode sim, ser formalizada.

\subsubsection{Incorporando a categoria Controle na Análise do Ponto de Referência}

No Capítulo 5, mencionamos a "incompletude" da Análise do Ponto de Referência (APR) para a distinção de possessivos com outros domínios conceituais. Neste ponto, achamos que temos agora em mãos elementos suficientes para tornar o construto de APR mais adequado para caracterizar possessivos, valendo-nos da categoria Controle. Observamos a grande similaridade na forma em que Langacker diagrama o Ciclo do Cotrole com os diagramas da Análise do Ponto de Referência. Não é por menos que na caracterização conceitual de possessivos, Langacker recorra constantemente ao papel do controle:

Tipicamente uma dada pessoa possui um considerável número de posses, cada uma das quais ela controla e pode acessar quando ela desejar. Portanto, acessando mentalmente, uma pessoa particular tem à sua disposição uma certa ordem de objetos associados os quais ele pode acessar - sendo eles os objetos que essa pessoa controla. (Langacker, 2009, P. 83) ${ }^{13}$

Até mesmo para a explicação das construções de pontos de referência, os construtos de perfilamento são sempre relacionados ao de controle:

É importante entender como o possessive esquemático é imanente no possessivo arquetípico. Nas instâncias prototípicas de posse, o possuidor (R) ativamente controla o possuído (T) de alguma maneira - fisicamente, socialmente ou experiencialmente. $\mathrm{O}$ outro lado da moeda, de $\mathrm{R}$ controlando $\mathrm{T}$ é que $\mathrm{R}$ tem um privilégio exclusivo de acessar $\mathrm{T}$. no caso de propriedade (ex.: minha caneta), $\mathrm{R}$ manipula $\mathrm{T}$, determinando onde $\mathrm{T}$ fica e pode usá-lo sempre que desejar. Esse controle também tem componentes sociais e experienciais. ${ }^{14}$

Seria esperado então, que, munidos de um novo construto teórico, as construções problemáticas da primeira parte deste Capítulo fossem solucionadas, permitindo uma melhor caracterização do que seja comitativo ou do que seja possessivo. Não temos, porém, a

\footnotetext{
13 "Typically a given person owns a considerable number of possessions, each of which he controls and can access when desired. Thus, mentally accessing a particular person affords a way of mentally accessing substantial array of associated objects - those which this person controls."

${ }_{14}$ "It is important to understand how the possessive schema is immanent in the possessive archetypes. In prototypical instances of possession, the possessor (R) actively controls the possessed $(\mathrm{T})$ in some manner physically, socially, or experientially. The flip side of $\mathrm{R}$ controlling $\mathrm{T}$ is that $\mathrm{R}$ has an exclusive privilege of access to $\mathrm{T}$. In the case of ownership (e.g. my pen), R manipulates $\mathrm{T}$, determines where $\mathrm{T}$ is kept, and can use $\mathrm{T}$ whenever desired. This control also has social and experiential components."
} 
pretensão de sugerir uma aplicação imediata de uma categoria cognitiva ainda em meio à sua formalização. É necessário nos eximir, por enquanto, de tal responsabilidade, por cautela. Por outro lado, correr um pouco de risco é sempre um bom estimulante. No momento só podemos ensaiar a forma como Controle pode atuar nas relações de pontos de referência para a configuração de um possessivo. Vejamos, a título de exemplo, o caso do locativo em lingala, apresentado em (6), no qual levantamos a questão de que a estrutura do locativo é a mesma para a expressão de um possessivo. Como não nos foi possível verificar com nosso colaborador sobre a possibilidade de "transformar" aquele locativo em possessivo, verificamos em nosso corpus que fizemos a eliciação de dois dados que nos chamou bastante a atenção, apresentados em (21):

\section{(22) Lingala (C36d)}
a. naja-li nà:-ndàkò
1sg.-COP COM-casa
'Tenho casa.'
b. naja-li nà-ndákò
1sg.-COP ESS-casa
'Eu estou na casa.'

Durante as sessões de eliciação, pedíamos aos nossos colaboradores a tradução das construções de nosso interesse separadamente, mas quando pedimos a sentença em (21a) e minutos depois a sentença de (21b), nosso colaborador ficou surpreso de ver que as duas eram praticamente iguais, tendo como diferença alguns mecanismos no nível fonológico da língua, como o alongamento da partícula na para a expressão possessiva. Para a construção locativa, em (21b), no lugar do alongamento, um tom alto foi usado em ndákò, o que para a sentença possessiva em (21a) era baixo. Não sabemos dizer, no entanto, se realmente há um alongamento em (21a), já que o lingala não possui alongamento vocálico (Meeuwis, 1998), mas pelo fato de nosso colaborador indicar que o nà do possessivo durava mais que o nà do locativo, resolvemos indicar no exemplo. Pode ser que a diferença entre as duas sentenças seja apenas entre os padrões tonais: baixo-baixo $(\mathrm{BB})$ na primeira, e alto-baixo ( $\mathrm{AB})$, na segunda, o que torna necessário um trabalho de eliciação sobre esse ponto.

Frente a esse breve exemplo, uma hipótese ainda inicial, baseada na categoria de Controle, seria a de que a preposição na do lingala serve como o elemento linguístico que 
direciona a atenção do falante conceitualizador, ${ }^{15}$ ora para a situação em que o elemento focalizado seja locativo (tom alto de ndákò?) ora em que o elemento focalizado seja a relação em si do processo, ou seja, o relator da construção, identificado aqui como a preposição na (Cf. Tabela 3.1), o que talvez explicaria o provável alongamento de nà. Se é um fenômeno fonológico ou não, o alongamento sugerido por nosso colaborador indicaria que o conceitualizador estaria dando proeminência ao controle que a pessoa tem sobre a "casa", em (21a).

\subsection{Em síntese}

O que estamos encarando aqui é o resultado de parte do nosso percurso de pesquisa, iniciado com a curiosidade da possível relação da estratégia de possessivos comitativos em português com línguas bantas. Nossa proposta de pesquisa teve como ponto de discussão central o argumento de que para entender a relação entre possessivos com locativos e existenciais nas línguas do mundo, o domínio do comitativo deveria ser englobado, para que se fizesse juz a uma das principais estratégias de codificação de posse predicativa (Stassen, 2005a; Cf. mapa no Anexo A), a qual tem com as línguas bantas suas maiores representantes. Se nos concentrássemos apenas sobre essa proposta, já teríamos uma agenda de pesquisa que tomaria todos os nossos esforços, considerando as implicações que a inserção da particularidade tipológica das línguas bantas teria para a revisão e aprimoramente de uma boa parte das discussões teóricas travadas até o momento (Cf. Cap. 4). No entanto, essas mesmas particularidades das línguas bantas nos levou um pouco mais longe, nos levou para a possibilidade de refinar a categoria semântico-gramatical de Controle, da forma como foi timidadmente apresentada neste Capítulo.

Concordamos que esta proposta se tornará mais evidente e empiricamente forte na medida em que a análise delineada aqui seja expandida para os demais tipos de possessivos, locacionais e de tópico, portanto, pautada numa verificação empírica mais consistente.

15 Talmy (2007) enumera diversos fatores linguísticos que são desencadeadores ou desencadeados por fenômenos de atenção. Sugerimos aqui que além das dinâmicas de força, os fenômenos atencionais deverão também participar da formalização da categoria Controle. 


\title{
Conclusão
}

\begin{abstract}
"Não se pode dizer que a ocorrência do mesmo fenômeno sempre se deve às mesmas causas, nem que ela prove que a mente humana obedece às mesmas leis em todos os lugares. Temos que exigir que as causas a partir das quais ofenômeno se desenvolveu sejam investigadas, e que as comparações se restrinjam àqueles fenômenos que se provem efeitos das mesmas causas."
\end{abstract}

Franz Boas

Nesta tese foi apresentada uma descrição de quatro construções relacionadas entre si nas línguas do mundo, enfatizando as particularidades das línguas bantas para essas construções e para uma discussão mais geral sobre suas relações conceituais. Considerando esse grupo de línguas, propomos que o domínio conceitual do comitativo oferece um quadro mais completo das relações de possessivos com outros domínios, além de se apresentar como uma estratégia de posse predicativa que lança nova luz sobre o chamado "Paradigma Localista" seguido por Freeze (1992) e outros. Ao focalizarmos as redes de relações entre locativos, existenciais, comitativos e possessivos demonstramos a necessidade de um refinamento teórico da categoria semântico-gramatical Controle como primordial para tratar de posse predicativa em relação com outros domínios conceituais. Para chegarmos até a categoria Controle, foram utilizados diversos construtos teóricos da linguística cognitiva, principalmente os da Gramática Cognitiva (Langacker, 2000; 2008; 2009), partindo principalmente da Análise do Ponto de Referência, considerada como a base conceitual comum às quatro construções objeto deste estudo.

A presente tese traz como contribuição duas propostas, uma preocupada com questões descritivas e outra com questões mais teóricas. A primeira, descritiva, mas pautada em uma discussão teórica, sugere que a estratégia para a expressão de posse predicativa da maioria das línguas bantas, de possessivos comitativos, deveria figurar nas discussões sobre possessivos, locativos e existenciais (Clark, 1978; Freeze, 1992; Langacker, 2003). A segunda proposta é basicamente consequência da primeira. Ao incluir o domínio do comitativo nas discussões 
sobre possessivos, as análises comumente aceitas para lidar com a complexidade das relações conceituais de possessivos tornam-se insuficientes, indicando que outros fatores devam ser postos como determinantes para explicar a grande proximidade conceitual de possessivos com, por exemplo, comitativos, ao mesmo tempo em que esses domínios possam ser distinguidos (Kemmer, 2003). Nesse ponto, a formalização da categoria Controle surge como uma alternativa às análises gerativistas, baseadas na operação sintática de incorporação, como também às análises cognitivistas, baseadas na Análise do Ponto de Referência (Langacker, 2003; Taylor, 1996). Pelas tipologias de posse predicativa, vimos que as línguas do mundo selecionam quatro estratégias principais para expressar posse predicativa, três construções intransitivas, originadas de construções locativas, existenciais e comitativas, e uma transitiva, com verbos prototípicos de ação geralmente com a semântica de "pegar", "segurar", "agarrar", etc. Para Stassen (2009), dois fatores seriam responsáveis por tal seleção: o sequenciamento temporal e a predicação não verbal. Enquanto Stassen (2009) chama a atenção para fatores formais de como as línguas codificam posse predicativa, é ainda incipiente o entendimento de como esses fatores formais interagem para que as línguas possam distinguir locativos, existenciais e comitativos de possessivos, apesar de ter neles sua origem. Neste caso, dos domínios conceituais das três estratégias intransitivas que as línguas têm à sua disposição para expressar posse predicativa um outro fator entraria em jogo para que uma construção seja processada como possessiva, e não, por exemplo, como localização ou companhia, tal fator seria a categoria Controle. Apenas uma formalização da categoria Controle, mais rica em detalhes descritivos e mais forte teoricamente, permitirá uma análise que contemple grande parte da complexidade das construções possessivas em relação com aqueles outros três domínios.

Para chegarmos, no entanto, até essa discussão teórica, a da necessidade de formalização de uma categoria semântica como a de Controle para lidar com os domínios conceituais de posse predicativa, fizemos um trajeto perpassado por três questionamentos: (i) aqueles relativos ao fazer a pesquisa de campo, elaborando assim os limites e alcances do nosso campo da pesquisa; (ii) o como nos posicionar quanto às questões teóricas e como consequência, o nosso posicionamento epistemológico frente à grande abrangência teórica relacionada a construções possessivas em linguística; e por fim, (iii) como abordar os tópicos relacionados às questões teóricas para uma descrição de um conjunto particular de línguas e como essa descrição poderia contribuir para os debates teóricos.

Em um primeiro momento, buscamos localizar nossa pesquisa na intersecção de um trabalho voltado para questões teóricas e descritivas focalizando um conjunto de línguas que 
pudessem contribuir com novos dados para os atuais debates sobre possessivos. Nesse caso, decidimos nos ocupar com as línguas bantas, especialmente as línguas de Angola. Essa decisão descortinou algumas das primeiras dificuldades, a da realização do trabalho de campo. Nos capítulos 1 e 2 foram apresentados alguns pontos da dificuldade de se trabalhar com uma temática semântica e cognitiva em línguas africanas, quando as descrições de muitas dessas línguas são ainda incipientes, e quando ainda existem muitos obstáculos para a realização de trabalho de campo in loco. Como forma de mitigar essas dificuldades operacionais, chamamos a atenção para a frequência de trabalhos sobre línguas africanas produzidos fora da África, e demonstramos que esses trabalhos são bem mais comuns do que poderíamos imaginar. Sob o epíteto de Linguística Africana na Diáspora, relacionamos alguns desses trabalhos e sugerimos que a nossa tese poderia pertencer a esse grupo de trabalhos. No capítulo 2 foram apresentados alguns aspectos gramaticais das línguas bantas, ressaltando a importância de se observar a organização de categorias cognitivas mesmo em línguas com poucas descrições.

Na segunda parte, nossos questionamentos se concentraram na apreciação de boa parte do material bibliográfico sobre posse predicativa, encarando com isso a dificuldade de lidar com teorias diversas que trataram de um mesmo tema sob lentes teóricas diferentes e até divergentes. Apontando para uma epistemologia anarquista, propusemos que uma alternativa de lidar com certos temas, como o de posse predicativa, seria adotar uma postura mais condizente com a complexidade do fenômeno estudado, dessa forma, nossa proposta foi a de que optássemos por uma postura feyerabendiana, a de um linguista-camaleão (Tarallo, 1986), não presos a uma única orientação teórica, mesmo que uma primeira diretriz teórica fosse assumida inicialmente. Dito isso, tal postura epistemológica permitiria que partíssemos de uma abordagem cognitivista, nesse caso a da Gramática Cognitiva, sem desconsiderar os resultados obtidos em outros campos de investigação. Essas considerações epistemológicas foram úteis como forma de organizar todas as informações coligidas na literatura sobre possessivos, procurando os pontos convergentes no ponto em que pareceriam mais divergentes. Por exemplo, fizemos um casamento entre os resultados dos estudos tipológicos sobre posse predicativa e identificamos onde os trabalhos na linha gerativista estavam generalizando demais, tornando mais problemático o tratamento de possessivos nas línguas do mundo. Percebemos que o processo de incorporação de partículas locativas em cópula para a formação de verbos do tipo "ter" pode sim acontecer em línguas de possessivos locacionais, a partir do processo de gramaticalização denominado por Stassen (2009) de transitivização. Nesse ponto, a criação de um verbo do tipo "ter" é válida para as línguas de possessivos 
locacionais, o que não é observado em línguas de possessivos comitativos, como as línguas bantas, sob os mesmos processos de gramaticalização.

$\mathrm{Na}$ perspectiva cognitivista (Langacker, 2008; 2009), agrupamos as construções locativas, existenciais, comitativas e possessivas a partir de uma mesma operação, a das relações de pontos de referência cognitivos. Demonstramos, também, no capítulo 5, que da mesma forma que uma única operação, a de incorporação, entendida como movimento de núcleos no arcabouço teórico gerativista, não seria suficiente para eleger uma única operação como denominador comum a todas as quatro construções. Além das operações de construal, de alinhamento de TR e MR, de enquadramento atencional, outros fatores deveriam estar em jogo para a verdadeira caracterização de uma construção possessiva. Para identificar esses possíveis fatores, buscamos apontar algumas subcontruções ou subdomínios de locativos, existenciais, comitativos e possessivos como evidências de que reduzir a um único domínio conceitual o espectro de fenômenos de quatro domínios conceituais não seria satisfatório.

Seguindo nessa perspectiva, indicamos que para o domínio das construções locativas, a configuração espacial deve ser considerada, se o locativo é estático ou dinâmico. Para as construções existenciais, demonstramos que o efeito de definitude não é tão obrigatório como atestado para línguas como o inglês (Freeze, 1992). Da mesma forma, as construções comitativas guardam um grande leque de sincretismo com outras funções gramaticais, como a coordenação entre SNs e o papel semântico de instrumento (Stolz; Stroh; Urdze, 2006). Tendo tudo isso em mente, concordamos que as construções possessivas não poderiam ser reduzidas a um só domínio, ou seja, as abordagens localistas estariam muito aquém de uma melhor caracterização de possessivos. Trazendo então as línguas bantas para os debates sobre possessivos, apontamos algumas possibilidades de descrição e análise para esse grupo de línguas e, na medida do possível, indicamos também as contraevidências encontradas nas línguas bantas para uma análise unitarista para possessivos. O capítulo 6 foi dedicado a algumas das particularidades das línguas bantas para as construções locativas, estáticas e dinâmicas; para as construções existenciais e o efeito de definitude; para as construções comitativas e o papel semântico de instrumento; e enfim, descrevemos parte das estratégias utilizadas por essas línguas para a expressão de posse predicativa.

No último capítulo, concentramos a discussão sobre a descrição de línguas bantas e as implicações para os debates sobre posse predicativa. Como conclusão, indicamos que não só a aplicação de movimentos sintáticos, como a operação de incorporação, nem só uma única operação conceitual como a da Análise do Ponto de Referência, são suficientes para dar conta de todos os fatos observados nas construções locativas, existenciais, comitativas e 
possessivas, seja em línguas bantas ou em quaisquer outras línguas. No entanto, a particularidade de línguas de possessivos comitativos, como as línguas bantas, aponta para a organização de possessivos como uma matriz de domínios, caracterizada pela atuação da categoria semântico-gramatical de Controle. Assim, dedicamos a última parte do capítulo 7 para uma possível alternativa de formalização dessa categoria, de modo que possa ser operacionalizada em análises sobre os domínios conceituais de possessivos, e isso para trabalhos seguindo numa linha tipológica ou cognitivista.

Felizmente, foram as particularidade das línguas bantas (Cap. 6), focalizadas em nosso estudo, que nos direcionaram para o fim de nossa investigação da forma como agora se apresenta. Ao tentarmos olhar para as línguas bantas, pensando nos domínios conceituais de possessivos em relação aos de locativos, existenciais e comitativos, um aspecto dessas relações que mais no chamou a atenção foi o porquê das línguas do mundo arregimentarem locativos, existenciais e comitativos para a expressão de posse predicativa, e depois disso o porquê de algumas dessas línguas tentarem fazer o caminho de transformar essas construções intransitivas em uma construção transitiva prototípica, similar à das línguas que usam verbos do tipo "ter" para possessivos (os processos de gramaticalização como o de transitivização de Stassen (2009). Cf. Figura 3.3). Olhar para as línguas bantas nos motivou a considerar mais seriamente os limites tênues entre um comitativo e um possessivo, e como consequência, a buscar uma alternativa para verificar conceitualmente a distinção entre ambos. Esse problema, o da delimitação de domínios conceituais, apontava insistentemente para a noção de controle, apesar dessa noção não aparecer codificada linguisticamente de forma tão explícita.

$\mathrm{Na}$ impossibilidade material de verificar a validade de nossas conclusões em línguas que exibem possessivos locacionais e existenciais, ficamos com a certeza de que o caso das línguas bantas, de possessivos comitativos, servirá como um primeiro modelo a ser contrastado, corroborado ou mesmo invalidado por estudos posteriores. O real alcance da categoria Controle para os debates sobre possessivos deverá andar junto com a descrição de línguas que ainda não mereceram uma análise adequada quanto às suas estruturas de posse, como também da modalidade de línguas de sinais, em comparação com as línguas faladas, essas bem mais estudadas. A categoria Controle passará então a ser não uma solução definitiva para a relação de possessivos com outros domínios conceituais, mas sim um elemento a mais a ser considerado em pesquisas futuras. 


\section{REFERÊNCIAS}

ABDOULAYE, Mahamane. Existential and possessive predication in Hausa. Linguistics 446, 1121-1164, 2006.

ALVES, Albino. Dicionário etimológico bundo-português. Lisboa: Tipografia Silvas, 1951.

ANDERSON, J. M. The Grammar of Case. Cambridge: Cambridge University Press, 1971.

ARAÚJO, Paulo Jeferson Pilar. Uma proposta metodológica feyerabendiana para uma análise da posse predicativa em português brasileiro: as construções com ter (have construction) e estar com (with construction). In: VII Congresso Internacional da ABRALIN, 2011, Curitiba. Anais do VII Congresso Internacional da ABRALIN, p. 3530-3540, 2011.

"Estar com" línguas bantas (LBs) no português do Brasil (PB): possíveis aproximações entre LBs e PB a partir de uma extensão metafórica de posse'. [s.ed.] Anais do I SIMELP - Simpósio Mundial de Estudos da Língua Portuguesa [16pp.], 2008. Disponível em: < (http://www.fflch.usp.br/dlcv/lport/pdf/slp36/08.pdf [15/11/2011]).> Acesso em 03 de abril de 2013.

ARAÚJO, Paulo Jeferson Pilar; ROCHA, Ivan. As expressões de localização, origem e destino de um percurso: possíveis implicações na descrição de duas línguas indígenas brasileiras e uma língua africana do grupo banto. Estudos Linguísticos, São Paulo, 40(1): p. 326-337, jan-abr., 2011.

ARAÚJO, P. J. P.; TECA, A.; FERNANDO, M. A grammatical sketch of kizombo (H. 16h), dialect of Kikongo (Angola). (Em preparação).

ARKHIPOV, Alexandre. Comitative as a cross-linguistically valid category. In: EPPS, Patience; ARKHIPOV, Alexandre. New challenges in typology - transcending the borders and refining the distinctions. Berlim: Mouton de Gruyter, 2009.

AVELAR, Juanito Ornelas. Expressões possessivo-existenciais de tempo decorrente na fala dos quilombolas de Muquém. Stockolm Review of Latin American Studies. N. 8, mar 2012.

The Comitative-Copular Basis of Possessive-Existential Construction in Brazilian Portuguese. In: NUNES, Jairo (org.) Minimalist Essays on Brazilian Portuguese Syntax. Amsterdam: John Benjamins, 2009a.

On the Emergence of TER as an Existential Verb in Brazilian Portuguese. In: Paola Crisma; Giuseppe Longobardi. (Org.).Historical Syntax and Linguistic Theory. 1 ed. Oxford: Oxford University Press, v. 1, p. 158-175, 2009 b.

Dinâmicas morfossintáticas com ter, ser e estar em português brasileiro. Dissertação de mestrado (Estudos da Linguagem) Universidade Estadual de Campinas - Unicamp, 2004.

AVELAR, Juanito; CYRINO, Sonia; GALVES, Charlotte. Locative inversion and agrément patterns: parallelisms between Brazilian Portuguese and Bantu languages. In: PETTER, Margarida; BELINE, Ronald (org.). Proceedings of the Special World Congress of African 
Linguistics, São Paulo, 2008: Exploring the African Language Conection in the Americas. São Paulo: Humanitas, 2009.

BACH, Emmon. Have and Be in English Syntax. Language, 43, 1967, p. 462-485.

BAIÃO, Domingos Vieira. Elementos de gramática Ganguela: idioma falado na região do Cubango, província de Angola. Lisboa: Centro de Estudos Filológicos, 1939.

BAKER, Mark C. Incorporation: a theory of grammatical function changing. Chigaco: University of Chigaco Press, 1988.

BARON, Irene; HERSLUND, Michel; SORENSEN, Finn. Dimensions of possession. Amsterdam: John Publishing, 2001.

BENVENISTE, Emil. Problemas de Lingüística Geral. São Paulo: Editora Nacional, 1976.

BICKERTON, Derek. Roots of Language. Ann Arbor: Karoma Publishers, Language \& Species. University of Chicago Press, 1981.

BLASZCZAK, Joanna. Predicate Inversion and Phase Extension: A new theory of syntactic locality or getting into trouble? GGS, Leipzig 22-24. Maio, 2009.

BODOMO, Adams B. Africans in China: A Sociocultural Study and Its Implications on Africa-China Relations. New York: Cambria Press, 2012.

BODOMO, Adams; SILVA, Roberval. Language Matters: The Role of Linguistic Identity in the Establishment of the Lusophone African Community in Macau. African Studies, 71 (1), 71-90. 2012.

BONVINI, Emilio. Línguas africanas e português falado no Brasil. In: FIORIN, José Luiz; PETTER, Margarida Maria Tadonni. (orgs). África no Brasil: formação da língua portuguesa. São Paulo: Contexto, 2008.

BORGES NETO, José. Ensaios de Filosofia da Linguística. São Paulo: Parábola Editorial, 2004.

BORGES NETO, José; MÜLLER, Ana Lúcia de Paula. Linguistas ou camaleões? Uma resposta a Tarallo. D.E.L.T.A., vol 3, n. 1, 1987.

BOURDIEU, Pierre; CHAMBOREDON, Jean-Claude; PASSERON, Jean-Claude. A profissão de sociólogo: preliminares epistemológicas. Petrópolis: Editora Vozes, 2000.

BRESNAN, Joan. Locative inversion and the Architecture of Universal Grammar. Language, vol. 70, n. 1 (Mar., 1994), p. 72-131.

BRESNAN, Joan; KANERVA, Jonni M. Locative inversion in Chichewa: a case study of factorization in grammar.Linguistic Inquiry 20. 1-50, 1989.

BUELL, Leston. Semantic and formal locatives: implications for the Bantu locative inversion typology. SOAS Working Papers in Linguistics 15. 105-20, 2007.

CARTER, Hazel. Syntax and Ton in Kongo. School off Eastern and African Studies, Unuversity off London, Malet Street, London WCIE7HP, 1973. 
CARTER, Hazel; MAKOONDEKWA, João. Kongo language course: maloongi makikoongo. A course in the dialect of Zoombo, Northern Angola. University of Wisconsin System: USA, 1987.

CASTILHO, Ataliba T. de. Aspectos da Lingüística Cognitiva: a tradição funcionalista na Lingüística Contemporânea. Relatório Científico submetido à FAPESP (Proc. 99/10399-9) e à USP, 2000 (Manuscrito).

CHACUSANGA, Alberto Graves. Guia de conversação em umbundu. Luanda: Mercocráfica, 2006.

CHATELAIN, Héli. Kimbundu grammar. Grammatica elementar do kimbundu ou língua de Angola. Genève: Type de Charles Schuchardt, 1888/1889.

CLANCY, Steven J. The chain of being and having in Slavic. Amsterdam: John Benjamins, 2010.

CLARK, Eve. Locationals: existencial, locative and possessive constructions. In: GREENBERG, Joseph. Universals of human language. Vol. 4. Stanford: University Press, 1978.

CHILDS, George Tucker. An Introduction to African Languages. Amsterdam: John Benjamins, 2003.

CHRISTIE; J. J. Locative, possessive and existential in Swahili. Foundations of Language, Vol. 6, n. 2,May, pp. 166-177, 1970.

COMRIE, Bernard. Language Universals and Linguistic Typology. Chicago: University of Chigaco Press, 1981.

CRANE, Thera M. ; HYMAN, Larry M.; TUKUMU, Simon Nsielanga. A Grammar of Nzadi [B.865]: a Bantu language of the Democratic Republic of the Congo. Berkeley: University of California Press, 2011.

CREISSELS, Denis. Control and the evolution of possessive and existential constructions. In: GELDEREN, Elly van; CENNAMO, Michela; BARODAL, Jóhanna. Argument Structure in Flux: The Naples-Capri Papers. Amsterdam: John Benjamins, 2013, p. 459-476.

. Syntaxe générale, une introduction typologique. Paris : Hermès, (2 vol.), 2006a

Encoding the distinction between location, source and destination. In: HICKMANN, Maya; ROBERT, Stéphane. Space in languages: linguistics systems and cognitive categories. Amsterdam: John Benjamins Publishing Company, 2006b.

Remarques sur l'émergence de verb avoir au cours de l'histoire des langues. La relation d'appartenance. Faits de Langues 7, Mars 1996, pp. 149-158.

Les constructions dites possessives, étude de linguistique génerale et de typologie linguistique. Thése de habilitación, Université Paris IV, 1979.

CREISSELS, Denni; DIMMENDAAL, Gerrit J.; FRAYZYNGIER, Zigmunt; KÖNIG, Christa. Africa as a morphosyntatic area. In: HEINE, Bernd; NURSE, Derek. A Linguistic Geography of Africa. Cambridge: Cambridge University Press, 2007. 
CROFT, William. Radical Construction Grammar: syntactic theory in typological perspective. Oxford: Oxford University Press, 2001.

Syntactic categories and grammatical relations: the cognitive organization of information. Chicago: Chicago University Press, 1991.

CROFT, William; CRUSE, Alan. Cognitive Linguistics. Cambridge: Cambridge University Press, 2004.

De BLOIS, K. F. The augment in the Bantu languages. Africana Linguistica, IV, 87-165, 1970.

DEMUTH, Katherine., MMUSI, Sheila. Presentational focus and thematic structure in comparative Bantu.Journal of African Languages and Linguistics 18.1-19, 1997.

Den DIKKENS, Marcel. Relators and Linkers : the syntax of predication, predicate inversion and copulas. Cambridge, MA: The MIT Press, 2006.

DEREAU, Léon. Cours de Kikongo. Bruxelas: Maison D’Edition AD. Wesmael-Charlier, 1955.

DEWELL, Robert B. Dynamic patterns of CONTEINMENT. In: HAMPE, Beate. From perception to meaning. Image schema in Cognitive Linguistics. Mouton de Gruyter, Berlim/Nova York, 2005.

DIAS, Pedro. Arte da língua de Angola. Officina de Miguel Delandes, 1697. Edição facsimilar da Fundação Biblioteca Nacional. Rio de Janeiro, 2006.

den DIKKEN, M. The Syntax of Possession and the Verb 'Have'. Lingua 101 (3/4):129-150, 1997.

Relators and linkers: the syntax of predication, predicate inversion and copulas.

Massachusetts: MIT Press, 2006.

DIARRA, Boubacar. Gramática Kikoongo. Luanda: UNESCO, 1989.

DRYER, Matthew. Clause types. In: SHOPEN, Thimothy. Language Typology and Syntactic Description.Vol I Clause Structure. Cambridge: Cambridge University Press, 2007.

Descriptive theories, explanatory theories, and basic linguistic theory. In: AMEKA, Felix K.; DENCH, Alan; EVANS, Nicholas. Catching Language: The standing challenge of grammar writing. Berlim: Mouton de Gruyter, 2006.

ELDERKIN, Edward D. Herero (R31) In: NURSE, Derek; PHILIPPSON, Gérard. The Bantu Languages. New York: Routledge. 2003.

ETAUNGO DANIEL, Henrique. Alupolo. Advinhas. Lisboa: EUROPRESS, 2002.

EVANS, Vyvyans; GREEN, Melanie. Cognitive Linguistics: an introduction. Edinburgh: Edinburgh University Press, 2006.

FAUCONNIER, Gilles; TURNER, Mark. The Way We Think: Conceptual Blending and the Mind's Hidden Complexities. New York: Basic Books, 2002. 
FERNANDES, J.; NTONDO, Z. Angola: povos e línguas. Luanda: Editora Nzila, 2002.

FERNANDO, Mbiavanga. An analysis of verbal affixes in kikongo with special reference to form and function. (Doctorate dissertation) University of South Africa, 2008.

FEYERABEND, Paul. Contra o método. São Paulo: Editora da Unesp, 2007 [1975].

FIVAZ, Derek. A reference gramar of Oshindonga (Wambo). (2a. Ed.) African Studies of the Academy Windhoek: Department of African Languages: University of Namibia, 2003 [1986].

FLEISCH, Axel. Lucazi grammar: a morphosemantic analysis. Berlin: Rüdiger Köppe, 2000.

FRANCIS, Elaine J. Two perspectives on the grammar of possession. Language Sciences 22 (2000) 87-107.

FREEZE, Ray. Existential and Other Locatives.Language, 68, p. 553-595, 1992.

Existential constructions. In: HASPELMATH, Martin. Language typology and language universals. An international handbook. Berlin: De Gruyter, 941-53, 2001.

FIORIN, José Luiz; PETTER, Margarida Maria Tadonni. (orgs). África no Brasil: formação da língua portuguesa. São Paulo: Contexto, 2008.

GEEAERTS, D.; CUYCKENS, H. (Eds.). The Oxford Handbook of Cognitive Linguistics. New York: Oxford University Press: 2007.

GOLDBERG, Adele. Constructions: a Construction Grammar Approach to Argument Structure. Chicago: University of Chigago Press, 1995.

GRÉGOIRE, Claire; JANSSENS, Baudoin. L'augment en batou du nord-ouest. In: HOMBERT, Jean-Marie; HYMAN, Larry M. Bantu Historical Linguistics: theoretical and empirical perspectives. Stanford, California: CSLI, 1999.

GRINEVALD, Colette. The expression of static location in a typological perspective. In: HICKMANN, Maya; ROBERT, Stéphane. Space in languages: linguistics systems and cognitive categories. Amsterdam: John Benjamins Publishing Company, 2006.

GUTHRIE, Malcon. Comparative Bantu. G. B.: Gregg Press Ltda, 1967/1971.

The classification of the Bantu languages. London: Oxford University Press, 1948.

HALME, Riikka. A tonal grammar of Kwanyama. Colônia: Rüdger Köppe Verlag, 2004.

HASPELMATH, Martin. Coordination. In: SHOPEN, Thimothy. Language Typology and Syntactic Description.Vol II Complex Constructions. Cambridge: Cambridge University Press, 2007.

Coordinating constructions. (Typological Studies in Language 58) Amsterdam: Benjamins, 2004.

Framework-free grammatical theory. In: HEINE, Bernd; NARROG, Heiko. (org.)

The Oxford Handbook of Linguistic Analysis. Oxford: Oxford University Press, 2010a.

Comparative concepts and descriptive categories in crosslinguistic studies.

Language, vol. 86, n. 3, p.663-687, 2010 b. 
HENDRIKS, Bernadet. Jordanian Sign Language: aspects of grammar from a cross-linguistic perspective. LOT: The Netherlands, 2008.

HEINE, Bernd. Possession.Cognitive Sources, Forces, and Grammaticalization. Cambridge: Cambridge University Press, 1997.

Ways of explaining possession. In: BARON, Irene; HERSLUND, Michel; SORENSEN, Finn. Dimensions of possession. Amsterdam: John Publishing, 2001.

HEINE, Bernd; CLAUDI, Ulrike; HÜNNEMEYER, Friederike. Grammaticalization: a conceptual framework. Chicago: The University of Chicago Press, 1991.

HEINE, Bernd; NARROG, Heiko. (org.) The Oxford Handbook of Linguistic Analysis. Oxford: Oxford University Press, 2010.

HEINE, Bernd; NURSE, Derek. African Languages, an introduction. New York: Cambridge University Press, 2000.

HEINE, Bernd; KUTEVA, Tania. World Lexicon of Grammaticalization. Cambridge: CUP, 2002.

HICKMANN, Maya; ROBERT, Stéphane. Space in languages: linguistics systems and cognitive categories. Amsterdam: John Benjamins Publishing Company, 2006.

HOMBERT, Jean-Marie; HYMAN, Larry M. Bantu Historical Linguistics: theoretical and empirical perspectives. Stanford: CSLI, 1999.

HOPPER, P. J.; THOMPSON, S. A. Transitivity in grammar and discourse., Language 56: 251-99.

HYMAN, Larry. Suffix ordering in Bantu: a morphocentric approach. In: BOOIJ, Geert; MARLE, Jaape van. Yearbook of Morphology 2002. Nova York, Londres, Moscou: Kluwerr Academic Publishing, 2003.

HYMAN, L. M.; KATAMBA, F. X. The augment in Luganda: syntax or pragmatics? In: MCHOMBO, S. A. (ed.). Theoretical Aspects of Bantu Grammar. Stanford: CSLI Publications, 1993.

JACKENDOFF, Ray. Semantic Structures. Cambridge, MA: MIT Press, 1990.

JUNG, Hakyung. The syntax of the be-possessive: parametric variation and surface diversities. Amsterdam: John Benjamins, 2011.

KAYNE, Richard S. Parameters and Universals. Oxford: Oxford University Press, 2000.

KATAMBA, Francis. Bantu nominal morphology. In: NURSE, Derek; PHILIPPSON, Gérard. The Bantu Languages. New York: Routledge. 2003.

KEMMER, Suzanne. Human cognition and the elaboration of events: some universal conceptual categories. In: TOMASELLO, Michael (Org.). The New Psychology of Language: cognitive and functional approaches to language structure. Vol. 2. Mahwah, NJ: Lawrence Earbaum, 2003. 
KIDIMA, Lukowa. Tone and Accent in KiYaka. (PhD Dissertation in Linguistics). Los Angeles. University of California, 1991.

KLAIMAN, M. H. Grammatical voice. Cambridge: Cambridge University Press, 1991.

$\mathrm{KOCH}$, Peter. Cognitive aspects of semantic change and polysemy: the semantic space HAVE/BE. In: BLANK, Andreas; KOCH, Peter. Historical Semantics and Cognition. Berlim: Mouton de Gruyter, 1999.

KÖNIG, Christa. Case in Africa. Oxford: Oxford University Press, 2008.

KUNZIKA, Emanuel. Dicionário de provérbios kikongo. Traduzidos e explicados em português, francês e inglês. Luanda: Editora Nzila, 2008.

LAKOFF, George; JOHNSON, Mark. Metaphors We Live By. Chicago \& London: The University of Chicago Press, 1980.

LANGACKER, Ronald. Investigations in Cognitive Grammar. Berlin: Mouton de Gruyter, 2009.

2008.

Cognitive Grammar: A basic introduction. New York: Oxford Universtity Press,

Strategies of clausal possession. International Journal of English Studies. Vol. 3 (2), 2003, pp. 1-24.

Concept, image and symbol: the cognitive basis of grammar. Berlim: Mouton de Gruyter, 2002.

Grammar and conceptualization. Berlin: Mouton de Gruyter, 2000.

. Foundations of Cognitive Grammar, Volume II, Descriptive application. Stanford, California: Stanford University Press, 1991.

Foundations of Cognitive Grammar, Volume I, Theoretical prerequisites. Stanford, California: Stanford University Press, 1987.

LEWIS, M. Paul; SIMONS, Gary F. (Org.). Ethnologue: languages of the world. 17. Dallas (Texas): SIL International, 2013.

LEVINSON, Lisa. Possessive WITH in Germanic: HAVE and the role of P. Syntax, 14: 4, dezembro 2011, 355-393.

LEVINSON, Stephen; WILKINS, David P. Grammars of Space: explorations in cognitive diversity. Cambridge: Cambridge University Press, 2006.

LI, Yafei. $X^{0}$ : A Theory of the Morphology-Syntax Interface. Cambridge, MA: The MIT Press, 2005.

LOURDES DOS SANTOS. Angolanos em São Paulo: socialização, rede familiar e suas histórias de vida e luta. Dissertação de Mestrado (Sociologia). FFLCH, Universidade de São Paulo, 2005.

LUMWAMU, François. Systematic test of morphosyntaxe of the Kongo speeches. Editions KLINCKSIECK, Paris, France, 1973. 
LYONS, J. A Note on Possessive, Existential, and Locative Sentences. Foundations of Language, 3, p. 390-396, 1967.

Introdução à lingüística teórica. São Paulo: Companhia Editora Nacional, 1979 [1968].

MAHO, Jouni F. The linear ordering of TAM/NEG markers in the Bantu languages. In: Kula, Nancy C. and Lutz Marten (eds.). Bantu in Bloomsbury: special issue on Bantu linguistics. SOAS Working Papers in Linguistics 15. London: Department of Linguistics, School of Oriental and African Studies. 2007, p. 213-225.

A classification of the Bantu languages: an update of Guthrie's referential system. In:

NURSE, Derek; PHILIPPSON, Gérard. The Bantu Languages. New York: Routledge. 2003.

A comparative Study of Bantu Noun Classes. Göteborg: Acta Universitatis Gothoburgensis, 1999.

MAIA, Antonio da Silva. Dicionário Complementar Português-Kimbundu-Kikongo (Linguas Nativas do Centro e Norte de Angola). Luanda: Cooperação Portuguesa, 1961.

MANIACKY, Jacky. Tonologie du ngangela. Munique: LICOM Europa, 2003.

MARTEN, Lutz. Locative inversion in Otjiherero: more on morphosyntactic variation in Bantu. ZAS Papers in Linguistics 43.97-122, 2006.

- The great siSwati locative shift. In: BREIBARTH, Anne; LUCAS, Christopher;WATTS, Sheila;WILLIS, David.Continuity and change in grammar.ed. Amsterdam: John Benjamins, 249-68, 2010.

MARTEN, Lutz; KAVARI, Jekura. Tone cases in Herero: the coding of head-complement relations, linear order and information structure. (em preparação).

MATSINHE, Sozinho; FERNANDO, Mbiavanga. A preliminary exploration of verbal affix ordering in Kikongo, a Bantu language of Angola. Language Matters: Studies in the Languages of Africa, 39: 2, 2008, p. 332-358.

MCGREGOR, William B. The expression of possession.Berlim: Mouton de Gruyter, 2009.

MCHOMBO, Sam. The Syntax of Chichewa. Cambridge: Cambridge University Press, 2004.

MEEUWIS, Michael. Lingala. Munique : LINCOM Europa, 1998.

MÖHLIG, Wilheim J. G.; KAVARI, Jeruka. Reference Grammar of Herero (Otjiherero). Köln: Rüdiger Köppe Verlag, 2008.

MÖHLIG, Wilheim J. G. ; MARTEN, Lutz; KAVARI, Jeruka. A Grammatical Sketch of Herero (Otjiherero). Alemanha: Köppe Verlag, 2002.

MUFWENE, Salikoko. Contact language in the Bantu area. In: NURSE, Derek; PHILIPPSON, Gérard. The Bantu Languages. New York: Routledge. 2003.

MULDER, Walter de. Force Dynamics. In: GEEAERTS, D.; CUYCKENS, H. (Eds.). The Oxford Handbook of Cognitive Linguistics. New York: Oxford University Press: 2007. 
MUNRO, Pamela. Field Linguistics. In : ARONOFF, Mark; REES-MILLER, Janie. (eds). The Handbook of Linguistics. Oxford: Blackwell, 2000.

NATHAN, Geoffrey S. Phonology: a cognitive grammar introduction. Amsterdam: John Benjamins Publishing, 2008.

NDONGA, Mfuwa. Systematique grammatical du kisikongo (Angola). Thése pour le Doctorat en Sciences du Langage. Université René Descartes Paris V-Sorbonne, Paris, 1995.

K Kíkôngò. In : BONVINI, Emilio ; BUSUTTIL, Joëlle; PEYRAUB, Alain. Dictionnaire des langues. Paris: Presses Universitaires de France, 2010.

NGUNGA, Armindo. Introdução à Lingüística Bantu. Maputo/Moçambique: Imprensa Universitária/Faculdade de Letras e Ciências Sociais, 2004.

NURSE, Derek. Tense and Aspect in Bantu. New York: Oxford University Press. 2008.

NURSE, Derek; PHILIPPSON, Gérard. The Bantu Languages. New York: Routledge. 2003.

OBENGA, Théophile. Les Bantu: langues, peuples civilisations. Libreville - Gabão: CICIBA, 1985.

OKOUDOWA, Bruno. Morfologia verbal do leembama. Tese (Doutorado) Faculdade de Filosofia, Letras e Ciências Humanas, Universidade de São Paulo, 2010.

OLANIYAN, Tejumola; SWEET, James H. The African Diaspora and the Disciplines. Bloomington \& Indianopolis: Indiana University Press, 2010.

ÖSTMAN, Jan-Ola; FRIED, Mirjam. Construction Grammars: cognitive grounding and theoretical extensions. Amsterdam: John Benjamins, 2004.

PAGOTTO, Emilio Gozze. De camaleão a tiranossauros rex - o sociolingüista como predador. Laços - Rev. da Assoc. de Est. Da Linguagem. Ano 1, vol. 1, jan/dez. 2000.

PAL, Dayane Cristina. Descrição e Análise de Séries Verbais em Baulê. Tese (Doutorado) Faculdade de Filosofia, Letras e Ciências Humanas, Universidade de São Paulo, 2010.

PAPAFRAGOU, Anna. Source-Goal Asymmetries in Motion Representation: Implications for Language Production and Comprehension. Cognitive Science, 34 (2010).

PAYNE, Doris. Is possession mere location? In: MCGREGOR, William B. The expression of possession.Berlim: Mouton de Gruyter, 2009.

; BARSHI, Immanuel (Org.). External Possession. Amsterdam: John Benjamins, 1999.

PAYNE, Thomas E. Describing morphosyntax. A guide for field linguists. Cambridge: Cambridge University Press, 1997.

PEDRO, José Domingos. Étude grammaticale du kimbundu (Angola). Thése de Nouveau Régime pour l'obtention du Doctorat en Linguistique. Paris, Universidade René Descartes, 1993. 
PETTER, Margarida. Variedades lingüísticas em contato: português angolano, português brasileiro e português moçambicano. Tese de Livre-Docência. Universidade de São Paulo, 2008.

PETTER, Margarida; VANHOVE, Martine (Org.). Portugais et langues africaines. Etudes afro-brésiliennes. Paris: Karthala, 2011.

PETZELL, Malin. What is the function of the pre-prefix in Kagulu. In: MAIA, Andreasson; KARLSSON, Susanna. (Org.) Langue.doc. Göteborg University Open Archive, 2003. Disponível em: < https://gupea.ub.gu.se/bitstream/2077/24/5/Petzell_M_2003.pdf> Acesso em 9 de maio de 2012.

PROGOVAC, L. Non-augmented NPs in Kinande as negative polarity items. In: MCHOMBO, S. A. (ed.). Theoretical Aspects of Bantu Grammar. Stanford: CSLI Publications, 1993.

PINHEIRO, Diogo. Homonímia, polissemia, vagueza: um estudo de caso em semântica lexical cognitiva. Revista Linguística, Vol. 6, n. 2, dez. de 2010a.

Indeterminação ou polissemia? A rede semântica do verbo ter no português brasileiro. In: ALMEIDA, Maria Lúcia L.; PINHEIRO, Diogo; FERREIRA, R. G.; LEMOS DE SOUSA, Janderson; GONÇALVES, Carlos. Linguística Cognitiva em Foco: Morfologia e Semântica. Rio de Janeiro: Publit, 2010b.

PINHEIRO, Diogo; GERHARDT, Ana Flávia. Gramática e Cognição: um estudo das construções possessivas e existenciais no português brasileiro. Revista Portuguesa de Humanidades, v.8, p. 155-177, 2004.

QUADROS, Ronice Müller de; VASCONCELOS, Maria Lúcia Barbosa de. Questões teóricas das pesquisas em línguas de sinais. Florianópolis: Editora Arara Azul, 2008.

RADDEN, Günter; DIRVEN, René. Cognitive English Grammar. Amsterdam: John Benjamins Publishing, 2007.

RAIMUNDO, Jaques. O elemento afro-negro na língua portuguesa. Rio de Janeiro: Renascença Editora, 1933.

REINTGES, C. H. LIPTAK, A. HAVE = BE + PREP(osition): New Evidence for the Preposition Incorporation Analysis of Clausal Possession. In: FRASCARELLI, M. (ed.) Phases in Interpretation. Berlin: Mouton de Gruyter, 2006, pp. 112-128.

ROSCH, E. Cognitive reference points. Cognitive Psychology, 7: 532-547, 1975.

SALZMANN, Martin. Towards a Typology of Locative Inversion - Bantu, perhaps Chinese and English - But beyond?Language and Linguistics Compass 5/4: 169-189, 2011.

. Theoretical Approaches to Locative Inversion. (MA Thesis) University of Zurich, 2004.

SAURÍ, Laura Garganta. Les construccions atributives, locatives, existencials i possessives en espanyol $i$ en romanès: descripció $i$ adquisició de segones llengües. Màster en Llengües, 
Moviments de Població i Construcció Social (Itinerari de Variació Lingüística i Diversitat Social), Universitat de Girona, Girona, 2008.

SCHADEBERG; Thilo C.A sketch of Umbundu. Köln: Rüdiger Köppe Verlag, 1990.

Tone cases in UMbundu. Africana Linguistica X, pp. 423-447. Tervuren, 1986.

_. Nasalization in UMbundu. Journal of African Languages and Linguistics 4: 109-132, 1982.

SEIDEL, Frank. A grammar of Yeyi: a Bantu language of Southern Africa. Colônia: Rüdiger Köppe, 2008.

SHAY, Erin; SEIBERT, Uwe. Motion, Direction and Location in Languages: in honor of Zygmunt Frajzyngier. Amsterdam: John Benjamins, 2003.

SOMMER, Gabriele. Western Savanna (K, R). In: NURSE, Derek; PHILIPPSON, Gérard. The Bantu Languages. New York: Routledge. 2003.

STASSEN, Leon. Predicative Possession. Oxford: Oxford University Press, 2009.

Predicative Possession. In: Haspelmath, Martin (eds.) The World Atlas of Language Structures. Oxford: Oxford University Press, 2005a.

Predicative Possession. In: BROWN, Keith (2 ed.). The Encyclopedia of Language and Linguistics (9 vols.) Oxford: Elsevier, 2005 b.

AND-languages and WITH-languages.Linguistic Typology 4 (1): 1-54, 2000.

STOLZ, Thomas. To be with $\mathrm{X}$ is to have $\mathrm{X}$ : comitatives, instrumentals, locative, and predicative possession. Linguistics, An Interdisciplinary Journal of the Language Sciences. May 2001, Vol. 39, n. 2: p 321-350.

STOLZ, Thomas; STROH, Cornelia; URDZE, Aina. On Comitatives and related categories: a typological study with special focus on the languages of Europe. Berlin/New York: Mouton de Gruyter, 2006.

STOLZ, Thomas; KETTLER, Sonja; STROH, Cornelia; URDZE, Aina. Split Possession: An areal-linguistic Study of the alienability correlation and related phenomena in the languages of Europe. Amsterdam: John Benjamins, 2008.

STORTO, Gianluca. Possessives in Context: Issues in the Semantics of Possessive Constructions. Tese de doutorado (Linguística). Los Angeles, University of California, 2003.

TALMY, Leonard. The representation of spatial structure in spoken and signed language. In: HICKMANN, Maya; ROBERT, Stéphane. Space in languages: linguistics systems and cognitive categories. Amsterdam: John Benjamins Publishing Company, 2006.

Toward a Cognitive Semantics: Vol. I Concept Structuring Systems. Cambridge, Massachusetts: The MIT Press, 2000.

Attention phenomena. In: GEEAERTS, D.; CHYCKENS, H. (Eds.). The Oxford Handbook of Cognitive Linguistics. New York: Oxford University Press: 2007. 
TARALLO, Fernando. Zelig: um camaleão-lingüista. D.E.L.T.A., São Paulo, v.2, n.1, p.127144, 1986.

TAYLOR, John. Cognitive Linguistics and Autonomous Linguistics. In: GEEAERTS, D.; CHYCKENS, H. (Eds.). The Oxford Handbook of Cognitive Linguistics. New York: Oxford University Press: 2007.

Possessives in English: An exploration in Cognitive Grammar. Oxford: Oxford University Press, 1996.

TAVARES, José Lourença. Gramática da Língua do Congo (Kikongo): dialeto kisolongo. Loanda: Imprensa Nacional de Angola, 1915.

TECA, Afonso. The verbal voice in Kizombo (H 16) through a translation studies perspective. Research Colloquium. University of Bayreuth, 16 de maio de 2012.

TRIBUSHININA, E. Cognitive reference points: semantics beyond the prototypes in adjectives of space and colour. The Netherlands : LOT, 2008.

TUGGY, David Harold. The Transitivity-Related Morphology of Tetelcingo Nahuatl: An Exploration in Cognitive Grammar. Tese de doutorado (Linguística). San Diego, University of California, 2008 [1981].

UNGERER, Friedrich. Word-formation. In: GEEAERTS, D.; CUYCKENS, H. (Eds.). The Oxford Handbook of Cognitive Linguistics. New York: Oxford University Press: 2007.

VALENTE, José Francisco. Gramática umbundu: a língua do centro de Angola. Lisboa, 1964.

Paisagem Africana. (Uma tribo angolana no seu fabulário). Luanda: Instituto de Investigação Científica de Angola, 1973.

VAN HOEK, K. Pronominal anaphora. In: GEEAERTS, D.; CHYCKENS, H. (Eds.). The Oxford Handbook of Cognitive Linguistics. New York: Oxford University Press: 2007.

VAN VALIN JR., Robert. Incorporation in Universal Grammar: A Case in Theoretical Reductionism. Journal of Linguistics, Vol. 28, n. 1 (Mar., 1992), pp. 199-220.

VERHAGEN, Arie. Construal and perspectivization. In: GEEAERTS, D.; CUYCKENS, H. (Eds.). The Oxford Handbook of Cognitive Linguistics. New York: Oxford University Press: 2007.

VIOTTI, Evani. A estrutura sintática das sentenças existenciais e o efeito de definitude: semelhanças e diferenças entre o inglês e o português do Brasil. Revista Letras, n. 58, p. 371395. Jul./dez. 2002.

WELMERS, William Everett. African Language Structures. Berkeley, Los Angeles e Londres: University of California Press, 1973.

XAVIER, Francisco da Silva. Fonologia Segmental e Supra-Segmental do Quimbundo Variedades de Luanda, Bengo, Quanza Norte e Malange. Tese de Doutorado (Linguística), Universidade de São Paulo, São Paulo, 2010. 
Is Kimbundu a stress and tonal language? In: PETTER, Margarida; BELINE, Ronald (org.). Proceedings of the Special World Congress of African Linguistics, São Paulo, 2008: Exploring the African Language Conection in the Americas. São Paulo: Humanitas, 2009.

ZEITOUN, Elisabeth; HUANG, Lillian M.; YEH, Marie M.; CHANG, Anna H. Existential, Possessive, and Locative Constructions in Formosan Languages. Oceanic Linguistics, Vol. 38, N. 1 (Jun., 1999), pp. 1-42.

ZERBIAN, Sabine. Expression of information structure in the Bantu language Northern Sotho. ZAS Papers in Linguistics 45, ZAS: Berlim, 2006.

ZERBIAN, Sabine; KRIFKA, Manfred. Quatification across Bantu languages. In: MATTHEWSON, Lisa (Org.) Cross-linguistic Perspectives on the Semantics of Quantification. Bingley: Emerald, 2008.

ZESHAN, Ulrike; PERNISS, Pamela. Possessive and existential constructions in sign languages. Nijmegen: Ishara Press, 2008. 
APÊNDICE A - Trechos do conto "O pescador e o filho" em quizombo ${ }^{1}$

$\begin{array}{lllllllll}\text { (01) } & \text { sé } & \text { dì-mósì } & \text { yé } & \text { mwa-ànà } & \text { à-yènd-àng-à } & \text { kú nkókò } & \text { tùkà } & \text { kù nzó } \\ & \text { Pai } & \text { NUM } & \text { COM } & \text { filho } & \text { MS-ir-HAB-VF } & 17 \text { rio } & \text { desde } & 17 \text {-casa }\end{array}$ 'Um pai com um filho iam de casa para o rio.'

(02) sé wà-kàlà yé mà-dýa màyìngì, kánsì ka kà-kàlà yé Pai MS-COP COM comida muita mas NEG1 MS-Fo-COP COM nzálà kó

fome NEG2

'O pai tinha consigo muita comida, mas não estava com fome.'

(03) mwa-ànà wà-kàlà yé nzálà yé vwìnà yé túlò Criança MS-COP COM fome COM sede COM sono 'O filho estava com fome, com sede e com sono.'

(04) Vàvà sé yé mwa-ànà à-tùk-à kùnà nzó, nsángà Quando pai COM criança MS-sair-VF LOC casa família yì-kù-d-ìd-ìl-à.

MS-MV-comer-PERF-APL-VF.

'Quando o pai e o filho saíram de casa, a família já tinha almoçado.'

(05) Sé wà-kàlá mbákì à nzónzì yé mùnà lúmbù yínà Pai MS-COP 9-caçador de peixe COORD LOC dia nesses yàndì kà-kàl-àng-à kà kùnà nkókò. 3ps MS-COP-PROG/HAB-VF sempre LOC rio

'O pai era pescador e nesses dias ele estava sempre no rio.'

(06) Kùnà

LOC

\begin{tabular}{l}
\multicolumn{1}{c}{ nkókó } \\
rio \\
námpí. \\
silêncio
\end{tabular}

kwà-kàlà (zi)nzónzì kó,

kwà-kàlà

$\begin{array}{cl}\text { kàkà } & \text { námpí. } \\ \text { só } & \text { silêncio }\end{array}$

MS-COP peixe NEG2 MS-COP

'No rio não havia peixes, no rio só havia silêncio.'

(07) Vànà

LOC

kàlà vá.

$\begin{array}{llll}\text { nsí } & \text { à } & \text { nkókó mì-ntí } \\ \text { perto } & \mathrm{CONEC(do)} & \text { rio } & \text { árvores }\end{array}$

mía-yìngí

mía

COP LOC(ENF)

'Havia muitas árvores perto do rio.'

(08) Mwa-ànà wà-kàlà yé kílù kía-yìngí wà-bànz-àngà:

criança MS-COP COM sono muito MS-pensar-HAB

kà vènà nzónzì yì-dì-àngà à à̀è $\quad$ kó é?

NEG1 COP peixe MS-comer-HAB moleque NEG2 INTER(ENF)

' $O$ filho com muito sono pensava: não existe peixe que come criança?'

\footnotetext{
${ }^{1}$ Usado para eliciação com falante de quizombo, em processo de transcrição. Colaborador: Afonso Teca, maio de 2012, Bayreuth).
} 
$(09)$

$\begin{aligned} & \text { Sé wà-kàlà } \\ & \text { Pai MS-COP }\end{aligned} \quad$ yé
mwa-ànà

(10)

$\begin{array}{llllllll}\text { Mwa-ànà } & \text { wà-kàlà } & \text { yé } & \text { lámbà } & \text { kànsì } & \text { kà } & \text { kà-kàlà } & \text { yé } \\ \text { criança } & \text { MS-COP } & \text { COM } & \text { bolsa } & \text { mas } & \text { NEG1 } & \text { MS-COP } & \text { COM } \\ \text { u-nkàbù } & \text { kó mùnà } & & \text { zíb-ùl-à } & \text { kío } & & & \\ \text { coragem } & \text { NEG2 LOC } & & \text { fechar-REV-VF } & & & \end{array}$

'O filho estava com a bolsa, mas não tinha coragem de abri-la.'

(11)

\begin{tabular}{llllll} 
Vàvà & fúkù & wà-b(w)úa, & sé & yé & mwaànà \\
Quando & noite & MS-cair/chegar-PASD & pai & COM & criança \\
à-kì-kà-dìl-à & \multicolumn{7}{c}{ yóyà (zoka) } \\
MS-REF-cansar-APL-VF & CoNC & muito \\
'Quando a noite chegou, o pai e o filho já estavam muito cansados.'
\end{tabular}

(12)

\begin{tabular}{llllll} 
Sé & wà-bàk-à & zì-nzónzì & yé & ndóbù & \multicolumn{2}{c}{ ỳ̀-mòsì } \\
Pai & MS-pescar-VF peixe & COM anzol & NUM & \\
kà & yà-kálà & yé & sìnsù kía & ndóbù & kó \\
NEG1 & MS-COP & COM & cara CONC anzol & NEG2 \\
'O pai pescou os peixes com um anzol que não tinha cara de anzol.' &
\end{tabular}

$(13)$

\begin{tabular}{|c|c|c|c|c|c|c|c|c|}
\hline Sé & yé & mwàn & & àdía & mù & mókò, & & \\
\hline Pai & $\mathrm{COM}$ & filho & & MS-comer & 18 & mão, & & \\
\hline kádì & & kà & à-kàlá & yé & nzálù & kó & ngàtù & mbélè. \\
\hline já que & & NEG & MS-COP & $\mathrm{COM}$ & garfo & NEG2 & & faca. \\
\hline
\end{tabular}

(14) Mwa-ànà wá-kàlà yé víangì kía nzó yé filho MS-COP COM saudades de casa COORD wà-sàkàn-àngà yé màtàdì màmòsì.

MS-brincar-HAB com pedras algumas

'O filho estava com saudades de casa e brincava com algumas pedras.' 


\section{APÊNDICE B - Lista de línguas bantas presentes na tese ${ }^{2}$}

\begin{tabular}{|c|c|c|}
\hline B62 & $\begin{array}{l}\text { Leembama } \\
\text { Lembaama; Obamba; Mbede, } \\
\text { Mbete; Mbama } \\
\text { (Okoudowa, 2010) }\end{array}$ & $\begin{array}{l}\text { Dialeto: ? } \\
\text { Distribuição geográfica: Sudeste do Gabão na província } \\
\text { Haut-Ogooué } \\
\text { Número de falantes: } 24.800 \\
\text { Status: ? }\end{array}$ \\
\hline B865 & $\begin{array}{l}\text { Nzadi } \\
\text { (Crane; Hyman; Kutuma, 2011) }\end{array}$ & $\begin{array}{l}\text { Dialeto: ? } \\
\text { Distribuição geográfica: Kwamuntu ao Ilebo, Norte do } \\
\text { Rio Kasai na Província de Bandundu (República } \\
\text { Democratica do Congo). } \\
\text { Número de falantes: ? } \\
\text { Status até recentemente desconhecida. }\end{array}$ \\
\hline $\mathrm{C} 36 \mathrm{~d}$ & $\begin{array}{l}\text { Lingala } \\
\text { Ngala } \\
\text { Lingála }\end{array}$ & $\begin{array}{l}\text { Dialeto: Similar ao Lusengo e Bangala.. } \\
\text { Distribuição geográfica: Bastante espalhado pela } \\
\text { República Democrática do Congo, República Centro } \\
\text { Africana e Angola. } \\
\text { Número de falantes: como língua de contato, é falada por } \\
\text { milhões, dentro e fora da África. } \\
\text { Status: Língua de contato. }\end{array}$ \\
\hline E15 & $\begin{array}{l}\text { Luganda } \\
\text { Ganda } \\
\text { (Hyman; Katamba, 1993) }\end{array}$ & 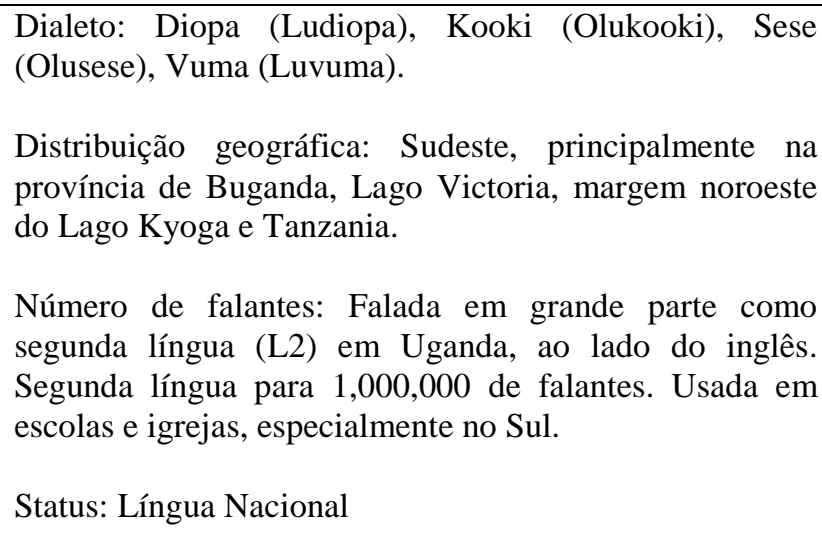 \\
\hline G42 & $\begin{array}{l}\text { Suaíli } \\
\text { Swahili } \\
\text { (Tanzania); Kisuaheli; } \\
\text { Kiswahili } \\
\text { (Christie, 1970) }\end{array}$ & $\begin{array}{l}\text { Dialeto: Mgao, Mrima, Pemba, Unguja (Kiunguja, } \\
\text { Zanzibar). } \\
\text { Distribuição geográfica: Praticamente toda a costa do } \\
\text { Zanzibar. Também no, Quenia (Kiswahili), Moçambique, } \\
\text { Ruanda, Somália, África do Sul, Uganda, e países fora da } \\
\text { África como Estados Unidos, Canadá e alguns países } \\
\text { árabes. }\end{array}$ \\
\hline
\end{tabular}

${ }^{2}$ Adaptado de Sommer (2003, p. 567) com informações etnolinguísticas (Lewis; Simons, 2013) e formas aportuguesadas (Fiorin; Petter, 2008). 


\begin{tabular}{|c|c|c|}
\hline & & $\begin{array}{l}\text { Número de falantes: Provavelmente } 80 \% \text { dos habitantes } \\
\text { de zonas rurais são usuários L2 da língua; usam suas } \\
\text { línguas étnicas localmente e com pessoas de fora usam o } \\
\text { suaíli. É bastante usada, também no contexto urbano. } \\
\text { Status: Língua Nacional. }\end{array}$ \\
\hline H16 & $\begin{array}{l}\text { Quicongo } \\
\text { Kikongo; Congo; Kikoongo; Kongo; } \\
\text { Koongo } \\
\text { (Ndonga, 1995; 2010); (Carter, 1973); } \\
\text { (Carter; Makoondekwa, 1987); (Fernando, } \\
\text { 2008); (Lumwamu, 1973); (Diarra, 1989); } \\
\text { (Dereau, 1955); (Tavares, 1915) }\end{array}$ & $\begin{array}{l}\text { Dialeto: Cerca de } 16 \text { dialetos: Kimanyanga, Kindibu, } \\
\text { Kisikongo, Kiwoyo (Cabinda, San Salvador Kongo), } \\
\text { Kiyombe (Cabinda), Kizombo, Mboka, Ndingi, South } \\
\text { East Kongo, South Kongo, West Kongo (Fiote, Fioti) } \\
\text { Distribuição geográfica: Norte de Angola e República } \\
\text { Democrática do Congo, ao longo do rio Zaire. } \\
\text { Número de falantes: 2,000,000 em Angola ( } 2012 \text { World } \\
\text { Factbook). } \\
\text { Status: Língua Nacional em Angola }\end{array}$ \\
\hline $\mathrm{H} 21$ & $\begin{array}{l}\text { Quimbundo } \\
\text { Kimbundo; Dongo; Kimbundo, Kindongo; } \\
\text { Loanda; } \\
\text { Mbundu; Loande; } \\
\text { Lunda; } \\
\text { Mbundu,N'bundo; North Mbundu } \\
\text { (Xavier, 2010); (Pedro, 1993); (Chatelain, } \\
\text { 1888/1889); (Dias, 1697/2006) }\end{array}$ & $\begin{array}{l}\text { Dialeto: Mbaka (Ambaquista), Mbamba (Bambeiro, } \\
\text { Kimbamba), Ngola, Njinga (Ginga, Jinga). } \\
\text { Distribuição geográfica: Nordeste de Angola e Província } \\
\text { de Luanda. } \\
\text { Número de falantes: 4,000,000. } \\
\text { Status: Língua Nacional em Angola. }\end{array}$ \\
\hline H31 & $\begin{array}{l}\text { Iaca } \\
\text { Yaka; Iaka; Iyaka; Kiyaka } \\
\text { (Kidima, 1991) }\end{array}$ & $\begin{array}{l}\text { Dialeto: Ngoongo } \\
\text { Distribuição geográfica: Província de Bandundu, } \\
\text { Popokabaka e territórios de Kasongo. Também falado em } \\
\text { Angola. } \\
\text { Número de falantes: ? } \\
\text { Status: Vigorosa }\end{array}$ \\
\hline K12 & $\begin{array}{l}\text { Ganguela } \\
\text { Nyemba; Gangela; Ganguella, } \\
\text { Ngangela; Nhemba } \\
\text { (Maniacky, 2003); (Baião, 1939) }\end{array}$ & $\begin{array}{l}\text { Dialeto: Parte do grupo Ngangela. Inteligível com o } \\
\text { Luchazi, Mbwela, e Ngonzela. } \\
\\
\text { Distribuição geográfica: Centro Sul, área do rio Cuchi, } \\
\text { Sudoeste do Kubango, norte do Kunene, leste da } \\
\text { Província do Huíla. Também na Namíbia, Zambia. } \\
\text { Número de falantes: 222,000 em Angola. } \\
\text { Status: Em desenvolvimento. }\end{array}$ \\
\hline K13 & $\begin{array}{l}\text { Luchazi } \\
\text { Lucazi; Chiluchazi; Lujash; Lujazi } \\
\text { Lutchaz; Lutshase; Luxage; Ponda } \\
\text { (Fleisch, 2000) }\end{array}$ & $\begin{array}{l}\text { Dialeto: Parte do grupo Ngangela. Inteligível com todas } \\
\text { as variedades do Ngangela. } \\
\text { Distribuição geográfica: Espalhado no Sudeste e áreas } \\
\text { adjacentes da Província do Moxico. Também na } \\
\text { Namíbia. } \\
\text { Número de falantes: 400,000 em Angola. }\end{array}$ \\
\hline
\end{tabular}




\begin{tabular}{|c|c|c|}
\hline & & $\begin{array}{l}\text { Status: Em desenvolvimento. Luchazi é uma forma de } \\
\text { prestígio no grupo Ngangela. }\end{array}$ \\
\hline K14 & $\begin{array}{l}\text { Luvale } \\
\text { Lovale; Lwena (topônimo) } \\
\text { (Sommer, 2003) }\end{array}$ & $\begin{array}{l}\text { Dialeto: ? } \\
\text { Distribuição geográfica: Nordeste de Angola; Zambezi e } \\
\text { distritos de Kabompo no Zambia. } \\
\text { Número de falantes: } 500.000 . \\
\text { Status: Língua oficial no Zâmbia, também lingua franca }\end{array}$ \\
\hline K31 & $\begin{array}{l}\text { Luyana } \\
\text { Siluyana; Aluyi } \\
\text { (Sommer, 2003) }\end{array}$ & $\begin{array}{l}\text { Dialeto: Relacionada a Kwangwa, Kwandi e Mbowe. } \\
\text { Distribuição geográfica: Província ocidental do Zambia. } \\
\text { Número de falantes: poucos falantes idosos. } \\
\text { Status: ainda usada como língua ritual. }\end{array}$ \\
\hline K33 & $\begin{array}{l}\text { Kwangari } \\
\text { Rukwangali; Mbunza (obsolete?) } \\
\text { (Sommer, 2003) }\end{array}$ & $\begin{array}{l}\text { Dialeto: Member of the Kavango group, for Mbunza see } \\
\text { Dammann (1957) } \\
\text { Distribuição geográfica: área Kavango, Namíbia. } \\
\text { Número de falantes: } 77.000 \text {. } \\
\text { Status: Língua Nacional na Namíbia, também lingua } \\
\text { franca na área Kavango. }\end{array}$ \\
\hline K38b & $\begin{array}{l}\text { Gciriku } \\
\text { Rugciriku, Mbogedo (xenonym), } \\
\text { Manyo (obsolete idiom) } \\
\text { (Sommer, 2003) }\end{array}$ & $\begin{array}{l}\text { Dialeto: Membro do grupo Kavango, inteligível } \\
\text { mutualmente com Shambyu. } \\
\text { Distribuição geográfica: área Kavango, Namibia, } \\
\text { Noroeste do Botsuana. } \\
\text { Número de falantes: (1) } 29.400 ? \\
\text { Status: Língua Nacional Namibiana }\end{array}$ \\
\hline K42 & $\begin{array}{l}\text { Subiya } \\
\text { eCisubiya; Ikuhane (autonym) } \\
\text { (Sommer, 2003) }\end{array}$ & $\begin{array}{l}\text { Dialeto: } \\
\text { Distribuição geográfica: Leste do Caprivi, Namibia; } \\
\text { Noroeste do Botsuana. } \\
\text { Número de falantes: } 24.500 \text { ? } \\
\text { Status: Lingua franca na área Caprivi. }\end{array}$ \\
\hline K43 & $\begin{array}{l}\text { Mbukushu } \\
\text { Thimbukushu; Gova (xenônimo) } \\
\text { (Sommer, 2003) }\end{array}$ & $\begin{array}{l}\text { Dialeto: Membro do grupo Kavango group } \\
\text { Distribuição geográfica: Sudeste do Kavango, Namíbia; } \\
\text { Noroeste do Botsuana. } \\
\text { Número de falantes: } 8,200 \text { ou } 14,000 \\
\text { Status: Língua Nacional Namibiana, usada na mídia, } \\
\text { administração e educação. }\end{array}$ \\
\hline
\end{tabular}




\begin{tabular}{|c|c|c|}
\hline N31 & $\begin{array}{l}\text { Chicheua } \\
\text { (chi)Chewa; Chinyanja; Nyanja } \\
\text { (Bresnan, 1994); (Brenan; Kanerva, 1989) }\end{array}$ & $\begin{array}{l}\text { Dialeto: Chewa (Cheva, Chichewa, Sheva), Manganja } \\
\text { (Cimanganja, Waganga), Ngoni, Nyasa, Peta (Cipeta, } \\
\text { Malawi, Marave, Maravi). Manganja é um dialeto do } \\
\text { Sena influenciado pelo chicheua. } \\
\text { Distribuição geográfica: Botsuana, Moçambique } \\
\text { (Nyanja), Suazilandia, Zâmbia, Zimbabue. } \\
\text { Números de falantes: ? } \\
\text { Status: Língua oficial na Zâmbia. }\end{array}$ \\
\hline R11 & $\begin{array}{l}\text { Umbundo } \\
\text { Úmbundù; Umbundu } \\
\text { (Alves, 1951); (Valente, 1964; 1973); } \\
\text { (Schadeberg, 1991; 1986; 1982); } \\
\text { (Chacusanga, 2006) }\end{array}$ & $\begin{array}{l}\text { Dialeto: Relacionado ao Ndombe e Mbalundu. } \\
\text { Distribuição geográfica: Bié, Huambo e Benguela, } \\
\text { províncias do Sudeste de Angola; também no Namíbia. } \\
\text { Número de falantes: 6,000,000 em Angola. } \\
\text { Status: largamente falado no Sudeste de Angola. }\end{array}$ \\
\hline R22 & $\begin{array}{l}\text { ochindonga } \\
\text { Oshindonga; ndonga } \\
\text { (Fivaz, 2003) }\end{array}$ & $\begin{array}{l}\text { Dialeto: Sudoeste do grupo Wambo. } \\
\text { Distribuição geográfica: Nordeste da Namíbia. } \\
\text { Número de falantes: } 280.000 \text { (Fivaz 2003) } \\
\text { Status: Língua Nacional na Namíbia, usada na mídia, } \\
\text { administração e educação até a universidade. }\end{array}$ \\
\hline R31 & $\begin{array}{l}\text { Herero } \\
\text { Otjiherero } \\
\text { (Möhlig; Kavari, 2008); (Möhlig; Marten; } \\
\text { Kavari, 2002); (Elderkin, 2003) }\end{array}$ & $\begin{array}{l}\text { Dialeto: Herero Central, variedade Kaokoland. } \\
\text { Distribuição geográfica: (1)Northern, Central Namibia, } \\
\text { (2)Northwestern } \\
\text { Botswana } \\
\text { Número de falantes: } 113.000 \text { ou } 15.000 \text {. } \\
\text { Status: Língua Nacional na Namíbia. O Herero Central é } \\
\text { a variedade padrão, usada na mídia, administração e } \\
\text { educação. }\end{array}$ \\
\hline R41 & $\begin{array}{l}\text { Yeyi } \\
\text { Shiyeyi, Shidzo; Makoba } \\
\text { (Seidel, 2008) }\end{array}$ & $\begin{array}{l}\text { Dialeto: Caprivi e variedade da Ngamiland. } \\
\text { Distribuição geográfica: Caprivi do Leste, Noroeste do } \\
\text { Botsuana. } \\
\text { Números de falantes: (1) } 5.200 \text { (Maho 1998), (2) } 20.000 \\
\text { (Vossen 1988). } \\
\text { Status: Língua minoritária no Botsuana. }\end{array}$ \\
\hline S11 & $\begin{array}{l}\text { Chona } \\
\text { Chishona; "Swina"; Zezuru } \\
\text { (Stassen, 2009) }\end{array}$ & $\begin{array}{l}\text { Dialeto: Karanga (Chikaranga), Korekore (Goba, Gova, } \\
\text { Northern Shona, Shangwe), Zezuru (Bazezuru, Bazuzura, } \\
\text { Chizezuru, Mazizuru, Vazezuru, Wazezuru) e diversos } \\
\text { outros subdialetos. } \\
\text { Distribuição geográfica: Mashonaland. Também no } \\
\text { Botsuana (Zezuru), Malawi, e África do Sul. }\end{array}$ \\
\hline
\end{tabular}




\begin{tabular}{|c|c|c|}
\hline & & $\begin{array}{l}\text { Número de falantes: Língua Africana dominante, } \\
\text { entendida por um número razoável de falantes. 1,800,000 } \\
\text { falantes de chona como L2. } \\
\text { Status: Língua Nacional. }\end{array}$ \\
\hline S31 & $\begin{array}{l}\text { Tsuana } \\
\text { Beetjuans; Chuana; Coana; Cuana; } \\
\text { Sechuana; Setswana } \\
\text { (Creissels, 2013) }\end{array}$ & $\begin{array}{l}\text { Dialeto: Kgatla, Kwena, Lete, Ngwaketse, Ngwatu } \\
\text { (Ngwato), Rolong, Sehurutshe, Tawana, Tlahaping } \\
\text { (Tlapi), Tlokwa. Inteligível com o soto do sudeste e soto } \\
\text { do nordeste. } \\
\text { Distribuição geográfica: lingua franca falada em diversos } \\
\text { países como Namíbia, Zimbábue e África do Sul. } \\
\text { Número de falantes: Vigorosa. Cerca de 150,000 falantes } \\
\text { L2. } \\
\text { Status: Língua Nacional. }\end{array}$ \\
\hline $\mathrm{S} 40$ & $\begin{array}{l}\text { Zulu } \\
\text { Isizulu; Zunda } \\
\text { (Marten, 2007) }\end{array}$ & $\begin{array}{l}\text { Dialeto: Lala, Qwabe. Similar ao Swazi e Xhosa. } \\
\text { Distribuição geográfica: KwaZulu Natal e províncias de } \\
\text { Mpumalanga. Em Botsuana, Lesotho, Malawi, } \\
\text { Mozambique, Swaziland. } \\
\text { Número de falantes: Cerca de } 15.700 .000 \text { falantes L2. } \\
\text { Status: Língua Nacional. }\end{array}$ \\
\hline
\end{tabular}


ANEXO A - MAPA POLÍTICO DE ANGOLA (United Nations Cartographic Section, 2004)

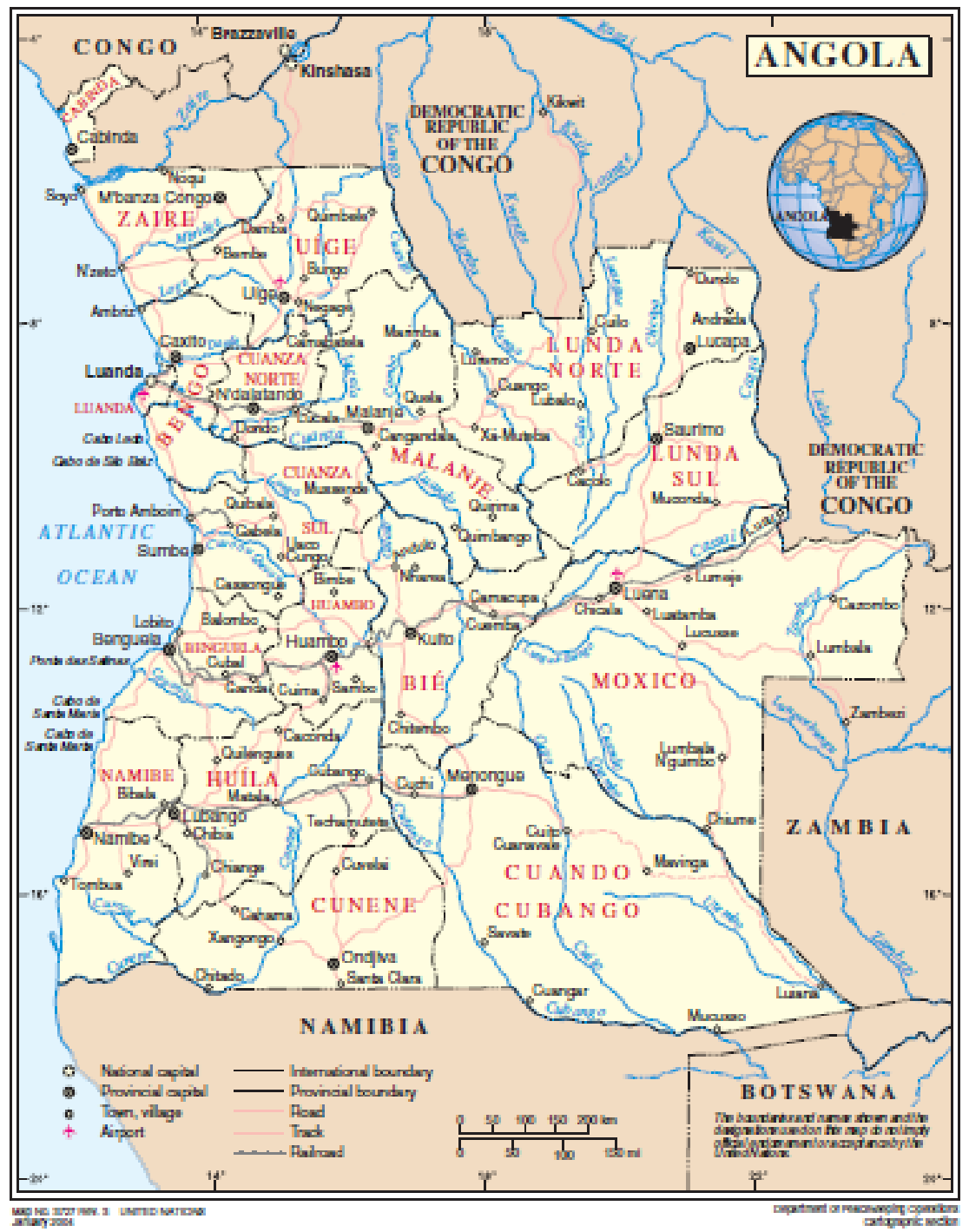


ANEXO B - MAPA ETNOLINGUÍSTICO DE ANGOLA (Lewis; Simons, 2013)

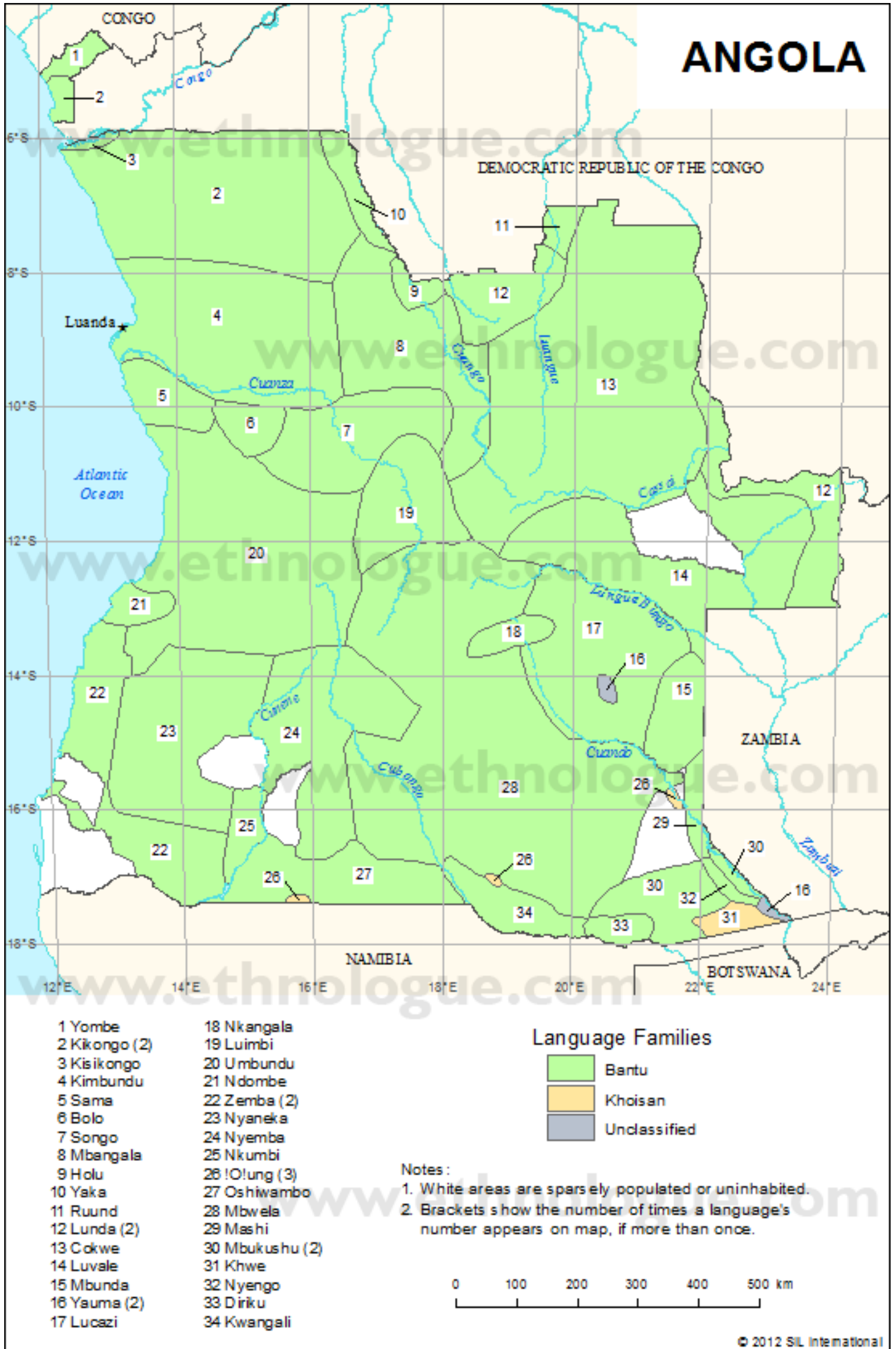


ANEXO C - Mapa da WALS - Posse Predicativa (Stassen, 2005a)
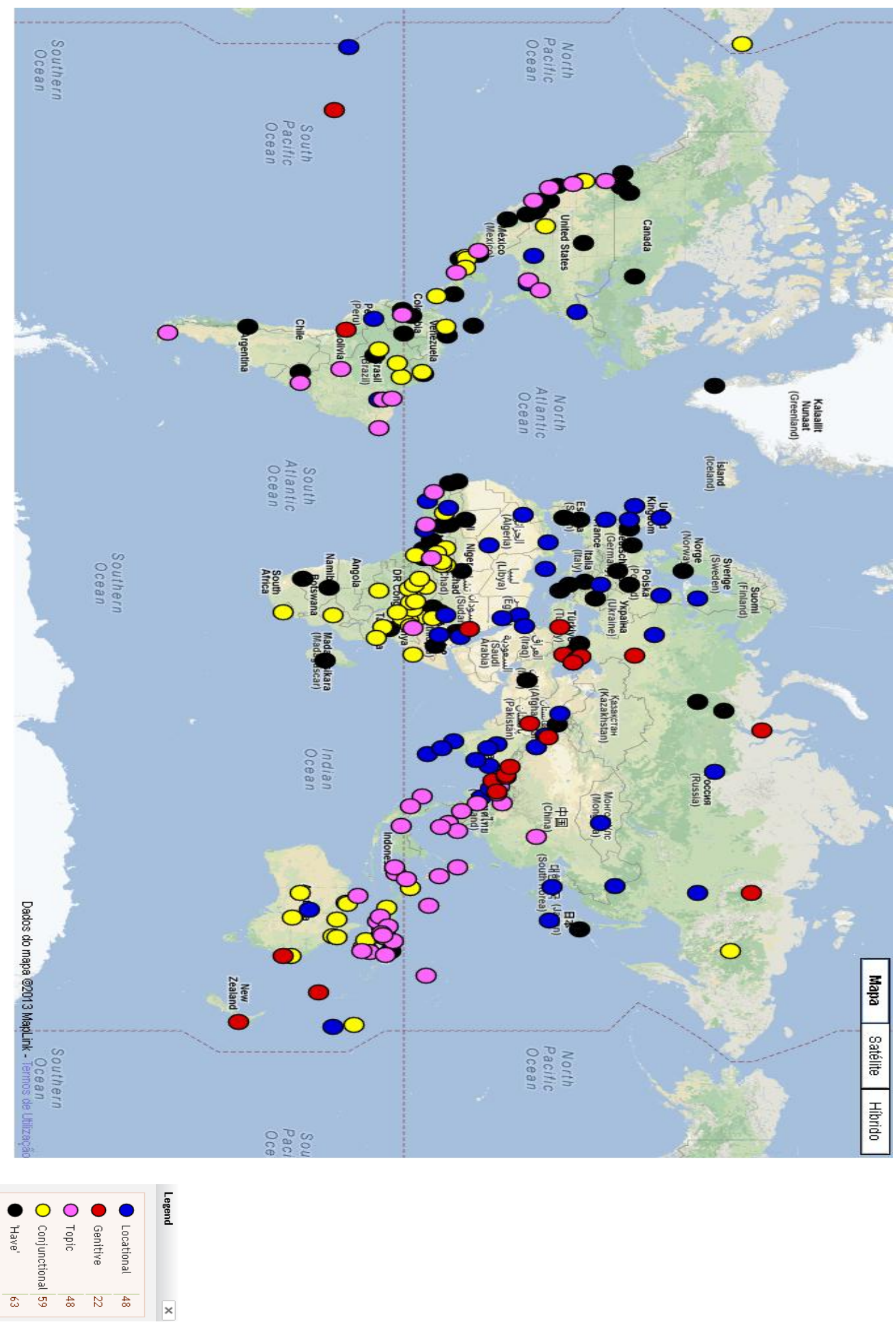